


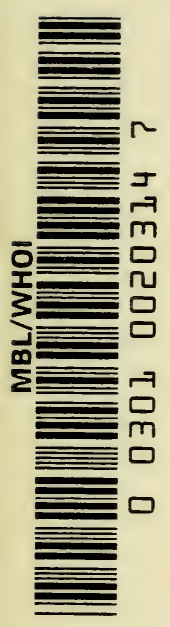





\section{PHOSPHORUS METABOLISM OF BRAIN}


I11401/ II,

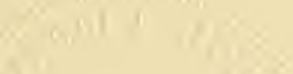

$+2$

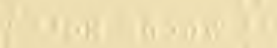

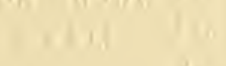

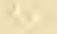

In mon o 


\title{
Phosphorus Metabolism of Brain
}

\author{
by \\ P. J. HEALD \\ M.Sc., Ph.D. \\ Senior Lecturer in Biochemistry \\ at the Institute of Psychiatry \\ (British Post Graduate Medical Federation) \\ in the University of London
}

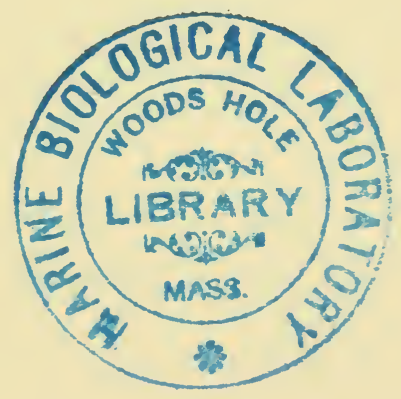

PERGAMON PRESS

NEW YORK $\cdot$ OXFORD $\cdot$ LONDON $\cdot$ PARIS 


\section{PERGAMON PRESS INC.}

122 East 55th Street, New York 22, N.Y.

P.O. Box 47715, Los Angeles, California

PERGAMON PRESS, LTD.

Headington Hill Hall, Oxford

4 E 5 Fitzroy Square, London W.I

PERGAMON PRESS S.A.R.L.

24 Rue des Écoles, Paris $V^{e}$

PERGAMON PRESS G.m.b.H.

Kaiserstrasse 75, Frankfurt-am-Main

Copyright

(c)

1960

Pergamon Press Ltd.

Library of Congress Card Number 60-10833 


\section{CON'TENTS}

PREFACE vii

INTRODUCTION 1

Section I. METABOLISM IN VIVO

1 Metabolism in the Normal Functional State 5

2 Metabolism under Conditions of Changed Activity 34

Section II. METABOLISM IN VITRO

3 Tissue Preparations and General Metabolism 73

4 Factors Affecting Phosphate Metabolism in vitro 101

5 Phosphate Metabolism and Therapeutic Agents 138

6 General Comments 154

Appendix: Analysis of Cerebral Tissues for Phosphate DeRivatives

NAME INDEX

Subject INDEX 



\section{PREFACE}

THIs book has derived from the research interests of the author but also includes material used in the teaching of Psychological Medicine in the University of London. The writing has been prompted by the need for a collected account of the present state of knowledge relating to connexions between the metabolism of phosphorylated compounds and the functioning of nervous tissue. Because studies of this nature are of increasing interest to workers in psychiatry and medicine who are not familiar either with the subject or with the biochemical techniques involved, the present account has been written with their requirements in mind. Nevertheless, biochemical detail necessary to a proper treatment of the subject has not been omitted. Selection of literature has been inevitable, but the effort has been made to include all relevant information published up to January 1959.

The writing of this book has been greatly assisted by the encouragement of Professor H. McIlwain, in whose Department the author has worked for several years. Thanks are also due to Dr. W. L. Magee and Dr. G. H. Sloane-Stanley who read several chapters of the manuscript and made many helpful comments. Dr. J. B. Brierley gave much assistance with the section relating to the blood-brain barrier, but is not responsible for the views expressed. Permission from the Biochemical fournal to reproduce Fig. 12,13 and 14 is gratefully acknowledged. It is a pleasure to acknowledge the help received from the Pergamon Press in the presentation of the material.

P. J. HEALD 


\section{INTRODUCTION}

ThE STUDY of the Biochemistry of Nervous Tissue has expanded rapidly over the past ten years. Today, the subject has attracted a number of workers from many disciplines, sufficient to have led to the holding of International Symposia specifically devoted to the topic and to the publication of a separate journal. The growth of the subject is well illustrated by the publication of a book concerned exclusively with the relationship of biochemistry to the central nervous system (McIlwain, 1959). This rapid expansion is an encouraging recognition of the importance of the brain both as a tissue possessed of unique biochemical properties and as the tissue comprising the "master organ of the body".

Amongst the many problems existing in relation to cerebral metabolism one of major importance concerns the manner in which the energy produced by the oxidation of glucose is used to maintain the ability of the neurone to respond to stimuli. In the normal brain this response can be detected as electrical activity recorded by the electroencephalograph. Many changed mental states are accompanied by changes in the electrical activity so recorded and also by equally marked changes in the rates of metabolism of many cellular components. Changes of this type provide a basis for considering that the changed functioning of the brain is closely related to some altered metabolic property of the tissue. A notable example of such an alteration has been demonstrated by Tower (1955) who has shown that tissue taken from the epileptogenic foci of brain specimens, removed during operation, lack the ability to resynthesize acetyl choline in the bound form in which it normally exists.

Amongst the earliest biochemical changes detected in brain during excitatory states were alterations in the metabolism of phosphate derivatives, observations which established a causal relationship between phosphates and the functioning of the brain. The study of these relationships forms the major theme of this 
book which contains an examination of relevant data, obtained both in vivo and in vitro. Such a study has, as its ultimate object, the description in biochemical terms of the linkages existing between a metabolic event, such as a change in the levels of phosphocreatine, and a physical event, such as the change in the electrical activity of the cortex. In this book an account is given first of the substances which have been studied, second of their change in the brain in vivo as affected by a variety of stimuli, and third of detailed examinations in vitro of the nature of the biochemical mechanisms likely to be involved in the changed metabolism. This latter study has made much use of techniques devised for electrically exciting cerebral tissues in vitro and these are described in the necessary detail. Understanding of the connections between metabolic and functional events in nervous tissue is still incomplete and requires much further examination. It is hoped that the following presentation of the subject will stimulate an increasing amount of investigation to this end.

\section{REFERENCES}

McIlwain, H. (1959) Biochemistry and The Central Nervous System, 2nd ed., Churchill, London.

Tower, D. B. (1955) Neurology 5, 113. 


\section{Section I}

\section{METABOLISM $I \mathcal{N} V I V O$}





\section{METABOLISM IN THE NORMAL}

\section{FUNCTIONAL STATE}

THE BRAIN in vivo derives its supply of energy by the oxidation of glucose, consuming in the process one-fifth of the total bodily consumption of oxygen. In common with other organs of the body such energy is stored and transmitted by phosphates of which adenosine triphosphate and phosphocreatine are prominent. In the brain, many other phosphorylated compounds exist, the functions of many of which are either partly or entirely unknown. A method of attempting to understand the role such phosphates play in cerebral metabolism is the examination of their behaviour under a variety of different conditions. In this Section the metabolism of the phosphorus compounds of brain in vivo is considered, first, as it occurs in animals under normal unstressed conditions, and second, as it is affected by a number of changed circumstances. The subject matter of Chapter 1 is, therefore, a description of the normal metabolic state of the brain as it relates to phosphorus metabolism.

\section{Quantities of Phosphorus Compounds in the Brain}

\section{Acid-soluble Phosphates}

Amongst the phosphates of brain those extracted by acid denaturants such as trichloracetic acid have received considerable attention over the past fifteen years. The major ones are the adenosine polyphosphates, phosphocreatine and inorganic phosphate. The quantities of these phosphates found in brain of different species are given in Table 1 . To obtain reliable estimates of the quantities such as these the brain must be frozen in situ with liquid oxygen or nitrogen and removed, while still frozen, to the acid denaturant with which it is then rapidly ground. Small animals such as the mouse, rat, or guinea pig, are frozen whole by dropping into a flask of liquid nitrogen. With larger animals such 
as the cat or dog, the skull must be opened under anaesthesia and liquid nitrogen or oxygen then poured on to the exposed cortex. Such a technique necessarily introduces the added complication of the effects of the anaesthetic in addition to those being studied. A fuller account and details of techniques are given in the Appendix. The values given in Table 1 were all obtained by this method with the exception of those from the rats studied by Abood et al. (1952) and Koransky (1958). In these experiments the animals were first decapitated and the brain rapidly removed and frozen in solid carbon dioxide or a mixture of carbon dioxide and acetone, before extracting the acid soluble phosphates.

The list given in Table 1 represents an accumulation of data over several years by many different investigators using different analytical methods, ranging from simple salt precipitations to chromatographic and enzymic techniques. Many of the results were obtained incidentally to other investigations and must perhaps be regarded with some reservations. Taken as a whole, however, with the exception of the monkey, the quantities of phosphocreatine show a marked similarity in all species, averaging some $3.0 \mu \mathrm{moles} / \mathrm{g}$ wet wt. tissue. Values for the quantities of inorganic phosphate show a similar agreement being about $4.0 \mu$ moles phosphorus/g wet wt. On the other hand quantities of adenosine polyphosphates show considerable fluctuation, adenosine triphosphate ranging from $0.62-4.4 \mu$ moles/g wet wt. and adenosine diphosphate from $0-2.38 \mu$ moles $/ g$ wet wt. These differences are probably attributable to the analytical methods employed, details of which and possible sources of error are given later (Appendix). Probably the results of Kratzing and Narayanaswami (1953) and Thorn et al. (1955), who used specific enzymic methods, are the most accurate of those listed. Certainly high levels of adenosine diphosphate are not compatible with a system actively carrying out a vigorous oxidative phosphorylation. With these considerations in mind, $2 \cdot 5-3 \cdot 0 \mu$ moles adenosine triphosphate/g wet wt. tissue would appear to be a reasonable normal level.

Other nucleotides present are found in much smaller amounts and quantitative data are still very scanty ('Table 2). Of them, guanosine nucleotides constitute by far the greatest quantity. It is of interest that the presence of such nucleotides was first postulated by Kerr (1942), who found that $17 \cdot 3 \%$ of the total nucleotide nitrogen of dog brain was in the form of a purine 
Table 1.-Quantities of Phosphocreatine, Adenosine Phosphates and Inorganic Phosphate in Brain in vivo

\begin{tabular}{|c|c|c|c|c|c|c|}
\hline \multirow[b]{2}{*}{ Animal } & \multicolumn{5}{|c|}{ Phosphates in $\mu$ moles/g wet wt. } & \multirow[b]{2}{*}{ Ref. } \\
\hline & $\begin{array}{c}\text { Inorganic } \\
\text { phos- } \\
\text { phate }\end{array}$ & $\begin{array}{c}\text { Adenosine } \\
\text { triphos- } \\
\text { phate }\end{array}$ & $\begin{array}{l}\text { Adenosine } \\
\text { diphos- } \\
\text { phate }\end{array}$ & $\begin{array}{c}\text { Adenosine } \\
\text { mono- } \\
\text { phosphate }\end{array}$ & $\begin{array}{l}\text { Phospho- } \\
\text { creatine }\end{array}$ & \\
\hline Mouse & $\begin{array}{c}5 \cdot 45 \\
- \\
\end{array}$ & $\begin{array}{l}2 \cdot 30 \\
2 \cdot 32 \\
\end{array}$ & - & - & $\begin{array}{l}3 \cdot 26 \\
2 \cdot 60\end{array}$ & $\begin{array}{l}\text { (1) } \\
\text { (2) }\end{array}$ \\
\hline Rat & $\begin{array}{c}4 \cdot 8 \\
4 \cdot 2 \\
5 \cdot 0 \\
- \\
- \\
5 \cdot 45 \\
4 \cdot 14 \\
- \\
-\end{array}$ & $\begin{array}{ll}1 \cdot 7 & \\
2 \cdot 3 & \\
1 \cdot 2 & \\
2 \cdot 0 & \\
4 \cdot 4 & \\
& 2 \cdot \\
1 \cdot 77 & \\
0.62 & \\
1 \cdot 61 & \\
2 \cdot 60 & \end{array}$ & $\begin{array}{cc} & 0.76 \\
& 1.0 \\
& 0.18 \\
& - \\
& - \\
& \\
& 0.57 \\
& 0.56 \\
& \\
1.0\end{array}$ & $\begin{array}{c}- \\
\overline{-} \\
1.68 \\
1 \cdot 0-1.5 \\
- \\
\overline{-} \\
0.26 \\
0.52 \\
\overline{0} \\
0.5\end{array}$ & $\begin{array}{c}3 \cdot 10 \\
3 \cdot 6 \\
3 \cdot 0 \\
3 \cdot 4-3 \cdot 0 \\
3 \cdot 15 \\
3 \cdot 06 \\
2 \cdot 46 \\
- \\
1 \cdot 95 \\
3 \cdot 2 \\
\end{array}$ & $\begin{array}{l}(3) \\
(4) \\
(5) \\
(6) \\
(7) \\
(8) \\
(9) \\
(10) \\
(11) \\
(12)\end{array}$ \\
\hline $\begin{array}{c}\text { Guinea } \\
\text { pig }\end{array}$ & $\begin{array}{l}3 \cdot 8 \\
\frac{-}{3 \cdot 58} \\
3 \cdot 20 \\
- \\
\end{array}$ & $\begin{array}{l}-\overline{3 \cdot 3} \\
3 \cdot 68 \\
3 \cdot 60 \\
\end{array}$ & $\begin{array}{r}\text { - } \\
\\
-\end{array}$ & $\begin{array}{c}- \\
\overline{1.02} \\
-\end{array}$ & $\begin{array}{l}3 \cdot 30 \\
2 \cdot 14 \\
2 \cdot 66 \\
2 \cdot 68 \\
- \\
\end{array}$ & $\begin{array}{l}\text { (13) } \\
(14) \\
(14) \\
(15) \\
(16)\end{array}$ \\
\hline Cat & $\begin{array}{l}-\overline{4 \cdot 7} \\
5 \cdot 20 \\
- \\
\end{array}$ & $\begin{array}{l}-\overline{1 \cdot 3} \\
0 \cdot 69 \\
2 \cdot 65\end{array}$ & $\begin{array}{c}- \\
1 \cdot 10 \\
2 \cdot 38 \\
- \\
\end{array}$ & $\begin{array}{l}- \\
- \\
-\end{array}$ & $\begin{array}{l}4 \cdot 0 \\
2 \cdot 2 \\
1 \cdot 72 \\
2 \cdot 70 \\
\end{array}$ & $\begin{array}{l}(17) \\
(18) \\
(19) \\
(20)\end{array}$ \\
\hline Rabbit & $3 \cdot 0$ & $2 \cdot 2$ & 0.5 & - & $3 \cdot 0$ & (21) \\
\hline Dog & $\begin{array}{l}2 \cdot 4 \\
3 \cdot 1 \\
\end{array}$ & $\begin{array}{l}2 \cdot 84 \\
2 \cdot 90\end{array}$ & - & - & $\begin{array}{l}3 \cdot 55 \\
2 \cdot 30 \\
\end{array}$ & $\begin{array}{l}(22) \\
(23) \\
\end{array}$ \\
\hline Monkey & $\begin{array}{l}3 \cdot 93 \\
4 \cdot 51\end{array}$ & $\begin{array}{l}1 \cdot 68 \\
0 \cdot 27\end{array}$ & $\begin{array}{c}1 \cdot 27 \\
-\end{array}$ & - & $\begin{array}{l}1 \cdot 72 \\
1 \cdot 55\end{array}$ & $\begin{array}{l}(24) \\
(25)\end{array}$ \\
\hline
\end{tabular}

(1) Stone (1940); (2) Kabat (1944); (3) Albaum et al. (1946); (4) Shapot (1957); (5) Abood, et al. (1952); (6) Le Page (1946); (7) Dawson and Richter $(1950 a)$; (8) Dawson and Peters (1955); (9) Doring and Gerlach (1957); (10) Koransky (1958); (11) Stoner and Threlfall (1954); (12) Lin et al. (1958); (13) McIlwain et al. (1951); (14) Kratzing and Narayanaswami (1953); (15) Heald (1956a); (16) Thomas (1957); (17) Kerr (1935); (18) Klein and Olsen (1947); (19) Bain and Pollock (1949); (20) Sacks and Culbreth (1951); (21) Thorn et al. (1955); (22) Stone (1943); (23) Pscheidt et al. (1954); (24) Bain et al. (1949); ${ }^{(25)}$ Shideman and Seevers (1953). 
considered to be guanine. However, not until 1954 was it again confirmed in rat brain (Schmitz et al., 1954). Subsequently the presence of guanine in the acid-soluble nucleotides of brain was confirmed by Thomas (1957) using Kerr's technique combined with paper partition chromatography, and by Heald (1957a) who isolated and characterized guanosine di- and triphosphates from extracts of guinea pig cerebral cortex and whole ox brain. Of the other nucleotides listed, specific roles for the uridine derivatives have not yet been fully described in brain, though studies on the conversion of ${ }^{14} \mathrm{C}$ labelled glucose to cerebrosidal galactose (Moser and Karnovsky, 1958) suggest that the mechanism for the conversion of UDP glucose to the galactose derivative (Leloir, 1953) is operative (see also Maxwell et al., 1955; Burton et al., 1958). Uridine derivatives of hexoses, hexuronic acids and amino sugars are known to participate widely in the synthesis of polysaccharides and of mucopolysaccharides in plant and animal tissues (Utter, 1958) and may be expected to be similarly involved in cerebral tissues. The formation of these derivatives requires sources of uridine triphosphate and, in the case of the $\mathrm{N}$-acetyl glucosamine derivative, a source of glutamine, ample quantities of which exist in brain (Weil-Malherbe, 1952). Uridine diphospho-N-acetyl glucosamine is readily converted to uridine diphospho- $\mathrm{N}$-acetyl galactosamine by a liver enzyme (Cardini and Leloir, 1957) and a similar conversion is likely in brain. Such a possibility makes the finding of the glucosamine derivative of interest in view of the presence of $\mathrm{N}$-acetyl galactosamine in brain gangliosides (Blix et al., 1952; Svennerholm, 1956a), which are included in strandin (Folch et al., 1951; Svennerholm, 1956b), and the accumulation of these lipids in the brain in the Tay-Sachs and Niemann-Pick diseases (see for example Klenk et al., 1957; Thannhauser, 1957). The presence of inosine monophosphate, but not the di- or triphosphate is indicative of its probable mode of formation as a de-amination product of adenosine monophosphate (Kerr, 1942; Muntz, 1953; Weil-Malherbe and Green, 1955) a process which, curiously, requires adenosine triphosphate. Cytidine triphosphate has been shown to be essential in the synthesis of lecithin in brain dispersions (McMurray et al., 1957), while the participation of the di- and triphosphopyridine nucleotides in the oxidation reduction reactions during cerebral respiration is well known and fully documented (McIlwain, 1957, 1959). Fuller discussions of the 
TABle 2.-Quantities of NuCleotides other THAN THOSE OF ADENOSINE, FOUND IN THE BRAIN in vivo

Superscripts denote references below

\begin{tabular}{|c|c|}
\hline Nucleotide & Quantity ( $\mu$ moles/g wet wt.) \\
\hline $\begin{array}{l}\text { Guanosine triphosphate } \\
\text { Guanosine diphosphate } \\
\text { Guanosine monophosphate }\end{array}$ & $\left.\begin{array}{l}0 \cdot 24^{(1)} 0 \cdot 20^{(9)} \\
0 \cdot 20^{(1)} \\
0 \cdot 08^{(1)}\end{array}\right\} 0 \cdot 6^{(2)} 0 \cdot 65^{(4)} 0 \cdot 3^{(5)}$ \\
\hline $\begin{array}{l}\text { Uridine triphosphate } \\
\text { Uridine diphosphate } \\
\text { Uridine monophosphate }\end{array}$ & $\left.\begin{array}{l}0.07^{(1)} 0 \cdot 14^{(0)} \\
0.03^{(1)} \\
0.05^{(1)}\end{array}\right\} \begin{array}{c}\text { Present }^{(6)} 11 \% \text { total } \\
\text { nucleotides }^{(7)}\end{array}$ \\
\hline $\begin{array}{l}\text { Cytidine triphosphate } \\
\text { Cytidine diphosphate } \\
\text { Cytidine monophosphate }\end{array}$ & $\left.\begin{array}{l}\text { Not } \\
\text { detected }^{(1)}\end{array}\right\} \begin{array}{l}\text { Present }^{(6)} 4 \% \text { total } \\
\text { nucleotides }^{(7)}\end{array}$ \\
\hline $\begin{array}{l}\text { Inosine triphosphate } \\
\text { Inosine diphosphate } \\
\text { Inosine monophosphate }\end{array}$ & $\begin{array}{ll}0^{(10)} 0^{(1)} & \\
0^{(1)} & 0 \cdot 14^{(2)} 0 \cdot 10^{(4)} \\
0^{(1)} 08^{(1)} & 4 \% \text { total nucleotides }\end{array}$ \\
\hline $\begin{array}{l}\text { Uridine diphosphate } \\
\text { glucose* } \\
\text { Uridine diphosphate } \\
\text { acetyl glucosamine } \\
\text { Uridine diphosphate } \\
\text { glucuronic acid }\end{array}$ & 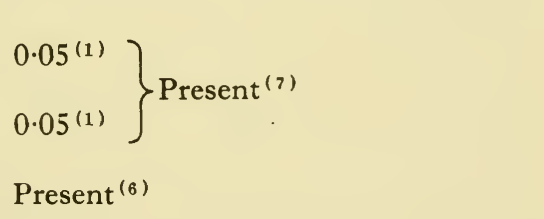 \\
\hline $\begin{array}{l}\text { Diphosphopyridine } \\
\text { nucleotide } \\
\text { Triphosphopyridine } \\
\text { nucleotide }\end{array}$ & $\begin{array}{l}0.04^{(1)} 0.40^{(3)} 0.26^{(8)} \\
-\quad 0.016^{(8)} 0.039^{(3)}\end{array}$ \\
\hline
\end{tabular}

(1) Rat; Koransky (1958). (2) Dog; Kerr (1942), Kerr and Seraidarian (1945). (3) Rat, guinea pig; Glock and McLean (1955). (4) Guinea pig; Thomas (1957). (5) Ox; Heald (1957), the brain was not frozen before removal and analysis. (6) Rat; Schmitz et al. (1954). (7) Rat, rabbit; Mandel and Harth (1957). (8) Rat; Abood et al. (1952). (9) Rat; Doring and Gerlach (1957). (10) Guinea pig; Heald (1956a).

* Probably a mixture of glucose and galactose derivatives (Leloir (1953); Hurlbert and Potter (1954)). 
reactions in which these and other nucleotides participate is deferred to later chapters.

The quantities of phosphorylated intermediates of the glycolytic pathway are given in Table 3. With few exceptions there is

Table 3.-Quantities of Phosphorylated Intermediates of

GLUCOSE IN BRAIN in vivo

Superscripts denote author references

\begin{tabular}{|c|c|}
\hline Intermediates & Quantities in $\mu$ moles/g tissue \\
\hline Glucose-1-phosphate & - $\quad$ - $\quad 22.8^{(7)}, 0.26^{(7)}$ \\
\hline Glucose-6-phosphate & $\left.2 \cdot 0^{(1)(3)}, 1 \cdot 35^{(8)}, 1 \cdot 0^{(11)}\right\}$ \\
\hline Fructose-1 : 6-diphosphate & $\begin{array}{l}0.08^{(1)}, 0.12^{(2)}, 0.05^{(9)}, 0.028-0.05^{(10)} \\
\text { absent }^{(8)}\end{array}$ \\
\hline 3-Phosphoglyceric acid & $0.95^{(1)}, 0.52^{(2)}, 1 \cdot 0^{(3)}$, absent $^{(8)}$ \\
\hline Triose-phosphates & $0.30^{(1)}, 0.02-0.03^{(10)}$, absent $^{(8)}$ \\
\hline Phosphopyruvic acid & $0.97^{(2)}$, absent $^{(8)}$ \\
\hline Phosphorylethanolamine & $1 \cdot 3-1 \cdot 6^{(8)}$ \\
\hline Glucose-1 : 6-diphosphate & $0.03^{(12)}$ \\
\hline
\end{tabular}

(1) Rat; Abood et al. (1952). (2) Rat; Albaum et al. (1946). (3) Rat; Le Page (1946). (4) Rat; Dawson and Richter (1950a). (5) Guinea pig; Kratzing and Narayanaswami (1953). (6) Guinea pig; Heald (1956a). (7) Cat; Klein and Olsen (1947). (8) Dog; Stone (1943). (9) Rabbit; Thorn et al. (1955). (102 Rabbit; Thorn, et al. (1958). (11) Rat; Vladimirov and Rubel (1957) (assuming $3 \mathrm{~g}$ wt. of brain). (12) Rat; Paladini (1951).

reasonable agreement between the results of various workers. As with the nucleotides, values are given for brains frozen in vivo and differences may be ascribed either to analytical methods or to treatment of the brain after freezing. Here also, quantities estimated by specific enzymic methods (Kratzing and Narayanaswami, 1953; Thorn et al., 1955, 1958) are preferred to those obtained by other techniques. It is of interest that the quantity of 
glucose 1 : 6-diphosphate, the coenzyme of phosphoglucomutase, though apparently low, is actually three times the amount found in liver. The quantity of an intermediate accumulating at any given time is governed as much by its rate of removal as by its rate of synthesis. The apparent absence, or small quantities, of many phosphates known to be produced during metabolism is therefore not necessarily an indication of the unimportance of such metabolites or of the routes on which they occur.

Phosphates other than those listed in the above tables include glycerylphosphorylethanolamine isolated from cattle brain (Walker, 1952) and rat brain (Ansell and Norman, 1953) and propanediol phosphate from cow brain (Lindberg, 1946). A fraction considered to be a choline ester of sphingosine phosphoric acid was obtained from extracts of sheep and horse brain (Booth, 1953) and later from dog brain (Stone, 1943), but the existence of this as a major component of such extracts is doubtful (Dawson, 1958).

Consideration of the data given above clearly indicates that the major interest has so far largely been centred on adenosine di- and triphosphates, phosphocreatine and inorganic phosphate. This is understandable largely because they were discovered earlier, but also owing to the interest arising when the demonstration of the role of phosphocreatine in muscular activity (Eggleton and Eggleton, 1927; Davenport and Sacks, 1929; Lundsgaard, 1930, 1931) was followed by the description of a similar relation for phosphocreatine in peripheral nerve (Gerard, 1932). However phosphocreatine was not identified in brain until 1935 (Kerr, 1935) nor was the presence of adenosine triphosphate unequivocally demonstrated until 1941 (Kerr, 1941). The elaboration of a system of analysis for the acid-soluble phosphates of brain by Stone $(1940,1943)$ and its application to cerebral tissues subjected to different treatments in vivo, revealed that in brain, as in muscle, changes in function could be related to changes in the quantities of these phosphates. For these reasons the major part of the work in vivo has been concerned with the amounts of such phosphates present under a wide variety of changed conditions.

\section{Acid-insoluble Phosphates}

After removal of materials soluble in acid denaturants the residue consists of a mixture of phosphorus compounds collectively known as "the acid-insoluble phosphates". The greater 
part of these consists of phospholipids. A list of the quantities of the various groups of components found in the residue is found in Table 4. Of the total phosphorus present some $80-90 \%$ consists of phospholipid phosphorus, the remainder coming from nucleic acids, phosphoproteins and a complex residue. The values given for most of the phospholipids are representative only and are included to illustrate the preponderance of this group over the other phosphates. More extensive summaries of the quantities and types of phospholipids in brain have been given by Sloane-Stanley (1952), Deuel (1955), Folch and Le Baron $(1956,1957)$ and Rossiter (1957). Two groups of lipids may be singled out for comment. Sphingomyelin constitutes part of the " myelin lipids" (Johnson et al., 1954) which include cholesterol and cerebrosides from which phosphorus is absent. It is believed that these form the major lipid components of the myelin sheaths of the axons both in the central nervous system and in the peripheral nerve. Evidence for this has been summarized by Johnson et al. (1954) and is based partly on the finding that sphingomyelin exists in greatest quantity in white matter, containing the bulk of the myelinated fibres of the brain, and least in the grey matter. The quantities of the inositol phospholipids are approximate only and have been calculated on the basis of information available. This group of lipids are extremely active as regards phosphorus metabolism but detailed studies have so far been hampered by the lack of a suitable method of analysis.

Similar considerations apply to the quantities of phosphorus found in the fractions containing nucleic acids, phosphoproteins and the residual organic phosphorus (see p. 14). Probably the most reliable figures are given by the methods of Strickland (1952) and Logan et al. (1952b). Quantities of phosphoprotein phosphorus are about $1.0 \mu$ mole phosphorus/g wet wt. and values in excess of this can be attributed to contamination with part of the residual organic phosphorus fraction (Logan et al., 1952a; LeBaron and Folch, 1956).

With the exception of certain of the phospholipids, the isolation or even partial purification of the majority of the components listed in Table 4 has not been achieved. The difficulties attendant upon any such separations are well illustrated both by the complexities already encountered with the phospholipids and by the demonstration that brain nucleic acids show numerous differences 


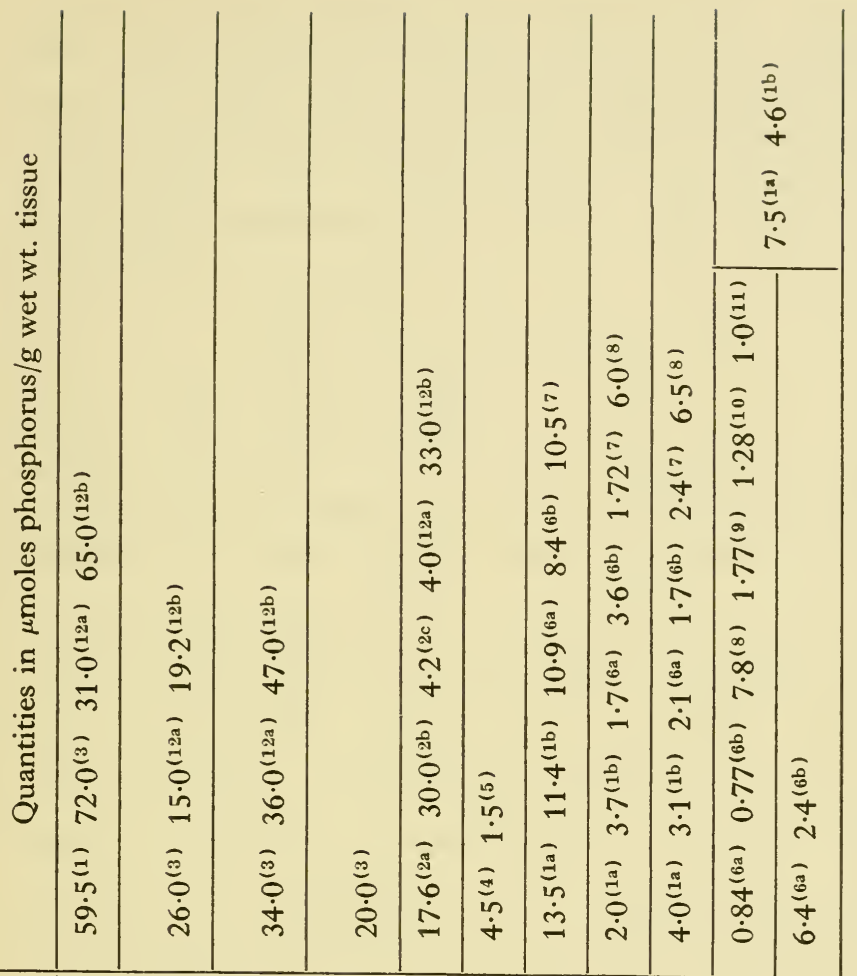

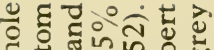

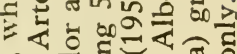

ثี

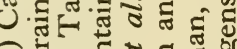

๙

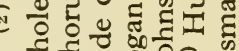

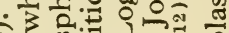
의 क्र

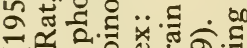

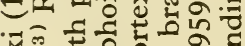
क 300

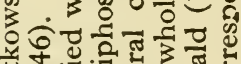

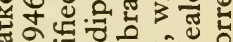
든

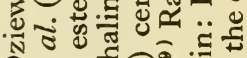

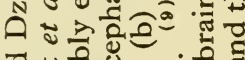
证

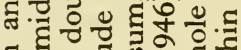
등..ㄹㄹ 응 作 政

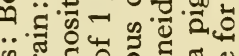
尊

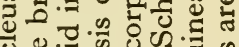
政. (1) 政

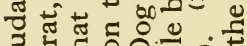
政 a. 政 ह

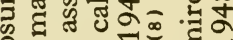

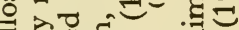

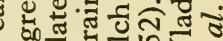
列

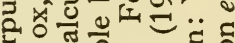

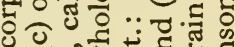

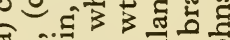


in type similar to those found with the nucleic acids from other tissues (Bendich et al., 1956; Bradley and Rich, 1956). The residual organic phosphorus fraction has been shown to contain inositol phosphates combined with protein and lipid as phosphatidopeptides (LeBaron and Folch, 1956), and also a phosphorus containing fraction from which inositol was absent (Vladimirov et al., 1957) and which was not a phosphoprotein. Middleton (1953) is reported to have shown that the Schmidt-Thannhauser digest of the residual organic phosphorus contains some seven different fractions at least two of which contain inositol. These examinations of the nature of the phosphorus in the residual fraction are the beginnings only of a study that is likely to prove difficult and prolonged, for the fractions which have so far been obtained have necessitated extensive degradation of the original material.

Similar obscurity exists regarding the phosphoprotein fraction. This has been shown to yield phosphoryl serine on acid hydrolysis (Heald, 1958; Vladimirov and Pravdina, 1956), a property in common with many phosphorylated proteins. It has been suggested (Englehardt and Lissovskaya, 1953; Rossiter, 1955) that the phosphorus is that of enzyme substrate complexes. It seems unlikely that the major part of the phosphorus arises from such sources. The enzymes known to be phosphoproteins and to yield phosphoryl serine on acid hydrolysis are yeast hexokinase (Agren and Engstrom, 1956), liver phosphorylase (Wosilait, 1958) and pepsin (see Neurath, 1957) with the possible inclusion of yeast phosphoglucomutase (Sidbury and Najjar, 1953). Excluding pepsin, which is absent, the rates of the reactions catalysed by the equivalent enzymes in brain are known (McIlwain, 1959). Assuming the brain enzymes to contain similar quantities of phosphorus it can be calculated from data already available (Colowick and Kaplan, 1955) that they contribute not more than $1-2 \%$ to the phosphorus of the phosphoprotein fraction. Present evidence (Heald, 1959) indicates that the phosphoproteins of brain constitute two main fractions, the larger of which appears to be a single entity as regards phosphorus exchange. This phosphoprotein fraction is metabolically extremely active and discussion of its metabolic role in brain is given later (pp. 120-22).

In contrast to the phosphates soluble in acid denaturants it can be seen that those remaining constitute by far the greater quantity 
and include a significant proportion of uncharacterized substances some of which fall into definite groups. Knowledge of their metabolism has come mainly through measurements of the amounts of radioactive phosphorus which is incorporated under different conditions. Since the groups are heterogeneous it follows that all members of any one group are not likely to be equally active in this respect.

\section{Metabolism of Phosphorus}

\section{Entry of Phosphorus to the Brain}

One of the simpler methods of studying the metabolism of phosphorus compounds in an organ is by measuring the amount of radioactive phosphate taken up in a given time. Such experiments were delayed with brain since the entry of phosphorus is very slow, giving rise to a belief that the bulk of the phosphorus compounds in brain were very stable. Administration of radioactive phosphate and subsequent analysis of the distribution in the body organs showed that, in animals such as the mouse or rat, not more than $0.1 \%$ of the original dose could be found in the brain (Table 5). This value was not markedly exceeded at any time in studies lasting up to $60 \mathrm{hr}$. It is now known that this is due to the existence of a "blood-brain barrier" which is only slowly permeable to inorganic phosphate from the blood stream. Equilibrium between the blood and brain inorganic phosphorus is a process occupying several days. This is illustrated, for the mouse, in Fig. 1 calculated from the data of Dziewiatkowski and Bodian (1951). Equilibrium was not achieved for almost seven days, thereafter the rate of decrease in activity in the blood exceeded that in the brain. Similar slowness in attaining equilibrium has been noted by other authors for the dog (Greenberg et al., 1943) and for the chicken (Webster, 1954).

Attempts to define the blood-brain barrier in terms of a single anatomical structure have not met with success (Dobbing, 1956; Brierley, 1957). Current thought tends to a description in which permeability of the nerve cell membrane and metabolism play a part (see McIlwain, 1959). That phosphate entry to the brain is regulated by metabolic processes similar to those excluding or concentrating salts or specific carbohydrates is made more probable by the recent work of Volkova (1957). Thus, raising the 
body temperature of the turtle from $10^{\circ}$ to $30^{\circ}$ increased the penetration of radioactive phosphorus from the blood to the brain to a rate in excess of that expected from a passive diffusion process.

The route by which phosphate enters the brain is still not settled. Sacks and Culbreth (1951) considered that phosphate enters the brain very largely by secretion via the choroid plexus into the cerebrospinal fluid, from which it is then presumably taken up into the brain phosphates by transport through the

Table 5.-The Incorporation of Radioactive Phosphate into Different Organs of the Rat

Radioactive orthophosphate was administered either by stomach tube or by intraperitoneal injection

\begin{tabular}{|c|c|c|c|}
\hline Tissue & $\begin{array}{c}\%{ }^{32} \mathrm{P} \text { administered } \\
\text { retained in the } \\
\text { whole organ }\end{array}$ & $\begin{array}{l}\text { Maximum amount } \\
\text { of phospholipid } \\
\text { synthesized as } \\
\% \text { of }{ }^{82} \mathrm{P} \text { dose }\end{array}$ & $\begin{array}{c}\text { Time } \\
\text { to } \\
\text { maximum } \\
\text { (hr) }\end{array}$ \\
\hline $\begin{array}{l}\text { Bone } \\
\text { Muscle } \\
\text { Gut } \\
\text { Liver } \\
\text { Blood } \\
\text { Kidney } \\
\text { Skin and hair } \\
\text { Spleen } \\
\text { Brain }\end{array}$ & $\begin{array}{c}48 \\
16 \\
4 \\
6 \\
1-2 \\
1-2 \\
1 \\
0 \cdot 3 \\
0 \cdot 1-0 \cdot 2\end{array}$ & $\begin{array}{c}\overline{1.3} \\
1.0 \\
1.3 \\
- \\
0.40 \\
- \\
- \\
0.02-0.03\end{array}$ & $\begin{array}{l}- \\
\overline{2} \\
2-6 \\
\overline{14 \cdot 5} \\
\frac{-}{60}\end{array}$ \\
\hline
\end{tabular}

Data from Perlman, Ruben and Chaikoff (1937); Cohn and Greenberg, (1938); Fries and Chaikoff (1941).

ventricle linings. It would seem more reasonable to suppose that plasma phosphate could enter the brain both by the choroid plexus and the capillary walls, in a manner analogous to that found with other anions (Wallace and Brodie, 1940), the question being the relative importance, if any, of either route. Bakay $(1951,1954)$ has attempted to answer this question by use of a radioautographic technique. Radioactive phosphate was injected intravenously into cats and at suitable time intervals the brain was removed, sectioned and radioautographs made of the various sections. It was found that radioactivity became detectable on the external 
surfaces of the cerebral cortex and on the inner lining of the ventricles at about the same time, a result which might be expected if both pathways were operating. Occlusion of one lateral ventricle by injection of paraffin wax one day before injecting radioactive phosphate prevented incorporation in that area for a period of at least 60 min following phosphate injection. On the basis of these

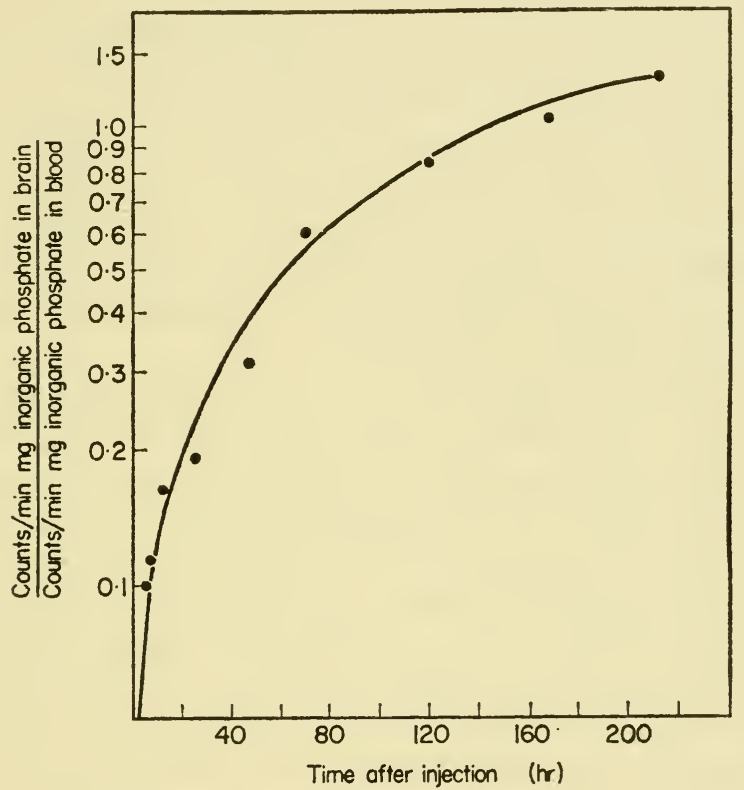

Fig. 1. The entry of phosphorus into the brain from the bloodstream. Data taken from Bodian and Dziewiatkowski (1950). Mice were injected with radioactive phosphate and killed at varying times after injection.

and similar results Bakay $(1954,1957)$ favours the cerebrospinal fluid as the main pathway by which phosphate enters the brain. This is considered to be supported by the finding that the anatomical pattern of tracer distribution was the same whether it was injected into the blood stream or directly into the cerebrospinal fluid. However, there is a well developed venous plexus underlying the epidermal lining of the ventricular system and it is known (p. 19) that the passage of phosphate from the cerebrospinal fluid to the blood is very rapid. Thus, Bakay's results could 
equally well be interpreted in terms of entry from the blood via the capillaries. Data presented by Bakay (1954) would seem to suggest this, for after an intravenous injection of radiophosphate the specific radioactivities of the cerebral cortex and of the ventricular walls were approximately equal over a period of some 21 days while the specific radioactivity of the cerebrospinal fluid was always lower than that of either surface. Cerebrospinal fluid was sampled from the cisterna magna and owing to the slow passage from the ventricles it is possible that in the early periods following the injection of radioactive phosphate, the fluid in the ventricles was of a higher specific radioactivity than that in the cistern. However, if the capillary route is to be excluded, this does not explain why the activities found in the cerebral cortex were higher than in the cisternal fluid. The present evidence would appear to be more in favour of entry via the capillaries than the cerebrospinal fluid, but the critical experiments have still to be done.

Penetration of phosphate from the surfaces to the depths of the brain is slow. Following intravenous injection in the cat, penetration from the linings of the ventricles and from the cortex to the centre of the brain took 9-21 days for completion as judged by radioautographs (Bakay, 1954). In contrast intracisternal injection led to an apparently much more rapid penetration, being complete within $1 \mathrm{hr}$, judged by the same technique (Bakay, 1951) though here also the area of brain closest to the site of injection incorporated radioactive phosphate faster than the other areas. This uneven rate of penetration would appear to set a limit to the use that can be made of intracisternal injection as a means of studying changes in the distribution of radioactive phosphorus between different phosphates samples from the whole brain. Bakay's experiments have been criticized by Selverstone (1958) on the grounds that the quantities of radioactive phosphate injected into the cistern were grossly disproportionate to the amount appearing in the brain following an intravenous injection. Selverstone found that the ratio of the doses chosen by Bakay produced a concentration of radioactive phosphate in the cisterna magna some fifteen times higher when given by intracisternal injection than when given intravenously. When comparable concentrations were presented by each route it was found that the overall exchange of phosphate between the blood and the brain was not much slower than exchange between the cerebrospinal fluid and the brain. Intra- 
cisternal injection therefore does not bypass any barrier but is simply a useful technique for rapidly presenting the brain with a high concentration of radioactive phosphate. Much of this phosphate is rapidly lost to the blood (Sacks and Culbreth, 1951; Strickland, 1952) though this has been denied (Lindberg and Ernster, 1950).

Certain areas of the brain appear to be relatively unprotected by a blood-brain barrier when compared with other areas as judged by the apparent entry of phosphate when injected into the bloodstream. In the human subject following intravenous injection of radioactive phosphate, radioactivity was found to be greatest in the thalamus and hypothalamus, while in the rabbit and rat radioactivity was greatest in the pituitary, pineal gland, choroid plexus and hypothalamus (Bakay, 1951, 1953; Bakay and Lindberg, 1949; Borell and Ostrom, 1945). It was suggested by Borell and Ostrom (1945) that the greater uptake of phosphate by the pituitary is a reflection of the high expenditure of energy involved in the synthesis of hormones. It is difficult to see how such an explanation could hold for the pineal gland. More probably an apparently greater uptake of phosphate in certain areas of the brain is a reflection of the degree of vascularity of that particular area and of the connexions existing, as in the case of the pituitary (Daniel et al., 1958), with the main blood stream. It should also perhaps be emphasized that all experiments of the type described above using radioactive phosphate simply measure the exchange of radioactivity across a membrane and do not measure amounts transported into the brain.

\section{Incorporation of Radioactive Phosphorus into the Acid-soluble Phosphates}

Although analytical data of the type given above showed that brain contained many phosphates known to be rapidly metabolized in normal cellular processes, direct evidence upon the rate of such metabolism in the brain in vivo is still lacking. Attempts to provide such data for the acid-soluble phosphates have been made by Bakay and Lindberg (1949), Lindberg and Ernster (1950) and Zetterstrom and Ljungren (1951). When radioactive phosphate was injected into rabbits by the intracisternal route it was found that phosphates soluble in trichloracetic acid became radioactive much more rapidly than those that were insoluble. Analysis of this 
situation in anaesthetized rats injected intracranially, i.e. into the ventricular fluid, showed that the acid-hydrolysable phosphorus of adenosine triphosphate incorporated radioactivity at the greatest rate followed by phosphocreatine. Of the total radioactivity of the sample some $30 \%$ was present as adenosine triphosphate within $2 \mathrm{~min}$ of the injection. Within $30 \mathrm{~min}$, the radioactivities of the acid-hydrolysable phosphorus of adenosine triphosphate and of phosphocreatine were equal to each other and to that of inorganic phosphate. Calculations (Lindberg and Ernster, 1950) based partly on the assumption that none of the injected phosphate was lost to the blood, showed that the phosphorus of phosphocreatine and adenosine triphosphate was renewed at the rate of $40 \mu \mathrm{g}$ phosphorus/g wet wt. $\mathrm{hr}^{-1}$ which corresponds to a rate of 77-78 $\mu$ moles phosphorus/g wet wt. $\mathrm{hr}^{-1}$.

This value is presumably a measure of oxidative phosphorylation in the brain in vivo and consequently is far too low. In vitro, slices of rat cerebral cortex metabolizing glucose in suitable salines, consume oxygen at the rate of $70 \mu$ moles $\mathrm{O}_{2} / \mathrm{g}$ wet wt. $\mathrm{hr}^{-1}$. Assuming a phosphorus/oxygen ratio of three (see Ochoa and Stern, 1952; McIlwain, 1959) this rate corresponds to a rate of renewal of the phosphorus of adenosine triphosphate of $420 \mu$ moles phosphorus/g wet wt. $\mathrm{hr}^{-1}$. There is good evidence to show that the rates of oxygen consumption of the intact brain in vivo are double those found with slices in vitro (Mcllwain, 1956, 1959). Thus the figure for the rate of renewal of the phosphorus of adenosine triphosphate is more probably $840 \mu$ moles phosphorus/g wet wt./hr. Anaesthesia is known to decrease the rate of oxygen consumption of the brain, but even so the rate of phosphorus renewal calculated by Lindberg and Ernster is probably no more than a tenth of the actual rate. A similar discrepancy between experimentally determined rates of renewal and those expected from rates of oxygen uptake has been noted by Vladimirov and Rubel (1957) in determinations of the renewal of phosphorus in hexose monophosphates from rat brain. Measurements were made upon rats injected subcutaneously with radioactive phosphorus. Thus the route of entry of phosphate to the brain differed from that in the experiments of Lindberg and Ernster. It was calculated that the phosphorus of the hexose monophosphate was renewed at a rate of $8.4 \mathrm{mg}$ phosphorus $/ 100 \mathrm{~g}$ tissue $\mathrm{hr}^{-1}$, which corresponds to about $3.0 \mu$ moles/g wet wt. $\mathrm{hr}^{-1}$. This value is considerably 
below the glucose consumption of human brain of about 17-20 $\mu$ moles/g wet wt. $\mathrm{hr}^{-1}$ (McIlwain, 1959) and even lower than that in the dog (Himwich and Fazekas, 1937) which can be calculated to be $36 \mu$ moles/g wet wt. $\mathrm{hr}^{-1}$.

Reasons for such differences are probably threefold and include,

(a) the unequal rate of penetration of phosphorus to all parts of the brain

(b) the possibility of localization of chemically identical substances with different rates of metabolism

(c) the methods of calculation of renewal rates.

As noted above, radioactive phosphate entering the brain, following either intracisternal or intravenous injection does not penetrate to all parts of the brain equally rapidly. In such circumstances samples taken from the whole brain shortly after injection will contain mixtures of phosphates of higher and lower radioactivities. Direct evidence relating to this has been provided by an interesting study of Baranov (1957). Rats, subcutaneously injected with radioactive phosphate, were frozen in liquid air $17 \mathrm{hr}$ later and the brain removed and slowly fixed in an acetone-alcohol mixture at $0^{\circ}$. It was shown that this procedure did not result in a loss of phosphocreatine or adenosine triphosphate which were found in quantities of $3.0 \mu$ moles $/ \mathrm{g}$ wet wt. cortical tissue, both before and after fixation. Transverse sections of the cerebellum, taken at $0.45 \mathrm{~mm}$ intervals were found to contain similar quantities of the phosphates but the specific radioactivities decreased as the depth from the surface of the cerebellum to the cut section increased. Differences of this type make the "equilibrium point" such as used by Lindberg and Ernster of doubtful value for calculations of renewal rates.

The presence of chemically identical substances with different rates of metabolism has so far only been hinted at in the brain. Such hints derive indirectly from the recognized differences existing in the oxygen consumption and enzymic activities of different parts of the brain and of the differing nerve cell bodies (Bollard and McIlwain, 1957; Lowry, 1957). Whether such differences are also reflected in rates of metabolism of radioactive phosphate is not known. Since oxygen uptake and phosphorylation are normally interdependent phenomena, regions with a lowered rate of oxygen consumption might reasonably be expected to have a lowered rate 
of phosphate metabolism. Views similar to these have also been expressed by Vladimirov and Rubel (1955).

Methods of calculation of the quantities of a phosphate renewed in a given time can be made with some degree of precision only if the specific radioactivities of the immediate stable precursor, as well as the product, are known. Criteria involved in such calculations have been detailed by Zilversmit et al. (1943), and Hearon (1951), and these criteria have not been fulfilled in experiments with brain. Most calculations of rates of renewal of cerebral phosphates appear to have been made on the basis of a simple multiplication procedure. Even when this is not the case (Lindberg and Ernster, 1950) the apparently insurmountable difficulties arising from the differential rates of entry and metabolism of phosphorus makes the accurate measurement of product-precursor relationships of the type required a seemingly impossible task. Comparisons have been made between the renewal rates of the acid-hydrolysable phosphates of various tissues including brain by injecting radioactive phosphate and subsequently analysing various organs for adenosine triphosphate and phosphocreatine (Sacks and Culbreth, 1951). While these experiments also show that the acid-soluble phosphates of brain exchange their phosphorus rapidly, they offer no means of computing turnover rates and comparisons between different organs are based on values which can have little real meaning in this respect.

These difficulties are not a drawback to the comparison of two sets of data obtained in identical fashions when the results may be expressed in terms of radioactivity relative to some standard of comparison. In the case of the acid-soluble phosphates this standard is usually the inorganic phosphorus of the brain since this is the precursor of the other phosphates. Corrections for the blood content (varying from $1 \cdot 3-6 \cdot 0 \%$ according to the method of obtaining the tissue) (Vladimirov, 1955; Dawson and Richter, 1951) are necessary to obtain the most precise figures but this correction is not always made.

The experiments described above provided the first clear demonstration that there was in brain a rapid metabolism of phosphate in phosphocreatine, adenosine triphosphate and the hexose monophosphates in vivo under unstressed conditions. Few other phosphates in this group have been similarly examined. The $\alpha$-phosphorus of adenosine triphosphate was found to be renewed 
only slowly when compared with the $\beta$ - and $\gamma$-phosphorus atoms (Zetterstrom et al., 1950), though the extent of the renewal was still considerable. Since the adenylic acid moiety of the diphosphopyridine nucleotide was found to incorporate radioactive phosphorus to the same extent as the $\alpha$-phosphorus of adenosine triphosphate (Zetterstrom and Ljungren, 1951) it appears that the pyridine nucleotide is split and resynthesized at an appreciable rate. In a study relating to the mechanisms of phospholipid synthesis incorporation of radioactive phosphorus into phosphorylethanolamine (Ansell and Dawson, 1950) was found to precede incorporation into glycerylphosphorylethanolamine (Ansell and Norman, 1953), suggesting a product-precursor relationship. It was shown that neither of these two phosphates arose by breakdown of the corresponding phospholipids. As with other acidsoluble phosphates incorporation was rapid, the specific radioactivity of phosphorylethanolamine being $50-70 \%$ of the specific radioactivity of the inorganic and acid-hydrolysable phosphorus within $3 \mathrm{hr}$ of a subcutaneous injection of ${ }^{32} \mathrm{P}$.

\section{Incorporation into Acid-insoluble Phosphates}

Phospholipids. At an early stage in the study of radioactive phosphate metabolism in the body it was recognized that the phospholipids of brain became only feebly radioactive when animals were either injected or fed with radioactive phosphate. The experiments of Hevesy and Hahn (1940), Changus et al. (1938), Fries et al. (1940) and others (Table 5) showed that the quantities of radioactive phosphorus entering the brain phospholipids constituted only a minute fraction of the total dose administered. Measurements extended over a period of 30 days showed that the maximum percentage incorporation in the phospholipids of adult rat brain was not attained until 8-10 days after a dose of radioactive phosphate and thereafter declined at a slow rate (Fig. 2). Experiments of this type were interpreted as showing that the phosphorus metabolism of the phospholipids in brain was extremely slow.

In the light of subsequent developments it would seem that this concept arose through the methods chosen to express the results. Since the passage of phosphate from the blood to the brain is slow the " acid-soluble" phosphates of brain do not exchange rapidly with the blood phosphate and do not become highly radioactive 
relative to the initial dose of phosphorus (Fig. 1). Since these phosphates are the precursors of the phospholipid phosphorus, the phospholipids themselves are likely to become radioactive to a similar relatively slight degree. When the radioactivity of the total phospholipids was related to the radioactivity of brain inorganic phosphate or acid-soluble phosphates, the relative radioactivity of the phospholipids was found to be appreciable within a few hours of giving the initial dose (Fig. 3). Even so the system is very slow

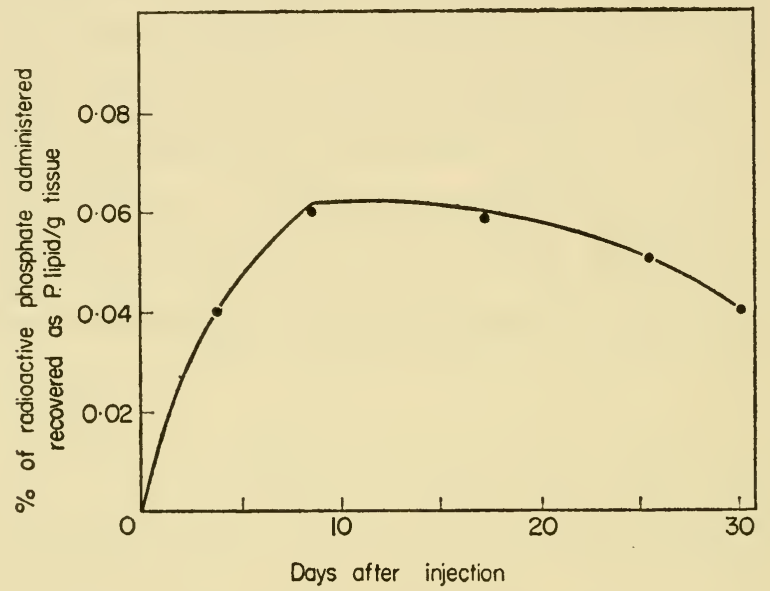

FIG. 2. The percentage of radioactive phosphate found in the total phospholipids of adult rat brain at different intervals after administration by stomach tube. Data from Changus et al., (1938).

to attain an equilibrium although the initial rise in the relative specific activities of the phospholipids is rapid. Comparison of the rates of rise, calculated from data given for the mouse and cat (Fig. 3), shows that equilibrium is not achieved even after 17 days. It is perhaps of interest that the rates of rise showed little difference whether the phosphorus was administered by stomach tube or injected intracisternally, results which tend to support conclusions arrived at when considering the entry of phosphate into the brain (pp. 18-19).

In spite of the relatively slow increase in radioactivity the quantities of phosphorus turned over are likely to be considerable. Thus from the relative specific activities of the total phospholipid 
phosphorus during the first three hours after administration of radioactive phosphorus to the rat Dawson and Richter (1950) calculated that an amount of phosphorus equivalent to the whole of the phospholipid phosphorus could be exchanged at least once in $70 \mathrm{hr}$. This rate corresponds to only $1.0 \mu$ moles $/ \mathrm{g}$ wet wt. $\mathrm{hr}^{-1}$ and must therefore be regarded as a minimum figure. Assessments

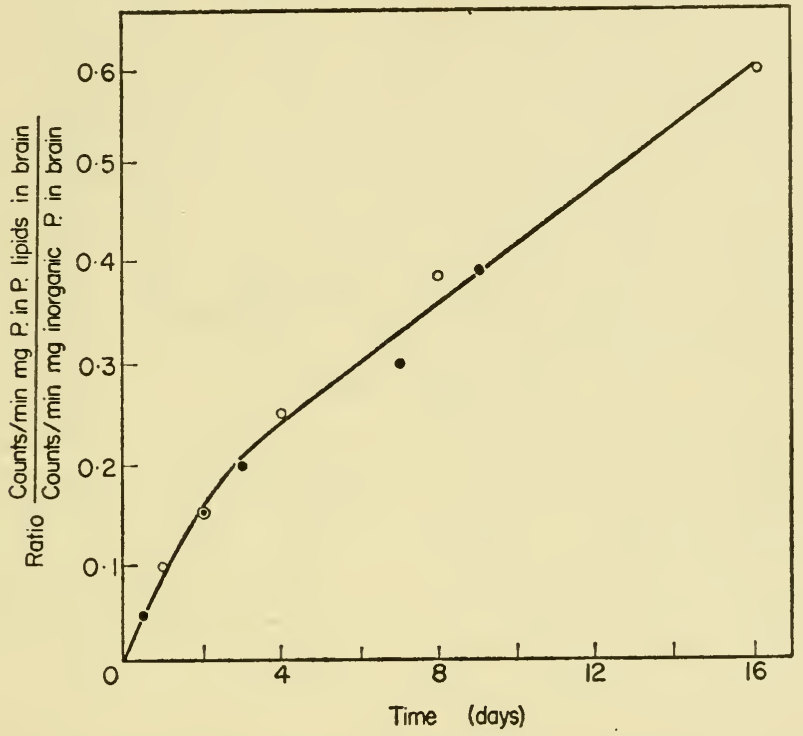

FIG. 3. The incorporation of radioactive phosphate into the phospholipids of brain. Data calculated to show the radioactivity of the phospholipids relative to that of the acid-soluble phosphates. $O=$ data from Dziewiatkowski and Bodian (1950), mouse; phosphate given by stomach tube. = Data from Strickland (1952), cat; phosphate administered by intracisternal injection.

of this type are difficult to make since the factors contributing to the results graphed in Fig. 3 are numerous. Amongst those to be taken into account are (a) the continuing presence for at least 16 days of a pool of radioactive inorganic phosphate of a specific activity higher than that of the total phospholipid phosphorus (Dziewiatkowski and Bodian, 1950), (b) the slow and uneven penetration of radioactive phosphate into the brain from the blood, and (c) the metabolic heterogeneity of the phospholipids. 
Of these, metabolic heterogeneity of the phospholipids is likely to be the major factor, but owing to a lack of suitable fractionation techniques there is still little information available regarding the relative rates at which most of the individual phospholipids exchange their phosphorus.

The turnover of phosphorus in brain phospholipids is known not to be uniform (Sloane-Stanley, 1952). Early studies had revealed that the cephalin fraction of the lipids of rabbit brain became radioactive to a markedly greater degree than did the lecithin fraction following an intraperitoneal injection of radioactive phosphorus (Hevesy and Hahn, 1940; Chargaff et al., 1940). Cephalin was then thought to be a single entity but was later shown (Folch, 1949) to be a mixture of at least three components. Following this Dawson $(1953,1954)$ showed both in vivo and in vitro that the greater exchange of phosphorus in the cephalin fraction was due to a rapid and almost exclusive incorporation of phosphate into the diphosphoinositide component. The cephalin diphosphoinositide fraction was isolated and hydrolysed to release inositol diphosphate. This was found to have a specific radioactivity more than ten times that of any other phospholipid estimated. The time course of the incorporation of radioactivity into the cephalin components and into the lecithins has been followed by Ansell and Dohmen (1957, Fig. 4). Within $3 \mathrm{hr}$ of an intraperitoneal injection of radioactive phosphate to the rat, the relative specific radioactivity of phosphoinositide phosphorus was 30-100 times as great as that in other phospholipids measured. The exchange of phosphorus with phosphatidyl serine and sphingomyelin was so low as to be scarcely detectable (cf. also Dawson, 1954). The recognition that phospholipids in the adult brain exchange their phosphorus at widely differing rates raises many questions regarding the significance of both the rapid and slow exchange processes.

The high rate of exchange in the inositide phospholipids is apparently peculiar to nervous tissue. In the liver of the rat the uptake of phosphate into phosphatidyl choline (lecithins) is much greater than into the inositol containing phospholipids (Dawson, 1955). In liver the inositol lipids contain a monophosphoinositide (McKibben, 1956) and it has recently been found that the cephalin diphosphoinositide fraction from brain also contains a mono- 


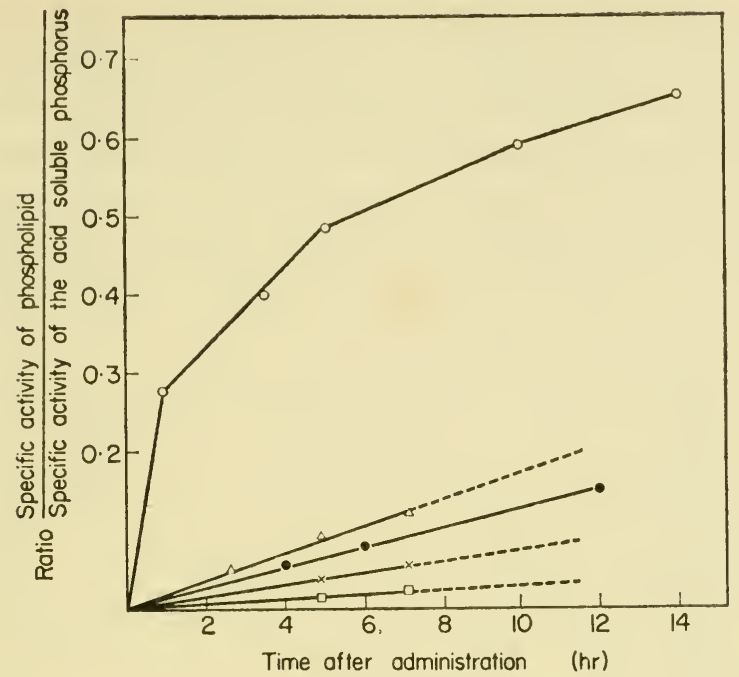

FIG. 4. The incorporation of radioactive phosphate into individual phospholipids of rat and mouse brain. Data from Dawson and Richter (1950); Dziewiatkowski and Bodian (1950); Ansell and Dohmen (1958). $\bigcirc=$ cephalin diphosphoinositide; $\Delta=$ phosphatidyl choline; $\square=$ phosphatidyl serine; $\times=$ phosphatidyl ethanolamine; = total phospholipids. Specific activity $=$ counts $/$ min per $\mu \mathrm{g}$ phosphorus.

phosphoinositide which exchanges its phosphorus rapidly (Hokin and Hokin, 1958a). It is likely that other phospholipids of similar metabolic character will be discovered as separative techniques improve. In this connexion the presence of phosphatidic acids, apparently localized in the microsomes, have been demonstrated in guinea pig brain (Hokin and Hokin, 1958b). 'These acids have also been found to exchange appreciable quantities of radioactive phosphorus in vivo.

\section{Incorporation into Phosphoproteins, Nucleic Acids and Residual Organic Phosphates}

Knowledge of phosphorus metabolism in these groups of compounds is still meagre. The incorporation of radioactive phosphorus, administered either by intravenous or by intracisternal injection is most rapid into the phosphoprotein fraction 
(Strickland, 1952; Johnson and Albert, 1953; Vladimirov, 1953; Lissovskaya, 1954). Within 3 or $4 \mathrm{hr}$ the specific radioactivity reaches values of $0.3-0.5$ of the specific radioactivity of the acidsoluble phosphorus (Vladimirov et al., 1956; Johnson and Albert, 1954). The time course of incorporation into this and other phosphates was studied by Strickland (1952). Radioactivity of

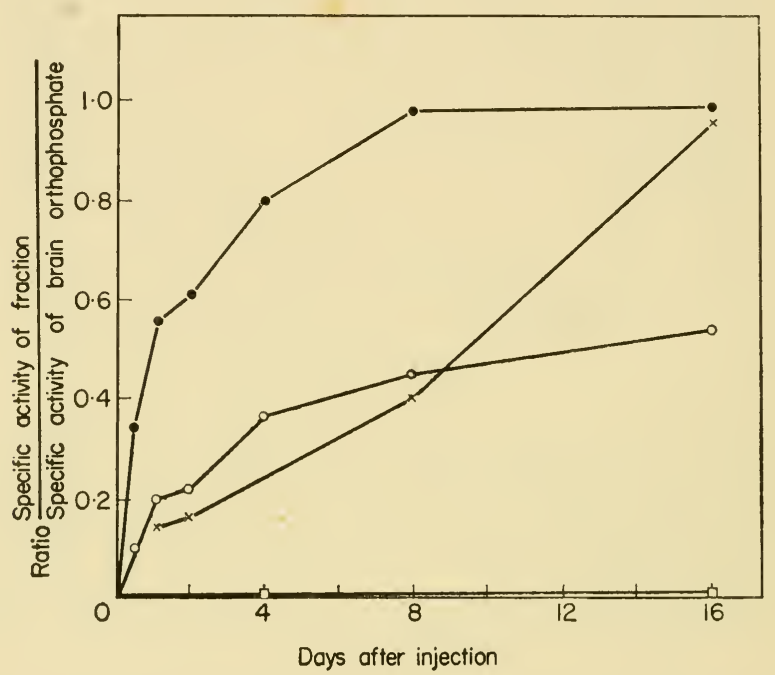

Fig. 5. The incorporation of radioactive phosphorus into the cerebral phosphates remaining after removal of the acid-soluble and lipid phosphorus. Data from Strickland (1952). Cat, phosphate administered by intracisternal injection. = phosphoprotein fraction; $x=$ ribonucleic acid; $O=$ residual organic phosphorus; $\square=$ desoxyribonucleic acid.

phosphoprotein phosphorus reached equilibrium with the inorganic phosphorus of the brain within 6 days (Fig. 5) and a relative specific activity of 0.5 within $6-12 \mathrm{hr}$. The initial rate of exchange in this fraction is comparable with that in cephalin diphosphoinositide (Fig. 4). The phosphoprotein fraction is not homogeneous with respect to phosphorus exchange. Two phosphoprotein fractions have been found in guinea pig brain (Heald, 1959), one soluble in isotonic sucrose, the other attached to particulate matter. In vivo radioactive phosphate injected intracisternally was incorporated to a greater extent into the soluble 
phosphoprotein fraction than into the fraction associated with the particles. Recently, Vladimirov et al. (1957) described a fraction, isolated from a lipid free brain residue, which was not a phosphoprotein but nevertheless exchanged its phosphorus at a comparable rate.

The finding that ribose nucleic acid exchanges its phosphorus at an appreciable rate (Fig. 5) is of considerable interest. It is now generally accepted that ribonucleic acid is in some way involved in protein synthesis, though it is not necessarily the case that protein synthesis and ribonucleic acid synthesis should proceed simultaneously. Recently it has been shown, contrary to earlier belief, that the proteins of brain are metabolically active, exchanging their aminoacids for others entering from the blood stream (Gaitonde and Richter, 1956, 1957; Clouet and Richter, 1959; Furst et al., 1958; Lajtha, 1958). It is likely that in the brain as in other cells the turnover of ribonucleic acid and protein synthesis will be found to be interdependent (cf. Einarson, 1957). Exchange of phosphorus with desoxyribonucleic acid is extremely slow, the significance of which is not entirely clear. It may be partly associated with the absence of cell proliferation in the adult brain. It should perhaps also be emphasized that the measurements so far made concern phosphorus exchange only. There is no reason to believe that other parts of the molecule exchange equally slowly. Present evidence (see Einarson, 1957, for summary) tends to suggest the contrary though biochemical evidence is lacking.

Incorporation of phosphorus into the residual organic phosphorus fraction is similarly a process the significance of which is obscure. The nature of this fraction has been commented upon above. Generally, measurement of change in the radioactivity of phosphorus in compounds of this type does no more than indicate the existence of a rapid or slow rate of exchange. It is for further work to establish the significance of such exchange.

\section{REFERENCES}

Abood, L. G., Gerard, R. W., Banks, J. and Tschirgi, R. D. (1952) Amer. F. Physiol. 168, 728.

Agren, G. and EngStrom, L. (1956) Acta. chem. scand. 10, 489.

Albaum, H. G., Tepperman, J. and Bodansky, O. (1946) \%. biol. chem.

164,45 . 
Ansell, G. B. and Dawson, R. M. C. (1951) Biochem. F. 50, 241.

Ansell, G. B. and Dohmen, H. (1957) f. Neurochem. 2, 1.

Ansell, G. B. and Norman, J. M. (1953) Biochem. F. 55, 768.

ARTOM, C. (1945) F. biol. chem. 157, 595.

BAKay, L. (1951) Arch. Neurol. Psychiat. Chicago 66, 47.

Bakay, L. (1953) Arch. Neurol. Psychiat. Chicago 70, 2.

Bakay, L. (1954) Arch. Neurol. Psychiat. Chicago 71, 673.

BAKAY, L. (1957) in Metabolism of the Nervous System (Ed. by D. Richter),

Pergamon Press, London \& New York.

BAKAY, L. and LindBerg, O. (1949) Acta physiol. scand. 170, 179.

Bain, J. A. and Pollock, G. H. (1949) Proc. soc. exp. biol. med. N. Y. 71, 95.

Bain, J. A., Pollock, G. H. and Stein, S. N. (1949) Proc. soc. exp. biol. med. N.Y. 71, 497.

Baranov, N. M. (1957) Biokhim. 22, 778.

Bendich, A., Pahl, H. B. and Beiser, S. M. (1956) Symp. Quant. Biol. 21, 31.

Blix, G., Svennerholm, L. and Werner, I. (1952) Acta. chem. scand. 6, 358. Bodian, D. and Dziewiatkowski, D. (1950) F. cell. comp. Physiol. 35, 155. Воотн, F. J. (1935) Biochem. F. 29, 2071.

Bollard, B. and McIlwain, H. (1957) Biochem. F. 66, 651.

Borell, U. and Ostrom, Å. (1945) Acta. physiol. scand. 10, 231.

Bradley, D. F. and Rich, A. (1956) F. Amer. Chem. Soc. 78, 58-98.

Brierley, J. B. (1957) in Metabolism of the Nervous System (Ed. by D. Richter), Pergamon Press, London \& New York.

Burton, R. M., Sodd, M. A. and Brady, R. O. (1958) Neurology 8, Suppl. 1, 84.

Cardini, C. E. and Leloir, L. F. (1957) F. biol. chem. 225, 315.

Changus, G. W., Chaikoff, I. L. and Ruben, S. (1938) f. biol. chem. 126, 493.

Chargaff, E., Olsen, K. B. and Partington, P. F. (1940) F. biol. chem. 134, 505.

Clouet, D. H. and Richter, D. (1956) Proc. Roy. Soc. B 145, 83.

Cohn, W. E. and Greenserg, D. M. (1938) F. biol. chem. 123, 185.

Colowick, S. P. and Kaplan, N. O. (1955) (Editors) Methods in Enzymology, Vol. I. Academic Press, New York.

Crosbie, G. W., Hutchinson, W. C., McIndoe, W. M., Childs, M. and Davidson, J. N. (1954) Biochim. biophys. Acta. 14, 580.

Daniel, P., Pritchard, M. M. and Schurr, P. H. (1958) Lancet, 3.

Dawson, R. M. C. (1952) Symp. Biochem. Soc. No. 8, 93.

Dawson, R. M. C. (1953) Biochem. F. 53, Proc. viii.

Dawson, R. M. C. (1954) Biochem. F. 57, 237.

Dawson, R. M. C. (1955) Biochem. F. 61, 552.

Dawson, R. M. C. (1958) Biochem. F. 68, 357.

Dawson, R. M. C. and Peters, R. A. (1955) Biochim. biophys. Acta. 16, 254.

Dawson, R. M. C. and Richter, D. (1950a) Amer. F. Physiol. 160, 203.

Dawson, R. M. C. and Richter, D. (1950b) Proc. Roy. Soc. B 137, 252.

Davenport, H. A. and Sacks, J. (1929) f. biol. chem. 81, 469.

Deuel, H. J. (1955) The Lipids, Vol. II, Interscience, New York. 
Dobing, J. (1956) Guy's Hospital Reports 105, 27.

Doring, H. J. and Gerlach, E. (1957) Arch. exp. Pathol. Pharmacol. 232, 271.

Dziewiatkowski, D. and Bodian, D. (1950) F. cell. comp. Physiol. 35, 141. Einarson, L. (1957) in Metabolism of the Nervous System, p. 403 (Ed. by D. Richter), Pergamon Press, London \& New York.

Englehardt, V. A. and Lissovskaya, N. P. (1953) Proc. 19th Intern. Congress Physiol. Montreal, p. 335.

Eggleton, P. and Eggleton, G. P. (1927) f. Physiol. 63, 155.

FolCH, J. (1949) F. biol. chem. 177, 497.

Folch, J., Arsove, J. A. and Meath, J. A. (1951) F. biol. chem. 191, 819. Folch, J. and LE Baron, F. N. (1957) in Metabolism of the Nervous System (Ed. by D. Richter), Pergamon Press, London \& New York.

Fries, B. A. and Chaikoff, I. C. (1941) f. biol. chem. 141, 469.

Fries, B. A., Changus, G. W. and Chaikoff, I. L. (1940) F. biol. chem. $132,32$.

Furst, S., Lajtha, A. and Waelsch, H. (1958) F. Neurochem. 2, 216.

Gaunt, W. E., Griffith, H. D. and Irving, J. J. (1942) F. Physiol. 100, 372. Gaitonde, M. K. and Richter, D. (1956) Proc. Roy. Soc. B 145, 83.

Gerard, R. W. (1932) Physiol. Rev. 12, 469.

Glock, G. E. and McLean, P. (1955) Biochem. F. 61, 385.

Greenberg, D. M., Aird, R. B., Boelter, M. D., Campbell, W. W., Cohn, W. E. and Marayama, M. M. (1943) Amer. F. Physiol. 140, 47. Heald, P. J. (1956) Biochem. F. 63, 235.

Heald, P. J. (1957) Biochem. F. 67, 539.

Heald, P. J. (1958) Biochem. F. 58, 580.

Heald, P. J. (1959) Biochem. F. 73, 132.

Hearon, J. Z. (1951) Amer. F. Physiol. 164, 13.

Hevesy, G. (1947) Advances in Enzymology 7, 143.

Hevesy, G. and Hahn, L. (1940) Kgl. Danske. Viderskalb. Selskab. Biol. Medd. XV, No. 5.

Himwich, H. and FazeKas, J. F. (1937) Endocrinol. 21, 800.

Hokin, L. E. and Hokin, M. R. (1958a) F. biol. chem. 233, 818.

Hokin, L. E. and НокIN, M. R. (1958b) F. biol. chem. 233, 822.

Hurlbert, R. B. and Potter, V. R. (1954) F. biol. chem. 209, 1.

Johnson, L. M. and Albert, S. (1953) F. biol. chem. 200, 325.

Johnson, A. C., McNabB, A. R. and Rossiter, R. J. (1948) Biochem. F. 43, 573.

Johnson, A. C., McNabb, A. R. and Rossiter, R. J. (1950) Arch. Neurol. Psychiat. 64, 105.

Kaвat, H. (1944) Science 99, 63.

KERR, S. E. (1935) F. biol. chem. 110, 625.

KERR, S. E. (1941) F. biol. chem. 140, 77.

KERR, S. E. (1942) F. biol. chem. 145, 647.

KERR, S. E. and Seraidarian, K. (1945) F. biol. chem. 159, 211.

Klein, J. R. and Olsen, N. S. (1947) F. biol. chem. 167, 742.

Klenk, E., Vater, W. and Bartsch, G. (1957) F. Neurochem. 1, 203.

Koransky, W. (1958) Arch. exp. Pathol. Pharmacol. 234, 46. 
Kratzing, C. C. and Narayanaswami, A. (1953) Biochem. F. 54, 317. Lajtha, A. (1958) f. Neurochem. 2, 209.

Le Baron, F. N. and Folch, J. (1956) F. Neurochem. 1, 101.

LeLorr, L. F. (1953) Advances in Enzymology 14, 238.

Le Page, G. A. (1946) Amer. F. Physiol. 146, 267.

Lin, S., Cohen, H. P. and Cohen, M. M. (1958) Neurology 8 (Suppl. 1), 72.

LindBerg, O. (1946) Ark. Kemi. Min. og. Geol. 23, 1.

LindBerg, O. and ERnster, L. (1950) Biochem. F. 46, 43.

Lissovskaya, N. P. (1954) Dokl. Akad. Nauk. SSSR 95, 1033.

Logan, J. E., Mannell, W. A. and Rossiter, R. J. (1952a) Biochem. F. 51,470 .

Logan, J. E., Mannell, W. A. and Rossiter, R. J. (1952b) Biochem. F. 51,480 .

Lowry, O. H. (1957) in Metabolism of the Nervous System (Ed. by D. Richter), Pergamon Press, London \& New York.

LundSGaARD, E. (1930) Biochem. Z. 217, 163.

LundsgaARd, E. (1931) Biochem. Z. 233, 322.

McIllwain, H. (1956) Physiol. Rev. 36, 355.

McIllwain, H. (1957) in Metabolism of the Nervous System (Ed. by D. Richter) Pergamon Press, London \& New York.

McIlwain, H. (1959) Biochemistry and the Central Nervous System, 2nd ed., Chapman \& Hall, London.

McIldain, H., Buchel, L. and Cheshire, J. D. (1951) Biochem. F. 48, 12.

McKibBEN, J. M. (1956) f. biol. chem. 220, 537.

McMurray, W. C., Strickland, K. P., Berry, J. F. and Rossiter, R. J. (1957) Biochem. F. 66, 634.

Mandel, P. and Harth, S. (1957) C.R. Acad. Sci., Paris 245, 183.

Maxwell, E. S., Kalkar, H. M. and Burton, R. M. (1955) Biochem. biophys. Acta. 18, 444.

Middleton (1953) Quoted by Rossiter, R. J. (1955a).

Moser, H. and Karnovsky, M. L. (1958) Neurology 8 (Suppl. 1), 81.

Muntz, J. A. (1953) F. biol. chem. 201, 221.

Neurath, H. (1957) in Advances in Protein Chemistry 12, 320.

Ochoa, S. and Stern, J. R. (1952) Ann. Rev. Biochem. 21, 547.

Paladini, M. T. (1951) quoted by Leloir (1953) Advances in Enzymology 14, 212.

Perlman, I., Ruben, S. and Chaikoff, I. L. (1937) ₹. biol. chem. 122, 169. Pscheidt, G. R., Benitez, D., Kirschner, L. B. and Stone, W. E. (1954) Amer. F. Physiol. 176, 483.

Richter, D. and Gaitonde, M. K. (1957) in Metabolism of the Nervous System (Ed. by D. Richter), Pergamon Press, London \& New York.

Rosenfeld, I. and Beath, O. A. (1952) Proc. soc. exp. biol. N.Y. 81, 608.

Rossiter, R. J. (1955a) Canad. F. biochem. Physiol. 33, 477.

Rossiter, R. J. (1955b) in Neurochemistry (Ed. by K. A. C. Elliot, I. H.

PAge and J. H. Quastel) Thomas, Springfield, Illinois.

Sacks, J. and Culbreth, G. G. (1951) Amer. F. Physiol. 165, 251.

Schmidt, G., Bennotti, J., Hershman, B. and Thannhauser, S. J. (1946) J. biol. chem. 166, 505. 
Schmitz, H., Potter, V. R., Hurlbert, R. B. and White, D. M. (1954) Cancer Research 14, 66.

SCHNeIder, W. C. (1946) F. biol. chem. 164, 747.

Selverstone, B. (1958) in The Cerebrospinal Fluid, Symposium of the

Ciba Foundation, Churchill, London.

Shapot, V. S. (1957) In Metabolism of the Nervous System, p. 257 (Ed. by

D. Richter), Pergamon Press, London \& New York.

Shideman, F. E. and Seevers, M. H. (1953) Proc. soc. exp. biol. N.Y. $82,63$.

Sidbury, J. and NaJjar, V. A. (1957) F. biol. chem. 227, 517.

Sloane-Stanley, G. H. (1952) Symp. Biochem. Soc. 8, 44.

STONE, W. E. (1940) F. biol. chem. 135, 43.

STONE, W. E. (1943) F. biol. chem. 149, 29.

Stoner, H. B. and Threlfall, C. J. (1954) Biochem. F. 58, 115.

Strickland, K. P. (1952) Canad. F. biochem. Physiol. 30, 484.

SvenNerHolm, L. (1956a) Nature, Lond. 177, 524.

SVENNERHOLM, L. (1956b) F. Neurochem. 1, 42.

TAYLOR, W. E. and McKibBen, J. M. (1953) f. biol. chem. 201, 609.

Thannhauser, S. J. (1957) in Biochemical Disorders in Human Diseases, p. 617 (Ed. by R. H. S. Thompson and E. J. KING), Churchill, London.

Thomas, J. (1957) Biochem. F. 66, 655.

Thorn, W., Pfleiderer, G., Frowein, R. A. and Ross, I. (1955) Pflügers Archiv. 261, 334.

Thorn, W., Scholl, H. Pfleiderer, G. and Mueldener, B. (1958) F. Neurochem. 2, 150.

Utter, M. F. (1958) Ann. Rev. Biochem. 27, 245.

Vladimirov, G. E. (1953) Fiziol. Zhur. SSSR 39, 3 (Chem. Abstr. 47, 4983e).

Vladimirov, G. E. (1955) in Biochemistry of the Developing Nervous System, p. 218 (Ed. by H. Waelsch), Academic Press, New York.

Vladimirov, G. E., Ivanova, T. N. and Pravdina, N. L. (1956) Biokhimiya. 21, 155.

Vladimirov, G. E., Ivanova, T. N. and Pravdina, N. I. (1957) Biokhimiya, 22, 327.

Vladimirov, G. E. and Rubel, L. N. (1957) in Metabolism of the Nervous System, p. 263 (Ed. by D. Richter), Pergamon Press, London \& New York.

Volkova, R. I. (1957) Biokhim. 22, 644.

Walker, D. M. (1952) Biochem. F. 52, 679.

Wallace, G. B. and Brodie, B. B. (1940) F. Pharmacol. 70, 418.

Webster, G. R. (1954) Biochem. F. 57, 153.

Weil-Malherbe, H. and Green, R. H. (1955) Biochem. F. 61, 218.

Weil-Malmerbe, H. (1952) Symp. Biochem. Soc. 8, 16.

Wosilait, W. (1958) F. biol. chem. 233, 97.

Zetterstrom, R. and Ljungren, M. (1951) Acta. chem. scand. 5, 291.

Zetterstrom, R., Ernster, L. and Lindberg, O. (1950) Arch. Biochem. $25,255$.

Zilversmit, D. B., Enteman, C. and Fishler, M. C. (1943) F. gen. Physiol. 26, 325. 


\section{METABOLISM UNDER CONDITIONS OF CHANGED ACTIVITY}

IN THE previous chapter the nature of the phosphate derivatives present in brain and their relative rates of exchange of phosphorus were discussed. The problem of assessing the significance of such exchange, or of the presence of a particular phosphate, as it relates to the functioning of the brain can be approached by altering the normal function and determining how this affects phosphate metabolism. Techniques have been developed and exist for experimental studies of this type and have provided the bulk of the available knowledge. On the other hand study of the changes taking place in brain metabolism during the period in which it is developing and signs of its co-ordinated functioning are appearing in the whole animal also offers a particularly suitable approach. This latter type of study, though not yet as extensive as might be wished, has provided much interesting information and will be considered first. An extended discussion upon the developmental aspects of cerebral metabolism and function has already appeared (Symposium, 1955).

\section{Phosphites During Development}

\section{Acid-soluble Phosphates}

The development of the brain may be conveniently divided into four stages (see McIlwain, 1959). The first stage is chiefly characterized by a marked increase in the number of cells. In the mouse, rat or cat this period lasts until birth or shortly afterwards, whereas in the guinea pig or man it is largely complete after twothirds of the gestation period. During this stage the brain is electrically silent (Hill, 1955; Crain, 1952; Libet et al., 1941; Flexner et al., 1950) and either does not respond or responds only slightly to stimulation, for example when strychnine is applied to the cortex. The second stage is characterized by the growth of 
cells, axons and dendrites and occupies roughly the first ten days of life in the rat, the first twenty days in the mouse and from the 40 th-46th day of gestation in the guinea pig. In man this process continues to birth. During this phase spontaneous electrical activity can be detected from the cortex though the subcortex may be silent (Flexner, 1955; Crain, 1952). Man differs in the activity since at birth the waking infant shows no spontaneous electrical activity recorded from the scalp (Hill, 1955). Topical application of strychnine to guinea pig or rat cortex results in bursts of activity. In the third stage growth largely ceases and the formation of myelin sheaths around the axons is the predominant feature. Co-ordination of muscular movement begins. In the rat this occupies the period between 10-20 days after birth, in the mouse from 10 to 30 days after birth, in man to 210 days after birth and in guinea pig from the 46th day of gestation to birth. The fourth stage comprises further myelination and the establishment of an adult pattern of cortical and subcortical activity.

During these stages there are marked increases in metabolic processes such as oxygen consumption (Himwich, 1951). This is accompanied by an increased dependence of the brain upon the oxidation of glucose as a major source of energy for the maintenance of its function. Since the generation of energy in the form of acid-hydrolysable phosphates is closely linked to such a process, it might be expected that the quantities of phosphocreatine and adenosine triphosphate would increase during the period of development.

This problem has been examined in several species. Data obtained for the quantities of phosphocreatine in the brain of the rat are shown in Fig. 6. The manner of presentation of results obtained from analyses of developing brain have been discussed in detail by Folch (1955) and McIlwain (1959), and should be referred to for details and sources of error. Here the data are presented in three ways; (a) related to wet weight, (b) as the total quantity/brain, and (c) related to the content of desoxyribonucleic acid. The period of maximal growth of the brain and development of function (stage 3 ) is marked by a doubling or trebling of the total quantity of phosphocreatine present, though the concentration/unit of mass increases only slightly. The concentration relative to the content of desoxyribonucleic acid showed little change. The amount of desoxyribonucleic acid is known to be 
constant for each nucleus in the somatic tissues of any given species and is a measure of the number of cells (Boivin et al., 1948; Vendrely and Vendrely, 1948, 1949). Thus the relatively constant ratio of phosphocreatine to desoxyribonucleic acid indicates that the quantity per cell was unchanged throughout this period of development. Similar results were obtained for the quantities of

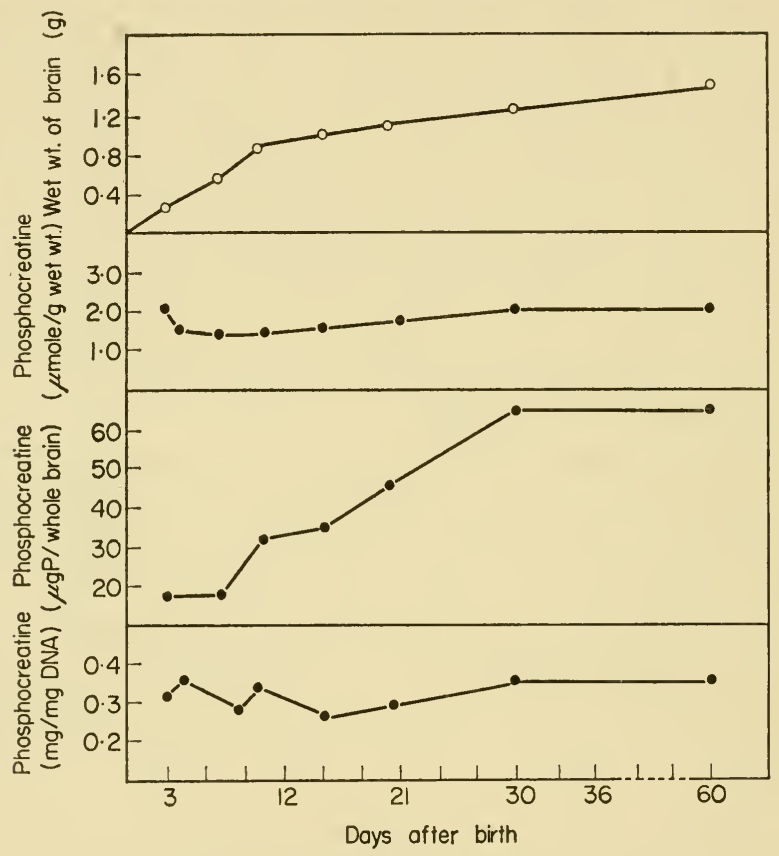

FIG. 6. The quantities of phosphocreatine in rat brain during development and growth. Data from Mandel et al. (1953). Animals were decapitated and the heads allowed to fall into liquid nitrogen before analysis.

adenosine triphosphate. In the guinea pig, changes analogous to these occur during foetal life (Flexner and Flexner, 1950). Foetuses were removed under general anaesthesia, and immersed in liquid nitrogen while the umbilical circulation was still intact and in good condition. Here also calculation of the quantities of phosphocreatine and adenosine triphosphate in terms of concentration/unit weight showed that little if any change occurred from the 30 th day of gestation to birth on the 66th day. On the other 
hand, the fraction containing hexose phosphates and diphosphopyridine nucleotide, when calculated on the same basis, was found to decrease by half during this period, a decrease which is also calculable from the data of Mandel et al. (1953).

Patterns of change in the acid-soluble phosphates in the brain of the developing chick embryo are similar, though individual differences have been noted. In the chick the relative physiological stages occur rapidly; from $0-10$ days incubation, stage I; 12-19 days, stage II; $19-26$ days, stage III and the beginnings of stage IV. From the 10th-19th days of incubation Mandel et al. (1947) found that the quantities of phosphocreatine increased from $0 \cdot 15 \mu$ moles/ g wet wt. at 10 days, to $1.8 \mu$ moles $/ \mathrm{g}$ wet wt. on the 19 th day. Quantities of pyrophosphate (presumably from adenosine triphosphate) decreased from $3.0 \mu$ moles/g wet wt. on the 10 th day. Szepsenwol and Partridge (1952) found no such change until the 18th-20th day of incubation when the quantities of phosphocreatine increased rapidly from $0 \cdot 6 \mu$ moles $/ \mathrm{g}$ wet wt. to $1 \cdot 2$ $\mu$ moles/g wet wt. on the $22 \mathrm{nd}-23 \mathrm{rd}$ day. Increase in phosphocreatine was accompanied by a decrease in adenosine triphosphate. Reasons for these differences are not readily apparent. In the chick embryo the period between 10-19 days incubation corresponds to the period of active myelination and the development of a fairly well defined electrocorticogram (Garcia-Aust, 1954). As noted above, in both the rat and guinea pig, this period in development is accompanied by an increase in the total quantities of phosphocreatine and adenosine triphosphate in the brain. The coincidence of the two processes suggests that during the period of increasing functional organization there is also an increase in the systems involved in the synthesis of the energy-rich phosphates.

There is no good reason why such an increase in synthetic activity need be reflected in an increased quantity/unit of mass of a phosphate such as phosphocreatine, though this clearly takes place in the chick brain. Indeed it seems more likely, as Flexner and Flexner (1950) consider, that during this period the rate of turnover of the phosphorus in such compounds is greatly increased. In so far as the respiratory activity increases, with which phosphorylation is linked, this view has much to support it, though critical data are lacking.

Increase in rates of synthesis while concentrations remain relatively constant, implies a simultaneous increase in systems 
degrading or metabolizing the phosphates formed. Enzymes capable of degrading energy-rich phosphates include acid and alkaline phosphatases, adenosine triphosphatase and adenosine5 '-nucleotidase. The onset of maturation of the cortex is accompanied by a rapid and marked increase in the activity of adenosine triphosphatase. In the rat activity increased rapidly from the low level existing from birth to the 6th day of age, to the adult level in 15 days (Potter et al., 1945). In the guinea pig a similar increase occurred from the 43rd day of gestation to birth (Flexner and Flexner, 1948). In the chicken embryo adenosine triphosphatase of the brain increased steadily from the 12th day of incubation (Moog, 1947). Other enzymes probably related to the metabolism of adenosine triphosphate include adenosine-5'-nucleosidase which in rat brain increases from a negligible quantity at birth to the adult level within 120 days (Naidoo and Pratt, 1954). Measurements upon the activity of creatine phosphokinase have not been reported but are likely to show a similar trend.

It must be admitted that the extent to which these enzymes govern the quantities of their substrates in the brain in vivo, or whether this is a sole or even a major function is not known. Some indication of the manner in which they might act is provided by studies with diphosphopyridine nucleotide and the corresponding nucleotidase. In rat brain the quantity of diphosphopyridine nucleotide remains relatively low at $0.18 \mu$ moles $/ g$ wet wt. until about 10 days after birth. Between the tenth and twentieth day quantities increase rapidly to the adult level of $0.3 \mu$ moles $/ \mathrm{g}$. At the same time the activity of the nucleotidase increases thirtyfold. This enzyme can be inhibited by nicotinamide (see also p. 88). When given by intraperitoneal injection, nicotinamide, as a dose of $500 \mathrm{mg} / \mathrm{kg}$ body wt., increased the quantities of cerebral diphosphopyridine nucleotide by $30 \%$ in the eight day old rat and by $50 \%$ in the 25 -day-old animal (Eurton, 1957). The nucleotidase is thus implicated, as part of its action at least, with control of the quantities of its sut .. iate. Such control is essential for the maintenance of the processes of respiration and phosphorylation and forms the subject of separate discussions (see pp. 109-111, 159).

\section{Phospholipids}

Simultaneously with the development of enzyme systems relating to energy metabolism there occur equally profound changes 
in structural components of the brain such as proteins, lipids and nucleic acids. Of these, lipids have received the major attention both as constituting some $20 \%$ of the fresh weight of the adult brain and for the suggested role of certain of them in the formation of the myelin sheath.

The stage of development corresponding to the period during which myelin is being formed and deposited most rapidly is marked by a major increase in both quantity and concentration of the phospholipids. Data, derived from several sources, for different species, are presented in Fig. 7. Although expressed in terms varying according to the authors, the major increases in quantity clearly take place within a relatively short period in the physiological time scale of each particular species. Certain lipids increase in quantity more markedly than others, and include the major "myelin lipids", cerebrosides, cholesterol and sphingomyelin. Measurement of changes in the quantities of sphingomyelin (Fig. 8) have shown that the increase is extremely rapid, occupying the period between 12-16 days after birth in the rat, and

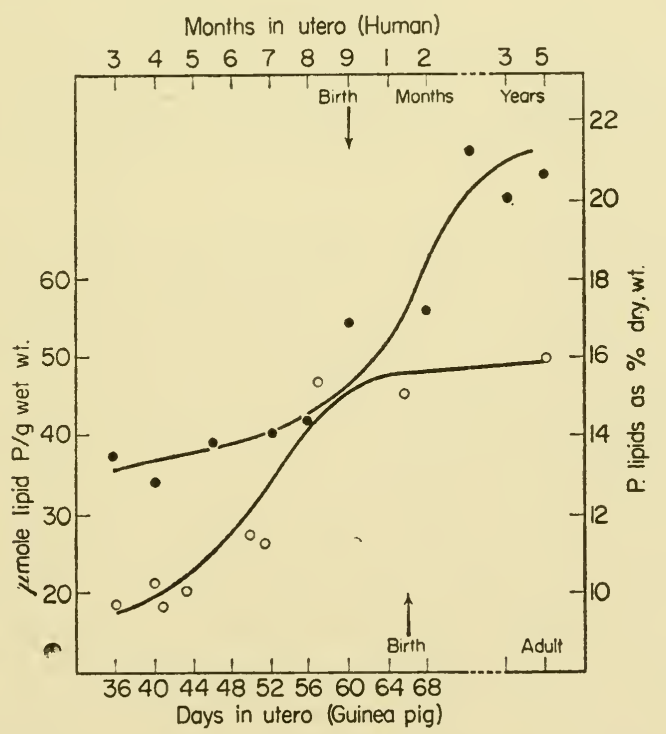

FIG. 7. The increase in the total phospholipids of brain during early growth and development. Data from Flexner and Flexner (1950), and Brante (1949). $\bigcirc=$ guinea pig; $\bullet=$ human. 


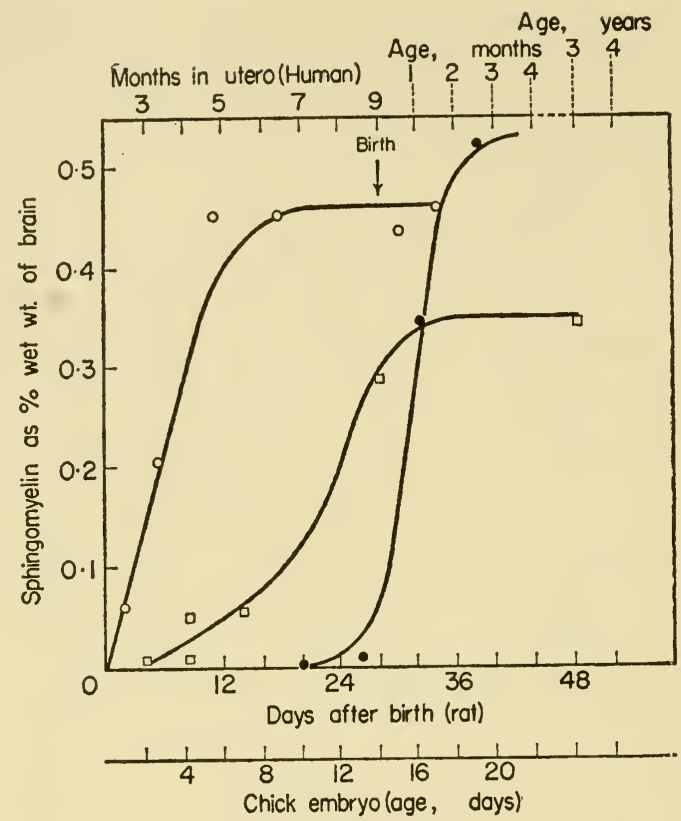

FIG. 8. The increase in sphingomyelin in brain during growth and development. $\bigcirc=$ rat, mouse, data from Folch (1955) and Brante (1949). = chick embryo, data from Mandel et al. (1949). $\square=$ human cerebral cortex, data from Brante (1949).

in the chick embryo the 12 th -16 th day of incubation. Since increase in quantity alone is a normal accompaniment of growth such rapidity of increase is a distinguishing feature. Other phospholipids increasing rapidly during this period include the acetal phospholipids or plasmalogens. In the mouse brain plasmalogens increase from $0.19 \%$ of the wet weight to $0.75 \%$ of the wet weight between the 5 th-30th day of age. In human grey matter the sum total of phosphatidyl serine, phosphatidyl ethanolamine, diphosphoinositide and plasmalogens increased some threefold between the time immediately before myelination and the adult stage. In white matter the increase was sixfold (Folch, 1955). This increase could be accounted for by an increase both in plasmalogens and phosphatidyl ethanolamine. The full significance of such increases is not fully understood. In so far as certain phospholipids such as sphingomyelin are considered to be part of the myelin sheath rapid 
increases during myelination are understandable. Similar explanations may hold for the plasmalogens which have been established histochemically as forming part of the myelin sheath (see Albert and Lebland, 1946). However, although such increases are suggestive it is widely recognized that equating increases in the quantities of certain lipids with the process of myelination suffers both from lack of information as to the nature of all the brain lipids and depends on certain assumptions which are not yet proven (Uzman and Rumley, 1958). These include: (a), that increase in a lipid component represents myelin lipid because it appears at the same time as myelin increases; (b), that the number of cells and cell types in brain remains constant so that (a) is possible, and (c), that the lipid components of various neuronal and glial elements remain quantitatively and qualitatively constant.

As with the acid-soluble phosphates increase in quantity implies the development of systems capable of synthesis which are presumably balanced to some degree by systems capable of further metabolism. However, it is still not clear whether the phospholipids arise solely by synthesis in the brain or are partly supplied from the blood or whether the capacity for synthesis is greater in the infant than in the adult. In the latter circumstances it might be expected that more phosphorus from the blood would be incorporated into brain phospholipids in early life than in the adult stage. In the infant rat it was found (Chaikoff et al., 1938) that the percentage of a given dose of radioactive phosphate incorporated into the phospholipids was markedly greater than in the adult (Fig. 9). Interestingly, in both adult and infant the decline of radioactivity, after the initial rapid rise, was a prolonged process. More extended observations have been made by Davison and Dobbing (1958). Here, radioactivity of the phospholipids was expressed as counts/whole brain, a method of calculation which presumably overcomes changes in quantity of phospholipids due to growth. The initial increase in radioactivity of the phospholipids in the infant rat brain was similar to that found by Chaikoff et al. (1938) though the decline in radioactivity was much slower. Thus at 70 days after the injection of radioactive phosphate the counts remaining in the brain were $60-70 \%$ of those present at the peak of incorporation some 50 days previously. Measurements of the amount of radioactivity incorporated in the phospholipids from different areas of rat brain, $24 \mathrm{hr}$ after a standard dose $/ \mathrm{kg}$ body 4-PMB 
weight were made by Fries et al. (1940) and Fries and Chaikoff (1941). Thus, radioactivity in lipids from the forebrain was twice as great in the 1-day-old rat as in the 7-day-old rat and some 10-20 times as great as in the 30-day-old rat. Similar decreases in phosphorus incorporation were found with the lipids from the cerebellum, medulla and spinal cord. In the cat radioactive phosphate was found to enter the phospholipids of the foetal brain some 3-4 times more rapidly than the maternal brain (Stern and Marshall,

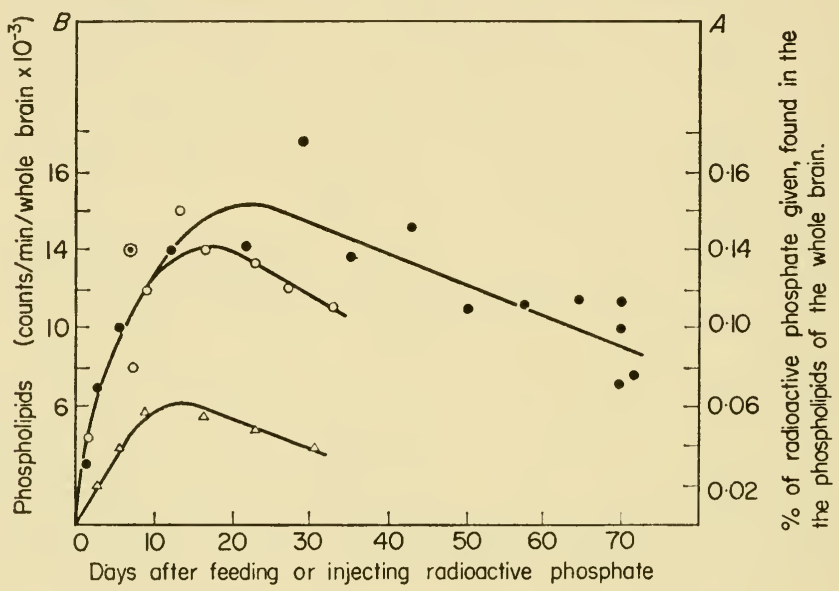

FIG. 9. The incorporation and retention of radioactive phosphate into the phospholipids of whole brain in the infant and adult rat. Infant rats were initially selected when $38 \mathrm{~g}$ body weight. Ordinate A, data from Changus et al. (1938); $O=$ infant rat; $\Delta=$ adult rat. Ordinate $\mathrm{B}$, data from Davison and Dobbing (1958): $\bullet=$ infant rat.

1951). Similar measurement in the rabbit (Bakay, 1953) showed that here also the foetal brain accumulated more of a dose of radioactive phosphorus in a given period than did the adult brain.

During development the entry into the brain of many ions such as phosphate, chloride, glutamate and thiocyanate is decreased, though the mechanism underlying the change is obscure (Bakay, 1953; Himwich and Himwich, 1955; Lajtha, 1957). Such changes are generally ascribed to the development of the blood-brain barrier but a decreased uptake of a substance by an organ may also reflect a change in the metabolic pattern of that organ. Difficulties 
inherent in the assessment of such situations are illustrated by data given by Dawson and Richter (1950a) (see Table 6). Mice were injected intraperitoneally with radioactive phosphorus, sacrificed $3 \mathrm{hr}$ later, and the specific radioactivities (in counts/min per $\mathrm{mg}$ phosphorus) of the brain phospholipids were determined. When related to the specific radioactivity of the acid-soluble phosphorus of brain, the incorporation of phosphorus into the phospholipids was found to decrease with increasing age. This accords with a decreased rate of lipid renewal as age increases. However, as Dawson (1955) has pointed out, it is to be remembered that the

Table 6.-The Effect of Age upon the Uptake of Radioactive Phosphorus into the Lipids of Mouse Brain

\begin{tabular}{|c|c|c|}
\hline \multirow{2}{*}{$\begin{array}{l}\text { Age } \\
\text { (days) }\end{array}$} & \multicolumn{2}{|c|}{ Specific activities $\times 10^{3}$} \\
\hline & $\frac{\text { Acid-soluble } \mathrm{P} \text { of brain }}{\text { Acid-soluble } \mathrm{P} \text { of blood }}$ & $\frac{\text { Lipid } \mathrm{P} \text { of brain }}{\text { Acid-soluble } \mathrm{P} \text { of brain }}$ \\
\hline $\begin{array}{c}8 \\
22 \\
47 \\
365\end{array}$ & $\begin{array}{r}-\overline{106} \\
99 \\
118\end{array}$ & $\begin{array}{l}64 \cdot 0 \\
59 \cdot 0 \\
38 \cdot 8 \\
41 \cdot 2\end{array}$ \\
\hline
\end{tabular}

Dawson and Richter (1950a). Mice killed $180 \mathrm{~min}$ after injection of ${ }^{32} \mathrm{P}$.

brain of the young animal contains less phospholipid and acidsoluble phosphorus than the adult. Since newly formed phospholipid will be diluted with material already present the lower relative specific activity in the older animals cannot be taken to mean that the renewal of phospholipids proceeds more rapidly in the young than in the old animal. It is also to be remembered that the evidence available relates to the total phospholipids and provides no information upon any differences which may occur in the relative rates of incorporation of phosphate into the different lipids during growth.

Although enzymes capable of metabolizing the phospholipids have been demonstrated in brain extracts (Chapter 3) the slow decrease in radioactivity shown in Fig. 9 suggests that, in vivo, many of these enzymes are likely to operate at a low level of 
activity. The similar rates of decline noted, whether adult or infant rats were chosen, also make it unlikely that the retention of radioactivity is associated specifically with phospholipids which increase rapidly during growth and later form part of more permanent structures, though it must be noted that studies upon the incorporation of phosphate into specific lipids over these periods have not yet been reported.

However, factors involved in assessing the decline must include both the initial slow rate of penetration of phosphorus to all parts of the brain and the level of radioactivity found in the acid-soluble phosphates which are presumably the precursors of the phospholipid phosphorus. In the mouse, 10 days after injection the specific activity of these phosphates was still $60-65 \%$ of that found within $6 \mathrm{hr}$ of injection (Dziewiatkowski and Bodian, 1950), a decrease in activity comparable in slowness with that of the phospholipids.

\section{Effects of Anaesthesia}

Anaesthesia, as recognized in vivo, is a clinical phenomenon and an analysis of the mechanisms involved as they relate to biochemical changes first requires a description of the phenomenon in biochemical terms. To date, such descriptions have been concerned largely with mechanisms involving energy metabolism.

Anaesthesia, in vivo, is normally accompanied by a marked reduction in the overall rate of cerebral metabolism. Thus, the consumption of oxygen and glucose, the formation of lactic acid and the electrical activity of the cortex are decreased (Himwich, 1951). Under these conditions changes have been found both in the quantities and rates of exchange of cerebral phosphates. In the brain of animals anaesthetized with barbiturates and dropped into liquid nitrogen, quantities of phosphocreatine were found to increase while the levels of inorganic phosphate fell (Table 7). Levels of adenosine triphosphate were not affected. However such general effects have not always been noted. Thus, Lin et al. (1958) found no change in the quantities of phosphocreatine if rats were anaesthetized with ether, results similar to those described by Bain (1957). Differences of this type tend to discount suggestions that the anaesthetic merely protects the brain from stimulation during sacrifice. More possibly it indicates a specific effect of barbiturates. Extensive data is lacking but it may perhaps be noted that Doring and Gerlach (1957) also using rats, were unable 
to find any differences from normal in levels of phosphocreatine in the brain of chloralosed animals. In a more recent study (Gerlach et al., 1958) rats were anaesthetized with a wide variety of agents and decapitated and the head allowed to fall into liquid nitrogen

Table 7.-Quantities of Energy-Rich Phosphates in the Brain of Normal and ANaesthetized Animals

\begin{tabular}{|c|c|c|c|c|c|}
\hline \multirow{2}{*}{ Animal } & \multirow{2}{*}{ Treatment } & \multicolumn{3}{|c|}{ Phosphates ( $\mu$ moles/g wet wt.) } & \multirow{2}{*}{ Author } \\
\hline & & $\begin{array}{l}\text { Inorganic } \\
\text { phosphate }\end{array}$ & $\begin{array}{l}\text { Phospho- } \\
\text { creatine }\end{array}$ & $\begin{array}{l}\text { Adenosine } \\
\text { triphosphate }\end{array}$ & \\
\hline Mouse & $\begin{array}{l}\text { None } \\
\text { Dial } \\
\text { anaesthesia } \\
\text { Nembutal } \\
\text { anaesthesia }\end{array}$ & $\begin{array}{l}5 \cdot 4 \\
4 \cdot 3 \\
4 \cdot 0\end{array}$ & $\begin{array}{l}3 \cdot 2 \\
4 \cdot 4 \\
4 \cdot 4\end{array}$ & $\begin{array}{l}2 \cdot 8 \\
2 \cdot 8 \\
3 \cdot 0\end{array}$ & $\begin{array}{l}\text { Stone } \\
\quad(1940 \\
1943)\end{array}$ \\
\hline Rat & $\begin{array}{l}\text { None } \\
\text { Nembutal } \\
\text { anaesthesia } \\
\text { Sleep }\end{array}$ & $\begin{array}{l}4 \cdot 4 \\
3 \cdot 6 \\
4 \cdot 0\end{array}$ & $\begin{array}{l}3 \cdot 1 \\
4 \cdot 5 \\
3 \cdot 1\end{array}$ & $\begin{array}{l}2 \cdot 4 \\
2 \cdot 3 \\
2 \cdot 2\end{array}$ & $\begin{array}{l}\text { Dawson } \\
\text { and } \\
\text { Richter } \\
(1950 b)\end{array}$ \\
\hline Rat & $\begin{array}{l}\text { None } \\
\text { Nembutal } \\
\text { anaesthesia }\end{array}$ & $\begin{array}{l}4.9 \\
4.9\end{array}$ & $\begin{array}{l}3 \cdot 1 \\
4 \cdot 1\end{array}$ & $\begin{array}{l}3 \cdot 8 \\
-\end{array}$ & $\begin{array}{r}\text { Le Page } \\
(1946)\end{array}$ \\
\hline Rat & $\begin{array}{l}\text { None } \\
\text { Ether } \\
\text { anaesthesia } \\
\text { Nembutal } \\
\text { anaesthesia }\end{array}$ & $\begin{array}{l}- \\
- \\
-\end{array}$ & $\begin{array}{l}3 \cdot 2 \\
2 \cdot 7 \\
4 \cdot 0\end{array}$ & $\begin{array}{l}2 \cdot 6 \\
2 \cdot 6 \\
2 \cdot 8\end{array}$ & $\begin{array}{l}\text { Lin, } \\
\text { Cohen } \\
\text { and } \\
\text { Cohen } \\
\text { (1958) }\end{array}$ \\
\hline
\end{tabular}

Animals were drowned in liquid nitrogen before removal of the brain.

10 min after the onset of anaesthesia. No differences were found in the cerebral concentrations of phosphocreatine, adenosine triphosphate, guanosine triphosphate and inorganic phosphate when compared with the concentrations in the brain of rats drowned in liquid nitrogen. The values were higher than those in cerebral tissue from controls decapitated in the same manner. The authors consider that the anaesthetic prevented the sudden breakdown of the phosphates in the moment of decapitation, thus 
having a stabilizing effect. In large animals such as the cat or dog (cf. Klein and Olsen, 1947) administration of barbiturates appeared to have no demonstrable effect upon the quantities of phosphocreatine in the brain. In the preparation of such animals, however, either a local anaesthetic or general ether anaesthesia was used and any additional effects of a barbiturate may not have been detected by changes in levels of phosphocreatine.

The effect of a barbiturate in increasing or stabilizing the quantity of a rapidly metabolized phosphate such as phosphocreatine is suggestive of an action resulting in a decreased rate of utilization. In vivo this problem has been approached by studying the rates of phosphorus exchange in both the acid-soluble phosphates and the phospholipids. Ansell and Dohman (1957) observed that anaesthesia, induced by thiopentone, had no effect upon the specific radioactivity of the total acid-soluble phosphates of the rat brain. They pointed out, however, that since the specific radioactivities of inorganic phosphate and energy-rich phosphates were not measured such data gave no indication of the effects of anaesthesia upon the formation of these phosphates. Such information is provided by some interesting experiments of Bain (1957) working with the mouse. It was found that after intracisternal injection of radioactive phosphate, the specific radioactivity of adenosine triphosphate was markedly greater in the brains of mice anaesthetized with thiopental or amytal than that found in unanaesthetized mice. These results would appear to suggest that barbiturates are without adverse effect upon the synthesis of adenosine triphosphate in vivo. On the other hand, Vladimirov and Rubel (1957) noted that amytal anaesthesia apparently decreased the rate of incorporation of phosphate into cerebral hexose monophosphates. This finding is not incompatible with that of Bain (1957) for the relative specific radioactivities of the hexose monophosphate were calculated as the ratio, specific radioactivity of hexose monophosphate/specific radioactivity of adenosine triphosphate. Increase in the specific radioactivity of adenosine triphosphate could therefore lead to a decrease in the relative specific activity of the hexose monophosphate.

Barbiturate anaesthesia also alters the rate of phosphorus exchange in the phospholipids. Thus, Dawson and Richter (1950a) found that the incorporation of radioactive phosphate into the total phospholipids of rat brain was significantly reduced by light pento- 
barbital anaesthesia. Deep anaesthesia and an accompanying drop in body temperature to $27^{\circ}$ was accompanied by a further decrease in phosphate incorporation. Similar results have been reported by Palladin (1955). Analysis of exchange in individual phospholipids during $3 \mathrm{hr}$ thiopentone anaesthesia in the rat, showed that phosphatidyl choline and phosphatidyl ethanolamine decreased in relative specific activity by $60-70 \%$. Decrease in the diphosphoinositide fraction was much less, being about 20\% (Ansell and Dohman, 1957). Depression of incorporation similar to this has been noted following a dose of the tranquillizing agent chlorpromazine. Wase et al. (1956) found that chlorpromazine at $25-50 \mathrm{mg} / \mathrm{kg}$ over a period of $24-48 \mathrm{hr}$, suppressed the quantity of phosphate incorporated into the phospholipids of rat cerebral cortex but was without effect upon or slightly increased the incorporation into the phospholipids of other parts of the brain. On the other hand, Ansell and Dohman (1956) found that over a $3 \mathrm{hr}$ exchange period, chlorpromazine administered to the rat at $20 \mathrm{mg} / \mathrm{kg}$ markedly reduced the exchange of phosphorus into the total phospholipids, phosphatidyl choline, phosphatidyl ethanolamine and phosphatidyl serine both in whole brain and in the cortex, pons, medulla, white matter and cerebellum. With this dose of chlorpromazine the rats showed no obvious signs of sedation (G. B. Ansell, personal communication).

Biochemical effects of barbiturate anaesthesia in vivo, in addition to those noted above in relation to glucose metabolism are thus seen to include an increase in the levels of phosphocreatine, an increased radioactivity of phosphorus in adenosine triphosphate, a decreased level of inorganic phosphorus and a decreased exchange of phosphorus into the phospholipids. Discussion of ways in which certain of these various effects may be related is deferred to a later chapter (Chapter 5).

\section{Hypoglycaemia}

Significant decrease in the levels of blood glucose are consistently accompanied by impaired mental and cerebral function and can result in loss of consciousness. Under these conditions in man, the brain uses oxygen at about half its normal rate (Kety, 1948). Since the oxidation of glucose provides the major energy source of the brain, changes in the amount oxidized might be expected to alter the quantities and rates of metabolism of cerebral phosphates. 
Early work in the dog (Kerr and Ghantus, 1936) indicated that hypoglycaemia induced by insulin was without effect upon the quantities of phosphocreatine in the brain. In these experiments, however, the animals were anaesthetized after giving insulin so as to facilitate removal of the brain. It seems likely that this procedure would permit the resynthesis of phosphocreatine to normal levels before analyses were begun. Later, Olsen and Klein (1947) working with cats anaesthetized and maintained by artificial respiration, found that the levels of cerebral phosphocreatine decreased as the severity of the hypoglycaemia increased; changes were from normal value of $2.4 \mu$ moles/g wet wt. to a final value of 0.9-1.4 $\mu$ moles/g wet wt. in hypoglycaemic coma. These decreases were also accompanied by a fall in levels of adenosine triphosphate and a rise in levels of inorganic phosphate.

Hypoglycaemia, when induced in the rat by insulin, was found to increase the specific radioactivity of the acid-soluble phosphates of brain, relative to that in the blood, by some $15-20 \%$ over that in the normal control animals. Nevertheless the exchange of phosphorus between the acid-soluble phosphates and the phospholipids was markedly decreased (Dawson and Richter, 1950a). These results imply either that the rate of turnover of the acid-soluble phosphates is decreased or that the metabolism of the phospholipids becomes predominantly catabolic in the absence of a normal glucose supply. Although evidence for the former does not appear to be available, evidence for the latter has been provided. Prolonged insulin hypoglycaemia was found to decrease the total quantities of phospholipid phosphorus of rabbit brain (Randall, 1940; McGhee et al. 1951) a decrease which was apparently irreversible and could not be restored when lecithin or glucose were administered even in large amounts. Similar changes have been described by Geiger and co-workers. Thus it was found that during perfusion of the isolated head of the cat with a modified "blood" free from glucose, the respiratory quotient of the brain decreased from a value of 1.0 at the start to about 0.5 though the oxygen consumption remained high (Geiger et al., 1952). Accompanying this decrease there was a loss of phospholipids, phosphoproteins and nucleic acids from the tissue. Catabolism of these appears to be selective since the major losses occurred in the particles in the microsomal fraction and not in the mitochondria (Abood and Geiger, 1955). These changes did not occur if 
glucose was present in the perfusate. However, continuing perfusion in the presence of glucose did not prevent an overall decrease in the total phospholipid phosphorus and an impairment in the ability of the brain to oxidize glucose. Interestingly, these defects could be prevented if small amounts of cytidine and uridine were added to the perfusion fluid (Geiger and Yamasaki, 1956).

The mechanism by which these latter effects are mediated is not known. It is also difficult to attempt correlations of changes in the perfused brain with changes in the hypoglycaemic animal. Nevertheless the evidence shows that hypoglycaemia in addition to causing immediate changes in energy producing systems can also lead to extensive and probably irreversible catabolism of phosphates which are likely to be part of structural components in the brain. In this connexion it perhaps is of interest to note that lesions developing in various areas of the brain following severe hypoglycaemia almost invariably include a loss of Nissl bodies (Meyer, 1958) which, it is suggested, are likely to form part of the microsomal fraction (cf. Einarson, 1957).

\section{Hypoxia, Hypothermia and Related Influences}

In man, a reduction in arterial oxygen tension to $24 \%$ leads to loss of consciousness (Lennox et al., 1935) though the oxygen uptake of the brain appears to be normal when the inspired air contains $10 \%$ oxygen (Kety and Schmidt, 1948). As is well known, brief periods of partial or complete hypoxia can lead to symptoms such as loss of memory and occasionally convulsions, associated with histologically demonstrable degeneration in selected cells and areas of the brain (see Meyer, 1958).

As may be expected, change in the cerebral oxygen supply is accompanied by changes in the quantities of energy-rich phosphates, the extent of the change being related to the degree of hypoxia. In animals breathing gas mixtures via a tracheal tube a gradual reduction of the percentage of oxygen in the inspired air did not affect levels of cerebral phosphocreatine until the arterial oxygen saturation was about 20\% (Gurdjian et al., 1944; Gurdjian et al., 1949). Cerebral lactic acid began to increase when the oxygen in the inspired air reached $11-13 \%$, corresponding to a level of saturation of $55-65 \%$ in arterial blood and $28-43 \%$ in the sagittal sinus. Further reduction to $7 \%$ oxygen in the inspired air induced phosphocreatine breakdown, at which the saturation was 
$23-35 \%$ in arterial blood and $15-22 \%$ in the sagittal sinus. The arterio-venous difference also decreased indicating an impaired oxygen uptake by the brain. Changes were complete within $15 \mathrm{~min}$ and were not increased by prolonging the hypoxia to $1 \mathrm{hr}$. The effects noted were due to lack of oxygen since the levels of glucose in the blood were consistently higher than normal.

These effects are apparently not obtained provided sufficient time has been allowed for the animal to become acclimatized to the lower oxygen tension. Albaum et al. (1953) exposed rats, in stepwise progression, to oxygen tensions representing increased altitudes until, over a period of weeks, a final tension equivalent to $20,000 \mathrm{ft}$ was obtained. At this tension blood haemoglobin was markedly increased. Animals were maintained at this altitude for 7 months, conditions under which unacclimatized adult rats die within a few hours (Britton and Kline, 1945) and were then anaesthetized and brought back to ground level before freezing in liquid nitrogen. No differences from normal were detected in the quantities of cerebral phosphocreatine, adenosine triphosphate or inorganic phosphate. Although anaesthesia and maintenance for a short period at normal oxygen tensions might have obliterated any temporary change in the quantities of these phosphates it would appear that they were metabolized at normal rates in the acclimatized rats. Thus, injection of radioactive phosphate $1 \mathrm{hr}$ before freezing failed to reveal any differences in the rate of incorporation of radioactivity into the phosphorus of adenosine triphosphate between the normal controls and acclimatized animals. Comparable experiments as regards phosphate turnover have not been reported with animals rendered anoxic as in the experiments of Gurdjian et al. Reducing the oxygen content of the inspired air to $4.2 \%$ was without effect upon the quantities of adenosine triphosphate in rabbit brain (Stone et al., 1941) though phosphocreatine had decreased.

Changes in adenosine triphosphate occur in complete anoxia and are accompanied by corresponding increases in the quantities of adenosine diphosphate and adenylic acid (Gurdjian et al., 1949; Albaum et al., 1953; Doring and Gerlach, 1957; Gerlach et al., 1958). Even so, levels remain high until phosphocreatine has completely disappeared (Table 8). Such decreases are always accompanied by increases in the quantities of inorganic phosphate, the increase in which greatly exceeds the amount made available 
by the breakdown of phosphocreatine and adenosine triphosphate. The source of this additional phosphate is not known.

Hypothermia, which in itself is without any marked effect upon the normal levels of energy-rich phosphates in the brain (Savchenko, 1958) retards their breakdown in anoxia (Table 8). Thus a drop of $11^{\circ}$ is sufficient to extend the period of breakdown by some 5-10 min. Such a retardation accords well with the known increases in survival time of rats under anoxic conditions but at

Table 8. - The Effects of Anoxia upon the Quantities of Adenosine Triphosphate, Phosphocreatine and Inorganic Phosphate in Brain

\begin{tabular}{|c|c|c|c|c|c|c|}
\hline \multirow{3}{*}{$\begin{array}{l}\text { Duration } \\
\text { (min) }\end{array}$} & \multicolumn{6}{|c|}{ Values in $\mu$ moles/g wet wt. } \\
\hline & \multicolumn{2}{|c|}{$\begin{array}{l}\text { Phospho- } \\
\text { creatine }\end{array}$} & \multicolumn{2}{|c|}{$\begin{array}{l}\text { Adenosine } \\
\text { triphosphate }\end{array}$} & \multicolumn{2}{|c|}{$\begin{array}{l}\text { Inorganic } \\
\text { phosphate }\end{array}$} \\
\hline & $37^{\circ}$ & $26^{\circ}$ & $37^{\circ}$ & $26^{\circ}$ & $37^{\circ}$ & $26^{\circ}$ \\
\hline $0 \cdot 0$ & $2 \cdot 03$ & $2 \cdot 94$ & 1.7 & 1.9 & $4 \cdot 24$ & $3 \cdot 19$ \\
\hline $3 \cdot 0$ & 0.87 & - & - & - & $6 \cdot 49$ & - \\
\hline $5 \cdot 0$ & 0.48 & - & $1 \cdot 18$ & - & $7 \cdot 65$ & - \\
\hline $10 \cdot 0$ & 0.0 & 0.79 & 0.48 & $1 \cdot 31$ & $10 \cdot 1$ & $7 \cdot 15$ \\
\hline $15 \cdot 0$ & $0 \cdot 0$ & $0 \cdot 0$ & 0.21 & 0.85 & 11.95 & $8 \cdot 53$ \\
\hline $25 \cdot 0$ & - & $0 \cdot 0$ & - & $0 \cdot 26$ & - & $10 \cdot 20$ \\
\hline
\end{tabular}

Data from Thorn et al. (1958) and Isselhard et al. (1959).

Rabbits were rendered anoxic by administration of nitrogen via a tracheal tube. The brain was frozen in liquid nitrogen before analysis.

markedly reduced temperatures (Britton and Kline, 1945; Himwich, 1951).

Restoration of normal levels of phosphocreatine following depletion in anoxia is rapid provided that the period of anoxia has not been prolonged. In the rabbit, breathing nitrogen for 2-3 min reduces the levels of phosphocreatine. Artificial respiration at this period was sufficient to restore the levels to normal or above

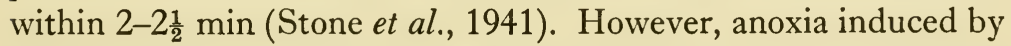
breathing $4.2 \%$ oxygen for 15 min required a recovery period of up to $1 \mathrm{hr}$ before levels of inorganic phosphate, lactic acid and the e.e.g. returned to normal, though levels of phosphocreatine were resynthesized much sooner (Gurdjian et al., 1944). 
The resynthesis of phosphocreatine to levels higher than normal during recovery from anoxia is likely to be due to hyperventilation during recovery. In the dog, hyperventilation with air was found to increase the levels of phosphocreatine from $2 \cdot 7-2 \cdot 8 \mu$ moles $/ g$ wet wt. to $3 \cdot 3 \mu$ moles $/ g$ (Gurdjian et al., 1949), while in the rabbit similar treatment increased phosphocreatine from $2.46 \mu$ moles/g to $3.0 \mu \mathrm{moles} / \mathrm{g}$ (Doring and Gerlach, 1957).

The effects of deprivation of oxygen are paralleled to a large degree by the effects of sodium cyanide. At doses of $0.4 \mathrm{mg} / \mathrm{kg}$ no changes were noted in the levels of phosphocreatine but levels of lactic acid increased. Higher concentrations leading to convulsive electrical activity in the brain and death induced changes identical with those caused by breathing nitrogen (Albaum et al., 1946; Olsen and Klein, 1947).

The changes in hypoglycaemia and anoxia are thus both complementary and different and may be compared as regards overall change in phosphates since in each case the brain suffers the loss of a factor necessary for the maintenance of an energy supply. However, the time scale is different, for changes in anoxia are much more rapid than in hypoglycaemia and anoxia cannot be withstood for so long a period. Nevertheless, the injection of glucose can partially overcome the effects of anoxia (Britton and Kline, 1945) as judged by survival time. Unfortunately no information exists on changes in energy-rich phosphate under these conditions nor has similar data been reported for the infant rat, in which the ability to withstand anoxia is many times that of the adult. Nevertheless, it seems clear that the maintenance of levels of energy-rich phosphate in the adult brain is more dependent upon a fully maintained oxygen uptake than upon the presence of excess glucose.

The effects of combined hypoglycaemia and anoxia are seen in severe cerebral ischaemia. It was noted (Stone et al., 1941) that partial interruption of the blood supply to the brain resulted in decreased levels of phosphocreatine and increased levels of inorganic phosphate. More detailed studies of cerebral ischaemia, with and without hypothermia, upon the ability of the brain to maintain adequate levels of energy-rich phosphates have been made by Thorn and collaborators (see also Schneider, 1957; Gerlach et al., 1958). At $37^{\circ}$ a reduction of $50 \%$ in the blood supply to the cat head results in a decrease in oxygen consumption by the brain (Hirsch et al., 1955). Since a reduction in temperature 
reduces the oxygen requirements of the brain, hypothermia permits the brain to survive under these conditions without a permanent impairment of metabolism (Himwich, 1951). Changes in phosphates under the two conditions show marked differences ('Table 9). At $37^{\circ}$, in the rabbit, cerebral ischaemia resulted in a total loss of phosphocreatine and a loss of half the adenosine triphosphate within $5 \mathrm{~min}$. At $26^{\circ}$, half the phosphocreatine was still present after 5.0 min together with $60-70 \%$ of the adenosine triphosphate.

Table 9.-The Effects of Cerebral Ischaemia upon the Quantities of Adenosine Triphosphate, Phosphocreatine and Inorganic Phosphate in Brain

\begin{tabular}{|c|c|c|c|c|c|c|}
\hline \multirow{3}{*}{$\begin{array}{l}\text { Duration } \\
\text { (min) }\end{array}$} & \multicolumn{6}{|c|}{ Values in $\mu$ moles/g wet wt. } \\
\hline & \multicolumn{2}{|c|}{$\begin{array}{c}\text { Phospho- } \\
\text { creatine }\end{array}$} & \multicolumn{2}{|c|}{$\begin{array}{l}\text { Adenosine } \\
\text { triphosphate }\end{array}$} & \multicolumn{2}{|c|}{$\begin{array}{l}\text { Inorganic } \\
\text { phosphate }\end{array}$} \\
\hline & $37^{\circ}$ & $26^{\circ}$ & $37^{\circ}$ & $26^{\circ}$ & $37^{\circ}$ & $26^{\circ}$ \\
\hline 0.0 & $2 \cdot 79$ & 2.94 & $1 \cdot 68$ & $1 \cdot 90$ & $4 \cdot 24$ & $3 \cdot 19$ \\
\hline $1 \cdot 0$ & - & $1 \cdot 86$ & - & $1 \cdot 85$ & - & 4.75 \\
\hline $2 \cdot 0$ & 0.59 & $1 \cdot 83$ & $1 \cdot 29$ & $1 \cdot 74$ & $5 \cdot 70$ & $4 \cdot 5$ \\
\hline $5 \cdot 0$ & $0 \cdot 0$ & $1 \cdot 40$ & 0.70 & $1 \cdot 4$ & $8 \cdot 5$ & $5 \cdot 8$ \\
\hline $10 \cdot 0$ & 0.0 & 0.99 & 0.55 & $1 \cdot 23$ & $9 \cdot 3$ & $6 \cdot 2$ \\
\hline $15 \cdot 0$ & $0 \cdot 0$ & 0.0 & 0.04 & $0 \cdot 23$ & $11 \cdot 25$ & $10 \cdot 5$ \\
\hline
\end{tabular}

Data from Thorn et al. (1958) and Isselhard et al. (1959).

Rabbits; ischaemia was produced by an inflatable cuff placed round the neck.

Restoration of the normal quantities of the phosphates is apparently rapid and occurs within $10 \mathrm{~min}$ of restoring the circulation (Schneider, 1957), though levels of lactate remain high for much longer (Savchenko, 1958). The changes found in cerebral ischaemia are similar in degree and rate to those found in anoxia. Taken together they re-emphasize the primary importance of oxygen in the maintenance of adequate levels of energy-rich phosphates in the adult brain.

In the majority of experiments commented upon above it has been noted (Gurdjian et al., 1949; Stone et al., 1941; Klein and Olsen, 1947; Gurdjian et al., 1944; Thorn et al., 1955) that the onset of anoxia or ischaemia was detectable by changes in the 
e.e.g. before any changes in levels of phosphocreatine could be measured. However, it is to be remembered that observations of this type do not necessarily mean that electrical activity of the brain is associated more closely with an oxidative rather than with a phosphorylative mechanism. Disappearance of spontaneous electrical activity before the breakdown of phosphocreatine is detectable may well mean that phosphocreatine is at one end of a chain of reactions, the other end of which is intimately connected with the changes leading to electrical disturbances. The quantity of a phosphate in a tissue is not a reliable indication of its rate of metabolism and situations such as above appear to offer considerable scope for investigations with radioactive phosphate.

\section{Electroshock and Convulsive Agents}

The simplest method of administering a major shock to the brain is by decapitation which severs the spinal cord and at the same time stops the supply of oxygen and glucose. Such a procedure results in an almost immediate decrease in the quantities of cerebral phosphocreatine and an increase in the levels of inorganic phosphate (Table 10). These changes are not wholly due to stimulation associated with decapitation since they do not occur if the head is allowed to fall into liquid nitrogen within 1-2 sec (see Table 1). The changes, however, are rapid and take place within $3 \mathrm{sec}$ of decapitation. Several minutes later, if the brain is left unfrozen, the increased quantities of inorganic phosphate far exceed the decrease in the quantities of energy-rich phosphate, a situation similar to that after prolonged anoxia or severe ischaemia.

Experiments such as these, though demonstrating extreme promptness of cerebral reactions, do not permit the separation of the effects of stimulation from those of anoxia and hypoglycaemia. This separation is essential in analysing the effects of convulsant agents. In early experiments, Kerr and Antaki (1937) failed to find any difference from normal in the quantities of phosphocreatine in the brains of animals convulsed by picrotoxin. However, the animals were anaesthetized with sodium amytal before freezing the brain, a procedure now recognized as sufficient to nullify changes which had taken place. The technique more widely adopted is that due to Stone et al. (1945) which permits the study of chemical changes in the cortex during convulsive activity 


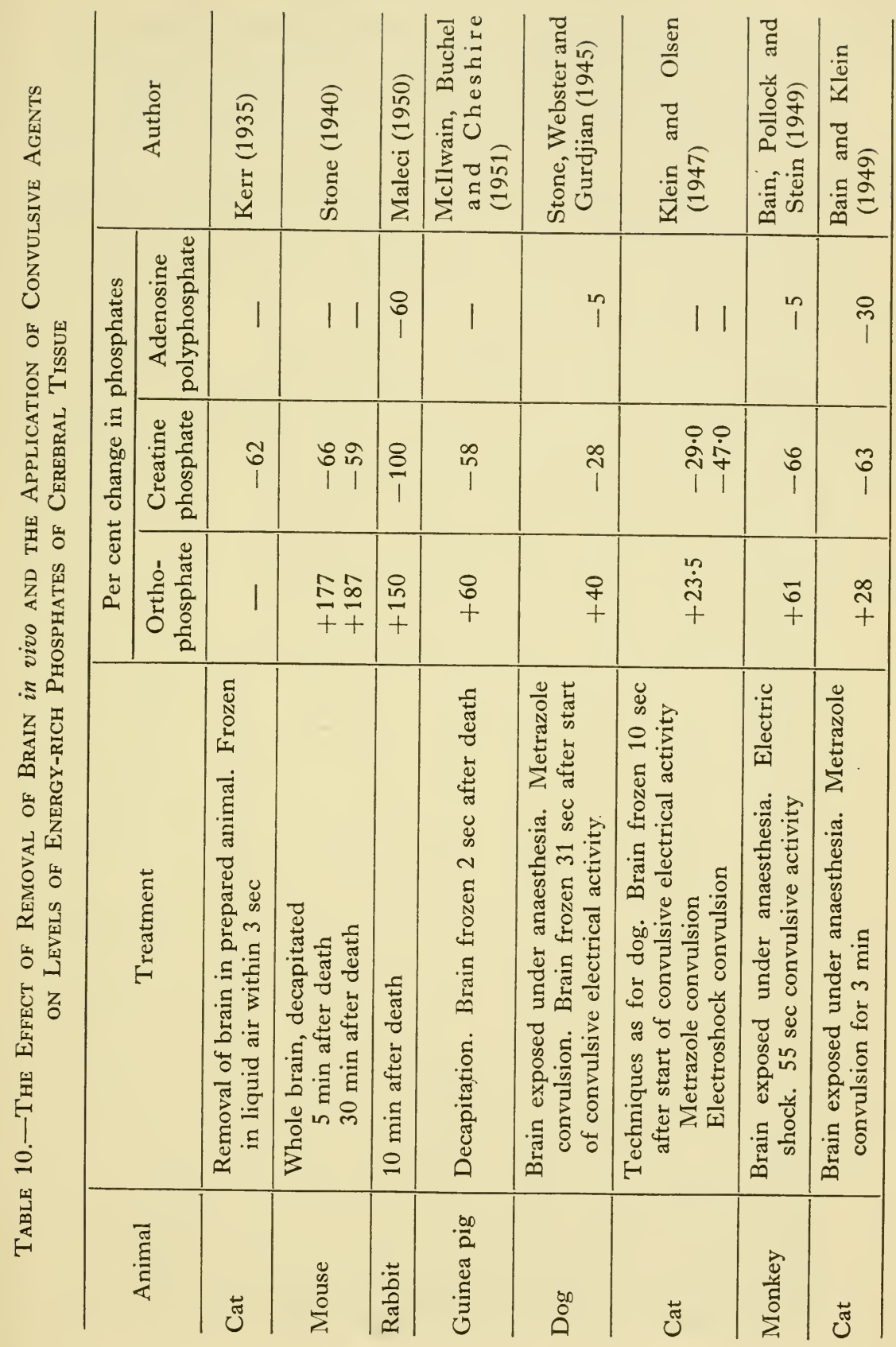


without the complications of an added hypoxia. Animals are anaesthetized and the skull opened, and after immobilization with dihydro- $\beta$-erythroidine are maintained with artificial respiration. Study of the electrocorticogram during the experiment enables the selection of a point at which convulsive electrical activity occurs following suitable stimulation, when the brain is then frozen with liquid nitrogen. With this technique it has been found that phosphocreatine decreases and inorganic phosphate increases during a seizure, the levels of adenosine triphosphate remaining reasonably constant (Table 10 ).

Provided the oxygen tension remains adequate the extent to which phosphocreatine decreases appears to be determined by the severity rather than by the duration of the convulsive discharge. Thus, in the dog (Table 11) during convulsive activity induced by metrazole the quantities of phosphocreatine, after an initial change, did not decrease further over a period of $2 \frac{1}{2} \mathrm{~min}$. However if the seizures were of the grand mal type phosphocreatine decreased further to levels of $1.9 \mu$ moles/g. Parallel with such changes levels of cerebral glucose decreased and those of lactic acid increased indicating that the changes in the labile phosphate were accompanied by an increase in cerebral metabolism. Throughout the convulsive discharge the arterial oxygen tension remained normal. In prolonged convulsions the increased inorganic phosphate appears to find its way into the blood, for in dogs examined with the above technique convulsive activity was associated with an increase in the acid-soluble phosphate in blood from the superior sagittal sinus but not in femoral blood (Cicardo, 1945).

The speed with which a change in phosphate levels can occur following administration of a convulsant is well illustrated by the experiments of Dawson and Richter (1950b). Unanaesthetized rats were given electroshock via cerebral electrodes during or after which they were drowned in liquid nitrogen. Animals drowned within $1 \mathrm{sec}$ of applying the shock had suffered a loss of $50 \%$ of their cerebral phosphocreatine with the final level not decreasing further as a result of continuing the shock for another $5 \mathrm{sec}$. Allowing for the time taken to freeze the entire brain (about $4 \mathrm{sec}$ ) the speed of breakdown can be calculated to be between 1000 and $3600 \mu$ moles phosphorus/g wet wt. $\mathrm{hr}^{-1}$, a rate considerably in excess of any known energy-consuming reactions in the brain.

A reasonable interpretation of the changes described above is in 
terms of the expenditure of energy during convulsive activity exceeding the energy production by oxidative mechanisms (Stone et al., 1945). However, although the arterial oxygen tension remained above levels known to induce hypoxic changes ('Table 11),

Table 11.-Effect of Metrazole-induced Convulsive Activity upon Levels of Cerebral Phosphates

\begin{tabular}{|c|c|c|c|c|}
\hline \multirow{2}{*}{$\begin{array}{l}\text { Time after } \\
\text { convulsive } \\
\text { discharge } \\
\text { (sec) }\end{array}$} & \multicolumn{3}{|c|}{ Phosphates in $\mu$ moles/g wet wt. } & \multirow{2}{*}{$\begin{array}{c}\text { Arterial } \\
\text { oxygen } \\
\text { tension } \\
(\%)\end{array}$} \\
\hline & $\begin{array}{l}\text { Inorganic } \\
\text { phosphate }\end{array}$ & $\begin{array}{l}\text { Phospho- } \\
\text { creatine }\end{array}$ & $\begin{array}{c}\text { Adenosine } \\
\text { triphosphate }\end{array}$ & \\
\hline Normal controls & $2 \cdot 5$ & $2 \cdot 9$ & $3 \cdot 1$ & $84 \cdot 5$ \\
\hline 0 & $3 \cdot 3$ & $2 \cdot 2$ & $2 \cdot 8$ & - \\
\hline 15 & $3 \cdot 1$ & $2 \cdot 1$ & $2 \cdot 8$ & - \\
\hline 15 & $3 \cdot 2$ & $2 \cdot 3$ & - & $95 \cdot 6$ \\
\hline 16 & $2 \cdot 7$ & $2 \cdot 5$ & $3 \cdot 2$ & $95 \cdot 8$ \\
\hline 15 & $3 \cdot 6$ & $1 \cdot 3$ & $2 \cdot 6$ & $76 \cdot 3$ \\
\hline 30 & $2 \cdot 3$ & $2 \cdot 4$ & $3 \cdot 0$ & - \\
\hline 31 & $3 \cdot 2$ & $1 \cdot 8$ & $2 \cdot 7$ & $92 \cdot 1$ \\
\hline 33 & 3.0 & $2 \cdot 0$ & 2.7 & 82.8 \\
\hline 44 & $3 \cdot 0$ & $2 \cdot 1$ & $2 \cdot 8$ & $99 \cdot 4$ \\
\hline 47 & $2 \cdot 4$ & $2 \cdot 9$ & $3 \cdot 1$ & $91 \cdot 7$ \\
\hline 60 & $3 \cdot 5$ & $2 \cdot 0$ & $2 \cdot 6$ & - \\
\hline 108 & $3 \cdot 4$ & 1.7 & $2 \cdot 9$ & - \\
\hline 128 & $2 \cdot 9$ & - & - & $72 \cdot 3$ \\
\hline 131 & $2 \cdot 5$ & $2 \cdot 4$ & $2 \cdot 8$ & 一 \\
\hline $\begin{array}{l}\text { Averages over } \\
\text { whole convulsive } \\
\text { period }\end{array}$ & $3 \cdot 0$ & $2 \cdot 1$ & $2 \cdot 8$ & - \\
\hline
\end{tabular}

Data from Stone et al. (1945).

such measurements record only that the oxygen supply is potentially adequate. Thus the changes in phosphate levels could have been secondary to a local hypoxia accompanying the increased metabolism (see Klein and Olsen, 1947). Localized changes in the oxygen tension of the cortex were measured by Davis et al. (1944), Davies and Rémond (1947), and Gurdjian et al. (1947). In dogs receiving metrazole, although convulsive activity was accompanied by a drop in the cortical oxygen tension, at no time did this fall to 5-PMB 
hypoxic levels. Nevertheless, phosphocreatine still decreased and inorganic phosphate increased. The change in oxygen tension was not detectable for some 20-30 sec after giving metrazole (Gurdjian et al., 1947).

It seems certain that the lowered tension is due to an increased oxygen consumption by the tissue. Thus, Davies and Rémond (1947) found that the oxygen tension of the blood in the smallest pial arterioles remained constant throughout seizure activity induced by metrazole, but that the tension was lowered in venous blood. Measurements of changes in regions removed from visible blood vessels revealed that the tension fell to about $30-35 \%$ of the initial value during the convulsive discharge. The drop began after the initial spike discharge had ended and took about $5 \mathrm{sec}$ for completion. Oxygen consumption was found not to increase until the electrical seizure activity was well developed and did not reach its maximum until the end of the convulsive discharge. The importance of a definite minimum oxygen tension for the maintenance of convulsive activity was shown by Gurdjian et al. (1947). Seizure activity, induced during hypoxia with $4 \cdot 1 \%$ oxygen rapidly ceased though the quantities of adenosine triphosphate and phosphocreatine were not altered further. Breathing air restored the electrical activity and restarted the seizures which subsequently disappeared and reappeared as hypoxia was alternately induced and released.

The above experiments were of critical importance in establishing that the changes in constituents, such as phosphates, during seizure activity were not due to a local hypoxia and that they preceded measurable changes in oxygen tension. Increased oxygen consumption is thus an after effect of increased nerve cell activity. It also seems clear that the actual quantities of energyrich phosphates in the brain vary little when compared with the factors of energy supply and expenditure. In convulsive activity a new steady state is established in which the levels of phosphocreatine, though lower than in the normal brain, are maintained by the oxidative metabolism of carbohydrate.

The balances which exist between the oxidative synthesis of phosphates and their metabolism during convulsions is well illustrated by the effects of including carbon dioxide in the inspired gas mixtures. Following the observation (Gibbs et al., 1938) that petit mal seizures could be interrupted by increasing the carbon 
dioxide content of the air breathed, Bain and Klein (1949) administered air/carbon dioxide mixtures to cats treated with metrazole. In such animals breathing $15 \% \mathrm{CO}_{2} / 85 \% \mathrm{O}_{2}$ there was apparently no decrease in the levels of phosphocreatine though these changes took place in animals breathing air. However, in the dog, Gurdjian et al. (1947) found that administration of up to $70 \% \mathrm{CO}_{2}$ with oxygen failed to prevent the decrease in phosphocreatine levels which occurred during metrazole seizures. A similar result was recorded following a $10 \mathrm{sec}$ electroshock given to a monkey breathing $30 \% \mathrm{CO}_{2} / 70 \% \mathrm{O}_{2}$. Cerebral phosphates changed as in the animals breathing air (Bain et al., 1949). Carbon dioxide is known to increase the rate of cerebral blood flow and in those instances where its presence has prevented a decrease in the levels of phosphocreatine it seems reasonable to assume that the increased oxygenation of the tissue assists in the adequate maintenance of phosphate levels (cf. Bain and Klein, 1949).

Even in the absence of added carbon dioxide not all convulsive activity or convulsive agents produce a marked decrease in cerebral phosphocreatine. Thus, in rats, following brief electroshock (Dawson and Richter, 1950a), convulsions were accompanied by a steady resynthesis of phosphocreatine, the convulsions ceasing when the normal level was regained. In rats in which convulsions were induced with fluorocitrate (Dawson and Peters, 1955), the levels of phosphocreatine, though decreasing by a statistically significant amount were not depleted sufficiently for the authors to consider the changes as being meaningful. Convulsions are the end point, or manifestation, of a series of changes which have already taken place and in such conditions the brain may not always show changes in levels of cerebral phosphates. In the dog, seizure activity of the cortex induced by fluoroacetate (which is converted to fluorocitrate) was accompanied by a decrease in phosphocreatine and an increase in inorganic phosphorus during the seizure, the pattern paralleling that induced by metrazole. In the period of post seizure depression with intermittent convulsions phosphocreatine decreased to $0 \cdot 1-0 \cdot 3 \mu$ moles/g wet wt. and adenosine triphosphate also decreased by about $60 \%$. The results were not attributed to hypoxia caused by a block of oxidative pathways since citrate accumulated in the precortical seizure period yet levels both of lactate and of phosphocreatine remained normal (Pscheidt, et al., 1954). 
Levels of phosphocreatine have been examined in rats in which trauma was produced either by intravenous injection of adenosine triphosphate or by hind limb ischaemia. No decrease in quantities was observed though here as in other experiments the use of anaesthesia before drowning in liquid air might have restored levels which had been depleted (Stoner and 'Threlfall, 1954). In cats or monkeys anaesthetized with dial, although topical application of strychnine to the cortex caused the distinctive "spike" discharge, the levels of phosphocreatine and adenosine triphosphate were unchanged (Dusser de Barrenne et al., 1941). It was suggested that here strychnine synchronizes cellular discharges rather than stimulates the cortex to greater activity than normal.

Maintenance of almost constant levels of adenosine triphosphate has been considered to be part of a regulatory system aimed at suppressing excess convulsive activity. 'Thus the discharge produced by topical application of acetyl choline to cat cerebral cortex was suppressed by a similar application of adenosine di- or triphosphate (Jordan et al., 1950; Robinson and Hughes, 1951). Similar results were obtained if the adenosine derivatives were injected intravenously. 'The latter results suggest that factors other than adenyl derivatives enter into such changes for it is unlikely that the transfer of adenosine triphosphate into the brain is rapid yet the effects were apparent within a few seconds of injection.

It seems likely that whether or not changes in the quantities of the acid-soluble phosphates occur as a result of seizures is determined both by the type of convulsant used and the criteria adopted in defining convulsive activity. Differences are in part attributable to the speed of action of the convulsant and to the extent to which the tissue suffers from a mild hypoxia. Thus, if the increased blood flow produced for example by admixture of carbon dioxide with the inspired air can maintain the tissue in an adequately oxygenated condition oxidative phosphorylation may proceed at a rate such as to maintain near normal levels of phosphocreatine, though the rate of cerebral metabolism is increased. Electroshock, since it is applied immediately, differs from metrazole in that no lag period is needed before an effective dose is built up. In such conditions stimulation of the energy consuming processes is likely to be extremely rapid and thus to enable effects to be seen before oxidative metabolism has begun to increase. However, it is to be remembered that an apparent absence of effect 
in overall phosphate levels may also indicate a highly localized site, or sites, of action.

The effects of convulsions upon the metabolism of the phospholipids is not clear. Dawson and Richter (1950a) found that brief electroshock applied to mice, reduced the relative specific radioactivity of the total phospholipid phosphorus by about $11 \%$, a difference which was statistically significant. Torda (1954) obtained reductions of a similar order when mice were treated either with electroshock or with metrazole. On the other hand, Ansell and Dohman (1957) were unable to find any changes in the amounts of radioactivity incorporated into the total phospholipid phosphorus or into the individual fractions of the cephalin group as a result of convulsions induced either by electroshock or by picrotoxin. At present it seems that since any changes detected were small, the phosphate moiety of the phospholipids is not markedly involved in changes brought about by brief convulsive activity. Similar changes have been noted in the phosphoproteins and in a fraction probably containing phosphatido peptides (Vladimirov, 1953; Vladimirov et al., 1957). 'Thus in rats, electrically stimulated via the paws, the specific radioactivities of the phosphorus in these fractions was generally considered to be higher than in unstimulated animals, though the magnitude of the differences was small. It has been shown (see p. 118) that at least one fraction (the phosphoproteins) shows a markedly increased rate of incorporation of phosphate during the application of an applied stimulus in vitro, which suggests that failure to find appreciable changes in vivo may be due to difficulties of technique rather than absence of response.

\section{Emotional Excitement}

Stimulation of the brain by means of convulsants is essentially a vigorous procedure. In attempts to examine cerebral metabolism as it is affected by more physiological stimuli, the measurements have been made of the changes occurring in various phosphates as a result of applying different excitatory procedures to conditioned and unconditioned animals.

Effects of excitement upon the acid soluble phosphates of brain were initially reported by Le Page (1946). In rats where death was induced by rapid tumbling in a drum, levels of phosphocreatine and adenosine triphosphate decreased while those of inorganic 
phosphate rose. The animals were frozen in liquid air immediately after or upon the point of death and it was considered that the changes observed could not be ascribed to the normal depletion occurring after death. No such effects were observed in rats which had been conditioned to tumbling in the drum. Further studies of this type have been carried out principally by Russian workers. Rats are conditioned to expect an electric shock to the paws when a light is switched on, and are able to escape by jumping out of a hole in the cage. In conditioned animals, switching on the light produces signs of fear, squealing, etc., together with the escape reaction. On jumping through the hole the animals fall into liquid air and are frozen. It was found that the conditioned reflex resulted in a decrease in levels of adenosine triphosphate (Sytinsky, 1956; Vladimirova, 1956). Curiously, little change was found in the levels of phosphocreatine. Similar changes were noted in unconditioned animals stimulated by electroshock. The increase in inorganic phosphate was found to exceed that derived from the loss of adenosine triphosphate, suggesting that phosphate derivatives other than adenosine triphosphate were involved in the response. Similar changes, including a decrease in phosphocreatine, were found in rats excited by persistent teasing (Shapot, 1957). Rats, injected with phenamine to enhance reflexes, were teased with straws for an hour, during which they showed signs of anger. In such a state cerebral adenosine triphosphate was decreased by half while adenosine diphosphate increased. Levels of phosphocreatine fell by $30 \%$. The changes were similar to those found in animals convulsed by the injection of camphor. The Russian workers generally attach considerable importance to the ratio ATP/ADP. Shapot (1957) considers it to be more indicative of the functional state of the brain than absolute quantities of either, since, in part, the rates of cerebral metabolism are conditioned by the levels of phosphate acceptors such as adenosine diphosphate (see p. 110). Excitation induced by intermittent electric shocks applied to the skin was found to increase the specific radioactivity of the hexose phosphates relative to that of adenosine triphosphate (Vladimirov and Rubel, 1957). Interpretation of this type of result is complicated by the probable changes occurring in adenosine triphosphate which is used as a standard of reference (see p. 46). The possibility of excitation affecting the metabolism of other phosphates has been examined with respect to the phos- 
pholipids by Dawson and Richter (1950a). Mice injected with radiophosphate were placed in a slowly rotating drum for $3 \mathrm{hr}$ during which they showed signs of fear, micturation, defaecation and attempts to escape. The specific radioactivity of the phospholipid phosphorus was decreased by an average of $25 \%$ of the normal values. No such decrease was detectable in animals which had previously been conditioned to the drum. The statistical significance of the decrease was small $(\mathrm{P}=0 \cdot 1)$ but was considered to indicate that the change was a genuine one.

Experiments of the above type seek to establish changes occurring as a result of stimuli which can be regarded as physiological and afford a valuable contribution to the understanding of the role of phosphate metabolism in relation to the activity of the brain. To a considerable extent such changes parallel those found to result from seizure activity suggesting involvement of similar mechanisms which are being stimulated to greater or lesser degrees. Though this is probably an oversimplification it nevertheless provides a starting point from which to continue further studies of cerebral phosphate metabolism as it relates to functional activity. These form the theme of the next chapters.

\section{Other Factors Affecting Phosphate Metabolism}

Amongst other factors affecting the metabolism of cerebral phosphates one of the more prominent is a lesion due either to surgical treatment, to injury or to the presence of tumorous tissue. The increased uptake of radioactive phosphate into lesions induced experimentally or into a tumour is most probably due to a breakdown of the blood-brain barrier (see Bakay, 1955, for extensive discussion). Thus in tumorous tissue or tissue in which surgical lesions had been made, the uptake of intravenously administered radioactive phosphate was extremely rapid and occurred solely in the acid-soluble phosphates (Stern and Marshall, 1951). This might perhaps be expected if permeability factors were involved. However, injury to one part of the cortex also affects the metabolism of other parts of the cortex. In cats, lesions produced by freezing portions of the exposed cortex with liquid air, and subsequent removal, resulted in changes in phosphate levels in portions of the cortex which were at a distance from the point of injury (Stone et al., 1941). Lactic acid levels were increased while levels 
of phosphocreatine decreased. Levels of inorganic phosphate were raised. The magnitude of these changes depended upon the extent of the initial injury and the distance from the injured portion of the tissue at which the second sample was taken. Changes of this type may explain the results of Shideman and Seevers (1953) who found that the levels of phosphocreatine in monkey brain were apparently much lower than in any other animal. The animals had been subject to operation for the removal of the calvarium the day before the fixation of the brain in liquid air.

Cerebral phosphates are also changed in virus infection. Thus in the infant mouse brain intracerebrally inoculated with Lancing poliomyelitis virus and drowned in a carbon dioxide/ethanol mixture when paralysis commenced, the levels of phosphocreatine had decreased by half while adenosine triphosphate had increased by $50 \%$. All other acid-soluble phosphates showed a marked decrease (Kabat, 1944). The rate of incorporation of intravenously injected radioactive phosphate into different areas of the monkey brain, similarly infected, showed no change from normal until clinical symptoms of paralysis appeared. Thereafter increased incorporation was observed first in the pons and medulla, spreading to the cerebellar tissues as the infection became more acute (Anderson, et al., 1950). It would appear that infection is accompanied by an increased turnover of phosphorus probably as the result of the increased synthesis of energy-rich phosphates which are presumably used in increased virus production.

Effects of the toxic trialkyl tin compounds have been examined by Stoner and Threlfall (1958). These compounds cause a significant interstitial oedema of white matter and the spinal cord (Magee et al., 1957). In cerebral slices taken from poisoned animals the oxygen uptake is reduced (Cremer, 1957). In rats given a lethal dose of triethyl tin sulphate, after which they survive for about $48 \mathrm{hr}$, it was found that the amount of radioactive phosphate entering the brain was reduced. The specific radioactivity of cerebral inorganic phosphate and of diphosphopyridine nucleotide was lowered, but no changes were detected within $24 \mathrm{hr}$ in the specific radioactivities of phosphocreatine or adenosine di- and triphosphates. The quantities of these phosphates in the brain were not affected. On the other hand, marked and significant decreases were found both in the quantity and specific radioactivity of the total lipid phosphorus. In this latter respect the action of 
triethyl tin resembles that of the barbiturates and may possibly be a reflection of the fall in tissue temperature produced by these substances (Stoner and 'Threlfall, 1958).

Dinitro-o-cresol, toxic to man where death is accompanied by extreme rigor, also affects levels of cerebral phosphates (Parker, 1954). In rats, killed by injection of the dinitrocresol the quantities of phosphocreatine and adenosine triphosphate fell from normal levels to $0 \cdot 3-0 \cdot 6 \mu$ moles $/ g$ wet wt. tissue, while levels of adenosine monophosphate increased. Such an effect is in accord with the known ability of this compound to " uncouple " oxidative phosphorylation (pp. 81-82) and thus decrease the levels of adenosine triphosphate and phosphocreatine.

The entry and metabolism of phosphate in cerebral tissue appears to be partly under hormonal control. In the rat during pro-oestrus there is a significant increase in radioactive phosphate uptake in the tubercinereum as compared with the uptake during any other stage of the oestrus cycle (Borell and Ostrom, 1947). Corticotrophic hormone exerts a regulatory function on the phosphate uptake of grey matter, olfactory bulb and the pineal gland in the rat (Reiss et al., 1949). Hypophysectomy reduced the uptake of intravenously injected phosphate into the olfactory bulb but increased it in grey matter and in the pineal gland. Values were brought to normal if corticotrophic hormone was administered $1 \mathrm{hr}$ before radioactive phosphate. The changes were not confined to acid-soluble phosphates but extended to the phospholipid and to the "residual" phosphate fraction. This differential effect upon various parts of the brain may offer an explanation for the finding (Zamurovic et al., 1953) that intraperitoneally injected radioactive phosphate is not incorporated into the whole brain of hypophysectomized rats at a rate lower than in the normal animal. Corticotrophic hormone when administered to normal rats increased the uptake of radioactive phosphate into cerebral phospholipids but not into nucleoprotein nor into the total phosphate of the brain (Torda, 1954). Since the radioactivity of the total brain phosphate was unaffected while that of the cerebral phospholipids increased some other cerebral phosphorus component presumably decreased in radioactivity.

Radiation by X-rays at 20,000 r did not affect the incorporation of peripherally administered radioactive phosphate into mouse 
brain (Florsheim and Morton, 1954) though no indication was given of the extent of any tissue damage.

Although studies of the effects of thiamine deficiency upon cerebral metabolism are numerous, few relate to phosphate metabolism. Boldyreva (1940) reported that levels of both cerebral phosphocreatine and inorganic phosphate were increased while those of adenosine triphosphate decreased in aneurin deficient pigeons. Brante (1949) found that thiamine deficiency, like pantothenic acid or choline deficiency, had no effect upon the synthesis of the total phospholipids of rat brain during the period of growth.

\section{REFERENCES}

Abood, L. G. and Geiger, A. (1955) Amer. F. Physiol. 182, 557.

Albaum, H. G., Noel, W. K. and Chinn, H. I. (1953) Amer. F. Physiol. $174,408$.

Albaum, H. G., Tepperman, J. and Bodansky, O. (1946) F. biol. chem. $164,45$.

Albert, S. and Leblond, C. P. C. (1946) Endocrinol. 39, 386.

Anderson, J. A., Gemzell, C., Gemzell, L. L., Bolin, V. S. and Samuels, L. T. (1950) Proc. soc. exp. biol. N.Y. 73, 690.

Ansell, G. B. and Dohman, H. (1956) F. Neurochem. 1, 150.

Ansell, G. B. and Dohman, H. (1957) F. Neurochem. 2, 1.

Bain, J. A. (1957) in Progress in Neurobiology, Vol. II, p. 139 (Ed. by H. WAELSCH), Hoeber, New York.

Bain, J. A. and Klein, J. R. (1949) Amer. F. Physiol. 158, 478.

Bain, J. A., Pollock, J. H. and Stein, S. N. (1949) Proc. soc. exp. biol. N.Y. 71, 497.

Bakay, L. (1953) Arch. Neurol. Psychiat. Chicago 70, 30.

Bakay, L. (1955) Arch. Neurol. Psychiat. Chicago 73, 2.

Boivin, A., Vendrely, R. and Vendrely, C. (1948) C.R. Acad. Sci., Paris 226, 1061.

Borell, U. and Ostrom, A. (1947) Biochem. F. 47, 398.

Britton, S. W. and Kline, R. F. (1945) Amer. F. Physiol. 145, 190.

Brante, G. (1949) Acta. physiol. scand. 18, Suppl. 63.

Burton, R. M. (1957) F. Neurochem. 2, 15.

Boldyreva, N. V. (1940) F. Physiol. U.S.S.R. 29, 582 (Chem. Abstr. 36, 6215).

Chaikoff, I. L., Changus, G. W. and Ruben, S. (1938) F. biol. chem. 126, 493.

Cicardo, V. H. (1945) Amer. F. Physiol. 145, 542.

Crain, S. M. (1952) Proc. soc. exp. biol. N.Y. 81, 49.

Cremer, J. E. (1957) Biochem. F. 67, 87.

Davies, P. W. and RÉMond, A. (1947) Res. pub. assoc. nerv. ment. dis. 21, 205. 
Davis, E. W., McCulloch, W. S. and Roseman, E. (1944) Amer. F. Physiol. 100, 825.

Davison, A. N. and DobBing, J. (1958) Lancet, 1158.

Dawson, R. M. C. (1955) in Metabolism of the Developing Nervous System, p. 268 (Ed. by H. WaELSCH), Academic Press, New York.

Dawson, R. M. C. and Peters, R. A. (1955) Biochem. biophys. Acta. 16, 254.

Dawson, R. M. C. and Richter, D. (1950a) Proc. Roy. Soc. B 137, 252.

Dawson, R. M. C. and Richter, D. (1950b) Amer. F. Physiol. 160, 203.

Doring, H. J. and Gerlach, E. (1957) Arch. expt. Pathol. Pharmacol. 232, 271.

Dusser de Barenne, J. G., Marshall, E., Nims, L. F. and Stone, W. E. (1941) Amer. F. Physiol. 132, 776.

Dziewiatkowski, D. and Bodian, D. (1950) F. cell. comp. Physiol. 35, 141.

Einarson, L. (1957) in Metabolism of the Nervous System (Ed. by D. Richter), Pergamon Press, London \& New York.

FleXner, L. B. (1955) in Biochemistry of the Developing Nervous System, p. 281 (Ed. by H. Waelsch), Academic Press, New York.

Flexner, J. B. and Flexner, L. B. (1948) F. cell. comp. Physiol. 31, 315.

Flexner, L. B. and Flexner, J. B. (1950) F. cell. comp. Physiol. 36, 351.

Florsheim, W. H. and Morton, M. E. (1954) Amer. F. Physiol. 176, 15.

Folch, J. (1955) in Biochemistry of the Developing Nervous System, p. 121

(Ed. by H. Waelsch), Academic Press, New York.

Fries, B. A. and Chaikoff, I. L. (1941) F. biol. chem. 141, 469.

Fries, B. A., Changus, G. M. and Chaikoff, I. L. (1940) F. biol. chem. 132, 23.

Garcia-Aust, E. (1954) Proc. soc. exp. biol. N.Y. 86, 348.

Geiger, A. and Yamasaki, S. (1956) F. Neurochem. 1, 93.

Geiger, A., Magnus, J. and Geiger, R. S. (1952) Nature, Lond. 170, 754.

Gerlach, E., Doring, H. J. and Fleckenstein, A. (1958) Pflïgers Archiv. 266, 266.

Gibbs, F. A., Gibbs, E. L. and Lennox, W. G. (1938) Arch. Neurol. Psychiat. Chicago 39, 298.

Gurdjian, E. S., Stone, W. E. and Webster, J. E. (1944) Arch. Neurol. Psychiat. Chicago 51, 472.

Gurdjian, E. S., Webster, J. E. and Stone, W. E. (1949) Amer. F. Physiol. 156, 149.

Gurdjian, E. S., Webster, J. E. and Stone, W. E. (1947) Res. publ. assoc. nerv. ment. dis. 26, 118.

Hill, D. (1955) in Biochemistry of the Developing Nervous System, p. 110 (Ed. by H. Waelsch), Academic Press, New York.

Hıмwich, H. E. (1951) Brain Metabolism and Cerebral Disorders, Williams \& Wilkins, Baltimore.

Himwich, H. E. and Нimwich, W. A. (1955) in Biochemistry of the Developing Nervous System, p. 202 (Ed. by H. WAELSCH), Academic Press, New York.

Hirsch, H., Krenkel, W., Schneider, M. and Schnellbacher, F. (1955) Pflügers Arch. ges. Physiol. 261, 402. 
Isselhard, W., Irmscher, K. and Thorn, W. (1959) Pflïgers Archiv. 268, 415.

Jordan, W. K., Budal, D. W. and March, R. (1950) Arch. Neurol. Psychiat. Chicago 63, 766.

Kabat, H. (1944) Science 99, 603.

KERR, S. E. (1935) F. biol. chem. 110, 625.

Kerr, S. E. and AnTaki, A. (1937) F. biol. chem. 122, 49.

Kerr, S. E. and Ghantus, M. (1936) F. biol. chem. 116, 91.

Kety, S. S. (1948) Amer. F. Physiol. 104, 765.

Kety, S. S. and Schmidt, C. F. (1948) F. clin. Invest. 27, 484.

Klein, J. R. and Olsen, N. S. (1947) F. biol. chem. 167, 747.

Lajtha, A. (1957) F. Neurochem. 1, 214.

Lennox, W. G., Gibbs, F. A. and Gibbs, E. L. (1935) Arch. Neurol. Psychiat. 34, 1001.

Le Page, G. A. (1946) Amer. F. Physiol. 146, 267.

Libet, B., Fazekas, J. F. and Himwich, H. E. (1941) Amer. F. Physiol. 132, 232.

Lin, S., Cohen, H. P. and Cohen, M. M. (1958) Neurology 8 (Suppl. 1), 72.

McIlwain, H. (1959) Biochemistry and the Central Nervous System, 2nd ed., Churchill, London.

McIlwain, H., Buchel, L. and Cheshire, J. D. (1951) Biochem. F. 48, 12.

Magee, P. N., Stoner, H. B. and Barnes, J. M. (1957) F. path. bact. 73, 107.

McGhee, E. C., Papageorge, E., Bloom, W. C. and Lewis, G. T. (1951) 7. biol. chem. 190, 127.

Maleci, A. (1950) Arch. Fisiol. 50, 18 (Chem. Abstr. 45, 7678).

Mandel, P., Bieth, R. and Stoll, R. (1947) C.R. soc. biol. 141, 1260.

Mandel, P., Bieth, R. and Weil, H. (1953) C.R. soc. biol. 147, 1273.

Meyer, A. (1958) in Neuropathology, Edward Arnold, London.

Moog, F. (1947) F. exp. Zool. 105, 209.

Naidoo, D. and Pratt, O. E. (1954) Enzymologia 26, 298.

Olsen, N. S. and Klein, J. R. (1947) Res. publ. assoc. nerv. ment. dis. 26, 118.

Palladin, A. V. (1955) 3rd Intern. Congr. Biochem., Report on Biochemistry of the Brain.

PARKer, V. H. (1954) Biochem. F. 57, 381.

Potter, V. R., Schneider, W. C. and Leibl, G. J. (1945) Cancer Research $5,21$.

Pscheidt, G. R., Benitez, D., Kirschner, L. B. and Stone, W. E. (1954, Amer. F. Physiol. 176, 483.

Randall, L. O. (1940) F. biol. chem. 133, 129.

Reiss, M., Badrick, F. E. and Halkerston, J. H. (1949) Biochem. F. 44) 257.

Robinson, F. and Hughes, R. A. (1951) F. Neurophysiol. 14, 387.

Savchenko, O. N. (1958) Voprosy. med. Khim. 4, 139 (Chem. Abstr. 52, 15699a). 
Schneider, M. (1957) in Metabolism of the Nervous System, p. 238

(Ed. by D. Richter), Pergamon Press, London \& New York.

Shapot, V. S. (1957) in Metabolism of the Nervous System, p. 257 (Ed. by

D. Richter), Pergamon Press, London \& New York.

Shideman, F. E. and Seevers, M. H. (1953) Proc. soc. exp. biol. N. Y. 82, 63.

Stern, W. E. and Marshall, C. (1951) Proc. soc. exp. biol. N.Y. 78, 16. STONE, W. E. (1940) F. biol. chem. 135, 43.

Stone, W. E., Marshall, C. and Nims, C. F. (1941) Amer. F. Physiol. 132, 770 .

Stone, W. E., Webster, J. E. and Gurdjian, E. S. (1945) F. Neurophysiol. 8, 233.

Stoner, H. B. and Threlfall, C. J. (1954) Biochem. F. 58, 115.

Stoner, H. B. and Threlfall, C. J. (1958) Biochem. F. 69, 376.

Symposium (1955) Metabolism of the Developing Nervous System (Ed. by H. Waelsch), Academic Press, New York.

Sytinsky, I. A. (1956) Biokhim. 21, 359.

Szepsenwol, J. and Partridge, M. H. (1952) Amer. F. Physiol. 171, 257. Szepsenwol, J., Mason, J. and Shontz, A. E. (1955) Amer. F. Physiol. $180,525$.

Torda, C. (1954) Amer. F. Physiol. 177, 179.

Thorn, W., Pfleiderer, G., Frowein, R. A. and Ross, I. (1955) Pflügers Archiv. 261, 334.

Thorn, W., Scholl, H., Pfleiderer, G. and Mueldener, B. (1958) F. Neurochem. 2, 150.

Uzmann, L. L. and Rumley, M. K. (1958) F. Neurochem. 3, 170.

Vendrely, R. and Vendrely, C. (1948) Experienta. 4, 434.

Vendrely, R. and Vendrely, C. (1949) Experienta. 5, 327.

Vladimirov, G. E. (1953) Fiz. Zh. SSSR 39, 3.

Vladimirov, G. E. and Rubel, L. N. (1957) in Metabolism of the Nervous System, p. 263 (Ed. by D. Richter), Pergamon Press, London \& New York.

Vladimirov, G. E., Ivanova, T. N. and Pravdina, N. I. (1957) Biokhim. 22, 327.

Vladimirova, E. A. (1956) Vopr. med. khim. 2, 47 (Chem. Abstr. 50, 10160c).

Wase, A. W., Christensen, J. and Polley, E. (1956) Arch. Neurol. Psychiat. Chicago 75, 54.

Zamurovic, D. A., Kanazir, D. and Beconevic, H. (1953) Rec. trav. inst. recherche struct. mat. 2, 99. (Chem. Abstr. 48, 1555d).

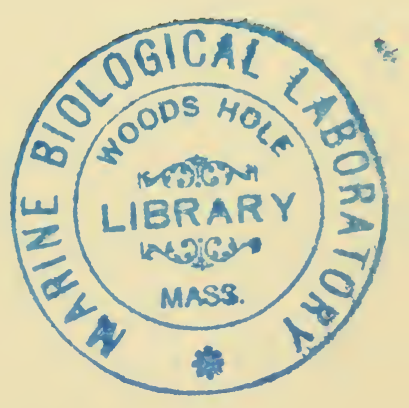



Section II

METABOLISM IN VITRO 



\section{TISSUE PREPARATIONS AND GENERAL METABOLISM}

THE CHAPTERS of the preceding section have summarized data relating to the composition of the brain with respect to phosphates and have illustrated ways in which their quantities and metabolism are affected in vivo under a variety of conditions. Such information has provided the basis for regarding the metabolism of the phosphates to be intimately linked with the functioning of the brain. The chapters of the present section are concerned with data relating to the changes occurring in vivo but obtained from a more detailed study of brain metabolism in tissue slices, homogenates and particulate preparations. In such preparations the metabolic potential of cerebral tissues can be displayed and detailed examination can be made of the response to different conditions. A detailed discussion of the merits, demerits and experimental arrangements with such preparations is not given here since adequate accounts have already been provided (Elliot, 1955; McIlwain, 1959).

\section{Tissue Slices}

Cerebral tissues can be sliced by hand using either a guide (Umbreit et al., 1949) or a recessed plate and a strip of razor blade moistened with an appropriate saline (Mcllwain, 1951), to yield slices approximately $0.35 \mathrm{~mm}$ thick. Slices or small sections of tissue may also be chopped into fragments either with scissors or with a mechanical chopper. Mechanically chopped tissue still retains the metabolic characteristics of the intact slice and can be pipetted as a suspension. 'This technique is particularly useful in dealing with small quantities of tissue excized from different areas of the brain. Although cutting a tissue must damage cellular elements and sever many processes, the actual extent of such damage appears to be remarkably small. McIlwain (1959) estimates it at not more than $0.2 \%$ of the total surface. The slice technique 
requires that the nutrients normally obtained from the blood be replaced by suitable salines. Of the many available, the bicarbonate- or phosphate-buffered slices of Krebs and Henseleit (1932), based upon the content of inorganic ions in the serum, have been the most widely used. Variations of these have been proposed by Krebs (1950). Many workers modify the proportions of calcium salts and replace the buffers by glycylglycine or 2-amino-2(hydroxymethyl)-1:3-propanediol according to the particular requirements of the experiment. In doing so it is to be remembered that the metabolism of the tissue can be markedly altered by small changes in the ionic composition of the medium (see for example McIlwain and Gore, 1952) and the effects of such changes in relation to the phenomena being studied need to be carefully assessed. Under suitable conditions slices of cerebral cortex floating freely in saline, will respire at a steady rate for 2-3 hr.

Other experimental arrangements with tissue slices include provision for excitation by electrical currents. Here the tissue is held between a grid of wire (Ayres and McIlwain, 1953) which does not prevent the oxygenation of the tissue but permits the application of alternating electrical potentials. Such wire grids may be constructed to fit into standard manometric flasks, to enable small quantities of bathing fluid to be used (Rodnight and McIlwain, 1954), or to permit the rapid transfer of the tissue from an incubating saline to an fixing agent such as trichloracetic acid within 0.2-0.3 sec (Heald and McIlwain, 1956). This latter arrangement has proved particularly useful in the study of changes occurring over periods of a few seconds or minutes. Choice of arrangement depends upon the problem being studied. Examples of the use of each are given throughout the following chapters.

\section{Tissue Dispersions}

Tissues can be ground, either by mashing on a warm, moist plate with a spatula, to provide a brei, or more completely in a glass tube with a fitting pestle of glass or plastic to yield dispersions loosely termed "homogenates". The brei is now little used being somewhat indeterminate in character and containing intact cells in addition to disrupted material. Dispersion destroys the cell structure. Nevertheless, the preparations obtained can exhibit many of the important metabolic activities of the intact tissue such as glucose oxidation, lactic acid production and oxidative phos- 
phorylation. With such preparations it is possible to study the details of metabolism either in terms of the individual, or as a sequence of, enzymic reactions. Dispersions can be prepared in distilled water, various buffers, salines or in isotonic sucrose. Generally the maintenance of metabolism in suspensions requires more exacting conditions than in the slice, since disintegration of cellular structures permits many enzymes to assume degradative rules. Co-factors usually added include magnesium, calcium and potassium salts, inorganic phosphate, nucleotides such as adenosine triphosphate, components of the cytochrome system such as cytochrome- $c$ and diphosphopyridine nucleotide, and substrates such as pyruvate together with fumarate or malate. Respiration in such preparations is not maintained as in slices, oxygen uptake decreasing markedly after $45 \mathrm{~min}$ at $37^{\circ} \mathrm{C}$.

\section{Particulate Preparations}

Dispersions of brain, containing many systems actively degrading phosphates, are not ideally suited to the detailed study of oxidative phosphorylation. For this purpose particulate fractions can be isolated which contain essentially the total oxidative capacity of the tissue. In comparison with other tissues, principally liver (see Lindberg and Ernster, 1954), relatively little work has been carried out with brain particles. After the disintegration of the tissue in a suitable medium, usually $0.25 M$ sucrose containing ethylenediaminetetra-acetate, fractions containing nuclei, mitochondria and microsomes can be obtained by differential centrifugation. The mitochondria are usually obtained free from major cellular structures (Brody and Bain, 1951; Abood et al., 1952; Christie et al., 1953; Hesselbach and Dubuy, 1953; Brody and Bain, 1954; Narayanaswami and McIlwain, 1954; Jordan and March, 1956; Aldridge, 1957; Dubuy and Hesselbach, 1958). The scheme of fractionation described by Brody and Bain (1952) has been almost universally accepted as providing a suitable separation of the main groups of particles in dispersions of whole brain and is illustrated in Fig. 10. The groups of particles obtained are far from homogeneous and also suffer from a degree of overlap with the preceding and following groups. The nuclear fraction has been subdivided into 5-7 distinct sub-fractions (Heald, 1959) and the mitochondrial fraction contains at least four distinct groups of particles (Hebb and Whittaker, 1958). Similar subdivisions were 
obtained with liver mitochondria (Kuff and Schneider, 1954). Nevertheless, the bulk of the oxidative activity of the cell is concentrated in particles of the mitochondrial fraction which thus

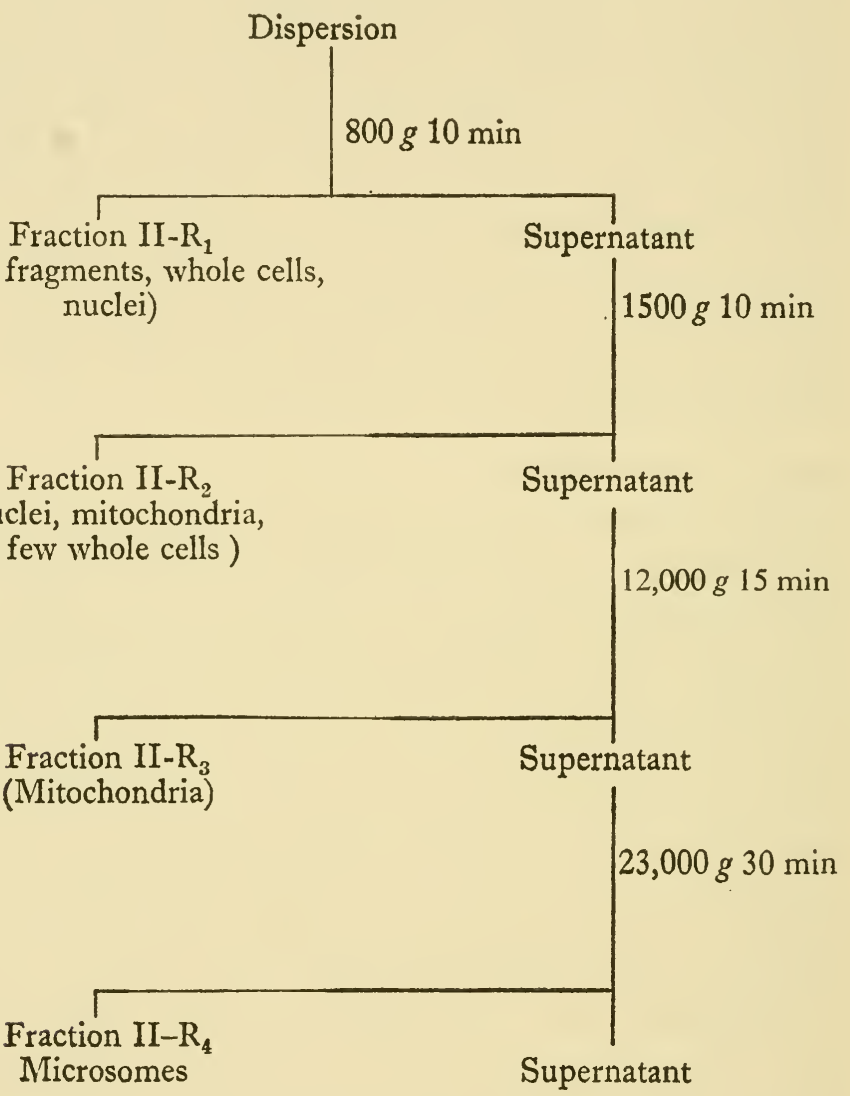

Fig. 10. The separation of subcellular fractions from dispersions of whole brain. Diagram after Brody and Bain (1952).

provides a cleaner preparation for the study of oxidative phosphorylation than does the whole dispersion.

Mitochondrial preparations from whole brain contain mitochondria from many different types of cell and exhibit certain differences in metabolism from liver mitochondria. Thus dispersion in $0.88 M$ aqueous sucrose, originally used in the preparation 
of liver mitochondria (see Schneider, 1944), results in cerebral mitochondrial preparations with a low capacity for oxidative phosphorylation (Brody and Bain, 1952) and a loss of dehydrogenase activity for vital dyes (Showacre, 1953) as compared with preparations made in $0.25 M$ sucrose. The oxidation of glutamate by mitochondria from cerebral tissues is greatly enhanced by treatment with a chelating agent such as $1: 10$ phenanthroline at $10^{-3} M$ whereas liver mitochondria are unaffected (Christie et al., 1953). Mitochondria from cerebral tissues carry out a complete oxidation of glucose to carbon dioxide and water (Dubuy and Hesselbach, 1956; Gallagher et al., 1956; see however, Aldridge, 1957) a process not occurring in liver mitochondria while octanoic acid, readily oxidized by liver mitochondria, is not oxidized by cerebral mitochondrial preparations (Christie et al., 1953; Aldridge, 1957). The stability of brain mitochondrial preparations as regards oxidation of pyruvate, is less than that of liver preparations (Aldridge, 1957). Nevertheless, in a suitable medium brain mitochondria respire at a linear rate for periods of up to $90 \mathrm{~min}$.

It is not clear whether mitochondrial preparations from brain contain enzymes from the glycolytic sequence. Thus, Brody and Bain (1952) and Abood et al. (1951) were unable to demonstrate glycolysis in their preparations, a result which has been more recently confirmed by Aldridge (1957). On the other hand the hexokinase of calf brain was found to be associated with particulate material which could be centrifuged from suspension (Crane and Sols, 1953) and the complete glycolysis of glucose to lactic acid has been shown to occur with several mitochondrial preparations (Hesselbach and Dubuy, 1953; Dubuy and Hesselbach, 1956, 1958; Gallagher et al., 1956). Whether these latter results represent adsorption of enzymes upon particulate material is not known. As noted above, brain mitochondrial preparations are heterogeneous and the discrepancies may be, in part, due to a variable inclusion of particles which are not mitochondria.

The above constitute the major types of preparations used for the study of metabolism of cerebral tissue. While choice of preparation must be determined partly by the nature of the problem being studied it is to be remembered that the greater the degree of dispersion the less the tissue preparation resembles whole brain and caution is needed in extrapolating results. 


\section{General Metabolism}

One of the major aims of studies of metabolism in vitro is the integration of the results obtained with the events occurring in vivo. This aim is most likely to be assisted if the preparations used in vitro correspond, in the metabolic activity being studied, to the tissue in vivo. Though this ideal is as yet only partly achieved, much information has been provided relevant to the major theme. The following account relates to the general metabolism, in tissue preparations in vitro, of phosphorylated compounds found to be affected by differing conditions and stimuli in vivo.

\section{Acid-soluble Phosphates}

Quantities and syntheses.-Removal of the brain results in a rapid breakdown of phosphocreatine and adenosine triphosphate (Table 10). When slices of cerebral tissue are incubated in a suitable oxygenated saline containing glucose these phosphates are resynthesized (Table 12), phosphocreatine reaching levels of about 1.3-1.5 $\mu$ moles/g wet wt. tissue. Although the levels of phosphocreatine and adenosine triphosphate finally reached appear to be lower than levels found in vivo (Table 1), differences can be partly ascribed to the higher water content of the slices. As normally prepared, slices imbibe some $20 \%$ of their weight of water before being weighed making the results in Table 12 too low by about one-fifth. Even so the levels of phosphocreatine and adenosine triphosphate finally reached do not normally exceed $60 \%$ of the quantities found in vivo. Other causes include loss of up to $50 \%$ of adenine from nucleotides to the medium (Acs et al., 1953 ) and $70-80 \%$ of the free creatine of the tissue (Thomas, 1956). Addition of these to the incubation medium (Thomas, $1956,1957)$ results in an increased resynthesis to quantities of $2 \cdot 0 \mu$ moles phosphocreatine and 1.8-1.9 $\mu$ moles adenosine triphosphate/g wet wt. tissue corrected for swelling. Resynthesis to these higher levels is extremely slow, requiring some $2-3 \mathrm{hr}$, in contrast to the initial rapid increase in phosphocreatine which takes place within a few minutes. This situation is analogous to the slow synthesis of glycogen in cerebral slices in vitro(Le Baron, 1955) but may also be due to a slow penetration of creatine and adenine into the tissue (Thomas, 1956).

The exchange of inorganic phosphate between a cerebral slice 
Table 12.-Quantities of Acid-soluble Phosphates In Cerebral Cortical Slices in vitro after Incubation in Salines Containing Glucose

Superscripts denote references below

\begin{tabular}{l|l}
\hline \multicolumn{1}{c|}{ Phosphate } & \multicolumn{1}{|c}{ Quantity, in $\mu$ moles/g wet wt. } \\
\hline $\begin{array}{l}\text { Adenosine di- and } \\
\text { triphosphates }\end{array}$ & $0 \cdot 80^{(1)} 1 \cdot 01^{(6)} 1 \cdot 85^{(10)} 0.92^{(4)}$ \\
\hline $\begin{array}{l}\text { Guanosine di- and } \\
\text { triphosphates }\end{array}$ & $0 \cdot 30^{(2)} 0 \cdot 17^{(3)}$ \\
\hline \begin{tabular}{l} 
Phosphocreatine \\
$1 \cdot 12^{(1)} 1 \cdot 35^{(4)} 1 \cdot 46^{(5)} 1 \cdot 12^{(6)} 1.0^{(10)}$ \\
\hline $\begin{array}{l}\text { Diphosphopyridine } \\
\text { nucleotide }\end{array}$
\end{tabular} & $0 \cdot 11^{(1)} 0 \cdot 23^{(11)}$ \\
\hline \begin{tabular}{l} 
Hexose monophosphates \\
\hline Adenylic acid
\end{tabular} & $0 \cdot 72^{(1)} 0 \cdot 23^{(6)} 0 \cdot 6^{(10)}$ \\
\hline Orthophosphate & $0.55^{(1)}$ \\
\hline
\end{tabular}

Generally, salines contained: $\mathrm{NaCl} 125 \mathrm{mM}, \mathrm{KCl} 6.3 \mathrm{mM}, \mathrm{CaCl}_{2} 2 \cdot 7$ $\mathrm{m} M, \mathrm{MgSO}_{4} 1.28 \mathrm{~m} M$, glucose $10.0 \mathrm{~m} M$, and either sodium phosphate $\mathrm{pH} 7 \cdot 40 \cdot 1 \mathrm{M}$, or 2-amino-2(hydroxymethyl)-1 : 3-propanediol $\mathrm{pH} 7 \cdot 4$ $50 \mathrm{~m} M$.

(1) Guinea pig, Heald, 1956a. (2) Guinea pig, Heald 1957. (3) Guinea pig, Thomas, 1957. (4) Guinea pig, Heald, 1954. (5) McIlwain et al., 1951. (6) Guinea pig, Kratzing and Narayanaswami, 1953. (7) Rat, Heald, unpublished. (8) Human, leucotomy specimens, Heald, unpublished. (9) Human, leucotomy specimen, Greengard (1955). (10) Cat, Tower, 1958. The medium contained $27 \mathrm{~m} M$ potassium salts. (11) Guinea pig, Gore et al., 1950.

and the surrounding medium is much more rapid. Thus on incubation in saline containing glucose, both in the presence and absence of inorganic phosphate, guinea pig cerebral slices lost $3.0-4.0 \mu$ moles of phosphate $/ g$ wet wt. during a period of $30-90$ min (McIlwain et al., 1951; Heald, 1956b). Comparison of the quantity lost with the amounts present as inorganic phosphate in the tissue suggests that part of the phosphate appearing in the medium 
must have arisen from sources other than inorganic phosphate itself. In this respect the production of inorganic phosphate resembles that occurring in vivo after decapitation. Entry of phosphate to the tissue slice is partly dependent upon the metabolism of glucose (Fries et al., 1942) for the addition of this substrate to slices metabolizing radioactive phosphorus markedly increased the amount accumulating in the slices. Heald (1956b) studied the rate of incorporation of radioactive phosphate into the labile phosphates and total inorganic phosphate of guinea pig cerebral slices metabolizing glucose. Since the contribution to the radioactivity of the tissue made by phosphate in the extracellular space could not be adequately assessed (for discussion see also Manery, 1952; Allen, 1955) no value was obtainable for the radioactivity of the intracellular phosphate. However, rough calculations based on the radioactivity of the total inorganic phosphate of the tissue slice indicated that between 10-15 $\mu$ moles inorganic phosphate/g wet wt. tissue $\mathrm{hr}^{-1}$ was transported between slices and medium. Thus even on the basis of this low rate, transport into the tissue appears to be more rapid than from the blood to the brain.

Levels of guanosine phosphates are not readily increased by the inclusion of guanine in the medium, the quantities actually falling from $0.38 \mu$ moles $/ g$ wet wt. in slices fixed immediately after cutting to about $0 \cdot 20 \mu$ moles $/ g$ in slices incubated for $100 \mathrm{~min}$ (Thomas, 1957). However, inclusion of both adenine (which increased levels of adenosine triphosphate) and guanine in the medium partially restored the levels of guanine nucleotides. This suggests that increased quantities of adenosine triphosphate are necessary to the synthesis of guanosine nucleotides, and is of interest in view of recent evidence (Heald and Stancer, 1960) that adenosine triphosphate is a probable precursor of guanosine triphosphate in the brain. The identity of phosphocreatine and the nucleotides has been well established both by specific enzymic methods (Kratzing and Narayanaswami, 1953) and by isolation and chromatographic techniques (Gore et. al., 1950; Heald, 1956, 1957b). Comparison of the quantities resynthesized by cerebral slices from different species is somewhat limited but in those so far examined there appears to be no major differences.

In addition to the phosphates listed, triphosphopyridine nucleotide is present in guinea pig cerebral slices at levels of $0.04 \mu \mathrm{moles} / \mathrm{g}$ 
wet wt. (Glock and McLean, 1955). It exists predominantly in the reduced form in contrast to diphosphopyridine nucleotide which was found to be present mainly in the oxidized form. Unlike other nucleotides the quantity of diphosphopyridine nucleotide is not markedly altered on removal and slicing of the brain (Gore et al., 1950) though the relative proportions of oxidized and reduced forms may well be changed. No increases in quantity were observed when a variety of possible precursors were added to the incubation medium. Nevertheless, it has been found (Heald, 1956b) that diphosphopyridine nucleotide in guinea pig cerebral slices incorporates radioactive phosphate at an appreciable rate, suggesting that it is split and resynthesized. Possible mechanisms include that described by Kornberg (1948, 1950) whereby nicotinamide mononucleotide is phosphorylated by adenosine triphosphate to form diphosphopyridine nucleotide. Other nucleotides such as those of cytidine and uridine have not yet been isolated from cerebral slices though there is good reason to suppose that they are present (see p. 90).

The total acid-soluble phosphorus of guinea pig cerebral slices after incubation varies from 10-15 $\mu$ moles phosphorus/g wet wt. according to whether slices were incubated in saline free from or containing added phosphate. Thus the phosphates listed in Table 12 comprise some $80 \%$ of the total present. Of those remaining little is known. In a fraction comprising $1.3 \mu$ moles phosphorus/g wet wt., the barium salts of which were soluble in $80 \%$ ethanol, only ethanolamine phosphate could be detected chromatographically.

Mechanisms of synthesis of the acid-soluble phosphates, principally adenosine triphosphate and creatine phosphate, have been studied mainly in disintegrated preparations and more recently in tissue slices. It had been shown quite early, that both inorganic phosphate and adenylic acid or adenosine triphosphate were essential for the oxidation of substrates, such as pyruvic acid, by dialysed preparations of pigeon brain (Banga et al., 1939). Further examination (Ochoa, 1941) showed that the oxidation of pyruvate in the presence of adenylic acid and inorganic phosphate yielded considerable quantities of an acid-hydrolysable phosphate presumably adenosine triphosphate, while at the same time inorganic phosphate was removed from the incubation medium. Adenosine triphosphate as such was not directly estimated but was 
used to esterify glucose to glucose-6-phosphate in the presence of hexokinase or to convert creatine to phosphocreatine (see also Colowick et al., 1941; Goranson and Elrulkar, 1949). In the presence of sodium fluoride, added at concentrations sufficient to inhibit adenosine triphosphatase, some 2-3 atoms of inorganic phosphate were consumed for each atom of oxygen yielding phosphorus/oxygen ratios of 2-3.0.

These experiments have been confirmed with a variety of dispersions (Case and McIlwain, 1951; Clowes and Keltch, 1952; Lee and Eiler, 1953) and more particularly with mitochondrial preparations oxidizing a wide variety of substrates (Table 13). Examination of the phosphorus/oxygen ratios obtained at different temperatures suggests that the efficiency of oxidative phosphorylation decreases as the temperature increases. Such a phenomenon has been previously suggested by Christie et al. (1953), with brain preparations, and by Dianzani (1954) with liver preparations. Also the phosphorylative activity of cerebral mitochondria, as judged by phosphorus/oxygen ratios in excess of $1 \cdot 5$, is maintained for a much longer period if measurements are carried out at $18^{\circ}$ rather than at $37^{\circ}$ (Brody and Bain, 1952). Thus at $37^{\circ} \mathrm{C}$ maximum activity was maintained for up to $20 \mathrm{~min}$ while at $18^{\circ}$ it could be maintained for up to $70 \mathrm{~min}$. On the other hand Aldridge (1957) obtained a steady and linear rate of oxygen consumption combined with phosphorus/oxygen ratios of $2-2 \cdot 3$ at $37^{\circ}$ over a period of 1-1 $\frac{1}{2}$ hr. Examination of Fig. 1 of Brody and Bain (1952) reveals that at $37^{\circ} \mathrm{C}$ the uptake of phosphate by the mitochondria in the first 10-20 min of the experiment was initially more rapid than was the oxygen uptake, thereafter the uptake of phosphate remained constant while the oxygen uptake steadily increased. At $18^{\circ} \mathrm{C}$ the rates of phosphate and oxygen uptake were slower and almost constant over a much longer period of time, thus contributing to an almost stable phosphorus/oxygen ratio.

Differences of this type are at least partly due to the nature of the preparation employed. Thus under suitable conditions, mitochondrial preparations can be obtained in which the adenosine triphosphatase activity is not apparent and in which the oxygen uptake can be stimulated by the addition of hexokinase and glucose (Aldridge, 1957). The particles in these preparations are considered to have suffered little physical damage. Concern over differences between preparations is of less importance if the preparations are 
Table 13.-Oxidative Phosphorylation in Cerebral Mitochondria During the Metabolism of Different Substrates

Superscripts denote references below

\begin{tabular}{l|c|c|c|c|c}
\hline \multicolumn{1}{c|}{ Substrate } & \multicolumn{2}{|c|}{ Phosphorus/oxygen ratios at different temperatures } \\
\hline & $\overbrace{}^{\circ}$ & $25^{\circ}$ & $30^{\circ}$ & $33^{\circ}$ & $37 \cdot 5^{\circ}$ \\
\hline Pyruvate & $2.7^{(1.5)}$ & - & $2.1^{(2)}$ & $2.9^{(3)}$ & $2.08^{(4)} 2.3^{(10)}$ \\
Oxaloacetate & $2.49^{(1)}$ & - & $1.9^{(2)}$ & - & - \\
$\alpha$-oxoglutarate & $2.38^{(1)}$ & $3.6^{(9)}$ & $2.0^{(2)}$ & - & - \\
Fumarate & $2.03^{(1)}$ & - & - & - & - \\
Malate & - & - & $1.9^{(2)}$ & - & - \\
Succinate & $1.84^{(1)}$ & - & $0.95^{(6)}$ & - & - \\
Citrate & $1.34^{(1)}$ & - & $1.30^{(2)}$ & & - \\
Isocitrate & - & $0.7^{(8)}$ & - & - & - \\
Glutamate & $2.54^{(1)}$ & - & $1.9^{(2)}$ & - & $1.14^{(7)}$ \\
Aspartate & $1.14^{(1)}$ & - & - & - & - \\
Alanine & $0.0^{(1)}$ & - & - & - & - \\
Acetate & - & - & $1.9^{(2)}$ & - & - \\
Octanoate & $0.0^{(1)}$ & - & - & - & - \\
\hline
\end{tabular}

(1) Brody and Bain (1952), period of incubation $30 \mathrm{~min}$. (2) Abood and Gerard (1952), period of incubation 20 min. (3) Abood and Romanchek (1955), period of incubation $10 \mathrm{~min}$. (4) Narayanaswami and McIlwain (1954), period of incubation $30 \mathrm{~min}$. (5) Brody and Bain (1951), period of incubation $30 \mathrm{~min}$. (6) Clowes and Keltch (1951), period of incubation $40 \mathrm{~min}$. (7) Christie et al. (1953), period of incubation $30 \mathrm{~min}$. (8) Vignais and Vignais (1957), period of incubation $40 \mathrm{~min}$. (9)Dianzani and Scuro (1956), period of incubation $10 \mathrm{~min}$. (10) Aldridge (1957), period of incubation $30 \mathrm{~min}$.

required purely for the study of biochemical reactions. If required to provide information relating to physiological and biochemical problems in the whole animal or organ, the obtaining of preparations which are undamaged and operate at $37^{\circ} \mathrm{C}$ becomes important. In this respect the preparative techniques of Aldridge (1957) and the study of factors affecting the stabilization of mitochondrial phosphorylation at $37^{\circ} \mathrm{C}$ (Christie et al., 1953; Gallagher et al., 1956) are major contributions.

The substrates supporting oxidative phosphorylation in mitochondrial preparations (Table 13) include all the members of the tricarboxylic cycle. However, it should be noted that Christie et al. (1953) and Aldridge (1957) found citrate unable to support 
respiration in their preparations. Treatment of mitochondria so as to alter the permeability of the membrane permits oxidation of the intermediates of the tricarboxylic acid cycle (Shepherd, 1953; Gallagher et al., 1956) and it is possible that the conditions used by Brody and Bain permitted the entry of citric acid. Similar considerations may be used in assessing the phosphorylation which is said to accompany the metabolism of acetate since attempts to demonstrate the oxidation of acetate by cerebral slices or in dispersions were unsuccessful (Webb and Elliot, 1951; Elliot et al., 1942). The high phosphorous/oxygen ratio of 3.6 found for the oxidation of $\alpha$-ketoglutarate is unusual. The errors inherent in measurements of oxidative phosphorylation over short periods of time have been commented upon by Slater and Holton (1954) who pointed out that the time taken for the contents of the reaction vessels to reach temperature equilibrium with the water in the thermostat bath is longer than is generally realized and can lead to artificially high phosphorous/oxygen ratios.

Although in preparations such as described above the synthesis of labile phosphates is measured by trapping the phosphate or glucose-6-phosphate the presence of added trapping agents is not essential for phosphorylation to proceed. Thus, Lee and Eiler (1953) using brain dispersions free from glucose and added creatine, were able to demonstrate a rapid incorporation of added radioactive phosphate into adenosine triphosphate during the oxidation of succinate. As with mitochondrial preparations phosphorylation was completely inhibited by anaerobiosis.

The establishment, in disintegrated preparations, of adenosine triphosphate as the major energy-rich phosphate first formed during oxidative phosphorylation is paralleled by its formation in intact cerebral slices. Thus in slices of guinea pig cerebral cortex metabolizing glucose, radioactive phosphate from the medium was incorporated most rapidly into the $\gamma$-phosphorus of adenosine triphosphate followed closely by incorporation into phosphocreatine (see p. 117). Incorporation into the hexose monophosphates was less rapid, followed in order of decreasing specific radioactivities by adenylic acid and diphosphopyridine nucleotide (Heald 1956b). With the exception of inorganic phosphate, these phosphates accounted for $70-80 \%$ of the radioactivity present in the tissue extracts. On the basis of product precursor relationships described by Zilversmit et al. (1943) it seems probable that the 
phosphorus in phosphocreatine derives from the $\gamma$-phosphorus of the adenosine triphosphate. However, resynthesis of phosphocreatine from creatine and adenosine triphosphate in cerebral homogenates, or with a purified preparation of creatine phosphokinase, takes place slowly under conditions which can only be regarded as highly artificial, such as $\mathrm{pH} 9 \cdot 0$ and with high concentrations of substrate (Narayanaswami, 1952; Ennor and Rosenberg, 1955). At present, little significance can be attached to this process as a means of resynthesis of phosphocreatine in the intact tissue. Attempts to replace adenosine triphosphate with phosphorylated amino acids did not lead to any appreciable synthesis of phosphocreatine ('Tseitlin, 1953). Accepting that adenosine triphosphate is the precursor of phosphocreatine the turnover rate for phosphocreatine in cerebral slices can be calculated to be $160-170 u$ moles phosphorus $/ \mathrm{g} / \mathrm{hr}$. Under these conditions the oxygen uptake of the tissue slice is $55 \mu$ moles $\mathrm{O}_{2} / \mathrm{g} / \mathrm{hr}$ from which it is calculated that for each atom of oxygen consumed 1.5 atoms of phosphate are converted to phosphocreatine. This value for the rate of synthesis of phosphocreatine is in good agreement with a similar value derived from studies under different conditions and with a simpler technique (p. 124). It is of interest that the rate is approximately half of the theoretical rate for synthesis of adenosine triphosphate.

Of other phosphates mentioned, incorporation of radioactive phosphorus into phosphorylethanolamine was studied by Ansell and Dawson (1951). As in vivo the rate of incorporation was sufficiently high to show that this phosphate was synthesized directly and was not formed as a result of a breakdown of phospholipid.

Generally the synthesis of the acid-soluble phosphates follows a pattern similar to that described for brain in vivo. Thus inorganic phosphate entering the tissue is incorporated most rapidly into adenosine triphosphate and slightly less rapidly into phosphocreatine. The establishment of the ability of the tissue slice to resynthesize quantities of phosphocreatine and adenosine triphosphate approaching those existing in vivo together with the demonstration that the pattern of synthesis is also similar, provided a cell containing preparation permitting the detailed examination of several agents and conditions known to alter phosphate metabolism in vivo. Details of these are given in Chapters 4 and 5 . 
Degradatory systems. - When the cellular structure is disrupted the balance between synthesis and metabolism is disturbed. The activity of many enzyme systems becomes predominantly one of degradation of substrates. Amongst such systems adenosine triphosphatase, myokinase, and creatine phosphokinase and inorganic pyrophosphatase predominate. Adenosine triphosphate is converted to inorganic phosphate and adenylic acid presumably by the combined action of an adenosine triphosphatase (Meyerhof and Geliazkowa, 1947; Gore, 1951; Lowry et al., 1954) and cerebral myokinase (Colowick and Kalkar, 1943; Oliver, 1954, 1955). The system, however, is not a simple one and probably contains at least two enzymes acting on adenosine triphosphate, one activated by magnesium ions and inhibited by calcium ions and the other activated by calcium ions (Pappius and Elliot, 1954; Naidoo and Pratt, 1956). The nature and extent of splitting by these enzymes is not clear. The adenosine triphosphatase studied by Lowry et al. (1954) removed only the terminal phosphate from adenosine triphosphate and was inhibited by adenosine diphosphate. The enzyme studied by Gore (1951) split two phosphate groups from adenosine triphosphate but it is not clear whether this preparation contained myokinase. In both instances the rates of splitting were extremely rapid being 800 and $2000 \mu$ moles/g wet wt. tissue $\mathrm{hr}^{-1}$ respectively (cf. Dubois and Potter, 1953). In contrast, other reactions consuming adenine nucleotides appear to operate at a low level of activity. These include the adenosine-5-phosphate de-aminase of dog brain (Muntz, 1953) and the transphosphorylations occurring between inosine triphosphate and adenosine monoand diphosphates in extracts of sheep brain (Krebs and Hems, 1955). The greatest rate calculable for any of these reactions is about $50 \mu$ moles/g wet wt. $\mathrm{hr}^{-1}$ for adenosine-5-phosphate deaminase. The preparations of Krebs and Hems may have been affected by preliminary treatment of the brain with acetonc. Adenosine-5-phosphate is split by a specific 5-nucleotidase at rates of up to $200 \mu$ moles/g wet wt. $\mathrm{hr}^{-1}$ (Naidoo and Pratt, 1954). The enzyme is also active against inosine-5-phosphate (Reis, 1951).

Although cerebral dispersions contain phosphatases such as thiamine pyrophosphatase and the nonspecific acid and alkaline phosphatases (see Pratt, 1953; Naidoo and Pratt, 1953; Feigen and Wolf, 1955) simple dispersions made in sodium chloride do not 
split phosphocreatine even after incubating for $1 \mathrm{hr}$ at $37^{\circ} \mathrm{C}$ (Narayanaswami, 1952), suggesting either that a simple hydrolytic enzyme was absent or that it was destroyed or inhibited under the conditions used. With such a dispersion in the presence of adenylic acid or adenosine diphosphate, phosphocreatine was split at a rapid rate presumably by the enzyme creatine phosphokinase. Inorganic phosphate accumulated in the medium but the formation of adenosine triphosphate was not measured. In dilute cerebral extracts it was found (Oliver, 1954, 1955) that adenosine diphosphate was the sole acceptor of phosphate from phosphocreatine, being converted to adenosine triphosphate in the process. Presumably the presence of myokinase in the more concentrated dispersions together with a small quantity of adenosine di- and triphosphates accounts for the results obtained by Narayanaswami (see Ennor and Rosenberg, 1954). The absence of a demonstrable phosphatase carrying out a hydrolytic split of phosphocreatine to phosphate and creatine, together with the demonstration that adenosine triphosphate is the product of creatine phosphokinase action provides good evidence that the initial stage of phosphocreatine metabolism in brain is the phosphorylation of adenosine diphosphate to adenosine triphosphate.

Many reactions involving adenosine triphosphate result in the formation of inorganic pyrophosphate and it is of interest that. brain contains a highly active inorganic pyrophosphatase (Gordon, 1950 1953; Gore, 1951) liberating inorganic phosphate at rates of up to $2000 \mu$ moles/g wet wt. $\mathrm{hr}^{-1}$. The function of this enzyme is not at present known. It is demonstrably different from adenosine triphosphatase, a preparation free from this enzyme having been obtained from swine brain (Seal and Binkley, 1957). The high activity of the enzyme is consistent with the absence of inorganic pyrophosphate in acid extracts of brain.

The potential degradative activity is thus considerable and in certain instances, for example adenosine triphosphatase, greatly exceeds the possible rate of synthesis. Nevertheless, appreciable quantities of many of the substrates are found in the intact tissues. Considerations of this type have led to views supported by growing evidence, that many enzymes previously considered to function as hydrolases are more probably synthetases. That they are still estimated by means of their degradative capacity is probably a reflection both of the means chosen to demonstrate their presence 
and the lack of knowledge of acceptors and the reactions in which they take part. At present only hints can be made at the mechanisms involved (see p. 159). Nevertheless, the function of certain of these enzymes can still be explained in terms of a degradative role. Thus in cerebral dispersions diphosphopyridine nucleotide is degraded by a nucleotidase which can operate at rates up to $200 \mu$ moles/g wet wt. $\mathrm{hr}^{-1}$ (Mann and Quastel, 1941; Utter et al., 1948; McIlwain and Rodnight, $1949 a, b)$. The nucleotidase is specific for the oxidized form of the nucleotide and does not degrade the reduced form. A possible role for the enzyme is thus the maintenance of a high ratio of reduced to oxidized form thereby exerting a partial control upon the rate at which oxidative phosphorylation, most of which occurs during the oxidation of reduced diphosphopyridine nucleotide, is able to proceed. Such a role in vivo would require proportions of the two forms different from those found by Glock and McLean (1955).

\section{Phospholipids}

Synthesis.-When slices of rat cerebral cortex were incubated in oxygenated salines containing glucose, radioactive phosphate was incorporated into the phospholipids of the slices (Schachner et al., 1942; Fries et al., 1942). Uptake was comparatively rapid, some $0.5 \%$ of the labelled inorganic phosphate added to the medium being incorporated into the total phospholipids within $4 \mathrm{hr}$. Incorporation was not considered to be due to a total synthesis of lipid but to be the result of a steady exchange between the phospholipid and some radioactive precursor. These findings were confirmed with cat cerebral slices by Strickland (1954) and Findlay et al. (1954), who showed that labelling of the lipid phosphorus depended upon the maintenance of conditions which were optimal for oxidative phosphorylation. As in vivo the degree of labelling of the lipids was not uniform. To study incorporation into the different lipids Dawson (1954) hydrolysed lipid fractions under alkaline conditions to yield identifiable fragments containing the phosphorus. It was found that during metabolism in a suitably reinforced brain brei, radioactive phosphorus was incorporated into cephalin diphosphoinositide to an amount some 50-100 times greater than into any other recognizable phospholipid (Dawson, 1953). The lipids phosphatidyl serine, phosphatidyl ethanolamine, phosphatidyl choline and sphingomyelin incorporated less than 
$5 \%$ of the total radioactivity. However it was noted that a glycerophosphate fraction was also obtained which was 4-5 times more radioactive than diphosphoinositide. Dawson considered this to arise from a phosphatidic acid formed from glycerolphosphate and a fatty acid. Recently phosphatidic acids have been isolated from brain tissues where they have been found to be present in the greatest concentrations in the microsomal fractions (Hokin and Hokin, 1958a). These acids were the only phospholipids present in the microsomes which incorporated radioactive phosphate rapidly and to a marked extent. The same workers (Hokin and Hokin, $1958 b$ ) have also demonstrated the presence of a monophosphoinositide, accompanying cephalin diphosphoinositide, which becomes highly radioactive when slices are incubated with radioactive phosphate. It seems probable that the hydrolytic products of monophosphoinositide would be a contaminant of the hydrolytic products of diphosphoinositide and thus contribute greatly to the radioactivity of the latter.

Labelling of phospholipids in simple saline dispersions of brain is extremely poor (Fries et al., 1942) and requires the presence of adenylic acid and pyruvate (Dawson, 1953). Under these latter conditions labelling takes place under aerobic conditions. Anaerobiosis abolished labelling. However it has been shown that brain contains two systems capable of supporting the labelling of phospholipids, a glycolytic system demonstrable in dispersions made in water, and an oxidative system demonstrable in mitochondrial preparations (McMurray et al., 1957a; McMurray et al., 1957b). Under anaerobic conditions a source of energy-rich phosphate was required which could be supplied by adding adenosine triphosphate, hexose diphosphate and adenylic acid, or a triphosphate such as guanosine triphosphate and adenosine diphosphate. A specific requirement for adenosine triphosphate was found, the triphosphates of uridine, cytidine, guanine, and inosine being ineffective when added alone. They become effective only in the presence of adenosine diphosphate which was presumably phosphorylated to adenosine triphosphate by nucleotide transphosphorylases. Under aerobic conditions, with mitochondrial preparations it was shown that optimum labelling of the phospholipids was obtained only under conditions optimal for oxidative phosphorylation. The requirement for adenosine triphosphate is indicative of the primary place occupied by this 7-PMB 
compound and it has been shown by means of an elegant technique (McMurray et al., 1957a; see also Berry and McMurray, 1957), that in both mitochondrial preparations and water dispersions, adenosine triphosphate is a closer precursor of total phospholipid phosphorus than is inorganic phosphate.

It now seems well established that the pathways involved in the synthesis of a phospholipid, such as lecithin, in brain are likely to be similar to those described in liver by Kennedy (1956) and Kennedy and Weiss (1956). Thus it has been shown (Rossiter, McLeod and Strickland, 1957; Rossiter, McMurray and Strickland, 1957, McMurray et al., 1957b) that the reactions involved in the synthesis of lecithin in the brain are:

$$
\mathrm{AT}^{32} \mathrm{P}+\text { choline } \longrightarrow{ }^{32} \mathrm{P} \text { choline }+\mathrm{ADP}
$$

$\mathrm{C}^{\mathrm{r}}{ }^{32} \mathrm{P}+{ }^{32} \mathrm{P}$ choline $\longrightarrow \mathrm{CMP} \sim{ }^{32} \mathrm{P}$ choline $+\mathrm{PP}$

$$
\begin{gathered}
\mathrm{AT}^{32} \mathrm{P}+\text { glycerol } \longrightarrow \text { L- } \alpha \text {-glycerol }{ }^{32} \mathrm{P}+\mathrm{ADP} \\
\text { Acyl-CoA }+\mathrm{L}-\alpha \text {-glycerol }{ }^{32} \mathrm{P} \longrightarrow
\end{gathered}
$$

$$
\mathrm{L}-\alpha-{ }^{32} \mathrm{P} \text { phosphatidic acid }+\mathrm{CoA}
$$

$\mathrm{L}-\alpha-{ }^{32} \mathrm{P}$ phosphatidic acid $\longrightarrow \mathrm{D}-\alpha \beta$-diglyceride $+{ }^{32} \mathrm{P}$

$\mathrm{D}-\alpha \beta$-diglyceride $+\mathrm{CMP} \sim{ }^{32} \mathrm{P}$ choline $\rightarrow \mathrm{L}-\alpha-{ }^{32} \mathrm{P}$ lecithin $+\mathrm{CMP}(6)$

$$
\begin{gathered}
\text { Fatty acid }+\mathrm{CoA}+\mathrm{A}^{\prime} \mathrm{TP} \rightarrow \text { Acyl }-\mathrm{CoA}+\mathrm{AMP}+\mathrm{PP} \\
\mathrm{CMP}+\mathrm{ATP} \longrightarrow \mathrm{CTP}+\mathrm{AMP}
\end{gathered}
$$

In such a synthesis adenosine triphosphate has a dual role. It can act as a source of radioactive phosphate in the labelling of intermediates (reactions (1) and (3)) cf. the synthesis of phosphoryl ethanolamine (Ansell and Dawson, 1951), and is also essential for the incorporation of these intermediates into the phospholipid molecule (reactions (4) and (7), and (8) and (9)). The requirement for cytidine triphosphate in the synthesis of lecithin is absolute for it cannot be replaced by other nucleotide triphosphates (McMurray et al., 1957a). The activation of phosphorylcholine via the cytidine derivative may prove to be a general pattern in phospholipid synthesis since the intermediate, cytidine diphospho- 
choline, has been found to contribute the choline moiety in the enzymic synthesis of sphingomyelin by both liver and brain preparations (Scribney and Kennedy, 1958). Also a similar activation with cytidine triphosphate occurs during the incorporation of ${ }^{32} \mathrm{P}$ phosphoryl ethanolamine into phosphatidyl ethanolamine (Kennedy, 1956).

The phosphatidic acid formed in reaction (4) loses its phosphate group to form an $\alpha \beta$-diglyceride and hence the phosphorus of glycerophosphate does not enter the final glycerophosphatide. Although the phosphatidic acid is an intermediate in the synthesis of lecithin, lecithin itself does not become highly radioactive. The reactions governing the introduction of radioactive phosphorus into lecithin (reactions (2), (6) and (9)) are those involved in the synthesis of cytidine diphosphate choline and have not yet been demonstrated in brain, though this is little reason to doubt their occurrence. Establishment of this sequence would assist in understanding why the labelling of phosphorus is markedly less than in the phosphatidic acids, for both phosphates presumably arise from adenosine triphosphate. A plausible explanation would appear to be in terms of a slow turnover of the phosphorylcholine moiety which does not come into equilibrium with the rest of the phosphorus pool during the course of the experiments. Alternatively the phosphatidic acids may be part of a separate cyclic process as suggested by Dawson (1955). The rapidity with which phosphatidic acids incorporate radioactive phosphorus is presumably indicative of their rate of synthesis. Steps in this synthesis and subsequent metabolism are fairly well established. Thus glycerol derivatives are known to be precursors of phosphatides in brain tissues (Hokin and Hokin, 1955; Pritchard, 1958) and the participation of $D-\alpha \beta$-diglycerides in the final stages of synthesis of lecithin have been described by Rossiter et al. (1957). The incorporation of palmitate- $1-{ }^{14} \mathrm{C}$ into the phosphatides of cerebral tissues and dispersions was demonstrated by Jedeicken and Weinhouse (1954), who also showed that CoA was essential for maximum activity. Attempts to isolate such acyl-CoA derivatives have not been accomplished in brain though the existence of mechanisms involved in their synthesis has been clearly established (see Wolleman and Feuer, 1957).

The recognition of sequences of the above type in the synthesis of glycerophosphatides, represents a considerable contribution to 
the knowledge of phospholipid synthesis in brain and it is not unlikely that the synthesis of other phospholipids will be found to follow a similar general pattern.

\section{Hydrolysis of Phospholipids}

By injecting rats with radioactive phosphate a few hours before removal of the brain, Schachner et al. (1942) obtained cerebral tissues in which the phospholipids were labelled with radioactive phosphorus. Incubation of dispersions under anaerobic conditions showed that phosphorus equivalent to $10-15 \%$ of the total intrinsic phospholipids was released within $4 \mathrm{hr}$. Direct estimation of the phospholipid phosphorus under similar conditions confirmed the extent of the breakdown (Sperry, 1947). The process was shown to be due to cerebral enzymes since heating the tissue markedly reduced the degree of splitting while the addition of blood, normally a contaminant of brain dispersions, had no additional effects.

Analyses of the changes taking place in various crude phospholipid fractions (Tyrell, 1950) revealed that the most significant decrease in phosphorus occurred in the cephalin fraction, sphingomyelin showing no change. Parallel investigations (SloaneStanley, 1951, 1953) in which various cerebral phospholipid fractions were added to dispersions of whole brain in a bicarbonate saline and incubated anaerobically for 3-4 hr, showed that the cephalin diphosphoinositide fraction was rapidly degraded at a rate of some $60-80 \mu$ moles/g wet wt. $\mathrm{hr}^{-1}$ to form inositol monophosphate and inorganic phosphate. All other lipid preparations such as lecithin, sphingomyelin and phosphatidyl ethanolamine and serine were hydrolysed at rates varying from $1 \cdot 0-7 \cdot 0 \mu$ moles $/ g$ wet wt. $\mathrm{hr}^{-1}$. Analysis of the products formed suggested that at least two enzymes were involved, one rapidly releasing inositol diphosphate and the second hydrolysing the product to form inositol monophosphate and inorganic phosphate. The residual parts were considered to remain intact either as monoglycerides or phosphatidic acids. In these experiments the diphosphoinositide was added as an aqueous suspension of the solid lipid and, in such a form, contact with the enzymes would be limited. Using the water-soluble potassium salt it has been shown (Rodnight, 1956) that the splitting of diphosphoinositide by cerebral tissues proceeds at a rate of $300 \mu$ moles/g wet wt. $\mathrm{hr}^{-1}$ and that the maximal rate is 
probably much higher. The enzyme is uniformly distributed throughout the brain but, with the exception of the kidney, occurs to a lesser extent in other tissues. The high rate of splitting of this phospholipid is in keeping with the high rate of phosphorus incorporation though the role of the enzyme is not known. It has been suggested (Sloane-Stanley, 1952) that it may be concerned with phosphoprotein metabolism and with the relatively slow extrusion of sodium from nerve fibres, similar to that taking place in resting peripheral nerve.

Although the hydrolysis of other phospholipids was found to be slow, hydrolysis of the phosphorylated bases and glycerol esters can proceed at an appreciable rate (Strickland et al., 1956a, b). Under conditions at which the alkaline phosphatase activity was greatest (about $\mathrm{pH} 9 \cdot 0$ ) the rates of hydrolysis of the phosphate esters of serine, ethanolamine, choline, and tyrosine were 20-25 $\mu$ moles/g wet wt. $\mathrm{hr}^{-1}$. Under acidic conditions ( $\mathrm{pH} 5 \cdot 5$ ) hydrolysis was extremely small. At $\mathrm{pH} 7 \cdot 4$ glycerylphosphorylcholine was hydrolysed at a rate of $30 \mu$ moles $/ \mathrm{g}$ wet wt. $\mathrm{hr}^{-1}$ ('Thompson, 1957). Hydrolyses under these conditions appear to be performed largely by non-specific phosphatases the functions of which are not understood.

The work on the degradation and synthesis of the phospholipids of brain emphasizes that their metabolism is an active process maintaining many of the lipids in a constant state of renewal. Though the mechanisms of synthesis are becoming clearer, the significance of the lipases and related enzymes is still obscure. Evidence previously presented (p. 48) indicates that the lipids or their hydrolysis products may be oxidized by the brain (see also Rossiter, 1957) in the absence of additional substrates under conditions of high metabolic demand. It is possible that the hydrolytic enzymes are involved in providing the substrates for such oxidations and thus may also contribute to the degradative changes occurring for example in myelin, as a result of tissue damage. Whether they are also involved in the synthesis is a matter for future work.

\section{Phosphoproteins}

It was noted (p. 28) that the exchange of radioactive phosphorus in the brain in vivo with the phosphoprotein fraction was more rapid than with the phosphorus of phospholipids or any other 
fraction insoluble in trichloroacetic acid. The phosphoprotein fraction has not been isolated and work relating to its metabolism has come exclusively from studies with radioactive phosphate.

Incubation of cerebral slices with radioactive phosphate in oxygenated salines containing glucose results in a rapid exchange of inorganic phosphorus with the phosphoprotein phosphorus (Table 14), the amount of radioactivity appearing in this fraction accounting for over a third of the total found. At all times during incorporation the specific radioactivity of the phosphoprotein is many times higher than that of any other fraction (Findlay et al., 1954). Although the phosphoprotein fraction incorporating radioactivity in vitro appears to be largely a single entity with respect to radioactive phosphate exchange, brain in vivo contains at least two fractions, one soluble in isotonic sucrose solutions and the other attached to particulate material. However during incubation of slices in saline, half the soluble fraction passes from the slice to the medium, the remainder incorporating radioactive phosphorus to only a small extent compared with that in the particulate material ('Table 15). The phosphoprotein attached to particulate matter has been found to occur in the greatest concentration in particles separable from the nuclear fraction. These particles are distinct from microsomes and mitochondria. Analysis of phosphoprotein by means of standard techniques (see appendix) has been open to error since inorganic phosphate adsorbed on tissue residues is

Table 14.-The Distribution of Phosphorus and Radioactivity in Various Fractions of Cerebral Tissues after Metabolizing

Radioactive Phosphate in vitro

\begin{tabular}{l|c|c|c|c}
\hline \multirow{2}{*}{\multicolumn{1}{c|}{ Fraction }} & \multicolumn{2}{|c|}{ Cat } & \multicolumn{2}{c}{ Guinea pig } \\
\cline { 2 - 5 } & $\begin{array}{c}\mu \text { moles } \\
\mathrm{P} / \mathrm{g}\end{array}$ & $\begin{array}{c}\% \text { total } \\
\text { radio- } \\
\text { activity }\end{array}$ & $\begin{array}{c}\mu \text { moles } \\
\mathrm{P} / \mathrm{g}\end{array}$ & $\begin{array}{c}\% \text { total } \\
\text { radio- } \\
\text { activity }\end{array}$ \\
\hline $\begin{array}{l}\text { Phospholipids } \\
\text { Phosphoprotein }\end{array}$ & 73.0 & $32 \cdot 5$ & $58 \cdot 3$ & $35 \cdot 6$ \\
$\begin{array}{l}\text { Nucleic acids } \\
\text { Residual organic } \\
\text { phosphorus }\end{array}$ & 1.0 & 36.6 & $1 \cdot 1$ & $38 \cdot 0$ \\
\hline
\end{tabular}

Data from Findlay et al. (1954) and Heald (1957a). 
Table 15.-Changes in the Distribution of Phosphoproteins of Guinea Pig Cerebral Slices and Incorporation of Radioactive Phosphate during Incubation in Salines Containing Glucose

\begin{tabular}{|c|c|c|c|c|}
\hline & \multicolumn{2}{|c|}{$\begin{array}{l}\text { Phosphoprotein } \\
\mu \text { moles } \mathrm{P} / \mathrm{g} \text { wet wt. }\end{array}$} & \multicolumn{2}{|c|}{$\begin{array}{l}\text { Specific radioactivity } \\
\text { (counts/min per } \mu \mathrm{g} \text { P) } \\
\text { after incubation }\end{array}$} \\
\hline & $\begin{array}{c}\text { Before } \\
\text { incubation }\end{array}$ & $\begin{array}{c}\text { After } \\
\text { incubation }\end{array}$ & 1 & 2 \\
\hline $\begin{array}{l}\text { Particulate } \\
\text { fraction } \\
\text { Soluble } \\
\text { fraction } \\
\text { Incubation } \\
\text { medium }\end{array}$ & $\begin{array}{l}0.57 \pm 0.1(4) \\
0.40 \pm 0.01(4) \\
0.0\end{array}$ & $\begin{array}{l}0.4 \pm 0.07(4) \\
0.22 \pm 0.01(4) \\
0.17 \pm 0.008(4)\end{array}$ & $\begin{array}{r}1700 \\
245 \\
-\end{array}$ & $\begin{array}{r}1748 \\
505 \\
-\end{array}$ \\
\hline
\end{tabular}

Slices of guinea pig cerebral cortex were incubated with radioactive phosphorus for $30 \mathrm{~min}$ at $37.5^{\circ} \mathrm{C}$ under oxygen in saline containing glucose and buffered with Tham (Heald, 1959). After dispersion in sucrose $\left(0.25 M+5 \times 10^{-4} M\right.$ ethylenediaminetetra acetate $)$ dispersions were centrifuged at $104,000 \mathrm{~g}$ for $30 \mathrm{~min}$.

included as a contaminant. This has now been partly overcome by the finding that radioactive phosphorylserine is an integral part of the radioactive phosphoprotein molecule (Heald, 1958) thus permitting a more precise identification. In this respect the phosphoprotein fraction of brain is similar to the majority of other phosphoproteins and it seems not unlikely that mechanisms involved in its metabolism will show similarities with those involved for example in the metabolism of phosphoproteins of liver (Burnett and Kennedy, 1954). The existence of a phosphoprotein phosphatase active against intrinsic cerebral phosphoprotein has not been clearly demonstrated, principally owing to the absence of a suitable substrate. Nevertheless, brain extracts are capable of splitting casein, with liberation of inorganic phosphate, at rates up to $60 \mu$ moles $\mathrm{P} / \mathrm{g} \mathrm{hr}^{-1}$ at $\mathrm{pH} 6.0$ (Feinstein and Volk, 1949). Whether such activity represents a true phosphoprotein phosphatase or is merely the action of a non-specific phosphatase is not clear.

Mechanisms involved in the synthesis and further metabolism of phosphoprotein are still partly unknown, as is its role in cerebral metabolism. Evidence relating to these points has been provided 
largely through studies of the effects of electrical stimulation upon cerebral tissues and will be presented in Chapter 4.

\section{Nucleic Acids}

It has been unequivocally demonstrated (Deluca et al., 1953) that nucleic acids in vitro are continuousiy synthesized and degraded. In these experiments nucleic acids were extracted by the method of Hammarsten (1947, see appendix) and hydrolysed to nucleotides which were then separated chromatographically from other radioactive contaminants before estimation. As in vivo it was found that slices metabolizing glucose incorporated radioactive phosphate almost exclusively into the ribose nucleic acids, little or no radioactivity being found in the desoxyribonucleic acids. The incorporation of radioactivity was the result of a true metabolic exchange since no net synthesis of nucleic acids took place during incubation. Nevertheless exchange was slow (Table 14) and compared with that of other body tissues was very slow indeed. Incorporation was abolished under anaerobic conditions (Deluca et al., 1953; Findlay et al., 1953; Strickland, 1954).

\section{Residual Organic Phosphorus}

Experiments in vitro have so far done little to clarify the nature of this fraction or details of its phosphorus metabolism. Compared with other phosphates insoluble in trichloracetic acid it incorporates radioactive phosphate less rapidly than phosphoprotein but at a markedly greater rate than ribonucleic acid or the total lipid phosphorus (Findlay et al., 1954). As with other fractions a prerequisite for incorporation is the maintenance of aerobic conditions.

The importance of adequate oxygenation in supporting the incorporation of radioactive phosphate is intimately connected with the maintenance of adequate levels of energy-rich phosphates in the tissue by oxidative phosphorylation. Factors altering these levels or the metabolism of the energy-rich phosphates also alter the metabolism of the other phosphates. Many of these factors, as they relate to different substrates and inhibitors, will be considered in the next chapter. 


\section{REFERENCES}

Abood, L. G. and Gerard, R. W. (1952) Amer. F. Physiol. 168, 739.

Aвood, L. G. and Romanchek, L. (1955) Biochem. F. 60, 233.

Abood, L. G., Gerard, R. W., Banks, J. and Tschirgi, R. D. (1952) Amer. F. Physiol. 168, 728.

Acs, G., Balazs, R. and Straub, F. B. (1953) Ukrain. Biokhim. Zhur. 25, 17. (Chem. Abstr. 48, 8923i).

Aldridge, W. N. (1957) Biochem. F. 67, 423.

Allen, J. N. (1955) Arch. Neurol. Psychiat. Chicago 73, 241.

Ansell, G. B. and Dawson, R. M. C. (1951) Biochem. F. 50, 241.

Ayres, P. J. W. and McIlwain, H. (1953) Biochem. F. 55, 507.

Banga, I., Ochoa, S. and Peters, R. A. (1939) Biochem. F. 33, 1980.

Berry, J. F. and McMurray, W. C. (1957) Canad. F. biochem. Physiol. 35, 799.

Brody, T. M. and Bain, J. A. (1951) Proc. soc. exp. biol. N. Y. 77, 50.

Brody, T. M. and Bain, J. A. (1952) F. biol. chem. 195, 685.

Brody, T. M. and Bain, J. A. (1954) F. Pharmacol. 110, 148.

Burnett, G. and Kennedy, E. P. (1954) F. biol. chem. 211, 969.

Case, E. M. and McIlwain, H. (1951) Biochem. F. 48, 1.

Christie, G. S., Judah, J. D. and Rees, K. R. (1953) Proc. Roy. Soc. B $141,23$.

Clowes, G. H. A. and Keltch, A. K. (1952) Proc. soc. exp. biol. N.Y. 81, 356.

Colowick, S. P., Kalkar, H. M. and Cori, C. F. (1941) F. biol. chem. 137, 343.

Colowick, S. P. and Kalkar, H. M. (1943) F. biol. chem. 148, 117.

Crane, R. L. and Sols, A. (1953) F. biol. chem. 203, 273.

Dawson, R. M. C. (1953) Biochem. F. 53, proc. viii.

Dawson, R. M. C. (1954) Biochem. biophys. Acta. 14, 374.

Dawson, R. M. C. (1955) in Biochemistry of the Developing Nervous System, p. 268 (Ed. by H. WaELSCH), Academic Press, New York.

Deluca, H. A., Rossiter, R. J. and Strickland, K. P. (1953) Biochem. F. 47, 139.

Dianzani, M. U. (1954) Biochim. biophys. Acta. 14, 514.

Dianzani, M. U. and Scuro, S. (1956) Biochem. F. 62, 205.

Dubois, K. P. and Potter, V. R. (1953) F. biol. chem. 150, 185.

Dubuy, H. G. and Hesselbach, M. L. (1956) F. Histochem. Cytochem. 4, 363.

Dubuy, H. G. and Hesselbach, M. L. (1958) F. Natl. Cancer Inst. 20, 403.

Elliot, K. A. C. (1955) in Methods in Enzymology, Vol. I p. 3 (Ed. by S. P. Colowick and N. O. Kaplan), Academic Press, New York.

Elliot, K. A. C., Scott, D. B. and Libet, B. (1942) F. biol. chem. 146, 251.

EnNor, A. H. and Rosenberg, H. (1954) Biochem. F. 57, 203.

Feigin, I. and Wolf, A. (1955) f. Neuropath. exp. Neurol. 14, 11.

Feinstein, R. N. and Volk, M. E. (1949) F. biol. chem. 177, 339. 
Findlay, M., Rossiter, R. J. and Strickland, K. P. (1953) Biochem. F. $55,200$.

Findlay, M., Strickland, K. P. and Rossiter, R. J. (1954) Canad. Y. biochem. Physiol. 32, 504.

Findlay, M., Magee, W. L. and Rossiter, R. J. (1954) Biochem. F. 58, 236.

Fries, B. A., Schachner, H. and Chaikoff, I. L. (1942) F. biol. chem. 144, 59.

Gallagher, G. H., Judah, J. D. and Rees, K. R. (1956) Biochem. F. 62, 436.

Glock, G. E. and McClean, P. (1955) Biochem. F. 61, 388.

Gordon, J. J. (1950) Biochem. F. 46, 96.

Gordon, J. J. (1953) Biochem. F. 55, 812.

Goranson, E. S. and Elrulkar, S. D. (1949) Arch. Biochem. Biophys. 24, 40.

Gore, M. B. R. (1951) Biochem. F. 50, 18.

Gore, M. B. R., Iвbot, F. and McIlwain, H. (1950) Biochem. F. 47, 121. Greengard, O. (1955) Ph.D. Thesis, University of London.

Hammarsten, E. (1947) Acta. med. scand. 128 (Suppl. 196), 634.

Heald, P. J. (1956a) Biochem. F. 63, 235.

Heald, P. J. (1956b) Biochem. F. 63, 242.

Heald, P. J. (1957a) Biochem. F. 66, 659.

Heald, P. J. (1957b) Biochem. F. 67, 529.

Heald, P. J. (1958) Biochem. F. 68, 550.

Heald, P. J. (1959) Biochem. F. 73, 132.

Heald, P. J. and McIlwain, H. (1956) Biochem. F. 63, 231.

Heald, P. J. and Stancer, H. C. (1960) Submitted for publication.

Hebi, G. O. and Whittaker, V. P. (1958) F. Physiol. Lond. 142, 187.

Hesselbach, M. L. and Dubuy, H. G. (1953) Proc. soc.exp. biol. N. Y. 83, 62.

Нокın, L. E. and Hoкin, M. R. (1955) Biochem. biophys. Acta. 18, 102.

Hokin, L. E. and Hokin, M. R. (1958a) F. biol. chem. 233, 822.

Hokin, L. E. and Hokin, M. R. (1958b) F. biol. chem. 233, 822.

Jedeiken, L. A. and Weinhouse, S. (1954) Arch. Biochem. Biophys. 50, 134. Jordan, W. K. and Marchi, R. (1956) F. Histochem. Cytochem. 4, 301.

Kennedy, E. P. (1956) Canad. F. biochem. Physiol. 34, 334.

KenNedy, E. P. and Weiss, J. B. (1956) F. biol. chem. 222, 193.

KornBerg, A. (1948) $\mathcal{F}$. biol. chem. 176, 1475.

KORNBERG, A. (1950) F. biol. chem. 182, 779.

Kratzing, C. C. and Narayanaswami, A. (1953) Biochem. F. 54, 317.

KreBs, H. A. (1950) Biochim. biophys. Acta. 4, 249.

Krebs, H. A. and Hems, R. (1955) Biochem. F. 61, 218.

Krebs, H. A. and Henseleit, K. (1932) Hoppe-Seyl-Z. 210, 33.

Kuff, E. L. and Schneider, W. C. (1954) F. biol. chem. 206, 677.

Le Baron, F. N. (1955) Biochem. F. 61, 80.

Lee, K. H. and Eiler, J. J. (1953) F. biol. chem. 203, 705.

Lindberg, O. and Ernster, L. (1954) Protoplasmatologia III A. 4.

Lowry, O. H., Roberts, N. R., Leiner, K. Y., Wu, M. L. and Farr, A. L. (1954) \%. biol. chem. 207, 19. 
McIlwain, H. (1951) Biochem. F. 49, 383.

McIlwain, H. (1959) Biochemistry and the Central Nervous System, 2nd ed., Churchill, London.

McIlwain, H. and Gore, M. B. R. (1952) F. Physiol., Lond. 117, 47.

McIllwain, H. and Rodnight, R. (1949a) Biochem. F. 44, 470.

MicIlwain, H. and Rodnight, R. (1949b) Biochem. F. 45, 337.

McIlwain, H., Buchel, L. and Cheshire, J. D. (1951) Biochem. F. 48, 12.

MicMurray, W. C., Berry, J. F. and Rossiter, R. J. (1957) Biochem. F. 66, 629.

McMurray, W. C., Strickland, K. P., Berry, J. F. and Rossiter, R. J. (1957a) Biochem. F. 66, 621.

McMurray, W. C., Strickland, K. P., Berry, J. F. and Rossiter, R. J. (1957b) Biochem. Y. 66, 634.

Manery, J. F. (1952) in The Biology of Mental Health and Diseases, Cassell, London.

Mann, P. G. J. and Quastel, J. H. (1941) Biochem. Y. 35, 509.

Meyerhof, O. and Geliazkowa, N. (1947) Arch. Biochim. Biophys. 12, 405.

Muntz, J. A. (1953) F. biol. chem. 201, 221.

Naidoo, D. and Pratt, O. E. (1953) Enzymologia 24, 91.

Naidoo, D. and Pratt, O. E. (1954) Enzymologia 25, 298.

Naidoo, D. and Pratt, O. E. (1956) Biochem. F. 62, 465.

Narayanaswami, A. (1952) Biochem. F. 52, 295.

Narayanaswami, A. and McIlwain, H. (1954) Biochem. F. 57, 663.

OCHOA, S. (1941) F. biol. chem. 138, 735.

Oliver, L. T. (1954) Biochim. biophys. Acta. 14, 587.

Oliver, L. T. (1955) Biochem. F. 61, 116.

Pappius, H. M. and Elliot, K. A. C. (1954) Canad. F. biochem. Physiol. 32, 117.

Pratt, O. E. (1953) Biochem. F. 55, 140.

Pritchard, E. T. (1958) Canad. F. biochem. Physiol. 36, 1211.

REIS, J. L. (1951) Biochem. F. 48, 548.

RodNight, R. (1956) Biochem. F. 63, 223.

Rodnight, R. and McIlwain, H. (1954) Biochem. F. 57, 649.

Rossiter, R. J. (1957) in Metabolism of the Nervous System, p. 355 (Ed. by D. Richter), Pergamon Press, London \& New York.

Rossiter, R. J., McLeod, I. and Strickland, K. P. (1957) Canad. $\mathcal{Y}$. biochem. Physiol. 35, 945.

Rossiter, R. J., McMurray, W. C. and Strickland, K. P. (1957) Fed. Proc. 16, 853.

Seal, U. S. and Binkley, F. (1957) f. biol. chem. 228, 193.

Schachner, H., Fries, B. A. and Chaikoff, I. L. (1942) F. biol. chem. 146, 95.

Scribney, M. and Kennedy, E. P. (1958) F. biol. chem. 233, 1315.

SHEPHERD, J. A. (1953) Intracellular distribution of enzymes in rat cerebral cortex. Thesis. University of Iowa.

Showacre, J. L. (1953) F. Natl. Cancer Inst.13, 829.

SCHNEIDER, W. C. (1946) F. biol. chem. 164, 747. 
Slater, E. C. and Holton, F. A. (1954) Biochem. F. 56, 28.

Sloane-Stanley, G. H. (1951) Biochem. F. 44, proc. iv.

Sloane-Stanley, G. H. (1952) Symp. Biochem. Soc. No. 8, 44.

Sloane-Stanley, G. H. (1953) Biochem. F. 53, 613.

SPERRY, W. W. (1947) F. biol. chem. 170, 675.

Strickland, K. P. (1954) Can. F. biochem. Physiol. 32, 50.

Strickland, K. P., Thompson, R. H. S. and Webster, G. A. (1956a) Arch. Biochem. Biophys. 64, 498.

Strickland, K. P., 'Thompson, R. H. S. and Webster, G. A. (1956b) F. Neurol. Neurosurg. Psychiat. 19, 12.

Thompson, R. H. S. (1957) in Metabolism of the Nervous System, p. 399 (Ed. by D. Richter), Pergamon Press, London \& New York.

Thomas, J. (1956) Biochem. F. 64, 335.

Thomas, J. (1957) Biochem. F. 66, 655.

TOWER, D. B. (1958) Y. Neurochem. 3, 185.

Tseitlin, L. A. (1953) Biokhim. 18, 311.

Trrell, L. W. (1950) Nature (Lond.) 166, 310.

Umbreit, W. W., Burris, R. H. and Stauffer, J. F. (1957) Manometric Techniques and Tissue Metabolism, Burgess, Minneapolis.

Utter, M. F. H., Wood, H. G. and Reiner, J. M. (1948) F. biol. chem. 161, 197.

Vignais, P. V. and Vignais, P. M. (1957) f. biol. chem. 229, 265.

Webi, J. C. and Elliot, K. A. C. (1951) F. Pharmacol. 103, 24.

Wolleman, M. and Feuer, G. (1957) Acta physiol. Hungarica. 11, 165.

Zilversmit, D. B., Enteman, C. and Fishler, M. C. (1943) F. gen. Physiol. 26, 325. 


\section{FACTORS AFFECTING PHOSPHATE METABOLISM IN VITRO}

OF THE numerous factors affecting the metabolism of cerebral slices in vitro, those whose action upon phosphate metabolism bear relationships to factors similarly active in vivo can be conveniently divided into two groups. In the first group are included different oxidizable substrates and metabolic inhibitors. In the second group, comprising factors whose action may be considered primarily to be linked to physical changes, are included electrical impulses and changes in the concentration of inorganic ions such as potassium salts. Metabolic relations exist between both groups but for the purposes of this chapter it is convenient to consider them separately.

\section{Different Oxidizable Substrates}

It was seen in Chapter 3, that preparations of cerebral mitochondria were able to oxidize a wide variety of substrates, the oxidation being accompanied by the phosphorylation of adenosine derivatives to the triphosphate. However, although in the intact slice the maintenance of adequate levels of energy-rich phosphates might be expected to be supported by the oxidation of similar substrates this has been found not to be the case. The quantities of phosphocreatine and adenosine triphosphate maintained by slices during incubation with different substrates vary widely (Table 16). Of all the intermediates tested only pyruvate was effective in supporting levels of phosphocreatine approaching those found when glucose was the substrate, with citrate somewhat less effective. Fumarate, succinate and glutamate were ineffective, and levels of adenosine di- and triphosphate were also low. All the substrates supported an uptake of oxygen by the tissue equal to or slightly greater than that found with slices oxidizing glucose. It seems possible that the differences between the ability to support oxidative phosphorylation in mitochondria 


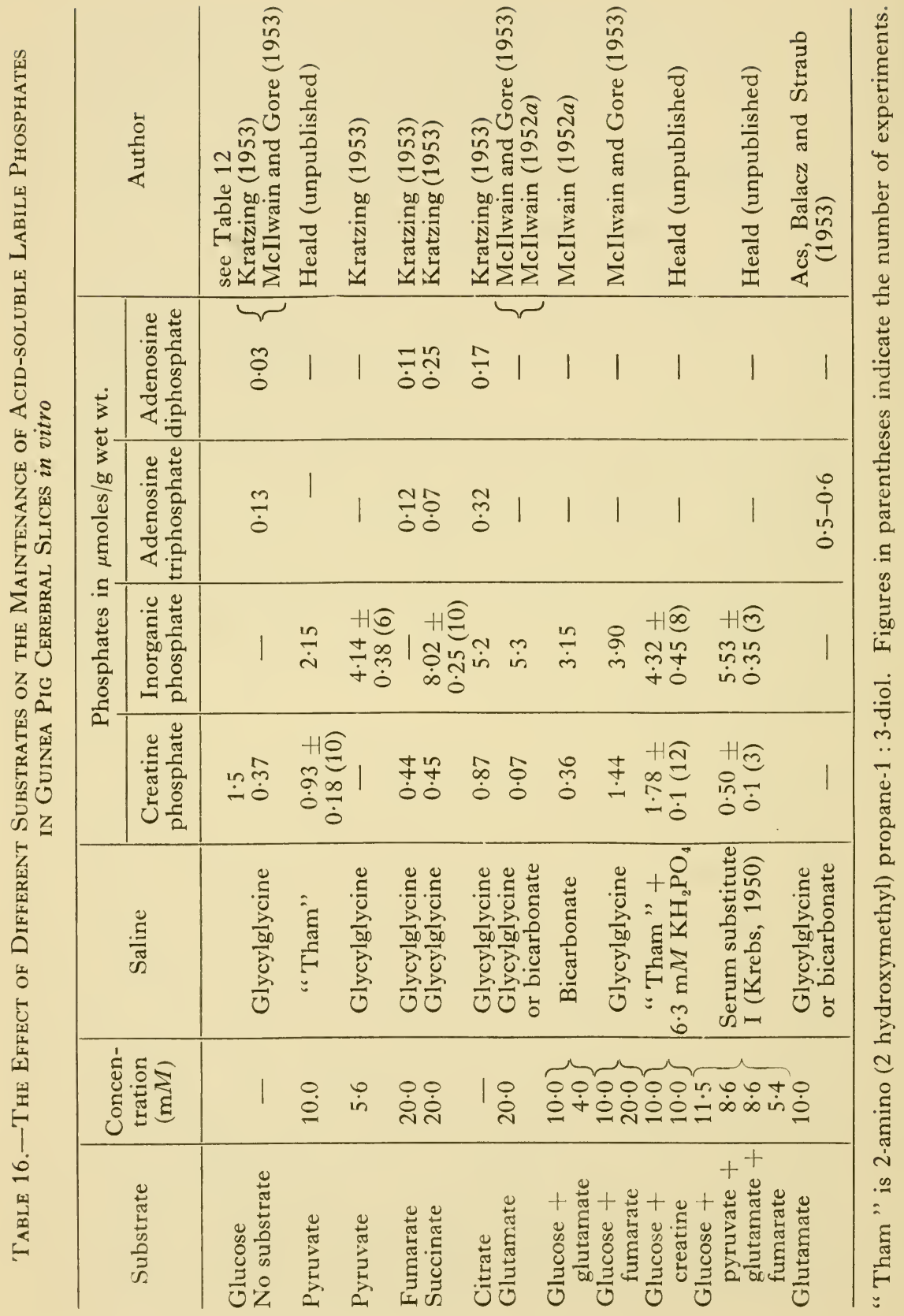


and inability to support phosphate levels in the slice is related to the balance between the energy requirements of the intact tissue and the energy yield during the oxidation of the substrate. 'The complete oxidation of glucose yields $-680 \mathrm{kcal}$ while the oxidation of pyruvate via the tricarboxylic acid cycle yields a free energy of about $-270 \mathrm{kcal}$. The oxidation of citrate to malate yields $-200 \mathrm{kcal}$ while the oxidation of $\alpha$-oxoglutarate to oxaloacetate yields $-160 \mathrm{kcal}$ (Burton and Krebs, 1953). There thus appears to be a correlation between the free energy of oxidation of a substrate and its ability to maintain adequate levels of phosphocreatine in the slice. It also seems relevant that of the intermediates listed in Table 16 only pyruvate, by combining with oxaloacetate via acetyl-CoA, is likely to be capable of maintaining the tricarboxylic acid cycle operating at its maximum speed. Glutamic acid occupies a curious position for when used as a sole substrate or in the presence of glucose, fumarate or malate, the levels of phosphocreatine or adenosine triphosphate are markedly reduced. Parallel with this reduction another labile phosphate accumulates (McIlwain, 1952a), the quantities reaching $0 \cdot 3-0.4 \mu$ moles phosphorus $/ g$ wet wt. Such a phosphate has not been found during the metabolism of other substrates. Although an identity with $\gamma$-glutamyl phosphate has been suggested its nature is unknown. Certainly its extreme lability in acidified molybdate solutions is similar to that of the N-phosphoryl amino acids. The action of glutamate in decreasing the levels of adenosine triphosphate has been connected with the increased synthesis of glutamine which takes place during the oxidation of glutamate (Acs et al., 1953), a process well known to require energy in the form of adenosine triphosphate. However, glutamic acid occurs free in cerebral tissues at concentrations of 8-10 $\mathrm{mM}$ (Weil-Malherbe, 1952; Schwerin et al., 1950) and at 10-20 $\mathrm{mM}$ appears to be essential for the maintenance of the potassium ion concentration of cerebral slices (Terner et al., 1950). Its effect in decreasing levels of energy-rich phosphates in vitro, particularly in the presence of glucose, thus seems to merit further examination.

Maintenance of phosphocreatine levels depends upon factors other than the substrate. Thus after incubation in the absence of glucose and in the presence of oxygen for $30 \mathrm{~min}$, depleted levels of phosphocreatine were restored by adding glucose (McIlwain and Gore, 1953). However incubation under anaerobic conditions 
in the presence of glucose, followed by metabolism in oxygen, failed to restore levels of phosphocreatine though the oxygen uptake of the tissue was only slightly less than normal (Thomas, 1956).

The results described in Table 16 are paralleled to a large degree by the ability of the individual substrates to support the incorporation of radioactive phosphate into phosphorus compounds present in the acid-insoluble residues of the tissue (Table 17). Thus, succinate, malate, glutamate and $\alpha$-oxoglutarate failed to support the incorporation of phosphorus into the phospholipid, nucleic acid, phosphoprotein and residual phosphorus of cat cerebral slices. In many instances the degree of incorporation was less than in cerebral slices metabolizing in the absence of substrate. Pyruvate and lactate supported some incorporation but generally to a less degree than glucose. The similarities between conditions supporting exchange of radioactive phosphate with the fractions

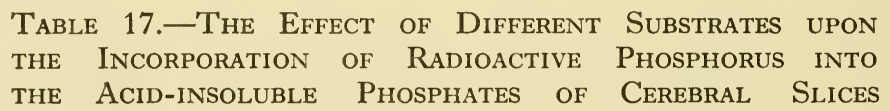

\begin{tabular}{l|r|r|r|r}
\hline \multicolumn{1}{c|}{ Substrate } & \multicolumn{2}{|c|}{$\begin{array}{c}\text { Specific radioactivity as } \% \\
\text { without substrate }\end{array}$} \\
\cline { 2 - 5 } & $\begin{array}{c}\text { Pentose } \\
\text { nucleic acid }\end{array}$ & $\begin{array}{c}\text { Phospho- } \\
\text { lipids }\end{array}$ & $\begin{array}{c}\text { Phospho- } \\
\text { proteins }\end{array}$ & $\begin{array}{c}\text { Residual } \\
\text { organic } \\
\text { phosphorus }\end{array}$ \\
\hline Glucose & 38 & 180 & 82 & 285 \\
Mannose & 25 & 192 & 62 & 308 \\
Fructose & 2 & 58 & 23 & 45 \\
Galactose & 10 & 1 & -3 & 13 \\
Pyruvate & 51 & 30 & 12 & 38 \\
Lactate & 16 & 25 & 13 & 19 \\
Succinate & -14 & -10 & -11 & -16 \\
L(+) Glutamate & -10 & -1 & -4 & -11 \\
$\alpha$-oxoglutarate & -30 & 2 & - & - \\
Citrate & -14 & 9 & - & - \\
Malate & -10 & 5 & - & - \\
\hline
\end{tabular}

Data from Findlay et al. (1953); Findlay et al. (1954); and Strickland (1954). All substrates were at final concentrations of $10 \mathrm{mM}$ with the exception of succinate which was $50 \mathrm{~m} M$. Specific radioactivity=counts/ $\min$ per $\mu \mathrm{g}$ P. 
in Table 17 and those enabling slices to maintain adequate levels of phosphocreatine suggest a common factor, the simplest of which would be a shared precursor such as adenosine triphosphate. Nevertheless, differences exist. Thus pyruvate and lactate support incorporation into phosphoprotein to a markedly less degree than does glucose but support incorporation into nucleic acids to an extent similar to glucose. Fructose does not support phosphate incorporation into the nucleic acids but does so into the other fractions though to a less degree than glucose or mannose.

Differences here may relate partly to the concentration of substrate in addition to its ability to maintain adequate levels of energy-rich phosphates. Thus, in contrast to the above, Schachner et al. (1942) found that glucose, mannose, fructose and galactose were all equally effective in supporting the incorporation of phosphate into rat cerebral phospholipids. It has been suggested (Strickland, 1954) that the difference between the results with fructose (Table 17) and those found by Schachner et al. may be explained by the inhibition of fructose metabolism by traces of glucose present in the tissue slices, though it was admitted that this did explain why the addition of fructose increased the oxygen uptake of the slice. Schachner et al. used substrate concentrations of $20 \mathrm{~m} M$ whereas Strickland used concentrations of $10 \mathrm{~m} M$. Such differences can be important for it has been shown (McIlwain, $1953 b)$ that whereas glucose at $10 \mathrm{~m} M$ was adequate to support the respiratory response of cerebral slices to applied stimuli, fructose at $10 \mathrm{~m} M$ was not, and higher concentrations were required before results comparable with glucose were obtained. Similar considerations might apply to the effects of pyruvate and lactate, though here a simpler correlation exists in relation to maintenance of levels of energy-rich phosphates. This would imply that quantity as well as rate of metabolism of, say, adenosine triphosphate is important in introducing the labelled phosphate into the phospholipids but it must be admitted that information relating to equilibria in these systems does not exist.

The decreased ability of fructose metabolism to support the incorporation of phosphate into the phosphoprotein fraction (Lissovskaya, 1956; see also review, Stekol, 1957) has been considered to be related to the lowered glycolysis with this substrate rather than to the levels of adenosine triphosphate which decreased to some $60 \%$ of the quantities found in the presence of glucose. 8-PMB 
From the data presented these latter appear to be $0.5 \mu$ moles $/ g$ wet wt. (cf. Table 12). Oxygen uptake by slices metabolizing fructose at $10 \mathrm{~m} M$ was similar to that when glucose was the substrate and it was suggested that this, together with the lowered lactic acid production and levels of adenosine triphosphate, indicated that fructose was metabolized by a route differing from glucose, leading to a lowered extent of phosphate exchange. At present it seems unnecessary to consider such differences in terms of differing metabolic routes for the substrates rather than as the balance between energy requirement and production. Glycolysis, as normally measured, is artificial in the sense that the lactic acid measured is that passing from the slice to the medium, the final quantity reached depending largely upon the ratio of the volume of the slice to the volume of the medium (Rodnight and McIlwain, 1954) and upon the extent to which pyruvate may be preferentially oxidized (cf. Heald, 1953; McIlwain, 1953b).

Study with disintegrated preparations has shown that with aqueous dispersions of rat brain, glucose, fructose-1 : 6-diphosphate, and mannose were effective in supporting the incorporation of radioactive phosphate into the phospholipids whilst galactose, citrate, malate, and succinate, though supporting oxygen uptake were not effective (McMurray et al., 1957), results similar to those found with the intact slice. In this system labelling was correlated with the ability to support glycolytic phosphorylation. In dispersions where phosphorylation was predominantly oxidative (Dawson, 1953; McMurray et al., 1957) pyruvate, succinate, fumarate, glutamate, malate, citrate and $\alpha$-oxoglutarate supported an active incorporation of phosphate into the phospholipids whereas glucose was ineffective.

Whether or not a substrate supports incorporation of radioactive phosphate in vitro into phosphates such as the phospholipids thus seems to be dependent largely upon the type of preparation used. In disintegrated preparations, the primary factor is the ability to form energy-rich phosphates. In the intact slice the ability to maintain levels of these phosphates comparable to those maintained by glucose appears to be essential. It is likely that the inability of other substrates to be as effective as glucose is related to the extent to which the energy released on oxidation is able to meet the energy requirements of the tissue. It seems noteworthy that glucose, which is the major substrate supporting function in vivo is the 
only substrate which appears fully capable of meeting the energy requirements of the tissue in vitro.

\section{Lack of Oxygen and Metabolic Inhibitors}

It was shown above that glucose was the substrate most actively supporting phosphorylation in cell-containing tissues in vitro. Information regarding the extent to which the various stages of its metabolism are necessary for this support can be obtained by inhibiting or restricting one particular enzymic system more than another. This can be achieved by studying metabolism under anaerobic conditions, where glycolysis is the sole energy-producing system or by the addition of various metabolic inhibitors such as fluorides, iodoacetates, malonates, cyanides, azides and 2:4dinitrophenol.

With cerebral slices metabolizing glucose, replacement of an oxygen atmosphere by nitrogen markedly reduces the levels of phosphocreatine (McIlwain, 1959b) and the incorporation of radioactive phosphate into the phospholipids of rat and cat cerebral slices (Schachner et al., 1942; Strickland, 1954). Incorporation into the ribose nucleic acids (Findlay et al., 1953) and the phosphoprotein fraction (Findlay et al., 1954) is also reduced. Under these conditions, glycolysis, although greatly increased was nevertheless insufficient to support the normal phosphorylation. processes. Analogous results were obtained with cyanides which at $10^{-2} M$ abolished incorporation of phosphate into the phospholipids, nucleic acids and phosphoproteins. At this concentration oxygen uptake is known to be almost completely suppressed whilst lactic acid production is markedly increased (Dixon and Elliot, 1929; Dixon, 1940, Stern, et al., 1952). Since the primary action of cyanide is the inhibition of the cytochrome oxidase system this situation is comparable with a lack of oxygen. Agents such as fluorides and iodoacetates at $10^{-2}-10^{-3} M$ yielded similar results. Malonate at $10^{-2} M$ has no effect upon the oxygen uptake or lactic acid production of slices metabolizing glucose (Heald, 1953) and similarly did not alter the incorporation of radioactive phosphate into the phospholipids (Strickland, 1954). However, Tsukada et al. (1958), also working with cerebral slices, have reported that incorporation of radioactive phosphate into the acid-soluble phosphates and residual organic phosphate fraction was decreased by $80-90 \%$ in the presence of $10^{-2} M$ malonate. It is difficult to 
see how these results can be reconciled. With the intact tissue slice, fluoride and iodoacetate are considered to act primarily upon enolase and 3-phosphoglyceraldehyde dehydrogenase respectively whereas malonate acts primarily by inhibiting succinic dehydrogenase. Although concentrations of inhibitors reducing the oxygen uptake of the slice make part of their action understandable in terms of decreased rates of oxidative phosphorylation, the effectiveness of low concentrations of iodoacetate in reducing phosphate incorporation emphasizes the importance of the glycolytic pathway in the maintenance of phosphate metabolism in the tissue. On the other hand an uninhibited glucose metabolism, unconnected with adequate levels of energy-rich phosphates appears to be insufficient. This is illustrated by the action of $2: 4$-dinitrophenol and sodium azide, agents which do not directly inhibit enzymes involved in the metabolism of glucose, but specifically interfere with the mechanisms whereby phosphate is esterified to adenosine triphosphate during oxidation. Their " uncoupling " action in cerebral slices is accompanied by an increased oxygen uptake and an increased consumption of glucose and production of lactic acid. At $10^{-3}-10^{-5} \mathrm{M}$, both dinitrophenol and azide reduced the levels of phosphocreatine and the total energy-rich phosphates in cerebral slices (McIlwain and Gore, 1951; Kratzing, 1956), and also markedly decreased phosphate incorporation into the phospholipids, nucleic acids and phosphoprotein fraction. Of these two agents dinitrophenol was the most effective, phosphocreatine levels being fully decreased by $10^{-5} \mathrm{M}$.

Dispersions of cerebral tissues react somewhat differently according to the type of preparation employed. Thus with preparations containing mitochondria and carrying out oxidative phosphorylation with pyruvate as substrate, fluoride at $10^{-2} M$, though decreasing the oxygen uptake slightly, resulted in an increase in the specific radioactivity of the phospholipids (McMurray et al., 1957) and phosphoprotein fraction (Heald and Stancer, 1960). These results are probably attributable to the wellknown effect of fluoride in inhibiting adenosine triphosphatase (Case and McIlwain, 1951) for in such preparations levels of adenosine triphosphate were higher in the presence than in the absence of fluoride (McMurray et al., 1957; Berry and McMurray, 1957). With preparations where the labelling of phospholipids was primarily a glycolytic mechanism, fluorides decreased such label- 
ling. Under aerobic conditions, 2:4-dinitrophenol decreased the incorporation of phosphate into adenosine triphosphate and lowered the total quantities present in addition to decreasing the labelling in the phospholipids, but was ineffective anaerobically. Analysis of metabolism in these systems by means of inhibitors provides a method of recognizing the various enzymic stages necessary, for example, to the incorporation of phosphate into a particular component. The results of such an analysis show that the normal phosphate metabolism of cerebral tissues requires both the uninhibited functioning of all stages in the metabolism of glucose and the maintenance of adequate levels of phosphocreatine and adenosine triphosphate.

\section{Inorganic Phosphate and Phosphate Acceptors}

In vivo a variety of conditions (Chapter 2) increase the levels both of inorganic phosphate and of phosphate acceptors such as adenosine diphosphate and creatine. Study of the effects on metabolism of different concentrations of these compounds has revealed that the rate of oxygen uptake is related to the quantities present in an interesting manner.

With dispersions of pigeon brain made in $0.9 \% \mathrm{KCl}$ and dialysed against $0.4 \% \mathrm{KCl}$ (treatment which probably preserved the mitochondria) Banga et al. (1939) found that the oxidation of pyruvate proceeded only slowly in the presence of inorganic phosphate at $0.01 M$ but was greatly increased when adenylic acid at $1.4 \times 10^{-4} M$ was added. Similar results were obtained by Long (1943, 1945) using a similar preparation; the oxidation of pyruvate, $\alpha$-oxobutyrate and fumarate being dependent upon the presence of inorganic phosphate and the nucleotide. Adenine nucleotide was required in catalytic amounts only, whereas oxygen uptake showed a marked dependence upon the concentration of inorganic phosphate. Thus, for the oxidation of pyruvate, the optimal phosphate concentration was $0.05 M$ with a half maximal velocity between $0 \cdot 01-0.05 M$. At high concentrations inorganic phosphate was inhibitory.

Attention has been drawn (McIlwain, 1952b, 1959) to similarities in the concentrations of inorganic phosphate at which the most rapid increases in oxygen uptake occurred in the above experiments and the concentrations existing in cerebral tissues in vivo in certain physiological states. Thus concentrations of 
inorganic phosphate (some $4-5 \mu$ moles $/ \mathrm{ml}$.) permitting a relatively low uptake of oxygen in vitro were similar to those found in vivo during sleep or narcosis (Table 7). On the other hand concentrations $(7-10 \mu \mathrm{moles} / \mathrm{ml}$.) associated with high rates of oxygen uptake in vitro are similar to those found in vivo in cerebral tissues suffering from injury or in a state of convulsive activity (Table 7). In vivo it is well known that narcosis or sleep reduces cerebral oxygen consumption which is increased during increased activity and parallelisms with changes in phosphates under these conditions have already been pointed out (Chapter 2).

Increase in oxygen uptake by dispersions in the presence of increased quantities of inorganic phosphate also requires the presence of a phosphate acceptor such as adenylic acid which is presumably phosphorylated to adenosine triphosphate, the three phosphates together forming a complete system. A similar system is formed by inorganic phosphate, phosphocreatine and creatine.

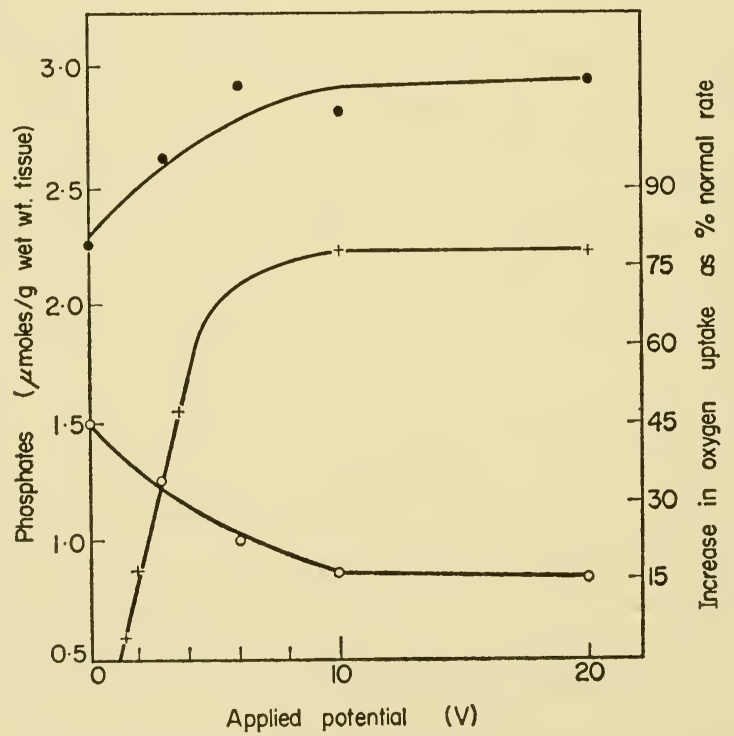

FIG. 11. Relationships between levels of phosphocreatine and inorganic phosphate, and the rate of oxygen uptake by slices of guinea pig cerebral cortex. Slices were stimulated electrically as described in the text. $\bigcirc=$ phosphocreatine; 0 inorganic phosphate; data from Heald (unpublished). $+=$ increase in oxygen uptake; data from Wollenberger (1955). 
When slices of cerebral cortex are suitably stimulated by electrical impulses (p. 113) the quantities of inorganic phosphate and phosphocreatine change in a reciprocal manner. By adjusting the intensity of the stimulus the extent of this change can be regulated. Comparison of the levels of these phosphates with the oxygen uptake of the intact slice under similar conditions (Fig. 11) then reveals a relationship of the type noted above in disintegrated preparations. Thus, when levels of phosphocreatine and inorganic phosphate had changed by about $20 \%$ oxygen uptake was increased by $40 \%$; when phosphate levels changed by $40 \%$ oxygen uptake had increased by $75 \%$. Although these results are a synthesis of two sets of data the use of identical conditions of stimulation permits a comparison in this manner. The results in Fig. 11 thus complement the deductions of McIlwain. However it will be noted that the increase in concentration of inorganic phosphate from $2 \cdot 3-3 \cdot 2 \mu$ moles phosphorus/g wet wt. represents only one-fifth of the increase needed to obtain the doubling in the rate of oxygen uptake which is normally obtained if the systems involved are similar to those studied in dispersions. Many phosphate dependent steps are involved in the oxidation of glucose and an increase of $20 \%$ in the levels of inorganic phosphate may produce a series of small but additive increases in their rates of reaction. Alternatively the overall change in concentration may represent a larger change taking place at localized areas for it is unlikely that inorganic phosphate is distributed evenly throughout the tissue.

\section{The Effects of Electrical Stimulus}

A major problem in the biochemistry of nervous tissue is the manner in which energy-yielding processes are connected to those requiring energy. In Chapter 2 an account was given of the way in which such relationships had been studied in vivo. However, the complexity of the in vivo system imposes severe limitations to experimentation and a major advance in the examination of these relationships has only become possible with the discovery that applied electrical stimulus could induce changes in tissue slices in vitro similar to those occurring in the whole brain in vivo. It was shown (McIlwain, 1951; McIlwain et al., 1951) that the application of alternating electrical impulses of a defined type to slices of cerebral cortex metabolizing glucose in a suitable oxygenated 
saline, promoted a marked increase in both the rates of oxygen uptake and in the production of lactic acid. These changes were rapid, occurring within $30 \mathrm{sec}$ of the application of impulses. This period represents the bottom limits of measurement with the apparatus used and it is likely that the changes in oxygen uptake are even more prompt. Since the use of this technique has provided the majority of evidence relating an electrical event in cerebral tissue in vitro to a metabolic event it is appropriate to describe certain major features. A detailed account of the many physical factors involved in the response of cerebral tissue to electrical stimulus has been given by McIlwain (1956).

Tissues consist of thin slices of cerebral cortex or other parts of the brain and are either held in the wire grids which act as the electrodes, or float, as chopped fragments, between concentric ring electrodes. Both types of electrodes are constructed to be used with conventional Warburg manometers slightly modified by fitting points of entry for the electrode contacts. The electrodes used consist of pure silver wire, platinum wire electroplated with gold, or molybdenum wire (McIlwain, 1951; Ayres and McIlwain, 1953). With such electrodes no difficulties are encountered due to artifacts such as electrolysis of the salines. The majority of experiments have been conducted with grid electrodes of pure silver wire, both in the manometers and in an apparatus permitting the removal and transfer of tissues from an incubation medium to a fixing agent such as trichloracetic acid within $0.2 \mathrm{sec}$, with pulses applied throughout this period or interrupted if necessary before fixing (Heald and McIlwain, 1956). Response to electrical stimulus is confined to intact nervous tissue or to tissue with a well-developed nervous supply, for kidney, liver and testis show no response (Kratzing, 1951). It also is essential that the cellular structure remains intact for the respiration of disintegrated preparations prepared in isotonic sucrose is not affected by impulses of varying types which produce a response with intact slices when incubated in the same apparatus (Narayanaswami and McIlwain, 1954; McIlwain, 1951) though alternative claims, discussed below, have been made. However, it should be noted that disintegrated systems are usually fortified to exhibit maximal respiratory capacity and under such conditions additional response to electrical stimulus is not likely to be detected.

Application of electrical stimuli to cerebral slices in vitro 
increased the glucose consumption, oxygen uptake and lactic acid production to rates similar to those calculable from data such as that of Klein and Olsen (1947) in cat brain in vivo following electroshock. Under anaerobic conditions pulses suppressed the formation of lactic acid. The presence of sodium ions at concentrations above $15 \mathrm{~m} M$ is essential to respiratory response. Below this concentration pulses were without effect on oxygen uptake but still increased lactic acid production (McIlwain and Gore, 1952). In slices metabolizing glucose under anaerobic conditions electrical pulses caused a loss of the bound acetyl choline of the tissue and, if eserine was included in the saline, a corresponding increase in the free form (Rowsell, 1954). Also, under aerobic conditions the levels of phosphocreatine were decreased from $1.5 \mu$ moles $/ g$ wet wt. to $0 \cdot 6-0.7 \mu$ moles/g wet wt., the levels of inorganic phosphate rising by an equivalent amount of $0.9-1 \cdot 0 \mu$ moles phosphorus $/ g$ wet wt. (McIlwain and Gore, 1951). Quantities of adenosine triphosphate decreased slightly while those of adenosine diphosphate increased (Kratzing, 1953). These changes are similar to those found in vivo following electroshock or convulsive activity induced by metrazole and established the validity of the techniques as a means of examining both the effect of different therapeutic agents upon the changed metabolism and also as a means of examining the linkage between an applied impulse and metabolic response in nervous tissue.

Since changes in phosphocreatine in vivo are known to take place within a few seconds, measurements of changes in response to electrical impulses in vitro were made over similar brief periods. It was found (Fig. 12) that within $5 \mathrm{sec}$ of the application of electrical impulses to slices of guinea pig cerebral cortex, phosphocreatine had decreased from $1.5 \mu$ moles $/ g$ to $0 \cdot 6-0.7 \mu$ moles $/ g$. The quantity did not decrease further upon continued stimulation and would appear to represent a new equilibrium in the balance between synthesis and degradation in the changed conditions. Impulses of a different type or a different strength and duration produce similar effects but to a different degree. Thus in contrast to the above results obtained using condenser impulses of $10-18 \mathrm{~V}$ peak potential and $0.4 \mathrm{msec}$ duration at a frequency of 50 cycles/ sec, Greengard and McIlwain (1955) using sine wave pulses at $2000 \mathrm{cycles} / \mathrm{sec}$ and $3.5 \mathrm{~V}$ peak potential obtained a final lower level of $1.2 \mu \mathrm{moles} / \mathrm{g}$ wet wt. Partial decrease in the quantities of 
phosphocreatine in relation to the applied potential was noted above (Fig. 11). Similar partial decreases are also related to the duration of the impulse. 'Thus with a condenser discharge of $10 \mathrm{~V}$ peak potential and a duration of $0.4-0.8 \mathrm{msec}$, phosphocreatine decreased to $0.8 \mu$ moles $/ \mathrm{g}$ wet wt. in $5 \mathrm{sec}$, a decrease which did not occur when the duration of the pulse was reduced to $0.1 \mathrm{msec}$. Since these experiments were carried out with slices in

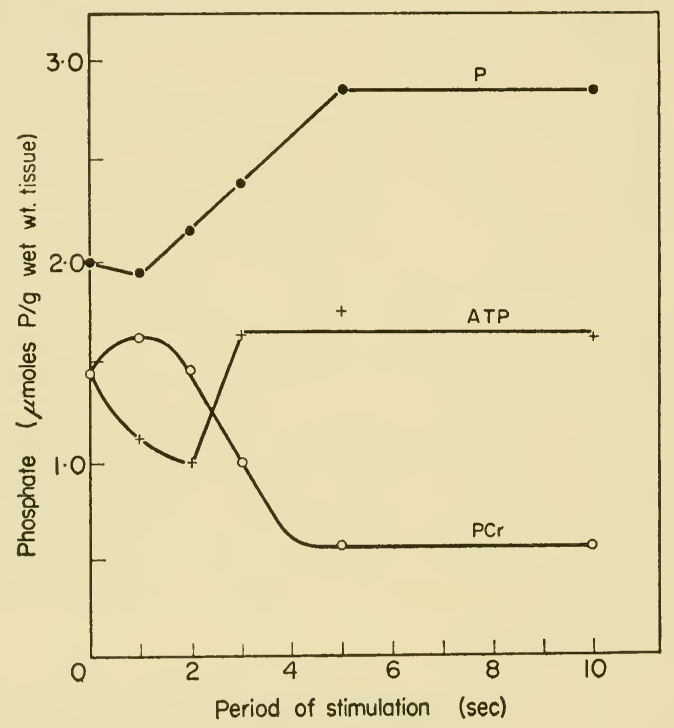

FIG. 12. Changes in phosphocreatine (PCr), inorganic phosphate (P) and adenosine triphosphate (ATP) in slices of guinea pig cerebral cortex during the passage of electrical pulses. Data from Heald (1954).

oxygenated saline depletion of phosphocreatine cannot be attributed to a partial anoxia accompanying electrical excitation and thus represents a direct response of the tissue phosphates to the stimulus. Results such as these are important in understanding the nature and extent of the stimulus required to evoke different degrees of metabolic response. They represent an interesting counterpart to those situations in vivo in which the application of different stimuli result in a breakdown of phosphocreatine to different degrees. Following the application of the pulses phos- 
phocreatine did not decrease immediately but after a lag period of $2 \mathrm{sec}$ (Fig. 12). During this period levels of adenosine triphosphate fell at a rate of some $700 \mu$ moles $/ \mathrm{g} \mathrm{hr}^{-1}$ but rose again when the breakdown of phosphocreatine commenced. Such a result is in harmony with the concept of phosphocreatine maintaining levels of adenosine triphosphate by means of creatine phosphokinase.

Breakdown of phosphocreatine was always accompanied by an increase in the amount of inorganic orthophosphate present in the tissue, the increase corresponding almost exactly in quantity to the amount of phosphocreatine disappearing. However, the rate of production, $800 \mu$ moles $/ \mathrm{g} \mathrm{hr}^{-1}$, was lower than the rate of breakdown of phosphocreatine (see below). Knowledge of the origin of this extra inorganic phosphate is still slight. It could not be derived directly from phosphocreatine for if phosphocreatine breakdown was induced by suddenly increasing the level of potassium salts in the medium to $90 \mathrm{~m} M$ (p. 130) levels of inorganic phosphate did not increase until those of phosphocreatine had fallen to about half the original level. The extra inorganic phosphate must also be firmly retained by the tissue for none passes to the medium during prolonged electrical stimulation. Although suggestions have been made that inorganic phosphate in tissues does not exist in a free but in a bound form, direct evidence for this is still lacking. At present it seems likely that the increase in inorganic phosphate is ultimately due to the breakdown of some phosphate derivative other than phosphocreatine.

The rate of breakdown of phosphocreatine is $1200-1400 \mu$ moles $/ g$ $\mathrm{hr}^{-1}$, a rate which is the greatest yet measured for a metabolic reaction involving phosphates in intact tissue, and one which agrees well with values calculated from experiments in vivo (p. 56). The rate gives no reason to suppose that the breakdown is the result of electrical impulses inhibiting oxidative phosphorylation. Under the conditions of the experiment the rate of oxygen uptake for slices of guinea pig cerebral cortex was $55 \mu$ moles $\mathrm{O}_{2} /$ g wet wt. $\mathrm{hr}^{-1}$ (Heald, 1954). Thus if the phosphorus/oxygen ratio in the intact slice is $3 \cdot 0$, the total requirement of the tissue for energy-rich phosphate to maintain a steady state in the absence of pulses would not exceed $330 \mu$ moles $/ g$ wet wt. hr ${ }^{-1}$. Even if this rate was equal to the turnover of phosphocreatine electrical pulses could not bring about a rate of $1400 \mu$ moles/g $\mathrm{hr}^{-1}$ merely by stopping oxidative 
phosphorylation from proceeding. There is good reason to believe that the normal turnover rate of phosphocreatine in cerebral tissues in vitro is about $150 \mu$ moles $/ \mathrm{g} \mathrm{hr}^{-1}$ making the rate of breakdown in response to pulses almost ten times greater. The rate of breakdown also exceeds the maximal rate of phosphorylation required for the metabolism of glucose when proceeding at its greatest rate in cerebral tissues both in vivo and in vitro. It was found (McIlwain and Tresize, 1956) that pulses, applied in the system described above, increased glucose metabolism, as judged by the rate of lactic acid production, to $200-220 \mu$ moles $/ \mathrm{g} \mathrm{hr}^{-1}$. The maximal rate of glucose uptake in cat brain stimulated in vivo with electrical impulses can be calculated to be $370 \mu$ moles $/ \mathrm{g} \mathrm{hr}^{-1}$ (Klein and Olsen, 1947) which accords well with the value of $390 \mu$ moles glucose $/ \mathrm{g} \mathrm{hr}^{-1}$ observed as the maximal rate of hexokinase activity in dispersions of rat brain (Long, 1951). Thus, even assuming that all the hexose monophosphate formed was immediately rephosphorylated to form fructose-1:6-diphosphate the maximum requirements for energy-rich phosphate would be unlikely to exceed $780 \mu$ moles/g wet wt. $\mathrm{hr}^{-1}$. More probably the rate is about $400 \mu$ moles $/ \mathrm{g} \mathrm{hr}^{-1}$. These considerations suggested that a major part of the energy-rich phosphate released in response to pulses was not used to phosphorylate glucose but was metabolized by some other pathway.

In experiments designed to follow this pathway slices of guinea pig cerebral cortex were incubated in a saline containing glucose for a preliminary period to allow metabolism to reach a steady state. Radioactive phosphate was then added to the medium and metabolism allowed to proceed for $3 \mathrm{~min}$, at the end of which period the specific radioactivity of phosphocreatine and the $\gamma$-phosphorus of adenosine triphosphate were in equilibrium (Fig. 13). The distribution of radioactivity in the other acidsoluble phosphates was not uniform, the time period being deliberrately chosen to obtain this situation. Upon removal of the tissues from the saline and replacing in fresh saline not containing radioactive phosphate, the specific radioactivities of the acidsoluble phosphates decreased partly owing to a loss of radioactivity to the saline and also to the redistribution of radioactivity into the other fractions. Electrical pulses applied for no more than $10 \mathrm{sec}$ during this phase produced a rapid and marked decrease in the specific radioactivity of inorganic phosphate, phosphocreatine and 
adenosine triphosphate (Table 18), while at the same time the specific radioactivity of the tissue residue increased. Thus an increased exchange of radioactive phosphate had taken place between the highly labelled acid-soluble phosphates and some less highly labelled unknown tissue component.

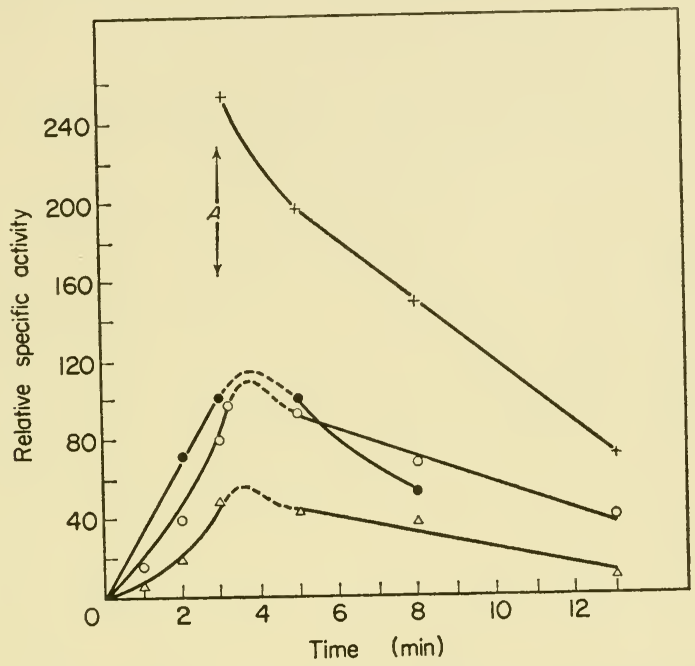

FIG. 13. The time course of incorporation of radioactive phosphate into guinea pig cerebral slices incubated in salines containing glucose. Tissues were removed at the time indicated by the arrows $A$, washed for $10 \mathrm{sec}$ in saline and reincubated in fresh saline. $+=$ orthophosphate; $=$ adenosine triphosphate $\gamma-\mathrm{P} ; \mathrm{O}=$ phosphocreatine; $\Delta=$ hexose monophosphates. The relative specific radioactivity is the specific radioactivity of a phosphate (counts/min per $\mu \mathrm{gP}$ ) relative to a standard specific radioactivity of the inorganic phosphate in the medium. Data from Heald (1956b).

Analysis of the acid-insoluble tissue residue after incubation of slices with radioactive phosphate followed by the passage of electrical pulses for $10 \mathrm{sec}$, showed that only the phosphorus of the phosphoprotein fraction increased in radioactivity (Heald, 1957a), the changes in the nucleic acids, residual organic phosphorus and the phospholipids being insignificant. The quantities of phosphoprotein did not change as a result of the stimulus the levels remaining constant at $1 \cdot 16-1 \cdot 17 \mu$ moles phosphorus/g wet wt. 'Thus, the 
increase in radioactivity represented a true metabolic exchange, and did not involve the synthesis of any new phosphoprotein. Analytical procedures for phosphoproteins involve the measurement of inorganic phosphorus liberated from the appropriate fraction during alkaline digestion and since brain contains numerous unknown phosphates analysis of this type is always open to some

Table 18.-The Effect of Electrical Stimulation upon the istribution of Radioactivity in the Phosphates of Guinea

Pig Cerebral Tissues

\begin{tabular}{|c|c|c|c|}
\hline \multirow{2}{*}{ Phosphate } & \multicolumn{3}{|c|}{ Relative specific activity } \\
\hline & $\begin{array}{l}\text { With electrical } \\
\text { pulses }\end{array}$ & Without pulses & $\begin{array}{l}\text { Change on } \\
\text { stimulation }\end{array}$ \\
\hline Orthophosphate & $160 \pm 6 \cdot 3(8)$ & $199 \cdot 3 \pm 9 \cdot 2(7)$ & $-39 \cdot 3$ \\
\hline Phosphocreatine & $40 \cdot 0 \pm 5 \cdot 9(7)$ & $92 \cdot 0 \pm 10 \cdot 0(9)$ & $-52 \cdot 0$ \\
\hline $\begin{array}{l}\text { Adenosine } \\
\text { triphosphate } \\
\gamma-P\end{array}$ & $43 \cdot 6 \pm 6 \cdot 4(9)$ & $110 \cdot 6 \pm 13 \cdot 5(8)$ & $-67 \cdot 0$ \\
\hline $\begin{array}{c}\text { Acid insoluble } \\
\text { phosphates }\end{array}$ & $\begin{array}{l}3.87 \\
1.47 \\
1.75\end{array}$ & $\begin{array}{l}2 \cdot 78 \\
1 \cdot 12 \\
1 \cdot 08\end{array}$ & $\begin{array}{l}+1.07 \\
+0.35 \\
+0.67\end{array}$ \\
\hline
\end{tabular}

Values for the acid-soluble phosphates are given in \pm S.E.M. Figures in brackets represent the number of determinations. Data from Heald (1956). Pulses were passed for $10 \mathrm{sec}$.

doubt regarding the origin of the phosphorus. Proof of the phosphorus arising from a phosphoprotein has been provided by the isolation of $o$-phosphorylserine from partial acid hydrolysates of cerebral phosphoprotein fractions. When derived from tissue incubated with radioactive phosphate and subjected to pulses for a few seconds the phosphorylserine increased in specific radioactivity (Heald, 1958) clearly indicating that it was derived from the phosphoprotein originally found to be involved in the response. O-phosphorylserine was the only radioactive phosphorylated amino acid isolated from the acid hydrolysates. Since it is well recognized as a component of many naturally occurring phospho- 
proteins (Perlman, 1955) including those from tissues (Kennedy and Smith, 1954) and certain enzymes (p. 14), its recognition as a component of brain phosphoprotein appears to establish the latter as a definite entity.

Attempts to isolate the phosphoprotein itself by methods less degradative than those previously employed led to the discovery that guanosine di- and triphosphates were also involved in the rapid response to electrical impulses (Heald, 1957b). Here, tissues were first fixed in the chloroform methanol extractant of Folch et al. (1951) and after removal of the phospholipids the residues were washed with saturated ammonium sulphate to remove inorganic phosphate and other soluble phosphates. From the residue the fraction increasing in specific radioactivity was extractable at pH 11.0 and analysis of the extracts revealed an identity with guanosine nucleotides. As with the phosphoprotein, no change in quantity was found on stimulation, the levels remaining at $0.5 \mu$ moles $/ g$ wet wt. The residue after alkaline extraction still contained a phosphoprotein (Heald, 1958) though the increase in radioactivity was not as great as had been expected. Reasons for this may relate to an effect of the alkaline conditions upon stability (Heald, 1957b). In addition to guanosine phosphates small quantities of adenosine di- and triphosphates were also found. These did not change in specific radioactivity when the tissue slice was electrically stimulated in contrast to the changes noted with adenosine triphosphate in trichloracetic acid extracts. Since washing with ammonium sulphate was continued until no further nucleotide absorbing at $250 \mathrm{~m} \mu$ could be detected it is possible that these adenine nucleotides represent a group which is metabolically distinct.

Change in specific radioactivity without a change in quantity is suggestive of the participation of these phosphates in a series of linked reactions involving phosphorylation and dephosphorylation. A simple system connecting such changes with those in phosphocreatine and inorganic phosphate is represented diagrammatically in Fig. 14, which is an elaboration of ideas previously presented in somewhat less detail Heald (1956). In a wider context it also represents a more detailed picture of specific points in a general scheme such as that discussed by Brink (1957). Thus, electrical impulses are considered to alter structures associated 
with the preservation of the ionic balance across nerve cell membranes and the resulting increase in energy utilization directs cellular metabolism towards a restoration of this balance. In this scheme phosphoprotein is conceived as an intermediate being broken down to yield inorganic phosphate and being rephosphorylated by phosphocreatine via the adenosine and guanosine nucleotides. In such a sequence only the quantities of phosphocreatine and inorganic phosphate need change in response to stimulus, the quantities of the other three components remaining constant, a situation which has been found to be the case. It must be admitted that since electrical stimulus has not yet been directly

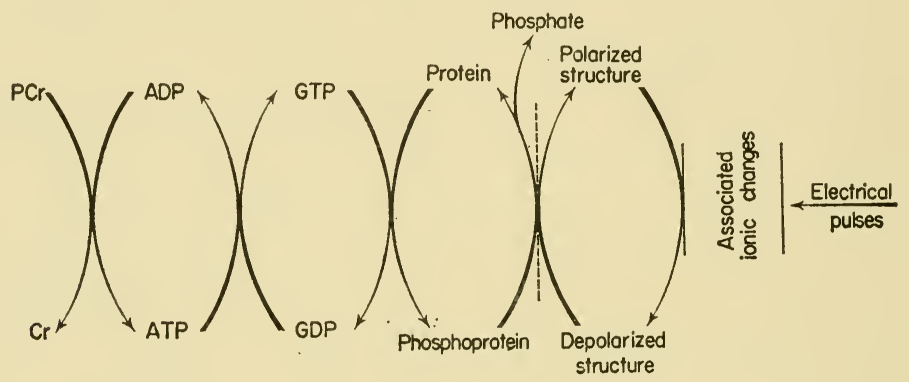

Fig. 14. Diagram illustrating possible connexions between energy-rich phosphates, phosphocreatine and electrical impulses.

shown to alter the ionic balances of cerebral tissues this section of the scheme must remain hypothetical. Nevertheless there seems no reason to suppose that the physical changes involved in the electrical stimulation of processes in the central nervous system are likely to differ greatly from those involved in the stimulation of peripheral nerve where the relationships between ionic balances and state of excitation are better established (cf. Hodgkin, 1951; Keynes, 1957).

The placing of guanosine nucleotide as an intermediate between adenosine triphosphate and the phosphoprotein was dictated by the finding that the specific activity of the guanosine derivatives increased whereas that of the adenine derivatives decreased when the tissue was stimulated electrically. Guanosine triphosphate could not therefore be phosphorylating adenosine diphosphate to the triphosphate. A closer examination of this sequence has been 
made on the basis of a principle described by McMurray et al. (1957) which enables some distinction to be made as to which of two precursors, $\mathrm{A}$ or $\mathrm{B}$, is the one more immediate in the phosphorylation of a compound $\mathrm{C}$. Radioactive $\mathrm{A}$ is added to a system containing inactive $\mathrm{B}$, and radioactive $\mathrm{B}$ to a system containing inactive $A$, inactive $C$ being present in each system. At the end of the incubation the specific activities of $\mathrm{A}, \mathrm{B}$ and $\mathrm{C}$ are determined and the specific activity of $\mathrm{C}$ relative to $\mathrm{A}$ is calculated. If $\mathrm{B}$ is

Table 19.-The Incorporation of Phosphate From ${ }^{32} \mathrm{P}$ Labelled Intermediates in the Phosphoprotein Fraction

(Data from Heald and Stancer, 1960)

\begin{tabular}{|c|c|c|c|c|c|c|c|}
\hline \multirow{2}{*}{$\begin{array}{c}\text { Experi- } \\
\text { ment }\end{array}$} & \multirow{2}{*}{$\begin{array}{l}\text { Inter- } \\
\text { mediate }\end{array}$} & \multirow{2}{*}{$\begin{array}{l}\text { Specific } \\
\text { radio- } \\
\text { activity } \\
\text { counts/min } \\
\text { per } \mu \mathrm{g} \mathrm{P}\end{array}$} & \multicolumn{3}{|c|}{$\begin{array}{l}\text { Specific radioactivity } \\
\text { at end of experiment }\end{array}$} & \multirow{2}{*}{$\begin{array}{l}\text { Phos- } \\
\text { pho- } \\
\text { pro- } \\
\text { tein }\end{array}$} & \multirow{2}{*}{$\begin{array}{l}\text { Relative } \\
\text { specific } \\
\text { radio- } \\
\text { activity } \\
\left(\times 10^{3}\right)\end{array}$} \\
\hline & & & $\mathrm{Pi}$ & ATP & GTP & & \\
\hline \multirow[t]{2}{*}{1.} & & - & $3.15 \times 10^{3}$ & - & - & $25 \cdot 0$ & $8 \cdot 4$ \\
\hline & $\mathrm{AT}^{32} \mathrm{P}$ & - & $1.62 \times 10^{3}$ & - & - & $61 \cdot 5$ & $38 \cdot 0$ \\
\hline \multirow[t]{2}{*}{2.} & $\mathrm{AT}^{32} \mathrm{P}$ & $1.68 \times 10^{3}$ & 一 & 531 & 352 & $5 \cdot 77$ & $10 \cdot 8$ \\
\hline & $\mathrm{GT}^{32} \mathrm{P}$ & $1.68 \times 10^{3}$ & - & 392 & 371 & $10 \cdot 0$ & $25 \cdot 5$ \\
\hline
\end{tabular}

Phosphoprotein was estimated as phosphorylserine. Carrier phosphorylserine was included in each experiment.

In experiment (1) relative specific radioactivity $=$ (s.a. of phosphoprotein/s.a. of inorganic phosphate at end of experiment) $\times 10^{3}$. In experiment (2) relative specific radioactivity $=$ (s.a. of phosphoprotein/s.a. of ATP at end of experiment) $\times 10^{3}$.

converted to $\mathrm{A}$ before forming $\mathrm{C}$ then the relative activity of $\mathrm{C}$ in both experiments would be equal. If $\mathrm{B}$ is a more immediate precursor than $\mathrm{A}$ then the relative specific activity of $\mathrm{C}$ should be higher than in the case where $\mathrm{A}$ is the precursor. Experiments based on this principle (Heald and Stancer, 1960; Table 19) showed that adenosine triphosphate was a more immediate precursor of phosphoprotein than was inorganic phosphate and that guanosine triphosphate was a more immediate precursor than was adenosine triphosphate. However, it can be argued that the latter experiment does not exclude the possibility that the phosphoprotein was acting as an intermediate between the adenosine and guanosine nucleotides. The possible reactions are: 


\section{ATP $\longleftrightarrow$ GTP $\longleftrightarrow$ Phosphoprotein \\ ATP $\longleftrightarrow$ Phosphoprotein $\longleftrightarrow$ GTP}

In experiment 2 ('Table 19) the radioactivity of the precursors was identical, and identical quantities of each were present in both systems. At the end of the experiment with adenosine triphosphate as the labelled precursor the specific radioactivity of adenosine triphosphate was higher than that of guanosine triphosphate, while with guanosine triphosphate as the labelled precursor the specific activity of the nucleotides was identical; in both experiments the specific activity of the guanosine nucleotide was similar at the end. Nevertheless, the specific activity of the phosphoprotein was lower with adenosine triphosphate as the precursor than with guanosine triphosphate as the precursor. If phosphoprotein was an intermediate between adenosine triphosphate and guanosine triphosphate it seems reasonable to expect that its specific radioactivity, with adenosine triphosphate as the labelled precursor, would be equal to or higher than that when guanosine triphosphate was the precursor. The data is thus more strongly in conformity with reaction (1) than reaction (2).

The existence of a nucleotide diphosphokinase of the type necessary for the exchange of phosphate between adenosine triphosphate and guanosine triphosphate might be inferred from the data given in Table 19, but for the reasons given above the reaction in the intact slice is a phosphorylation of guanosine triphosphate by adenosine triphosphate and not the reverse. In this respect the system differs from that described by Ayengar et al. (1956). Here guanosine nucleotides were found to be intermediates in the phosphorylation of adenosine diphosphate to the triphosphate which occurred during the metabolism of succinylcoenzyme A. It also differs in direction from the reaction described by McMurray et al. (1957) whereby guanosine triphosphate phosphorylated adenosine diphosphate to the triphosphate in aqueous dispersions of rat brain under anaerobic conditions. Of the nucleoside diphosphokinases, that mentioned above together with the enzyme catalysing a reaction between uridine triphosphate and adenosine diphosphate are the only ones described in brain which appear to possess an appreciable activity. Thus, although extracts of sheep brain can catalyse the phos- 
phorylation of adenosine diphosphate by inosine triphosphate (Krebs and Hems, 1955) the reaction is extremely slow (about $0.5 \mu$ moles $/ \mathrm{g} \mathrm{hr}^{-1}$ ) and does not contribute to the formation of adenosine triphosphate in aqueous dispersions of rat brain; the reaction between cytidine triphosphate and adenosine diphosphate also appears to proceed only slowly (McMurray et al., 1957).

Evidence to support a sequence such as that of Fig. 14, as a major pathway of energy metabolism of the tissue during excitation at present rests upon the finding that these components together with inorganic phosphate were the only phosphates changing rapidly upon brief application of electrical pulses to the intact tissue. For such a sequence to be prominent the rates of reaction must be high. So far, accurate data in intact tissue are known only for phosphocreatine and inorganic phosphate. In dispersions, enzymes operating at similar rates are phosphocreatine phosphokinase $\left(3600 \mu\right.$ moles $/ \mathrm{g} \mathrm{hr}^{-1}$, Narayanaswami, 1952) and adenosine triphosphatase $\left(1600 \mu \mathrm{moles} / \mathrm{g} \mathrm{hr}^{-1}\right.$, Gore, 1951). However, the latter enzyme does not appear to be involved, for in systems where it is inhibited with sodium fluoride the labelling of phosphoprotein is increased (Heald and Stancer, 1960). The rate of metabolism of phosphoprotein has been computed at a rough minimum value of $400 \mu$ moles $/ \mathrm{g} \mathrm{hr}^{-1}$ (Heald, 1958). It is possibly significant that brain contains a phosphoprotein phosphatase which operates at rates up to $60 \mu$ moles $/ g \mathrm{hr}^{-1}$ with casein as a substrate (Feinstein and Volk, 1949). The nature of the phosphoprotein is largely unknown, but it is envisaged as being an intermediate capable of accepting and donating energy-rich phosphate, analogous to the reaction described for phosvitin (Rabinowitz and Lipmann, 1958) rather than an enzyme the activity of which is increased by the general increase in metabolism of the tissue. For this role the energy of the phosphate group(s) must be readily transferable and the group(s) are presumably labile. In this connection the finding of the phosphorus attached to $o$-phosphorylserine is an anomaly for the oxygen-phosphorus link in this amino acid is remarkably stable (Plimmer, 1941). The normal procedures for isolation of phosphorylserine involve an acid hydrolysis which is well known to catalyse rearrangements such as the transfer of a group linked to a nitrogen atom to one linked to an oxygen atom. Suggestions as to how such rearrangements may occur to yield $o$-phosphorylserine from phosphoprotein enzymes 
have been discussed (cf. Rydon, 1958; Aldridge, 1956) but whether they apply to phosphoproteins of the type considered above is not known.

A system such as that of Fig. 14 is necessary to any chemical linkage of labile phosphates to the functional events in the tissue, and at present the phosphoprotein fraction appears to occupy a prominant place. Whether this is the only substance of high molecular weight involved in this manner, and the mechanism by which the energy is used, are subjects for further work.

\section{Resynthesis of Phosphocreatine after Electrical Stimulus}

In vivo, in the period following the administration of electroshock, the phosphocreatine of rat brain was resynthesized at a rate of $240 \mu$ moles/g wet wt. $\mathrm{hr}^{-1}$ (Dawson and Richter, 1950). Rates similar to this have been found in slices of guinea pig cerebral cortex also following brief electrical stimulus. After applying pulses for $7 \mathrm{sec}$, a period sufficient to reduce the levels of phosphocreatine, the phosphate was resynthesized to the normal level at a rate of $150 \mu$ moles $/ \mathrm{g} \mathrm{hr}^{-1}$ (Fig. 15). At the same time the levels of inorganic phosphate decreased. Here, as in other experiments with tissue slices, the supply of oxygen could not be a limiting factor and it seems probable that $150 \mu$ moles $/ \mathrm{g} \mathrm{hr}^{-1}$ represents the normal rate of synthesis of phosphocreatine. Experiments with radioactive phosphate (p. 117) have supported the view that phosphocreatine is resynthesized by adenosine triphosphate. Nevertheless such resynthesis appears to involve other factors which are not understood. Thus the continued passage of electrical pulses for $20 \mathrm{~min}$ increased the time required for resynthesis from $17 \mathrm{sec}$ to $90 \mathrm{sec}$ (Fig. 15), the latter process having a lag period of $10 \mathrm{sec}$ before any resynthesis was detectable. The factors involved do not appear to include fumarate, found by McIlwain and Gore (1953) to restore the oxygen uptake and phosphocreatine levels depleted by a similar technique, nor do they include additional creatine, for inclusion of both of these in the medium at $20 \mathrm{mM}$ failed to increase the rate of phosphocreatine resynthesis following depletion by prolonged electrical stimulus.

So far, direct measurements of the oxygen uptake by slices during the short periods studied, have not been reported. It seems probable (McIlwain, 1952) that changes in oxygen uptake in response to pulses are prompt and cease within $30 \mathrm{sec}$ or less of 


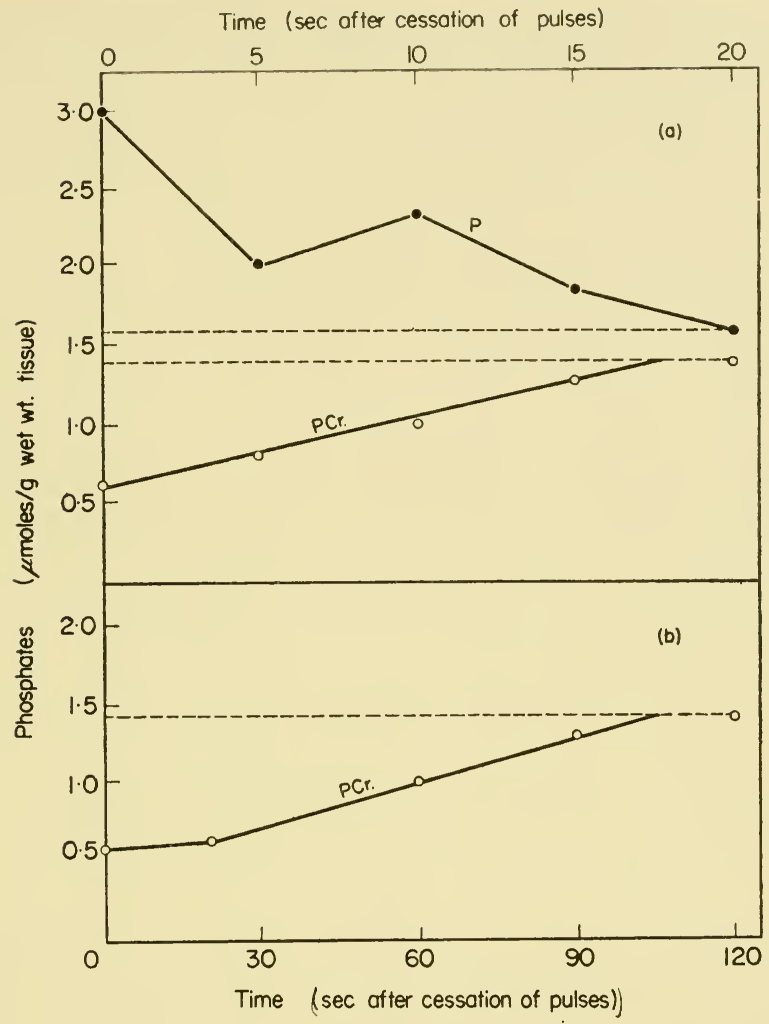

FIg. 15. The resynthesis of phosphocreatine in guinea pig cerebral slices after depletion by electrical pulses passed for differing times. (A) pulses passed for 7-10 sec only. (B) pulses passed for $20 \mathrm{~min}$. In both (A) and (B) the dotted lines represent the levels of phosphocreatine before passing pulses. Data from Heald (1954).

switching off the pulse. If the increased oxygen uptake ceases immediately pulses are stopped, then the oxygen uptake of unstimulated slices of guinea pig brain being $55 \mu$ moles $/ \mathrm{g} \mathrm{hr}^{-1}$, a rate of phosphocreatine resynthesis of $150 \mu \mathrm{moles} / \mathrm{g} \mathrm{hr}^{-1}$ represents a phosphorus/oxygen ratio of $1 \cdot 35$. If the increased rate of oxygen uptake continues at $100 \mu$ moles/g hr-1 the phosphorus/ oxygen ratio becomes 0.75 . These values are of an order similar to those found for oxidative phosphorylation in brain dispersions and with mitochondrial preparations (Table 13) and taken in con- 
junction with the data of Fig. 15 suggest that phosphocreatine may be regarded as a sensitive indicator of the extent of oxidative phosphorylation in the intact tissue. Use has been made of these findings in analysing the effects of certain depressants and anticonvulsants upon cerebral metabolism in vitro (Chapter 5).

\section{Electrical Pulses and Disintegrated Preparations}

It was noted above that preparations of cerebral mitochondria or disintegrated preparations of whole tissue, showed no respiratory response to electrical stimuli applied in apparatus which yielded such a response with intact tissue. In a series of papers the effects of pulses upon cerebral homogenates and mitochondria were described (Abood, Gerard and Ochs, 1952; Abood, 1954; Abood and Romanchek, 1955; Abood, Gerard and Tschirgi, 1952; Abood, 1956) from the results of which the following conclusions were drawn-(a) Electrical pulses increase the rate of oxygen uptake by cerebral homogenates, but having done so this effect cannot be repeated once the pulses have been switched off. (b) Electrical pulses decrease the rate of oxidative phosphorylation in preparations of cerebral mitochondria; this latter effect is reversible, phosphorus/oxygen ratios which decrease in the presence of pulses return to normal when the pulses are switched off. (c) The decreased levels of phosphocreatine found in cerebral tissues following electrical stimulus is more probably due to a decreased rate of synthesis than to an increased rate of breakdown (see however p. 116). However, Narayanaswami and McIlwain (1954) were unable to demonstrate any effect of electrical pulses upon oxidative phosphorylation with dispersions of cerebral tissue or with preparations of cerebral mitochondria. Although differences in behaviour may perhaps be expected between cell-containing and cell-free systems the two sets of results with cell-free preparations clearly do not agree. Major differences exist both in the manner of applying the pulses and in the composition of the electrodes. Thus respiratory response with dispersions was obtained with an arrangement of electrodes which would include only a few per cent of the dispersion (cf. Abood and Romanchek, 1955) imposing a severe limitation on the quantity of material exposed to the electrical field at any one time. No information was given describing the effects of the arrangement upon oxygen uptake in the absence of tissue dispersion. Such points are of importance since 
components of the saline can give rise to spurious increases in oxygen uptake owing to oxidation at the electrodes (Lewis and McIlwain, 1954). Thus the results with homogenates might be taken to imply either a greater response of the particles within the electrode field or interaction of the particles with contaminants released from the electrodes. This latter seems not unlikely for oxidative phosphorylation was inhibited when pulses were applied from electrodes originally described as silver, but actually consisting of sterling silver (a silver-copper alloy), and was not inhibited when electrodes of pure silver, platinum or carbon were used (addendum in Abood, 1954), suggesting that the previous results were due to artifacts caused by the electrode material. Heavy metals are known to alter the efficiency of oxidative phosphorylation in preparations of cerebral mitochondria (Clowes and Keltch, 1951; Chapell and Greville, 1954). With electrodes of pure silver the latter authors found that the passage of electrical pulses released silver ions to the saline and increased the activity of mitochondrial adenosine triphosphatase. This in turn increased the amount of inorganic phosphate present and produced an apparent inhibition of oxidative phosphorylation. Electrodes of gold or molybdenum had no such effect. Although silver ions were claimed to be without effect upon the oxygen uptake of cerebral dispersions (Abood et al., 1952) addition of silver nitrate at $10^{-5}-10^{-6} M$ decreased oxidative phosphorylation in cerebral mitochondria (Chapell and Greville, 1954). Addition of agents capable of binding heavy metals also abolished any effects of pulses from sterling silver electrodes upon oxidative phosphorylation (Abood and Romanchek, 1955). There is thus ample scope for considering the inhibition of oxidative phosphorylation in such systems to be due not to electrical pulses but to artifacts. This might be considered not to apply to the supposed effect of electrical pulses in bringing about a reversible inhibition of oxidative phosphorylation even though the electrodes were of sterling silver (Abood, 1954). The evidence for this does not appear convincing, being presented as a graph of four points, the standard deviations of which are not given. If such deviations were similar to those given in a table of phosphorus/oxygen ratios in the same paper, the apparent variations of the graph would seem to be of no significance. When the uptake of radioactive phosphate was measured in various fractions of mitochondrial suspensions 
stimulated by passing pulses through sterling silver electrodes for $10 \mathrm{~min}$ (the duration of the experiment) a lower radioactivity was found in the acid-soluble phosphates and a fraction considered to be phosphoprotein (Abood, 1954). The significance of these results is difficult to assess. Comparison with the effects of pulses in intact tissue is not possible since both the systems used and the period of application of pulses are markedly different. Further, the phosphoprotein showing response to pulses in the intact tissue is not contained in the mitochondria (Heald, 1959).

There is thus no really sound evidence supporting the view that either electrical pulses support increased respiration or decrease oxidative phosphorylation in cell-free systems and consequently suggestions that such changes have a significance in cell-containing tissues are open to considerable doubt.

\section{Effects of Potassium and Other Ions}

Amongst the normal environmental constituents of brain which are capable of markedly affecting its metabolism, potassium salts have long been known to be prominent. In the brain in vivo potassium ions are present at a concentration of $92 \mathrm{~m} M$ (Hoagland and Stone, 1948), but on slicing and placing in saline the quantities rapidly fall to $10-20 \mathrm{~m} M$. In the presence of oxygen and glucose, levels of potassium ions gradually increase to reach $50 \mathrm{~m} M$. Under these conditions, potassium ions in the medium exchange with those in the slice at $4-5 \%$ of the total/minute, the equilibrium being complete within $30 \mathrm{~min}$ (Krebs et al., 1951; Terner et al., 1950; Korey, 1952). The quantities exchanged are approximately $180 \mu$ moles $/ \mathrm{g} \mathrm{hr}^{-1}$ (Davies and Krebs, 1952). Restoration, exchange and maintenance of adequate levels of potassium ions requires a continuous expenditure of metabolic energy and it is understandable that changes in the concentration of potassium salts in the medium surrounding a slice should be accompanied by changes in the general metabolism.

When added to the medium, potassium salts increase oxygen uptake and aerobic glycolysis the effect being maximal with $100 \mathrm{~m} M \mathrm{~K}^{+}$, when oxygen uptake is almost doubled, but already apparent at $20 \mathrm{mM}$ (Ashford and Dixon, 1935), results which have since been confirmed by numerous workers. The effect is not specific to potassium salts, those of caesium and rubidium promoting an equal response (Dickens and Greville, 1935). In 
the absence of sodium ions of $15 \mathrm{~m} M$ the stimulation of oxygen uptake is not obtained, if anything respiration is depressed (Dickens and Greville, 1935; Tsukada and Takasadi, 1955). The increased respiration is also not due to changes in the tonicity of the medium, since addition of equimolar or greater amounts of sodium salts is without effect (Dixon, 1949; McIlwain and Gore, 1952). Under anaerobic conditions, increased potassium salts depress lactic acid production (Ashford and Dixon, 1935; McIlwain, 1953). With cortical slices respiring in an oxygenated saline containing glucose and eserine, potassium salts increased the quantities of free acetyl choline in the medium (Mann et al., 1939). The effect of potassium salts is confined to nervous tissue or tissue having a well-developed nervous plexus, for slices of kidney, testis and liver were unaffected by $100 \mathrm{~m} M \mathrm{KCl}$ (Dickens and Greville, 1935). It also seems that for the response the tissue must be intact. Instances where the potassium salts are effective in increasing the oxygen uptake in dispersions are probably due to the stimulation of phosphoenol pyruvate-adenosine diphosphate transphosphorylase in a system where levels of adenosine triphosphate are low (Boyer et al., 1942).

Thus, to a large degree, increasing the quantities of potassium salts in the medium produces changes in oxygen and glucose consumption in cerebral tissues similar to those induced by applied electrical impulses. These similarities extend to phosphate metabolism. Thus, $100 \mathrm{~m} M \mathrm{KCl}$ decreased levels of phosphocreatine from $1.5 \mu$ moles $/ g$ wet wt. to $0.5 \mu$ moles $/ g$, at the same time increasing levels of inorganic phosphate by $1.0 \mu \mathrm{moles} / \mathrm{g}$. However, under these conditions the time course of phosphocreatine breakdown differs from that induced by electrical pulses. When slices were incubated in salines containing an additional $83 \mathrm{~m} M \mathrm{NaCl}$, phosphocreatine levels were maintained at $1.5 \mu$ moles $/ g$ wet wt. On transferring to salines containing normal sodium levels but an additional $90 \mathrm{mM} \mathrm{KCl}$, levels of phosphocreatine fell rapidly for the first $10 \mathrm{sec}$ and thereafter more slowly until the change was complete in $60 \mathrm{sec}$ (Fig. 16). In contrast, during this period the levels of inorganic phosphate were little affected and increased only after $20-30 \mathrm{sec}$. Although a rate of breakdown slower than that obtained with electrical pulses may well be a reflection of the rate of entry of potassium ions into the slice, the delay in the increase in levels of inorganic phosphate is 
markedly different from the changes found with electrical stimulus. Possibly some intermediate first increases in quantity before being broken down to yield inorganic phosphate. Whatever the reason, the experiments provide clear evidence that the increased levels of

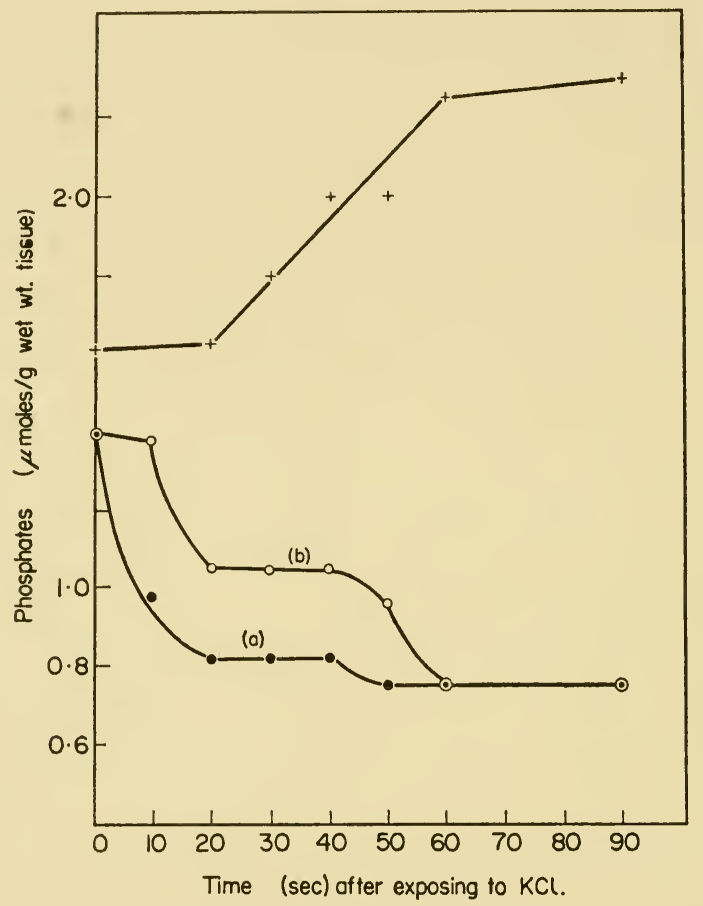

Fig. 16. The breakdown of phosphocreatine induced in guinea pig cerebral slices by addition to the medium of $0.091 M \mathrm{KC} 1$. (a) $=$ phosphocreatine; $+=$ inorganic phosphate, slices preincubated in saline containing $0.091 M$ sucrose. (b) $\bigcirc=$ phosphocreatine, slices preincubated in $0.045 M$ sucrose. Data from Heald (1954), and unpublished.

inorganic phosphate accompanying the breakdown of phosphocreatine are not necessarily derived directly from it. Change in phosphocreatine levels as a result of potassium stimulation may in fact assume a more complex pattern than that shown in Fig. 16, when changes in tonicity of the medium are also involved. Thus, if slices were incubated in salines containing $90 \mathrm{~m} M$ sucrose (as a partial compensation for the subsequent osmotic change) and 
later transferred to salines containing an additional $90 \mathrm{mM} \mathrm{KCl}$, breakdown of phosphocreatine occurred in two steps, the first and second steps each occupying some $20 \mathrm{sec}$, between each was a stable period of $30 \mathrm{sec}$ (Fig. 16). Whether curves $a$ and $b$ represent the same processes carried out at different rates can only be conjectured. The time course of the overall change was the same in both experiments. Changes of this type are not likely to permit of simple interpretation and such situations require further analysis.

Conditions leading to decreased levels of phosphocreatine were noted to decrease the rate of incorporation of radioactive phosphate into compounds such as the phospholipids. Analogous effects have been found with increased concentrations of potassium salts (Table 20). Thus, potassium salts at $124.0 \mathrm{~m} M$ markedly decreased the amount of radioactive phosphate incorporated into phospholipids, phosphoprotein and nucleic acids of cerebral slices. This effect was obtained to a lesser degree with potassium

Table 20.-EFfect of Potassium Salts upon the Incorporation of Radioactive Phosphate into Phospholipids, Phosphoproteins and Nucleic Acids of Cerebral Cortical Slices

\begin{tabular}{|c|c|c|c|c|c|c|c|c|c|}
\hline \multirow{3}{*}{$\begin{array}{l}\text { Experi- } \\
\text { ment }\end{array}$} & \multirow{2}{*}{\multicolumn{2}{|c|}{$\begin{array}{l}\text { Concentration } \\
\text { of ions in } \\
\text { medium }(\mathrm{m} M)\end{array}$}} & \multirow{3}{*}{$\begin{array}{l}\text { Period } \\
\text { of } \\
\text { incuba- } \\
\text { tion } \\
\text { (hr) }\end{array}$} & \multicolumn{6}{|c|}{$\begin{array}{c}\text { Specific radioactivity counts } / \mathrm{min} \\
\text { per } \mu \mathrm{g} \mathrm{P}\end{array}$} \\
\hline & & & & \multirow{2}{*}{$\begin{array}{l}\text { Phos- } \\
\text { pho- } \\
\text { lipids }\end{array}$} & \multirow{2}{*}{$\begin{array}{c}\text { Nucleic } \\
\text { acids }\end{array}$} & \multirow{2}{*}{\multicolumn{3}{|c|}{$\begin{array}{l}\text { Phospho- } \\
\text { proteins }\end{array}$}} & \multirow{2}{*}{$\begin{array}{l}\text { Resi- } \\
\text { dual } \\
\text { organic } \\
\text { phos- } \\
\text { phorus }\end{array}$} \\
\hline & $\mathrm{K}$ & $\mathrm{Na}$ & & & & & & & \\
\hline \multirow[t]{2}{*}{1.} & 5.9 & 127 & 4 & 15.9 & $27 \cdot 2$ & \multirow{2}{*}{\multicolumn{3}{|c|}{$\begin{array}{l}1390 \\
680\end{array}$}} & 432 \\
\hline & $124 \cdot 0$ & $9 \cdot 0$ & 4 & $7 \cdot 1$ & $7 \cdot 8$ & & & & 95 \\
\hline \multirow[t]{2}{*}{2.} & $5 \cdot 9$ & 127 & 4 & $12 \cdot 1$ & $26 \cdot 1$ & \multirow{2}{*}{\multicolumn{3}{|c|}{$\begin{array}{l}540 \cdot 0 \\
440 \cdot 0\end{array}$}} & 162 \\
\hline & 29 & 104 & 4 & $8 \cdot 2$ & $15 \cdot 3$ & & & & 109 \\
\hline \multirow{5}{*}{3.} & & & & & & a & b & c & \\
\hline & $5 \cdot 1$ & 127 & 1.5 & - & - & 1150 & 2780 & 1990 & \\
\hline & 100 & 127 & 1.5 & - & - & - & 3640 & 4420 & \\
\hline & 50 & 70 & 1.5 & - & - & 1085 & 2740 & - & \\
\hline & $5 \cdot 1$ & 0 & 1.5 & - & - & - & - & 1170 & \\
\hline
\end{tabular}

Data from Findlay et al. (1954) (Expts. 1 and 2) and Tsukada et al. (1958) (Expt. 3). 
salts at $29 \mathrm{mM}$ (Findlay et al., 1954). On the other hand, Tsukada et al. (1958) found that potassium salts at $100 \mathrm{~m} M$ markedly increased the incorporation of radioactive phosphate into the phosphoprotein fraction and into the phosphorus derived from the sum of phosphoprotein and residual organic phosphorus, called "protein bound" phosphorus. The results are not necessarily incompatible. Thus, differences exist between the media used (bicarbonate buffered saline by Findlay et al., glycylglycinebuffered saline by Tsukada $e t$ al.) the period of incubation and the relative concentrations of sodium and potassium ions in the medium. With high concentrations of potassium ions respiration, initially increased, gradually falls and after $4 \mathrm{hr}$ is little more than the normal respiration (Dickens and Greville, 1935), reasons which governed the choice of $90 \mathrm{~min}$ incubation by Tsukada et al. Even here the stimulated respiration had still decreased markedly from its initial value. Relative concentrations of sodium and potassium ions appear to be the most important factor. In the experiments of Findlay et al. levels of sodium ions were decreased when the potassium ions were increased, the final level of sodium ions being in the region where respiratory response to potassium ions is not observed. Tsukada et al. added potassium salts to the medium without altering the concentration of sodium ions. In both sets of experiments the use of intermediate concentrations led to essentially similar results. Thus, potassium ions at $29-50 \mathrm{~m} M$ with a corresponding decrease in levels of sodium ions decreased the incorporation of radioactive phosphate into the fractions measured, as did the presence of $5 \mathrm{~m} M$ potassium ions in the absence of sodium ions. At $26-30 \mathrm{~m} M$, potassium salts deplete levels of phosphocreatine in cerebral slices.

Lowered rates of incorporation are not apparently explicable in terms of changes in the specific radioactivity of the inorganic phosphate either in the medium or in the slice (Findlay et al., 1954). Thus in the presence of $29 \mathrm{~m} M$ potassium salts, the specific radioactivity of inorganic phosphate in the slice was little changed from that in slices incubated in a medium containing $5.1 \mathrm{mM}$ potassium salts, yet the specific activities of the individual phosphates was decreased ('Table 20, Expt. 2). However it must be remembered that situations such as this present difficulties of interpretation owing to changes in the intracellular space during metabolism in media containing varying quantities of potassium 
salts (Pappius and Elliot, 1956) and to the absence of a satisfactory method of determining the specific radioactivity of the intracellular inorganic phosphate.

Changes in levels of phosphocreatine and the incorporation of radioactive phosphate into different phosphorylated compounds are brought about by ions other than potassium. The omission of calcium or magnesium ions, or the addition of ammonium ions at $10 \mathrm{~m} M$ to the medium increased respiration and aerobic glycolysis and decreased levels of phosphocreatine (McIlwain, 1952; McIlwain and Gore, 1952). With similar changes in the ionic composition of the medium the incorporation of radioactive phosphate into phospholipids, nucleic acids, phosphoproteins and residual organic phosphorus was markedly decreased (Findlay et al., 1954).

A basis for these changes is perhaps more readily suggested for potassium salts than for the others. It is widely held that part of the energy expended by nervous tissue is involved in the performance of osmotic work, extruding sodium and maintaining a high concentration of potassium ions within the cell. An increase in the concentration of potassium ions outside the cell might therefore be expected to increase the energy expenditure necessary tn maintain the ionic balance. This in turn would decrease the amount 0 : energy-rich phosphate available for other purposes. This view is certainly an oversimplification of mechanisms which also involve sodium and calcium ions. Nevertheless the technique described provides a direct method of relating changes in metabolism to changes in ionic balances by varying the concentrations of the ions themselves.

\section{Acetylcholine}

An effect of acetylcholine upon the metabolism of the phospholipids considered to be related to part of its action in vivo has been the subject of several papers by Hokin and Hokin. In the presence of eserine, acetylcholine at $10^{-2}-10^{-3} M$ increased the incorporation of radioactive phosphate into the phospholipids of cerebral slices by $50-100 \%$, the increase being greatest in the lecithins and cephalins (Hokin and Hokin, 1955a). The effect was barely detectable within $1 \mathrm{hr}$ but after $3 \mathrm{hr}$ incubation in oxygenated saline measurable changes were obtained. Further fractionation of the phospholipids showed that the greatest change took place 
within the phosphatidic acid fraction (Hokin and Hokin, 1955b). The effect was found not to be specific for phosphate, the incorporation of inositol- $2-{ }^{3} \mathrm{H}$ into the phosphoinositide fraction being stimulated $150 \%$ by $10^{-2} M$ acetylcholine (Hokin and Hokin, 1958 ) though the incorporation of glycerol- $1-{ }^{14} \mathrm{C}$ into the phospholipids was apparently unaffected. With mitochondrial and microsomal fractions of brain the incorporation of phosphate into the phosphatidic acids was increased if $10^{-4} M$ acetylcholine, together with eserine, was included in the medium from which fluoride was absent. In the presence of sodium fluoride the incorporation of phosphate into the phosphatidic acids was increased 8-10 times more than the incorporation in the absence of fluoride, acetylcholine then having no additional effect (Hokin and Hokin, 1958b). It is considered that the overall response to acetylcholine is really an exaggeration of the type of response occurring locally in cerebral tissue when acetylcholine is released during nervous transmission. The reasoning here is not readily followed. The concentrations of acetylcholine used are some $100-1000$ times greater than those existing in the brain and though effects have been described at lower concentrations of $10^{-5}-10^{-6} M$ these are either extremely small or apparent only upon extrapolation of a concentration/response curve. The specificity of the response to acetylcholine is also not clear, carbamylcholine at $10^{-3}-10^{-4} M$ having been earlier reported to increase the incorporation of radioactive phosphate into cerebral phospholipids to a small degree (Hokin and Hokin, 1953). At present it would seem that further clarification of this interesting effect is necessary before correlation with events during nervous transmission can be attempted.

\section{REFERENCES}

Aвоod, L. G. (1954) Amer. F. Physiol. 176, 247.

Aвоо, L. G. (1956) 20th Intern. Physiol. Congr., Brussels. Abstracts of communications, p. 29.

Aвood, L. G. and Romancheк, L. (1955) Biochem. F. 60, 233.

Abood, L. G., Gerard, R. W. and Ochs, S. (1952) Amer. F. Physiol. 171, 134.

Aвood, L. G., Gerard, R. W. and Tschirgi, R. D. (1952) in Phosphorus Metabolism, Vol. II, p. 799 (Ed. by W. D. McElroy and B. Glass), Johns Hopkins Press, Baltimore. 
Acs, G., Balazs, R. and Straub, F. B. (1943) Ukrain. Biokhim. Zhur. 25, 17 (Chem. Abstr. 48, 8923i).

Aldridge, A. N. (1956) Annual Rep. Chem. Soc. 53, 294.

Ashford, C. A. and Dixon, K. C. (1935) Biochem. F. 29, 159.

Ayengar, P., Gibson, D. M., Peng, G. H. L. and Sanadi, D. R. (1956) F. biol. chem. 218, 521.

Ayres, P. J. W. and McIlwain, H. (1953) Biochem. F. 55, 607.

Banga, I., Ochoa, S. and Peters, R. A. (1939) Biochem. F. 33, 1980.

Boyer, P. D., Lardy, H. A. and Phillips, P. H. (1942) F. biol. chem. 146, 673.

BRINK, F. (1957) in Metabolism of the Nervous System 187 (Ed. by D. Richter), Pergamon Press, London \& New York.

Burton, K. and Krebs, H. A. (1953) Biochem. F. 54, 94.

Berry, J. F. and McMurray, W. C. (1957) Canad. F. biochem. Physiol. 35, 799.

Case, E. M. and McIlwain, H. (1951) Biochem. F. 48, 1.

Chapell, J. and Greville, G. D. (1954) Nature, Lond. 174, 930.

Clowes, G. H. A. and Keltch, A. K. (1951) Proc. soc. exp. biol. N.Y. 77, 369.

Davies, R. E. and Krebs, H. A. (1952) Symp. Biochem. Soc. No. 8, 37.

Dawson, R. M. C. (1953) Biochem. F. 53, proc. viii.

Dawson, R. M. C. and Richter, D. (1950) Amer. F. Physiol. 160, 203.

Dickens, F. and Greville, G. D. (1935) Biochem. F. 29, 1468.

Dixon, K. C. (1940) Brain 63, 191.

Dixon, K. C. (1949) F. Physiol. Lond. 110, 87.

Dixon, M. C. and Elliot, K. A. C. (1929) Biochem. F. 23, 812

Feinstein, R. N. and Volk, M. E. (1949) F. biol. chem. 177, 339.

Findlay, M., Magee, W. L. and Rossiter, R. J. (1954) Biochem. F. 58, 236.

Findlay, M., Rossiter, R. J. and Strickland, K. P. (1953) Biochem. F. 55, 200.

Findlay, M., Strickland, K. P. and Rossiter, R. J. (1954) Canad. $\mathcal{J}$. biochem. Physiol. 32, 504.

Folch, J., Ascoli, I., Lees, M., Meath, J. A. and Le Baron, F. N. (1951) F. biol. chem. 191, 833.

GORE, M. B. R. (1951) Biochem. F. 50, 18.

Greengard, O. and McIllwain, H. (1955) Biochem. F. 61, 61.

Heald, P. J. (1953) Biochem. F. 55, 625.

Heald, P. J. (1954) Biochem. F. 57, 673.

Heald, P. J. (1956) Biochem. F. 63, 242.

Heald, P. J. (1957a) Biochem. F. 65, 31.

Heald, P. J. (1957b) Biochem. F. 66, 659.

Heald, P. J. (1958) Biochem. F. 68, 580.

Heald, P. J. (1959) Biochem. F. 73, 132

Heald, P. J. and McIlwain, H. (1956) Biochem. F. 63, 231.

Heald, P. J. and Stancer, H. C. (1960) Submitted for publication.

Hodgkin, A. L. (1951) Biol. Rev. 26, 339.

Hoagland, H. and Stone, J. E. (1948) Amer. F. Physiol. 152, 423. 
Hokin, L. E. and Hokin, M. R. (1953) f. biol. chem. 203, 967.

Hoкin, L. E. and Hokin, M. R. (1955a) Biochim. biophys. Acta. 16, 229.

Hokin, L. E. and Hokin, M. R. (1955b) Biochim. biophys. Acta. 18, 102.

Hokin, L. E. and Hokin, M. R. (1958a) F. biol. chem. 233, 818.

Hokin, L. E. and Hokin, M. R. (1958b) F. biol. chem. 233, 822.

Kennedy, E. P. and Smith, S. W. (1954) F. biol. chem. 207, 153.

Keynes, R. D. (1957) in Metabolism of the Nervous System, p. 159 (Ed. by

D. Richter), Pergamon Press, London \& New York.

Klein, J. R. and Olsen, N. S. (1947) F. biol. chem. 167, 747.

Kratzing, C. C. (1951) Biochem. F. 50, 253.

Kratzing, C. C. (1953) Biochem. F. 54, 312.

Kratzing, C. C. (1956) Biochem. F. 62, 127.

Krebs, H. A. (1950) Biochem. biophys. Acta, 4, 249.

Krebs, H. A. and Hems, R. (1955) Biochem. F. 61, 435.

Krebs, H. A., Eggleston, L. V. and Terner, C. (1951) Biochem. F. 48, 530.

Korey, S. R. (1952) Biochim. biophys. Acta. 9, 633.

Lewis, J. L. and McIlwain, H. (1954) Biochem. F. 57, 680.

Lissovskaya, N. P. (1956) Biokhimiya. 21, 434.

Long, C. (1943) Biochem. F. 37, 215.

LoNG, C. (1945) Biochem. F. 39, 143.

LoNG, C. (1951) Biochem. F. 50, 407.

McIlwain, H. (1951) Biochem. F. 49, 383.

McIlwain, H. (1952a) Biochem. F. 52, 289.

McIllwain, H. (1952b) Symp. Biochem. Soc. No. 8, 27.

McIlwain, H. (1953b) Biochem. F. 55, 618.

McIlwain, H. (1956) Physiol. Rev. 36, 355.

McIlwain, H. (1959) Biochemistry and the Central Nervous System, Churchill, London.

McIllwain, H. and Gore, M. B. R. (1951) Biochem. F. 50, 24.

McIllwain, H. and Gore, M. B. R. (1952) F. Physiol. 117, 431.

McIllwain, H. and Gore, M. B. R. (1953) Biochem. F. 54, 305.

McIlwain, H. and Tresize, M. A. (1956) Biochem. $\mathcal{F . ~ 6 3 , ~} 250$.

Mcilwain, H., Anguiano, G. and Cheshire, J. D. (1951) Biochem. F. 50, 12.

Mann, P. J. G., 'Tennenbaum, M. and Quastel, J. H. (1939) Biochem. F. 33, 1506.

McMurray. W. C., Berry, J. F. and Rossiter, R. J. (1957) Biochem. F. 66, 621 .

McMurray, W. C., Strickland, K. P., Berry, J. F. and Rossiter, R. J. (1957) Biochem. F. 66, 634.

Narayanaswami, A. (1952) Biochem. F. 52, 295.

Narayanaswami, A. and McIlwain, H. (1954) Biochem. F. 57, 663.

Pappius, H. and Elliot, K. A. C. (1956) Canad. F. biochem. Physiol. 34, 1007.

Perlanan, G. E. (1955) Advances in Protein Chemistry 10, 1.

Plimmer, R. H. A. (1941) Biochem. F. 35, 461 
Rabinowitz, M. and Lipmann, F. (1958) Proc. iv Intern. Congr. Biochem. Vienna. Vol. XV, Abstracts of Communications, 4-68. Pergamon Press, London \& New York.

Rodnight, R. and McIlwain, H. (1954) Biochem. F. 57, 649.

Rowsell, E. V. (1954) Biochem. F. 57, 666.

Rydon, H. N. (1958) Nature, Lond. 182, 927.

Schachner, H., Fries, B. A. and Chaikoff, I. L. (1942) F. biol. chem. 146, 95.

Schwerin, P., Bessman, S. P. and Waelsch, H. (1950) F. biol. chem. 184, 37.

Stekol, J. A. (1957) Ann. Rev. Biochem. 26, 611.

Stern, J., Weil-Malherbe, H. and Green, R. H. (1952) Biochem. F. 52, 119.

Terner, C., Eggleston, L. V. and Krebs, H. A. (1950) Biochem. F. 47, 139.

'Tsukada, Y. and Takasadi, G. (1955) Nature, Lond. 175, 725.

Tsukada, Y., Takaguki, G. and Hirano, S. (1958) F. Biochem. Fapan 145, 489.

Thomas, J. (1956) Biochem. F. 64, 335.

Weil-Malmerbe, H. (1952) Symp. Biochem. Soc. No. 8, 16.

Wollenberger, A. (1955) Biochem. F. 61, 77. 


\section{PHOSPHATE METABOLISM AND THERAPEUTIC AGENTS}

OF THE therapeutic agents affecting the central nervous system those producing sedation and general anaesthesia have probably received most attention and studies of their action have given rise to many hypotheses concerning the mechanisms by which they produce their effects. These have included, alterations in the physical state of surface membranes, depression of cellular oxidation by interference with specific flavoproteins, depression of oxidation at certain selected neurones, inhibition of energy production, " uncoupling " of oxidative phosphorylation, and inhibition of the passage of impulses along the usual neural pathways. These hypotheses have been discussed in detail by various authors (Butler, 1950; Brody, 1955; Quastel, 1955; Hunter and Lowry, 1956; Cohen and Cohen, 1957).

The major biochemical changes observed in cerebral metabolism during anaesthesia have been described in Chapter 2 and include increased levels of phosphocreatine, decreased levels of inorganic phosphate, no change or an increase in the levels of adenosine triphosphate, decreased incorporation of phosphorus into the phospholipids. Accompanying these changes, cerebral oxygen uptake and lactic acid production decrease. In the present chapter an account is given of the effects of various therapeutic agents upon phosphate metabolism in cerebral tissues and preparations in vitro, and the relationship of such effects to the changes found in vivo.

\section{Effects on Unstimulated Systems}

A major criterion to be satisfied in comparing metabolic effects of therapeutic agents in vivo and in vitro is the correspondence of the concentrations at which the substances are active in both systems. This is of importance since such agents presumably act by entering into chemical combination with certain sensitive receptors and at excessive concentrations such as are toxic in vivo, 
are likely also to combine with others not normally affected. The metabolic changes then measured could be of a non-specific type. Concentrations of some of the agents most studied, which have been found in the brain in vivo following a therapeutic dose are of the order of $1-5 \times 10^{-4} M$ for the barbiturates and $10^{-7} M$ for a tranquillizing agent such as chlorpromazine (Table 21). Concentrations much in excess of these alter the phosphate metabolism of cerebral slices and homogenates but do so largely as a result of their first depressing the oxygen uptake. Thus, chloral at

Table 21.-Concentrations of Various Agents in Animal Brain Following the Administration of a Therapeutic Dose

\begin{tabular}{l|c}
\hline \multicolumn{1}{c|}{ Agent } & $\begin{array}{c}\text { Concentration } \\
\left(M \times 10^{4}\right)\end{array}$ \\
\hline $\begin{array}{l}\text { Thiopentone } \\
\text { (5-ethyl-5(1-methylbutyl)-2-thiobarbituric acid }\end{array}$ & $0 \cdot 75$ \\
$\begin{array}{l}\text { Pentabarbitone } \\
\text { (5-ethyl-5(1-methylbutyl)-barbituric acid }\end{array}$ & $1 \cdot 0-2 \cdot 0$ \\
$\begin{array}{l}\text { Thiophenobarbitone } \\
\text { (5-ethyl-5-phenyl)-2-thiobarbituric acid }\end{array}$ & $3 \cdot 0$ \\
$\begin{array}{l}\text { Phenobarbitone } \\
\text { (5-ethyl-5-phenyl)barbituric acid }\end{array}$ & $4-5 \cdot 0$ \\
Thiobarbitone & $5 \cdot 0$ \\
(5:5-diethyl)-2-thiobarbituric acid & $5 \cdot 0$ \\
$\begin{array}{l}\text { Barbitone } \\
\text { Hexobarbitone }\end{array}$ & $4 \cdot 0$ \\
$\begin{array}{l}\text { (5-ethyl-5- } n \text {-hexyl)barbituric acid } \\
\text { Amobarbitone }\end{array}$ & $5 \cdot 0$ \\
$\begin{array}{l}\text { Secobarbitone } \\
\text { (5-allyl-5-methylbutyl)barbituric acid }\end{array}$ & $1 \cdot 0-1 \cdot 5$ \\
Chloral & $1 \cdot 0-1 \cdot 5$ \\
Chlorpromazine & $3 \times 10^{-3}$ \\
(10-C-dimethylaminopropyl)-3-chlorophenothiazine & \\
$\begin{array}{l}\text { Viadril } \\
\text { (21-hydroxypregnane-3 : 2-dione hemisuccinate }\end{array}$ & $2 \cdot 0$ \\
\hline
\end{tabular}

Depressants were assayed following an anaesthetic dose in dogs and rabbits. Chlorpromazine following $100 \mathrm{mg} / \mathrm{kg}$ given to mice. Data from Mark et al. (1958); McClennan and Elliot (1951); Butler (1950); Berti and Cima (1954); Buchel and McIlwain (1950); Truitt et al. (1956); and Goldbaum (1948). 
$5 \times 10^{-4} M$ decreased levels of phosphocreatine in slices of guinea pig cerebral cortex from $1.5 \mu$ moles $/ g$ to $1.0 \mu$ moles $/ g$ but also decreased the oxygen uptake by $10-12 \%$. Higher concentrations of $10^{-3} M$ decreased phosphate levels and oxygen uptake still further (Buchel and McIlwain, 1950). Similar results were obtained when soneryl (5-butyl-5-ethyl barbituric acid) and dial (5:5-diallyl barbituric acid) were used at concentrations of $10^{-2}-10^{-3} M$ (McIlwain and Buchel, 1951). On the other hand chloral at $10^{-4} M$ was without effect upon oxygen uptake or levels of phosphocreatine though this concentration is fully sedative in vivo. Decrease in levels of energy-rich phosphates are also brought about by the convulsants, picrotoxin, strychnine and pentamethylene tetrazole at $10^{-2}-10^{-3} M$, reducing the levels of phosphocreatine parallel with reductions in the oxygen uptake of guinea pig cerebral slices (Anguiano and McIlwain, 1951).

Some interesting effects of tranquillizing agents and depressants upon the incorporation of radioactive phosphate into the phospholipids and other phosphates have been noted by Magee et al. (1956). Thus, chlorpromazine at $10^{-4}-10^{-5} M$ and azacyclonol at $10^{-3} M$, concentrations which did not alter the oxygen uptake of the slices, increased the radioactivity of the inositol phosphatides, phosphatidic acids and glycerylphosphorylserine by $100 \%$, the radioactivity of the other phospholipids being unaffected. Curiously, no changes were detected either in the quantities or specific radioactivities of phosphocreatine and adenosine triphosphate. The results are puzzling, for present evidence implicates adenosine triphosphate as the primary source of phosphorus in cerebral phospholipids. It is difficult to see how an increase in radioactivity of the product could be accomplished without an increase in the radioactivity of the precursor.

An impaired ability to maintain normal levels of energy-rich phosphates when the oxygen uptake is suppressed is indicative of the inability of the oxidative phosphorylation to keep pace with the energy requirements of the tissue. In such situations it seems reasonable to expect the incorporation of radioactive phosphate into phosphorus derivatives such as the phospholipids, also to be decreased. At concentrations of $10^{-3} M$, pentobarbitone and chloretone inhibited the incorporation of radioactive phosphate into the phospholipids, nucleic acids and phosphoproteins of cerebral slices by $60-80 \%$ of the control values (Strickland, 1954; 
Findlay et al., 1954; Findlay et al., 1953). Although measurements of oxygen uptake were not made in these experiments concentrations of this order are known to be inhibitory and the decreased incorporation of radioactivity probably reflects a decreased rate of synthesis of adenosine triphosphate. Indirect measurements of the rate of synthesis of adenosine triphosphate in slices of cerebral cortex in the presence of barbiturates have been made by Messer (1958). It was found that the synthesis of glutamine (a process known to be dependent upon an adequate supply of adenosine triphosphate) was decreased by a number of barbiturates, but only in direct ratio to the decrease in oxygen uptake (Table 22). Concentrations to produce this effect were some 5-10 times higher than those found to be depressant in vivo. Since similar changes were found when cyanides were added to the system it was

Table 22.-Effect of Depressants upon the Synthesis of Energy-Rich Phosphates in Cerebral Slices and Dispersions of Whole Brain

\begin{tabular}{|c|c|c|c|c|c|c|}
\hline \multirow[b]{3}{*}{ Depressant } & \multirow{3}{*}{$\begin{array}{c}\text { Concen- } \\
\text { tration } \\
M \times 10^{4}\end{array}$} & \multicolumn{5}{|c|}{ Tissue preparations } \\
\hline & & \multicolumn{2}{|c|}{ Slices } & \multicolumn{3}{|c|}{ Dispersions } \\
\hline & & $\begin{array}{l}\text { Oxygen } \\
\text { uptake } \\
\text { as } \% \\
\text { control }\end{array}$ & $\begin{array}{c}\text { Glutamine } \\
\text { synthesis } \\
\text { as } \% \\
\text { control }\end{array}$ & $\begin{array}{l}\text { Oxygen } \\
\text { uptake } \\
(\mu \\
\text { atoms })\end{array}$ & $\begin{array}{c}\text { Pi } \\
\text { uptake } \\
(\mu \\
\text { moles })\end{array}$ & $\mathrm{P} / \mathrm{O}$ \\
\hline \multirow[t]{3}{*}{ Phenobarbitone } & 5 & 100 & 100 & - & 一 & - \\
\hline & 20 & 95 & 80 & - & - & 一 \\
\hline & 50 & 60 & 50 & 一 & - & - \\
\hline \multirow[t]{2}{*}{ Thiopentone } & 2 & 85 & 80 & - & 一 & - \\
\hline & 5 & 80 & 65 & 一 & - & 一 \\
\hline \multirow[t]{4}{*}{ Pentobarbitone } & 0 & 100 & 100 & $14 \cdot 6$ & $22 \cdot 5$ & $1 \cdot 5$ \\
\hline & $1 \cdot 6$ & 95 & 95 & $12 \cdot 8$ & $20 \cdot 3$ & $1 \cdot 6$ \\
\hline & $3 \cdot 0$ & 90 & 85 & $10 \cdot 1$ & $17 \cdot 6$ & $1 \cdot 7$ \\
\hline & $7 \cdot 5$ & 70 & 65 & $1 \cdot 9$ & $2 \cdot 0$ & $1 \cdot 1$ \\
\hline \multirow[t]{3}{*}{ Chloral } & 0 & - & 一 & $7 \cdot 06$ & $19 \cdot 2$ & $2 \cdot 7$ \\
\hline & 50 & - & - & $3 \cdot 3$ & $10 \cdot 9$ & $3 \cdot 3$ \\
\hline & 100 & - & - & $2 \cdot 4$ & $9 \cdot 3$ & $3 \cdot 8$ \\
\hline \multirow[t]{2}{*}{ Chlorpromazine } & $5 \times 10^{1}$ & 90 & 100 & - & - & 一 \\
\hline & $1 \cdot 0$ & 90 & 100 & - & - & 一 \\
\hline
\end{tabular}

Data from Messer (1958); Case and McIlwain (1951); and Eiler and McEwan (1949). 
concluded that depression of glutamine synthesis, and therefore synthesis of adenosine triphosphate, was secondary to the depression of oxygen uptake.

The finding that decreases in both the oxygen uptake and the synthesis of glutamine occurred in simple proportion suggests that the overall efficiency of oxidative phosphorylation was impaired. This had been previously shown to be the case during phosphorylation in cerebral dispersions (Table 22; see also Grenell et al., 1955). In dispersions of whole brain oxidizing pyruvate the efficiency of the process of oxidative phosphorylation of adenosine diphosphate to the triphosphate was not altered by pentobarbitone or chloral at concentrations markedly suppressing the overall oxygen uptake, though the actual quantities of adenosine triphosphate synthesized were considerably reduced. A decrease in the production of adenosine triphosphate during the action of chloretone upon cerebral dispersions was also demonstrated by Johnson and Quastel $(1953 a, b)$. In this system the generation of adenosine triphosphate by rat brain dispersions was coupled with the acetylation of sulphanilamide by pigeon liver extracts. Chloretone at $4 \times 10^{-3} M$ suppressed acetylation, an effect which could be reversed by adenosine triphosphate. Since the acetylation mechanism itself was unaffected by this concentration of chloretone it was concluded that the action of chloretone was upon the synthesis and not the utilization of adenosine triphosphate. These experiments have formed the basis of a suggestion (Johnson and Quastel, 1953) that cerebral narcosis generally is the result of a decreased rate of production of adenosine triphosphate rendering less energy available for the normal functioning of the tissue.

Decrease in the quantities of adenosine triphosphate made available for the maintenance of function has also been proposed as a mechanism responsible for the action of depressants and other agents as a result of different investigations of their action upon oxidative phosphorylation in preparations of cerebral mitochondria (Brody and Bain, 1951; Bain, 1952; Brody and Bain, 1954). In the presence of barbiturates such as thiopental, pentobarbitone and amobarbitone at concentrations of $1-4 \times 10^{-4} M$, the amount of inorganic phosphate disappearing from the medium during the oxidation of pyruvate was suppressed to a markedly greater degree than was the oxygen uptake, resulting in a decrease in the phosphorus/oxygen ratios. In the presence of an uncoupling agent, 
such as "dinitrophenol", increased quantities of inorganic phosphorus and phosphate acceptors, such as adenosine diphosphate are formed. If the quantities of these have previously been limited in the system being studied then an increase in these quantities results in an increase in the oxygen uptake (p. 109). When tested with preparations of cerebral mitochondria in a medium containing limiting amounts of inorganic phosphate, the addition of the barbiturates resulted in an increased oxygen uptake. Similar changes were found with dinitrophenol. In both the systems containing either a high or a low level of inorganic phosphate decreased phosphorylation was not attributed to a partial inhibition of oxygen consumption since the concentrations of depressants which were chosen did not alter the oxygen uptake by more than $10 \%$. Similar changes ascribed to the " uncoupling " of oxidative phosphorylation have been found with other agents. Thus, after preincubating preparations of cerebral mitochondria with chlorpromazine Abood (1955) found that the phosphorus/ oxygen ratios were decreased by concentrations of $5 \times 10^{-5} \mathrm{M}$. Without preincubation, Century and Horwitt (1956) and Berger (1957) were unable to obtain this effect with concentrations below $2 \times 10^{-4} M$. With particulate preparations of rat brain, ether in surgical concentrations, was found to decrease the phosphorus/oxygen ratios slightly and the steroid anaesthetic Viadril (21-hydroxypregnane-3:20-dione hemisuccinate) at $5 \times 10^{-4} \mathrm{M}$ produced a decrease of $17 \%$. Higher concentrations of $5 \times 10^{-3} M$ decreased the phosphorus/oxygen ratio by $87 \%$ (Hulme and Krantz, 1954; Truitt et al., 1956).

However, not all depressants or barbiturates are effective in this manner. Thus, anaesthetic mixtures of nitrous oxide/oxygen and xenon/oxygen were without effect upon the phosphorus/oxygen ratios of rat cerebral mitochondria (Levy and Featherstone, 1954). Ethanol at $21 \times 10^{-2} M$, chlorobutanol at $10^{-3} M$, chloral at $10^{-3} \mathrm{M}$, urethane at $10^{-3} \mathrm{M}$ and morphine at $10^{-3} \mathrm{M}$ are similarly ineffective. Of the barbiturates, dial and phenobarbitone at $10^{-3} M$ though depressing the phosphate uptake also depressed oxygen uptake to a similar degree leaving the phosphorus/oxygen ratios unaltered (Brody and Bain, 1954; Wolpert et al., 1956). On the other hand a convulsant barbiturate (1:3-dimethyl butyl ethyl barbituric acid) at $1-2 \times 10^{-4} M$ also decreased the phosphorus/oxygen ratios markedly (Brody and Bain, 1954). 
Depression of phosphorus/oxygen ratios is clearly therefore not a general property of depressants nor yet of all barbiturates. It seems probable that in several instances much of the depression is due to the activation of mitochondrial adenosine triphosphatase. Thus, it has been shown (Bain, 1957; Maxwell and Nickel, 1954; Abood, 1955; Bernsohn et al., 1956; Century and Horwitt, 1956) that depressants and convulsant barbiturates and chlorpromazine, at concentrations decreasing the phosphorus/oxygen ratios markedly, increase the adenosine triphosphatase activity of the mitochondrial preparations. Since an increased activity of adenosine triphosphatase results in an increased formation of inorganic phosphate, measurement of oxidative phosphorylation by determining the overall quantity of inorganic phosphate removed from the medium under such conditions will yield a decreased phosphorous/oxygen ratio. However, since the function of adenosine triphosphatase is not known such activation in itself does not preclude the possibility that the action of some therapeutic agents in the mitochondrial system is an "uncoupling" of oxidative phosphorylation. Difficulties in ascribing to them such an action arise from a lack of knowledge of the mechanisms by which the "classical" uncoupling agents such as dinitrophenol, produce their effects. In some interesting experiments designed to compare the action of the two types of agents Bain (1957) found that thiopental at concentrations sufficient to decrease the phosphorus/ oxygen ratios by $50 \%$ had no effect upon the incorporation of radioactive phosphate into the intra-mitochondrial adenosine triphosphate nor into adenosine triphosphate in the medium. Dinitrophenol, also at concentrations completely suppressing a total uptake of phosphate, nevertheless failed to prevent a rapid exchange of inorganic phosphate with adenosine triphosphate in the mitochondria. Neither of these phenomena are satisfactorily explained by a process involving an activation of adenosine triphosphatase since in such a case, the system might be expected to turnover faster and thus increase the amount of labelled phosphate incorporated. However, an increase in activity of adenosine triphosphatase is not likely to be a simple stimulation of the enzyme(s) for depressant barbiturates at concentrations of $10^{-2} M$ neither increased nor decreased its activity when measured in aqueous dispersions of brain (Gore, 1951). The phenomenon is 
more likely to be connected with other changes such as alteration of the mitochondrial structure.

These experiments though of interest in relation to the mechanisms by which depressants alter mitochondrial metabolism as yet throw little light on the manner in which these agents affect phosphate metabolism in vivo. The mechanisms of action suggested by Johnson and Quastel and by the experiments of Brody and Bain though differing in detail (the former relating to a decreased formation of adenosine triphosphate, the latter to a decrease in the efficiency of the phosphorylating systems) nevertheless yield the same end result; a decreased quantity of energyrich phosphate being made available for the normal functioning of the brain. Such a picture cannot be considered to provide an adequate explanation of the effects of depressants noted in vivo. Difficulties concern the increases in vivo both in the levels of phosphocreatine and in the incorporation of radioactive phosphate into adenosine triphosphate during barbiturate anaesthesia; neither of these effects being compatible with an action requiring a decreased production of energy-rich phosphates. It is possible, as seems to be implied in the papers of Johnson and Quastel, that the changes in levels of adenosine triphosphate are confined to certain selected areas or neurones in the brain. This view is attractive but is difficult both to examine experimentally and to. reconcile with the overall changes taking place without the further assumption that decreased functioning at these points results in a decrease of activity throughout the whole brain. Although an action of depressants on synaptic transmission in the superior cervical ganglion, has been described (Larabee and Posternak, 1952) there is no direct evidence to suggest that similar effects occur in the central nervous system or that such effects would be connected with a decreased local production of adenosine triphosphate.

Major difficulties also relate to the concentrations of depressants necessary to produce the effects in vivo and in vitro. Thus the levels found in vivo (Table 21) are below those producing any measurable effect upon the oxygen uptake of cerebral slices and comparison with the data of Brody and Bain (1954) shows that such concentrations would alter the phosphorus/oxygen ratios in mitochondrial preparations by less than $10 \%$; changes which are at the bottom limits of measurement in the systems employed. Further, 
barbiturates such as dial and phenobarbitone, inactive upon phosphorus/oxygen ratios in vitro are nevertheless effective as anaesthetics at concentrations some 10 times less than those necessary to produce an inhibition of oxygen uptake in the mitochondrial preparations. Other differences include the fact that dinitrophenol is not a depressant and that anaesthesia is not accompanied by fever and increased metabolism, both of which normally follow the administration of an agent uncoupling oxidative phosphorylation. At present it must be concluded that there is little basis for attributing the action of depressants in vivo to the inhibitions of phosphorylative mechanisms which have been observed with particulate preparations in vitro. Closer correlations have been found with intact tissues stimulated in vitro by electrical impulses, and these are now described.

\section{Effects upon Stimulated Tissues}

The development of systems capable of responding biochemically to applied electrical stimulus, in a manner analogous to the brain in vivo (see p. 115), has led to a re-examination of the action of depressants and anticonvulsants upon cerebral metabolism under the new conditions. It is relevant to note that the metabolic rates of the systems involved in the metabolism of glucose and the uptake of oxygen in cerebral slices in vitro are normally below the rates operating in vivo presumably because of the restraint imposed by the low levels of phosphate acceptors and inorganic phosphate. Removal of such a restraint by increasing the levels of those phosphates raises the metabolic rate to that found in vivo. This state is achieved when cerebral tissues are subjected to electrical impulses. In such a condition a partial inhibition of a reaction is more readily detectable by its overall effect. For example, a reduction of half in the activity of an enzyme need not be detectable in unstimulated tissue if the activity is not rate limiting. In stimulated tissue a similar reduction could make the remaining activity the rate limiting step and thus the inhibition would become detectable. Such a case is the effect of $10^{-5} M$ iodoacetic acid upon the oxygen uptake of cerebral slices for at this concentration the electrically stimulated oxygen uptake was suppressed though no effect was detectable upon the unstimulated oxygen uptake (Heald, 1953).

The effects of depressants upon oxygen uptake and lactic acid 
production in cerebral slices, stimulated electrically, were first described by McIlwain (1953). It was shown that concentrations of barbiturates similar to those found in vivo during anaesthesia decreased both the stimulated oxygen uptake and lactic acid production but were without effect upon the unstimulated metabolism. Subsequent development has shown that such a system is sensitive in vitro to a wide variety of therapeutic agents at concentrations similar to those active in vivo (Forda and McIlwain, 1953; Greengard and McIlwain, 1955; McIlwain and Greengard, 1957). Such an action cannot be considered to be the result of a simple inhibition of oxidative mechanisms, for the stimulated production of lactic acid also decreased whereas the simple inhibition of oxygen uptake would be expected to lead to an increase. Decrease in oxygen uptake and lactic acid production are two of the changes found in vivo in anaesthesia and recognition of these similarities prompted an examination of the effects of depressants and anti-convulsants upon phosphate metabolism under similar conditions.

Examination has been most extensive in the case of phenobarbitone at a concentration of $1.7 \times 10^{-3} M$. This concentration was deliberately chosen as being that which completely blocked response to electrical stimulus, as measured by oxygen uptake, yet was without effect upon unstimulated respiration (McIlwain, 1953; Cohen and Heald, 1959). At this concentration levels of phosphocreatine and adenosine triphosphate were unaffected in unstimulated cerebral slices, the quantities being $1.5 \mu \mathrm{moles} / \mathrm{g}$ and $1.0 \mu$ moles/g respectively. However, response to electrical pulses was greatly suppressed, the breakdown of phosphocreatine being slow (a rate of 15-30 $\mu$ moles/g $\mathrm{hr}^{-1}$ ) and occupying some 2-3 min in comparison with the period of $5 \mathrm{sec}$ found in the absence of phenobarbitone. Concentrations lower than this also exerted a similar effect, a decrease in the rate of breakdown being clearly detectable at $5 \times 10^{-4} M$ phenobarbitone (Table 23). This concentration is similar to that found and calculated to exist in brain following an anaesthetic dose (Table 21). The decreased rates of breakdown are not considered to be attributable to a partial inhibition of phosphocreatine phosphokinase since phenobarbitone at $10^{-2} M$ was without effect upon the enzyme when tested with aqueous dispersions of brain (Narayanaswami, 1952). Also no change in the phosphocreatine phosphokinase activity of rat 
brain was detectable in animals anaesthetized with phenobarbitone (Carr et al., 1955).

The effect of phenobarbitone upon the rate of resynthesis of phosphocreatine was examined in cerebral slices in which the levels of phosphocreatine had been first decreased by electrical pulses applied for a few seconds. It was found that phenobarbitone at $1.7 \times 10^{-3} M$ had no effect upon the resynthesis which proceeded at the same rate $\left(140-150 \mu\right.$ moles $\left./ \mathrm{g} \mathrm{hr}^{-1}\right)$ as in the absence of phenobarbitone (Fig. 17). These two effects, a decreased rate of breakdown and an unimpaired rate of synthesis of phosphocreatine point to an action which prevents the tissue from utilizing

Table 23.-Phenobarbitone on the Breakdown of Phosphocreatine in Cerebral Slices Subjected to Electrical Stimulation

(Values are levels of phosphocreatine in $\mu$ moles/g wet wt.)

\begin{tabular}{c|c|c|c}
\hline \multirow{2}{*}{$\begin{array}{c}\text { Phenobarbitone } \\
\left(M \times 10^{4}\right)\end{array}$} & \multicolumn{3}{|c}{ Duration of stimulus (seconds) } \\
\cline { 2 - 4 } & 0 & 5 & 10 \\
\hline 0 & $1.36 \pm 0.13(4)$ & $0.73 \pm 0 \cdot 12(3)$ & $0.72 \pm 0.03(8)$ \\
5 & $1.38 \pm 0.06(8)$ & - & $1.03 \pm 0.05(6)$ \\
6.8 & $1.36 \pm 0.09(4)$ & $1.2 \pm 0 \cdot 1(8)$ & $1.2 \pm 0.06(6)$ \\
\hline
\end{tabular}

Data from Cohen and Heald (1960). Slices were incubated in oxygenated saline at $37 \cdot 5^{\circ} \mathrm{C}$ and stimulated with condenser pulses, $15 \mathrm{~V}$ peak potential, $0.4-0.5 \mathrm{msec}$ duration.

its energy-rich phosphates in response to stimulus, a situation similar to that considered to apply during anaesthesia in vivo (p. 46). A more detailed examination of this process was made with slices metabolizing radioactive phosphate in the system described in Chapter 4 (p. 116). Cerebral slices were incubated in the presence of $1.7 \times 10^{-3} M$ phenobarbitone for $30 \mathrm{~min}$, radioactive phosphate was added and 3 min later the slices were removed, washed and transferred to fresh non-radioactive saline containing phenobarbitone. After a further 2 min the radioactivity of the phosphates was determined. It was found that the specific radioactivity of inorganic phosphate, phosphocreatine adenosine triphosphate and the phosphoprotein fraction were all considerably higher than the specific radioactivity of similar 
phosphates in slices incubated without phenobarbitone. Since measurements of radioactivity were made at a time when the general movement of radioactivity was out of rather than into these phosphates (see Fig. 13) the results were considered to mean that the point of the action of phenobarbitone lies in blocking some

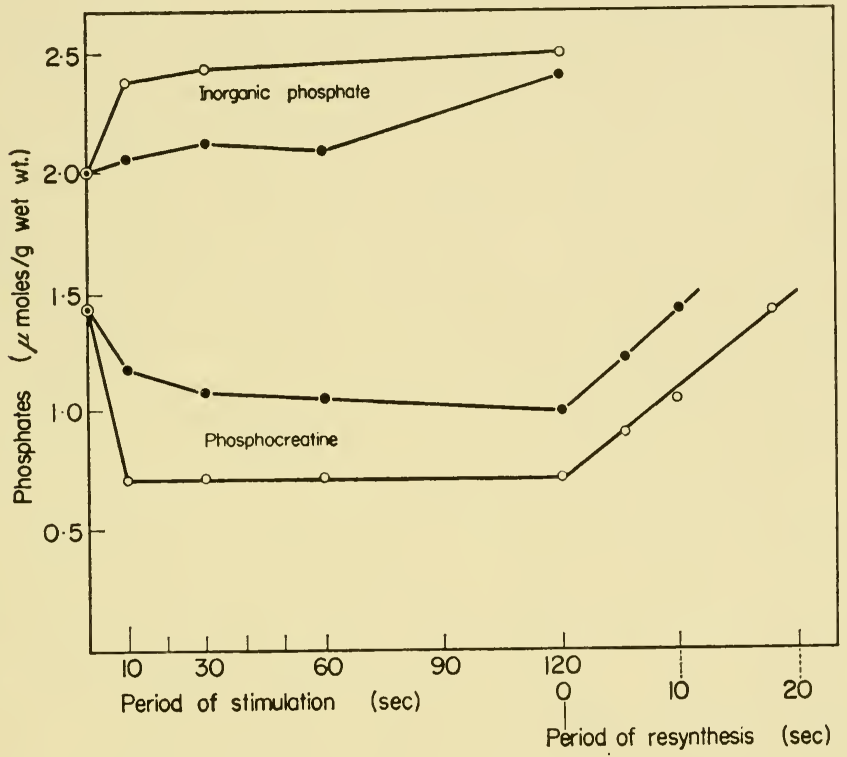

FIG. 17. The breakdown and resynthesis of phosphocreatine in cerebral slices in the presence and absence of phenobarbitone, $1.7 \times 10^{-3} M$. Slices were stimulated with electrical condenser impulses. $\quad$ = with phenobarbitone; $\bigcirc=$ without phenobarbitone. Data from Cohen and Heald (1960).

processes involved in the utilization of energy-rich phosphates beyond the point of phosphoprotein.

Other agents active upon stimulàted respiration have so far been studied only in relation to their effects upon phosphocreatine metabolism. Thus with guinea pig cerebral slices cocaine at $2 \times 10^{-5} M$ reduced the breakdown of phosphocreatine in response to electrical pulses the rate being some $30 \mu \mathrm{moles} / \mathrm{g} \mathrm{hr}^{-1}$ or $3 \%$ of the normal rate. At this concentration little effect was noted upon the resting oxygen uptake and the normal levels of phosphocreatine were not altered (Bollard and McIlwain, 1959). On the other 
hand breakdown of phosphocreatine was not affected by the anticonvulsant trimethadione ( $4: 4^{\prime}$-dimethyl-N-methyl-oxazolidine dione) at $10^{-3} M$, a concentration which partly suppressed the stimulated oxygen uptake (Greengard and McIlwain, 1955).

The effects of these agents upon stimulated tissues in vitro bear a considerable resemblance to their effects in vivo. In the stimulated system the general depressant, phenobarbitone, decreased the stimulated oxygen uptake and lactic acid production and increased levels of phosphocreatine above those found in stimulated tissues in the absence of phenobarbitone. Levels of inorganic phosphate showed a similar relative decrease. The action may therefore be regarded as an inhibition of the changes induced by stimulus. This situation parallels the situation in vivo. Here also, electroshock is equally effective in finally reducing the levels of phosphocreatine and increasing the levels of inorganic phosphate in the brains of anaesthetized cats and dogs (Chapter 2). With both types of preparation the extent of the changes is related to the degree of stimulus which is applied. The finding that concentrations of phenobarbitone some 3-4 times higher than those anaesthetic in vivo were without effect upon the synthesis of phosphocreatine and adenosine triphosphate appears to negative suggestions that the action of such a depressant is via a decreased production of these phosphates. In nervous tissue it has been considered that a large part of the energy produced by the consumption of oxygen and glucose, is used in the maintenance of ionic gradients which give rise to the resting potentials detectable in the intact slice $(\mathrm{Li}$ and McIlwain, 1957). Thus a depression of the ionic movements induced by electrical pulses could give rise to metabolic changes of the type found. Similar relations have been described for the action of cocaine by Bollard and McIlwain (1959) who have pointed out that the concentrations effective in reducing the breakdown of phosphocreatine are similar to those found to delay the decline in action potential caused in frog sciatic nerve by anoxia and to inhibit the loss of potassium and gain of sodium during the depolarization of squid axon.

The lack of effect of anticonvulsants upon phosphate in vitro cannot yet be interpreted upon similar lines but it should be noted that the effects of such agents upon phosphate metabolism in vivo have not been recorded. There is thus an absence of a physiologically comparative situation. Also the stimulus required to 
demonstrate the action upon cerebral metabolism in vitro differs from that used to study phenobarbitone and cocaine. Thus the anticonvulsants were not effective in inhibiting metabolism increased by condenser pulses at $50 \mathrm{cycles} / \mathrm{sec}$, as are cocaine and general depressants, but are effective in inhibiting metabolism increased by sine wave pulses at $2000 \mathrm{cycles} / \mathrm{sec}$ (Forda and McIlwain, 1953). Such selectivity is in accord with their action in vivo of reducing a higher activity to a lower level rather than to producing a general suppression. Further differences include their failure to decrease oxygen uptake stimulated by $2: 4$-dinitrophenol or increased concentration of potassium salts (Greengard and Mcllwain, 1955), a decrease obtained with general depressants (McIlwain, 1953).

There is no reason why all such agents should act through a single mechanism or that only one mechanism should be affected by any one agent. For example, although suppressing the rate of breakdown of phosphocreatine, phenobarbitone and cocaine did not prevent the levels finally decreasing to those found in the absence of either substance. In such circumstances the increased levels of phosphate and phosphate acceptors might reasonably be expected to be accompanied by an increase in oxygen uptake (p. 111). The prevention of this increase may, therefore, be indicative of a direct action upon respiratory processes. These views are in accord with those expressed in more detail by Larabee and Posternak (1952) indicating that such agents, inhibiting cerebral function, are likely to effect both respiration and the consumption of energy-rich phosphate but it is to be remembered that the concentrations effective clinically, for example as an anaesthetic, are considerably lower than those required to produce a complete block of the stimulated oxygen uptake and that concentrations effective as sedatives are lower still. At present the evidence suggests that suppression of energy consumption is the major action.

Experiments with therapeutic agents in vitro have not yet provided an unequivocal metabolic basis for their action in the sense that specific structures or enzymes are known to be inhibited. Indeed it seems clear that the systems most sensitive to these agents in mitochondrial preparations differ from those in whole dispersions, which again differ from those in cerebral slices. However, in serving to clarify the locus of such action are regards phosphate 
metabolism such experiments also serve in the framing of more precise questions regarding the nature of the mechanisms by which they act.

\section{REFERENCES}

Aвоod, L. G. (1955) Proc. soc. exp. biol. N.Y. 88, 688.

Anguino, G. and McIlwain, H. (1951) Brit. F. Pharmacol. 6, 448.

Bain, J. A. (1952) Fed. Proc. 11, 653.

Bain, J. A. (1957) in Progress in Neurobiology, Vol. II (Ed. by H. WaELSCH), Hoeber, New York.

BERgER, M. (1957) F. Neurochem. 2, 30.

Bernsohn, J., Namayuska, I. and Cochrane, L. S. G. (1956) Proc. soc. exp. biol. N.Y. 92, 201.

Berti, T. and Cima, C. (1954) Arch. Intern. Pharmacodyn. 98, 452.

Bollard, B. and McIlwain, H. (1959) Biochem. Pharmacol. 2, 81.

Brody, T. M. (1955) Pharmacol. Rev. 7, 335.

Brody, T. M. and Bain, J. A. (1951) Proc. soc. exp. biol. N.Y. 77, 50.

Brody, T. M. and Bain, J. A. (1954) F. Pharmacol. 110, 148.

Buchel, L. and McIlwain, H. (1950) Brit. F. Pharmacol. 5, 465.

Butler, T. C. (1950a) F. Pharmacol. 100, 219.

Butler, T. C. (1950b) Pharmacol. Rev. 2, 121.

Carr, C. T., Bell, F. K. and Krantz, J. C. (1955) Anaesthesiol. 16, 738.

Case, E. M. and McIlwain, H. (1951) Biochem. F. 48, 1.

Century, B. and Horwitt, M. K. (1956) Proc. soc.exp. biol. N. Y. $91,493$.

Cohen, H. P. and Cohen, M. M. (1957) in Progress in Neurobiology, Vol. II (Ed. by H. WAELSCH), Hoeber, New York.

Cohen, M. M. and Heald, P. J. (1960) F. Pharmacol. In the press.

Eiler, J. J. and McEwen, W. K. (1949) Arch. Biochem. Biophys. 20, 163.

Findlay, M., Rossiter, R. J. and Strickland, K. P. (1953) Biochem. F. 55, 200.

Findlay, M., Strickland, K. P. and Rossiter, R. J. (1954) Canad. $\mathcal{F}$. biochem. Physiol. 34, 504.

Forda, O. and McIllwain, H. (1953) Brit. F. Pharm. 8, 225.

Gore, M. B. R. (1951) Biochem. F. 50, 18.

GoldBaum, L. R. (1948) F. Pharmacol. 94, 68.

Greengard, O. and McIlwain, H. (1955) Biochem. F. 61, 61.

Grenell, R. G., Mendelsohn, J. and McElroy, W. D. (1955) F. cell. comp. Phy'siol. 46, 143.

Heald, P. J. (1953) Biochem. F. 55, 625.

Hulme, N. A. and Krantz, J. C. (1954) Fed. Proc. 13, 368.

Hunter, F. E. and Lowry, O. H. (1956) Pharmacol. Rev. 8, 89.

Johnson, W. J. and Quastel, J. H. (1953a) Nature, Lond. 171, 602.

Johnson, W. J. and Quastel, J. H. (1953b) F. biol. chem. 205, 163.

Larabee, R. G. and Posternak, J. M. (1952) F. Neurophysiol. 15, 91.

Levy, L. and Featherstone, R. M. (1954) F. Pharmacol. 110, 221.

Li, C. L. and McIlwain, H. (1957) F. Physiol. Lond. 139, 178. 
Magee, W. L., Berry, J. F. and Rossiter, R. J. (1956) Biochim. biophys. Acta 21, 408.

Mark, L. C., Burns, J. J., Brand, L., Copomanes, C. I., 'Traisof, N., PAPER, E. M. and Brodie, B. B. (1958) F. Pharmacol. 123, 70.

Messer, M. (1958) Austr. F. exp. biol. Med. Sci. 36, 65.

McClennan, H. and Elliot, K. A. C. (1951) F. Pharmacol. 103, 35.

McIllwain, H. (1953) Biochem. F. 53, 403.

McIllwain, H. and Buchel, L. (1951) Mecanisme de la Narcose. Centre Naitonal de la Recherche Scientifique, p. 123, Paris.

McIlwain, H. and Greengard, O. (1957) F. Neurochem. 1, 348.

Maxwell, R. E. and Nickel, V. S. (1954) Proc. soc. exp. biol. N.Y. 86, 846.

Narayanaswami, A. (1952) Biochem. F. 52, 295.

Quastel, J. H. (1955) in Neurochemistry (Ed. by K. A. C. Elliot, I. H. PAGE and J. H. Quastel), Thomas, Springfield, Illinois.

Strickland, K. P. (1954) Canad. F. biochem. Physiol. 32, 50.

Truitt, E. B., Bell, F. K. and Krantz, J. C. (1956) Proc. soc. exp. biol. N. Y. 92, 296.

Wolpert, A., Truitt, E. B., Bell, F. K. and Krantz, J. C. (1956) F. Pharmacol. 117, 358. 


\section{GENERAL COMMENTS}

THE FOREGOING chapters have presented in detail various aspects of the phosphate metabolism of brain tissue, both in vitro and in vivo. The purpose of the present chapter is to comment briefly upon some of the general points which have not previously been discussed.

\section{Comparison of the Types of Information Obtained from Experiments in vivo and in vitro}

The ultimate object of any study of the metabolism of an organ is the detailed description of events taking place in the intact organ when functioning normally in vivo. The manner in which this description is given depends partly upon the orientation of the information obtained and in the present context is largely biochemical. At first sight it would appear most appropriate to carry out such studies under conditions closely approaching the normal functional state of the organ. Descriptions of ways in which this problem has been approached with respect to the brain in vivo, together with some of the results obtained formed the major part of Chapters 1 and 2. Attempts to relate metabolic changes to changes in functional activity have been made in two principal ways; either with animals subjected to operative procedures or with animals not so subjected. The first group comprises larger animals such as the cat or dog under anaesthesia the skull of which is opened, the brain exposed, and changes in functional activity following a given treatment are detected by means of the electroencephalograph. The second group comprises smaller animals such as the rat or mouse, which have been subjected to differing stimuli and the change in cerebral functioning detected by clinically recognizable signs. Though the animal in this condition might be considered to be in a state more physiological than one subjected to operation, nevertheless the latter has provided the bulk of the information relating a metabolic event in brain to a 
change in its functioning. Thus, the decrease in the levels of phosphocreatine induced by convulsants such as metrazole or by partial or complete anoxia, have been correlated with changes in the electrical activity of the cortex and have shown that the metabolism of phosphate derivatives is amongst the first detectable major biochemical events associated with such changes. Experiments with intact animals do not permit detailed studies of this type but nevertheless have provided confirmatory evidence that the changes noted do in fact take place as a result of procedures stimulating the brain. On the other hand changes induced by emotional excitation can be studied only in conscious animals. The ability to link a biochemical change with a functional change in the brain in vivo makes it appropriate that the study of new phenomena, the appraisal of different techniques, or the determination of quantities of new compounds should first be investigated at this level of tissue organization to provide the basic information necessary to further investigation with other preparations of brain.

It must be noted however that the nature of the technique involving freezing of almost the whole brain, permits as yet only a study of gross effects and the examination of details of metabolism is difficult. For example, only one experimental figure can usually be obtained from one animal, which can lead to considerable variability in the data, and the fixation of the brain in liquid air is not an immediate process, which renders difficult investigations of relative speeds of reaction. The use of radioisotopic phosphorus and other intermediates appears to offer little solution of some of these problems. Though intracisternal injection leads to a rapid accumulation of appreciable radioactivity the rate of entry into all parts of the brain is not uniform, and at the best, values calculated for metabolic rates can only represent a bottom limit for the actual rate of metabolism. It is therefore not altogether surprising that work in vivo has centred upon phosphates such as adenosine triphosphate, phosphocreatine, phosphoprotein and the cephalin diphosphoinositide, all of which incorporate radioactive phosphate to a marked extent in vivo. While this defect has perhaps operated advantageously in focusing attention upon those phosphates which are metabolically the most active, it serves to detract from others, such as certain of the phospholipids, whose apparent stability may be equally important to the normal functioning of the 
brain. In spite of these limitations, comparison of different treatments made in a standardized manner is possible provided suitable bases for comparison are chosen (see pp. 22-29).

Preparations of cerebral tissue in vitro permit a more detailed examination of the metabolic potential of the tissue but here also problems arise when cellular structure is disrupted. Intact cerebral slices retain many characteristics of the whole brain, amongst which the ability to respond metabolically to applied electrical stimulus, or to increased concentrations of potassium salts, is lost upon disintegration. Investigations of the relationships between metabolic changes and physical stimuli are therefore limited at present to the intact cell containing tissue. Nevertheless, the examination with such preparations of a wide variety of agents known to effect cerebral metabolism and function in vivo, has provided the closest parallels yet found between changes taking place in vivo and those in vitro. It has permitted the study both of the linkages between phosphate metabolism and applied stimulus and of the effects of therapeutic agents upon such metabolism. This type of study is not possible with disintegrated preparations which offer advantages over intact cerebral slices in the elucidation of synthesis and degradation and of the interactions of the various cellular constituents with one another. Choice of the level of tissue organization at which work is carried out is thus governed by the nature of the problems to be studied. Ideally, a problem is investigated at all three levels, though rarely by the same group of workers.

\section{Speed of Change of Labile Phosphates}

Possibly the most striking feature of phosphorus metabolism in the brain is the rapidity with which the levels of phosphocreatine and inorganic phosphate change in response to an applied stimulus. The rate of change of phosphocreatine in vivo has been calculated to be between 900-3000 $\mu$ moles $/ \mathrm{g} \mathrm{hr}^{-1}$; experiments in vitro suggest a more probable figure of $1500 \mu$ moles $/ \mathrm{g} \mathrm{hr}^{-1}$. The breakdown of phosphocreatine almost certainly precedes any event such as the increase in oxygen uptake which also follows a stimulus, and places changes in phosphate metabolism amongst the primary events involving a change in cerebral activity. It has also been shown that levels of adenosine triphosphate decrease markedly before changes in levels of phosphocreatine commenced. This 
sequence of events is fully in accord with the view that in brain, as in muscle, phosphocreatine serves largely to maintain normal levels of adenosine triphosphate. This view is strengthened by the observations that, in cerebral dispersions, the only reaction so far described for phosphocreatine is the phosphorylation of adenosine diphosphate to the triphosphate. In this respect, changes in the labile phosphates of cerebral tissue are similar to those found in muscle during contraction and rest but the analogy cannot be carried too far. In muscle the energy released appears largely as contractile work, but in the brain where contractile mechanisms are mainly absent the energy must be used for other purposes of which that of maintaining a continuous balance in the ionic shifts which give rise to fluctuating potentials detected by the electroencephalogram, probably requires the largest portion. Ideas expressing ways in which metabolically derived energy may be used for such a process in nervous tissue have been summarized in Fig. 14. In this sequence, the energy-rich phosphates of adenosine and creatine are linked metabolically with guanosine nucleotides and phosphoprotein, which in turn is considered to be linked to the mechanism transporting ions from one surface of a membrane to the other. When this mechanism is altered, for example by an externally applied potential, an increased rate of metabolism and turnover of phosphate occurs as the system endeavours to reattain equilibrium. The existence of a chain of reactions such as this affords a possible explanation of the effects in vivo of partial anoxia abolishing spontaneous cortical potentials while leaving levels of phosphocreatine unaffected.

A scheme somewhat similar to that of Fig. 14 has been discussed by Richter (Richter and Crossland, 1949; Richter, 1952) in which the breakdown of phosphocreatine is linked, via adenosine triphosphate, with the maintenance of adequate levels of acetylcholine. This type of sequence undoubtedly occurs, but it is unlikely that it accounts for more than a small part of the energy available. The greatest rate of breakdown of acetylcholine observed in vivo is some $5 \mu$ moles $/ \mathrm{g} \mathrm{hr}^{-1}$ and the rate of synthesis is less than this, though rates of up to $70 \mu \mathrm{moles} / \mathrm{g} \mathrm{hr}^{-1}$ have been obtained with preparations from the head of the blowfly (Hebb, 1957). These rates are to be compared with the rates of breakdown of phosphocreatine.

Although the mechanism linking the energy of the phosphate 
bond with ion transport is not known (for some suggestions see Davies and Krebs, 1952) it is likely to involve a variety of factors, amongst which the relative speeds of the reactions concerned are of some importance. It has been calculated (Sloane-Stanley, 1952) that for a tissue consisting of closely packed nerve fibres, similar to those of squid axon but all between 1 and 10 micron diameter a quantity of $10^{6} \mu$ moles of sodium/g wet wt. $\mathrm{hr}^{-1}$ would need to be transported. This rate is very considerably in excess of any reaction involving lipid metabolism which has so far been studied in brain and at the moment would appear to be a serious obstacle to interpretation of ion transport in terms of a lipid carrier molecule. Another discrepancy occurs between events such as the rise and fall of the action potential which may occupy $1 \mathrm{msec}$ or less and the rates of change in the levels of energy-rich phosphates which have been measured in seconds only. That the energy derived from the metabolism of, say, phosphocreatine, may be more than sufficient for the above processes to occur can be inferred from experiments upon Electrophorus electricus (Nachmansohn et al., 1943) in which it was found that the energy released during a discharge was only a quarter of that made available by the accompanying breakdown of phosphocreatine. It is unlikely that experiments of this type can be performed with cerebral tissues in vivo, for whereas the electrical energy derived from the electric fish is a summation from a series of cells discharging in a similar direction, the electrical energy of cerebral tissue measured across any large section is the summation of discharges many of which cancel one another out. In considering the above discrepancies, it is to be remembered that the speeds of the chemical reactions measured have been determined in arbitrary units, i.e. $\mu$ moles $/ g$ wet wt. tissue $\mathrm{hr}^{-1}$, which is not a true measure of enzymic activity. Estimated in this way, phosphate metabolizing systems of brain such as phosphocreatine phosphokinase and adenosine triphosphatase can split off or transfer the phosphorus of their substrates at 3600 and $2000 \mu$ moles $/ \mathrm{g} \mathrm{hr}^{-1}$ respectively. In terms of enzymic protein or of the weight of tissue occupied by the enzyme these rates are probably very much higher and further work on their localization, isolation and purification is needed. In this connexion, work aimed at analysing, and localizing enzyme action in microquantities of tissue or in individual nerve cells (see Lowry, 1957) is of major importance. 


\section{Phosphates as Regulatory Systems}

Evidence has been presented (p. 109) showing that the rates of oxygen uptake by cerebral preparations in vitro are governed both by the quantities of inorganic phosphate and of an acceptor such as adenosine diphosphate or creatine, which are present in the system at any one time. Suggestions have been made as to how these may operate in vivo. Thus, situations leading to a breakdown of phosphocreatine, by increasing the levels of inorganic phosphate, in turn permit metabolic activity and oxidative phosphorylation to increase until such time as the initial equilibrium is restored. Systems involving this type of change may therefore be regarded as self regulatory ones, the " pacemaker" reaction of which is the speed with which energy-rich phosphates are consumed. Viewed in this manner it seems unnecessary to regard metabolism which has been increased by various stimuli such as the addition of potassium salts to the medium, as being anything other than the speeding up of a metabolic process which is normally operating below its maximum potential.

Another "pacemaker" reaction involves the levels of oxidized and reduced diphosphopyridine nucleotide in cerebral tissues. It is well established that most of the energy-rich phosphate formed during metabolism is derived during the oxidation of reduced diphosphopyridine nucleotide and in normal tissues the ratio of the amount of the reduced to the oxidized coenzyme at any given moment, is likely to be a governing factor in the rate of this process. Maintenance of levels of reduced diphosphopyridine nucleotide is found to be assisted by the presence of an enzyme actively degrading the oxidized but not the reduced form of the nucleotide, thus presumably serving to maintain cerebral oxidations at a high rate. It might also be felt that a similar role could apply to the adenosine triphosphatase of cerebral tissues. Thus, by increasing the quantities of inorganic phosphate and adenosine diphosphate these enzymes could conceivably increase the rate of cerebral metabolism. There is little evidence either to suggest or deny such a role. It has been suggested that the enzymes are in fact phosphokinases transferring phosphate either from adenosine triphosphate to some other substrate, or phosphorylating adenosine diphosphate to the triphosphate in the intact tissue (Myers and Slater, 1957). 
Considerations such as the above indicate a delicate balance operating between the levels of the phosphates, the activity of the enzymes involved in their degradation and synthesis and the general metabolic activity of the tissue. Disturbances in this balance may be expected to have a marked effect upon the functional activity of nervous tissue and this account by comparing results obtained both in vivo and in vitro has illustrated some of these interconnexions in different ways. It is clear that work, as yet, is proceding only from one end of a reaction sequence, few steps of which are known. It is to be hoped that elucidation of such processes, in leading to an understanding of the way in which metabolic defects produce functional defects will also lead to suitable ways of overcoming them.

\section{REFERENCES}

Davies, R. E. and Krebs, H. A. (1952) Symp. Biochem. Soc. No. 8, 77. Hebi, C. O. (1957) Physiol. Rev. 37, 196.

Lowry, O. H. (1957) in Metabolism of the Nervous System, p. 323 (Ed. by D. Richter), Pergamon Press, London \& New York.

Myers, D. K. and Slater, E. C. (1957) Biochem. F. 67, 558.

Nachmanson, D. Cox, R. T., Coates, C. W. and Machado, A. L. F. Neurophysiol. 6, 383.

Richter, D. (1952) Symp. Biochem. Soc. No. 8, 62.

Richter, D. and Crossland, J. (1949) Amer. F. Physiol. 159, 247.

Sloane-Stanley, G. H. (1952) Symp. Biochem. Soc. No. 8, 77. 


\section{ANALYSIS OF CEREBRAL TISSUES FOR PHOSPHATE DERIVATIVES}

THE DETERMINATION of phosphorus derivatives in cerebral tissues presents special problems. The quantities of many of the phosphates are small in comparison with those of other tissues and the amounts of tissue available particularly from experiments in vitro is usually limited to some $100-300 \mathrm{mg}$ wet wt. The presence of large quantities of phospholipids can complicate the preparation of suitable extracts. The following is an account, based on the writer's experience, of the various methods employed in the analysis of cerebral phosphates. No attempt has been made to describe analytical methods in detail, for which the original papers should be consulted.

Surveys of some analytical methods have been given by Le Page (1948, 1957), Stone (1948), Lindberg and Ernster (1956), and Mommaerts (1958).

\section{Preparation of Tissues}

The rapid changes in cerebral phosphates consequent upon death can be avoided if the brain in vivo is rapidly frozen and removed while in this state. Small animals such as the mouse, rat or guinea pig can be frozen by dropping into liquid nitrogen contained in a wide mouthed vacuum flask (Le Page, 1957; Dawson and Richter, 1950). The body weight should not be in excess of $100 \mathrm{~g}$ unless dictated by special circumstances. In the latter case volumes of liquid nitrogen of 1-2 1. are required for each animal. The low temperature of the coolant $\left(-180^{\circ}\right)$ provides an excellent temperature gradient and the coolant does not contaminate the preparation. Most use has been made of this method though where liquid air or nitrogen are not readily available, drowning in a mixture of acetone and solid carbon dioxide (Le Page, 1946; Lindberg and Ernster, 1950; Abood, 1956) would appear to be a satisfactory alternative. Le Page recommends light 
anaesthetization before freezing though this is not always used, and may mask the effects being studied. Decapitation into liquid air is a procedure which contains the risk of breakdown of labile phosphates in the time intervening between severance of the head and its immersion in the coolant, but has been used successfully by various authors (cf. Kratzing and Narayanaswami, 1953; Gerlach et al., 1958). Large animals such as the cat, dog or monkey are first anaesthetized and the brain exposed by operative procedures before pouring on liquid air or nitrogen (Kerr, 1935; Klein and Olsen, 1947). The use of a carbon dioxide-ethyl chloride mixture yielded variable and somewhat lower values for phosphocreatine in cat brain than did the use of liquid air (Kerr, 1935). Generally, freezing in situ is the technique to be preferred for an examination of the levels of labile phosphates in the brain of rabbits determined in this manner, and in the samples removed and transferred as rapidly as possible to liquid air with a sharp, prechilled spoon, revealed that even the briefest time lapse was sufficient to permit considerable changes to have taken place (Table 24).

The whole of the brain is not frozen immediately. Thus, it takes about $16 \mathrm{sec}$ to freeze completely the brain of a small animal and as long as $30 \mathrm{sec}$ to freeze the brain of larger animals to a depth of $1 \mathrm{~cm}$ (Richter, 1950). It seems probable that the blood supply to the interior of the brain continues at the normal rate while the wave of freezing is spreading from the cortex, thus preventing anoxia. The intense cold is considered to block nervous transmission so that no stimulation occurs. Whatever the mechanisms

Table 24.-The Effect upon Levels of Cerebral Phosphates of Two Different Procedures for the Fixation of Brain Samples

(Quantities are in $\mu$ moles/g wet wt.)

\begin{tabular}{l|c|c}
\hline \multicolumn{1}{c|}{ Phosphate } & $\begin{array}{c}\text { Brain frozen } \\
\text { in situ }\end{array}$ & $\begin{array}{c}\text { Sample transferred } \\
\text { to liquid air with a } \\
\text { prechilled spoon }\end{array}$ \\
\hline Adenosine triphosphate & $2 \cdot 0-2 \cdot 2$ & $1 \cdot 8-2 \cdot 0$ \\
Adenosine diphosphate & $0 \cdot 5$ & $0 \cdot 5$ \\
Phosphocreatine & $3 \cdot 0$ & $1 \cdot 8-2 \cdot 0$ \\
Inorganic phosphate & $3 \cdot 0$ & $4 \cdot 5-5 \cdot 0$ \\
Fructose-1 : 6-diphosphate & $0 \cdot 05$ & $0 \cdot 15-0 \cdot 20$ \\
\hline
\end{tabular}

Data from Thorn et al. (1958), rabbit. 
involved in preventing change the method yields high values for the quantities of phosphocreatine, approaching those found in anaesthetized animals, and low values for the quantities of cerebral lactic acid, both of which change markedly within a few seconds when the brain is stimulated. After freezing, the brain can be chiselled out with precooled chisels before further extraction. During removal it is desirable that it be cooled at frequent intervals by returning the animal to the liquid air. With coolants such as acetone-carbon dioxide such a procedure is likely to contaminate the tissue.

\section{Extraction of the Tissues}

Breakdown of labile phosphates is avoided if the denaturation of the proteins and extraction of the phosphates is rapid. This is assisted if the lumps of tissue are powdered while frozen. An apparatus designed for this purpose has been described by Le Page (1948). Alternatively an ordinary pestle and mortar precooled in liquid nitrogen have proved successful. The sample is cooled in the mortar by covering with liquid nitrogen. When this has boiled off the tissue can be powdered by striking the pestle with a hammer. The powdered residue is transferred rapidly to a weighed, cooled homogenizing tube containing extractant at $0-2^{\circ}$ and immediately ground with the homogenizing pestle. Speed is essential for it has been shown that the rate of penetration of the extractant into the frozen tissue is insufficient to prevent extensive breakdown of phosphocreatine and adenosine triphosphate if the lumps of brain are simply allowed to thaw in the extractant before grinding (Table 25). These problems do not arise with tissue slices which appear to be fixed, as judged by overall change of colour, within 1-2 sec of immersion into trichloracetic acid. Presumably the thinness of the slice permits rapid penetration.

The extractants most widely, used are trichloracetic acid $(10 \% \mathrm{w} / \mathrm{v})$, perchloric acid $(19 \% \mathrm{w} / \mathrm{v})$ and, when very labile phosphate esters, such as acetyl phosphate, are to be studied, a saturated solution of ammonium sulphate, buffered at $\mathrm{pH} 4 \cdot 0$ with sodium acetate-acetic acid (Lowry and Lopez, 1946). The removal of glycogen from extracts made in trichloracetic acid (Le Page, 1957; Sacks, 1949; Kaplan and Greenberg, 1944) before fractionating the phosphates is only rarely practised with extracts of cerebral tissues where the glycogen level is about $4.0 \mu$ moles $/ g$ 
wet wt. (Chance and Yaxley, 1950; Le Baron, 1955). A more probable source of error lies in the large amounts of phospholipid which is present in fine suspension in extracts made with trichloracetic acid. This is not removed by centrifuging in fields of up to $3000 \mathrm{~g}$, the field normally obtainable in average centrifuges. For complete removal a field of $12-20,000 \mathrm{~g}$ for $10-15 \mathrm{~min}$ is necessary (Heald, 1956a). Failure to remove the phospholipids can lead to difficulties in constructing a balance sheet for the total phosphates present in the extracts. In this respect perchloric acid appears to possess a distinct advantage for it has been found (Dr. G. H.

Table 25.-Effect upon Labile Phosphates of Thawing Frozen Brain Tissue in Trichloracetic Acid before Grinding

(Quantities are in $\mu$ moles/g wet wt. \pm the S.E.M.)

\begin{tabular}{l|c|c}
\hline \multicolumn{1}{c|}{ Phosphate } & $\begin{array}{c}\text { Tissues frozen and } \\
\text { ground immediately } \\
\text { in denaturant }\end{array}$ & $\begin{array}{c}\text { Tissue allowed to } \\
\text { thaw in denaturant } \\
\text { before grinding }\end{array}$ \\
\hline Phosphocreatine & $3 \cdot 21 \pm 0.05$ & $1 \cdot 10 \pm 0 \cdot 2$ \\
Adenosine triphosphate & $2.58 \pm 0.07$ & $0.79 \pm 0 \cdot 12$ \\
Adenosine diphosphate & $0.99 \pm 0.09$ & $1.36 \pm 0.04$ \\
Adenosine monophosphate & $0.46 \pm 0.06$ & $0.63 \pm 0.04$ \\
\hline
\end{tabular}

Data from Lin et al. (1958).

Sloane-Stanley, personal communication) with this extractant that centrifuging at low speeds yields a supernatant free from phospholipid. A further advantage is that the potassium salt is insoluble at $0^{\circ}$ enabling the extractant to be easily removed by centrifuging after neutralization. This is important when enzymic methods of analysis are subsequently used. However, the major analytical procedures still widely adopted depend upon preliminary fractionation of the extracts. Such fractionation methods were developed specifically for use with extracts made in trichloracetic acid and similar extensive studies have not been reported with extracts made in perchloric acid. Trichloracetic acid may be removed by extraction with ethyl ether without any apparent loss of phosphorus. Whichever extractant is used its removal is essential before analysis of the phosphates either by enzymic, chromatographic or ion exchange techniques. 
Fractionation of Phosphates in the Extracts

The methods of fractionation adopted depend largely upon the problem being investigated. Generally interest has concentrated upon inorganic phosphate, phosphocreatine, and adenosine di- and triphosphate. However, with the recognition of the presence of numerous nucleotides and other phosphorylated derivatives the problems of complete fractionation of the phosphates in acid extracts

Trichloracetic acid extract 、

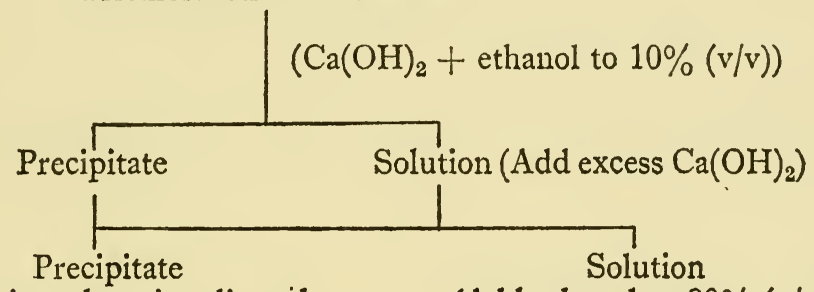

(Contains adenosine di- and triphosphates, inorganic phosphate, hexose phosphates)

(Add ethanol to $80 \%(\mathrm{v} / \mathrm{v})$ )

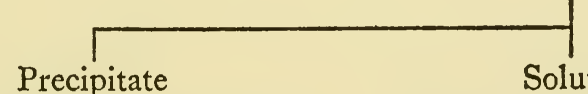

(Contains phosphocreatine and unidentified phosphates)

(Ethanol soluble phosphorusi)

FIG. 18. Outline of a scheme for the fractionation of acid-soluble phosphates of brain (Stone, 1943).

have become more acute. Usually such a separation is not necessary; simple separation into groups being sufficient for most purposes.

The early procedures for the separation of the calcium salts of the phosphates developed by Stone $(1940,1943)$ specifically for use with extracts of cerebral tissues have been widely applied by many workers. The later method is illustrated in Fig. 18. The groups of phosphates obtained are heterogeneous but the separation of adenosine triphosphate + inorganic phosphate from phosphocreatine is good. The fraction with calcium salts soluble in $10 \%$ $(\mathrm{w} / \mathrm{v})$ aqueous ethanol is complex and contains many components, the total phosphorus of which exceeds in amount the phosphocreatine present. It is reported (Bodian and Dzeiwiatkowski, 1951) 
that the calcium fractionation procedure completely separates radioactive orthophosphate from the fraction containing phosphocreatine. Successful adaptations of this technique for the analysis of phosphocreatine and inorganic phosphate in small quantities (100-200 mg) of tissue have been described (McIlwain, 1951; Kratzing and Narayanaswami, 1953).

An alternative fractionation procedure based upon the differing solubility of the barium salts of the phosphates was developed by Le Page $(1948,1957)$. The essential features are summarized in Fig. 19. Certain points need careful attention. The amount of barium acetate added needs defining for each system studied particularly where the quantities and concentrations of the phosphates differ from those used by Le Page. A second point concerns

Trichloracetic acid extract

Adjust to $\mathrm{pH} 8.4$, add excess barium acetate

Precipitate

(Take up in $0.1 \mathrm{~N} \mathrm{HC1}$ and reprecipitate)

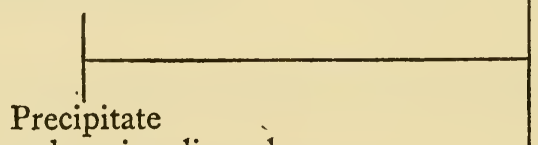

(Contains adenosine di- and triphosphates, hexose diphosphate,

3-phosphoglyceric acid)

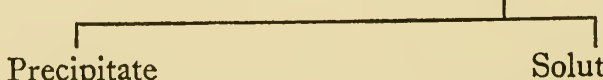

(Contains phosphocreatine, hexose monophosphates, di- and triphosphopyridine nucleotide, (Contains propane diol (Add ethanol to $75 \% \mathrm{v} / \mathrm{v}$ Adjust to $\mathrm{pH} 8.4$ ) adenylic acid, triose phosphates)

FIG. 19. Outline of a scheme for the fractionation of acid-soluble phosphates of brain (Le Page, 1957). 
the use of sodium hydroxide to adjust the $\mathrm{pH}$ of the extract. It has been reported that under such conditions inorganic phosphate and adenosine triphosphate are incompletely precipitated by barium acetate (Kosterlitz and Ritchie, 1943; Ennor and Stocken, 1945), the precipitation being more complete either at a $\mathrm{pH}$ higher than $8.2-8.4$ or if potassium hydroxide was used to adjust the $\mathrm{pH}$ instead of sodium hydroxide. Although it has been considered that the barium fractionation method leaves appreciable quantities of adenosine triphosphate and inorganic phosphate in solution (Stone, 1948; Gurdjian et al., 1947) it has been found that the adjustment of the $\mathrm{pH}$ with potassium hydroxide and the addition of a large excess of barium acetate results in a quantitative precipitation of adenosine triphosphate (cf. Ennor and Stocken, 1948). With small quantities of tissue (100-400 mg wet wt.) the precipitation of inorganic phosphate is incomplete, some $5-10 \%$ being carried over into the phosphocreatine fraction. It is now well recognized that removal of inorganic phosphate by precipitation as the magnesium ammonium complex is incomplete and that the precipitate absorbs up to $40 \%$ of the adenine nucleotides present (Friedkin and Lehninger, 1949; Abood and Gerard, 1952). Also, since both the calcium and barium procedures do not precipitate all the inorganic phosphate, use of these techniques in the determination of radioactivity of phosphocreatine is likely to lead to high and variable results.

Nucleotides may be quantitatively precipitated from extracts made in trichloracetic acid, as the mercury salts (Kerr, 1942). The precipitate also contains nucleosides and free purines. Nucleotides alone are precipitated with uranyl acetate (Kerr and Seraiderian, $1945 a, b)$, purines and nucleosides being separated from the supernatant solution by precipitation of the silver salts under acid and alkaline conditions. The procedure has been adapted for use with $200 \mathrm{mg}$ of cerebral tissues (Thomas, 1957). It has not been examined from the point of view of precipitation of nucleotides other than those of adenine and guanine, but seems capable of development for the examination of nucleotides in systems metabolizing radioactive phosphate since inorganic phosphate is either not precipitated or the traces present can be readily removed. Whatever method of fractionation is selected it is important to keep to the concentrations of reactants and the tissue/extractant ratios recommended by the original authors. The methods are not 
suitable for work with radioactive phosphate and require supplementation by chromatographic techniques to avoid the errors introduced by the overlapping of various fractions and contamination with radioactive inorganic phosphate.

\section{Chromatographic Methods}

Application of chromatographic methods to the separation of the acid-soluble phosphates of the brain has developed over the past 4-5 years. Since the individual investigators have been concerned with specific problems no general scheme resolving all the major phosphates has been described. After a preliminary fractionation by the barium procedure followed by the removal of barium with anion exchange resins, electrophoresis on paper of the free phosphates or their ammonium salts yields phosphates free from contamination with inorganic phosphate (Heald, 1956a). Under these conditions adenosine nucleotides were separable from inorganic phosphate and phosphocreatine, while phosphocreatine, adenylic acid, the hexose monophosphates and inorganic phosphate were separable from one another and from the phosphopyridine nucleotides. Cross contamination with inorganic phosphate was negligible. The method provides an unequivocal separation and identification of phosphocreatine, which is separated at an alkaline $\mathrm{pH}$ and does not decompose, and has proved valuable for work involving radioactive phosphate (Heald, 1956b). The method appears capable of extension by elution of the phosphates from the paper followed by further separation by different chromatographic techniques. The fraction containing adenosine triphosphate is now known to contain guanosine nucleotides and separation of the two groups and inorganic phosphate may be achieved first by chromatographing on paper in the acid solvent of Eggleston and Hems (1952), which remove inorganic phosphate from the mixture, followed by an alkaline propanol solvent to separate the adenosine from the guanine nucleotides (Heald, 1957b). The nucleotide di- and triphosphates are not separated by this method. A more complete separation of nucleotides upon paper has been described (Doring and Gerlach, 1957; Gerlach et al., 1958), adenosine mono-, di-and triphosphates being separated from one another and from guanosine di- and triphosphates. These latter were also separated from one another but the guanosine phosphate diphosphate fraction contained some uridine triphosphate. The separations 
were made upon portions of the total trichloracetic acid extracts of cerebral tissues and since the nucleotides were detected with ultra-violet light, the position of inorganic phosphate and other phosphates is not clear. The method appears to be a good one and has been used to study changes in the nucleotides in brain in vivo following anaesthesia, ischaemia and anoxia.

The detailed separation of nucleotides and nucleosides and derivatives upon ion exchange columns described by Schmitz et al. (1954) has not yet been applied extensively (see however Mandel and Harth, 1958) probably owing to the length of time involved in a single run. However, the basic procedure is simple and offers considerable scope for the detection and isolation of new nucleotides and derivatives (Koransky, 1958). It is to be noted that the extract containing the acid-soluble nucleotides also contains phosphocreatine, inorganic phosphate and the hexose and triose phosphates, and the position of these relative to the nucleotides in the eluants from such columns have not yet been determined. A separation of phosphocreatine and the hexose phosphates upon a resin column has been described by Abood (1956). Extracts were absorbed on Dowex-1-formate and eluted with formic acid. Separation of inorganic phosphate, phosphocreatine, adenosine mono-, di- and triphosphates, glucose-6-phosphate and fructose$1: 6$-diphosphate was achieved. The analytical figures for phosphocreatine in brain $(4.25 \mu$ moles/g) appear to be higher than normally found but the separation yielded this phosphate free from contamination with radioactive inorganic phosphate. A similar separation of adenosine mono-, di- and triphosphates, phosphocreatine and inorganic phosphate from brain extracts has been described by Lin et al. (1958).

Although many basic methods have been described for the separation of hexose phosphates and derivatives by means of paper chromatography or ionophoresis (Hanes and Isherwood, 1949; Bandurski and Axelrod, 1951; Ganguli, 1953; Lindberg and Ernster, 1956; Wade and Morgan, 1956; Schwimmer et al., 1956), application to the analysis of cerebral extracts has not been extensive. Tower (1958) found that the separation of hexose and pentose phosphates from trichloracetic acid extracts of cerebral slices was readily achieved. The phosphates were first precipitated as the barium salts and, after removal of barium by cation exchange resins, were separated by descending chromatography in an acetic 12-PMB 
acid-amyl acetate solvent. Provided the conditions of separation have been acidic, phosphates on the paper can readily be made visible by means of an acetylsalicylic acid + ferric chloride reagent (Wade and Morgan, 1953). This reagent possesses the advantage of not degrading phosphates such as adenosine triphosphate which can be eluted intact from the paper after detection.

\section{Analysis of Phosphates}

\section{Chemical Methods}

Inorganic phosphate.-In extracts of tissue inorganic phosphate can be determined directly by the method of Lowry and Lopez (1946). This involves the measurement of the blue colour developing upon the reduction of phosphomolybdate with ascorbic acid at $\mathrm{pH} 4 \cdot 0$. By careful choice of the strengths of the reagents the method can be kept sensitive to inorganic phosphate without hydrolysing labile phosphates. Many extracts inhibit the reaction. This can be overcome either by diluting some $10-100$ fold as recommended by Lowry and Lopez or by the inclusion of $\mathrm{Cu}^{++}$ ions in the reaction mixture to a final concentration of $5 \times 10^{-4} \mathrm{M}$ (Peel, 1955; Furchgott and Gubareff, 1956). With copper ions present, dilution of the extract by a factor of 5 is the maximum needed. Extracts made in trichloracetic acid or perchloric acid require adjustment to neutrality either using an external indicator or by adding a predetermined quantity of alkali before sampling for the final analysis.

A method most widely used is that of Fiske and Subbarow (1925, see Le Page, 1957) which is fully adequate when applied to extracts of cerebral tissues. Inorganic phosphate must first be separated from phosphocreatine by means of the calcium salt. The chief disadvantage is the relatively large quantity of phosphate required (range $4-40 \mu \mathrm{g}$ ) necessitating $0.3-0.5 \mathrm{~g}$ cerebral tissue. With experiments in vitro this is equivalent to 3-4 slices. A more sensitive method is that of Berenblum and Chain (1938) which has been modified so that estimations can be carried out in a single tube (Long, 1943). This method involves the extraction of phosphomolybdate from acidic solution into isobutanol and the reduction of the inorganic complex with stannous chloride. The extraction is extremely rapid and complete at $0^{\circ}$ and separates inorganic phosphate from many substances likely to interfere in the final 
reduction. With solutions containing protein the $i$ sobutanol can be separated by centrifugation and then removed to a separate tube or the protein may first be precipitated by silico-tungstate as described by Martin and Doty (1949). The latter authors use a mixture of isobutanol/benzene as extractant. Under the conditions of extraction phosphocreatine is not broken down (Ernster et al., 1950) and the method may be used to estimate inorganic phosphate in the presence of this ester. The stability of other phosphates under these conditions has been described by Weil-Malherbe and Green (1951). With extracts made in perchloric acid, isobutanol is apparently not so effective in removing the phosphomolybdate complex and can be replaced by isopropanol (Wahler and Wollenberger, 1958). If phosphocreatine is also to be estimated, inorganic phosphate is first separated by means of the barium fractionation procedure, the residue being dissolved in $0.1 \mathrm{~N} \mathrm{HCl}$ before the final estimation. The method is extremely sensitive and has been used with samples of brain weighing 50-100 mg (Heald, 1954; Bollard and McIlwain, 1959).

\section{Phosphocreatine}

Phosphocreatine is usually determined by methods depending upon the lability of the phosphate group in acid solution. In the methods described by Le Page (1957) and Stone (1948) it is calculated as the difference between the total inorganic phosphate determined by incubating extracts for 20-30 min under acid conditions and the inorganic phosphate determined by the calcium precipitation technique. A procedure based upon the LowryLopez technique has been described using the same principle (Furchgott and Gubareff, 1956). The method is sensitive and has been used with $50 \mathrm{mg}$ of tissue. An alternative procedure for use with small quantities of cerebral tissues involves a preliminary removal of inorganic phosphate as the barium salt followed by acidification of the extracts and incubation at $25^{\circ}$ with molybdate solution. Under these conditions, phosphocreatine is quantitatively hydrolysed in $30 \mathrm{~min}$ (Ernster et al., 1950) and the inorganic phosphate released is estimated by the modified Berenblum and Chain procedure (Heald, 1954). Separation of inorganic phosphate is considered to be a necessary preliminary since use of the direct extraction method for inorganic phosphate followed by hydrolysis of phosphocreatine at $30^{\circ}$ in the same solution tends to yield 
values for phosphocreatine higher than found by other methods. A third alternative involves the precipitation of the calcium or barium salts of phosphocreatine with ethanol and estimation as creatinine formed in the Jaffe reaction (McIlwain, 1951) or as creatine, liberated upon acid hydrolysis of the residue under standard conditions, by means of the colour reaction with $\alpha$-naphthol and diacetyl (Ennor and Rosenberg, 1952). Estimations based upon determinations of creatine require appreciable quantities of tissue $(0 \cdot 3-1 \cdot 5 \mathrm{~g})$ the latter method requiring the least (Heald, 1956a).

With cerebral tissues metabolizing glucose the above methods have yielded similar values for phosphocreatine indicating that the phosphorus determined actually arises from phosphocreatine and not from labile esters such as phosphopyruvic acid or acetyl phosphate (Weil-Malherbe and Green, 1951). The values also agree with values obtained by ionophoretic and enzymic techniques.

\section{Adenosine Di- and Triphosphates}

Chemical methods are generally based upon the release of inorganic phosphate when the polyphosphates are hydrolysed in $N$ acid for $10 \mathrm{~min}$ at $100^{\circ}$. Since the fraction containing the nucleotides is usually obtained by precipitation as the calcium or barium salts, this involves a correction for the inorganic phosphate present. Provided only small quantities of the diphosphate is present, the method is fairly reliable. To estimate adenosine diand triphosphate by this method the ratios of the acid hydrolysable phosphate and the ribose content are determined and used to calculate the percentage of each phosphate. This method is not particularly accurate and has been stated to yield errors of $20-30 \%$ in the values so obtained (Block and Alberty, 1951). Better methods involve estimation by chromatographic or enzymic techniques (see below). Nucleotides other than those of adenosine have been only recently recognized and the chromatographic methods used for identification also serve as a means of estimation by determining the absorption of fractions at $260 \mathrm{~m} \mu$.

\section{Total Phosphorus}

Various methods have been proposed. All involve the removal of organic material by wet oxidation followed by the determination of the inorganic phosphate formed in solution. Digestion with concentrated sulphuric acid and hydrogen peroxide (Le Page, 
1957) has been largely replaced by perchloric acid (King, 1932; see Lowry et al., 1954). When large amounts of organic material are present, as in extracts containing phospholipids or in strips of paper cut from chromatograms, the sulphuric acid-perchloric acid digestion mixture of Hanes and Isherwood (1949) has proved very suitable. Explosions, occasionally obtained with perchloric acid alone, have not occurred and digestion of the last traces of carbon can be assisted by the cautious addition of hydrogen peroxide without excessive risk. Since the mixture contains sulphuric acid, dilution and hydrolysis of the pyrophosphates formed is necessary (Heald, 1956a). Inorganic phosphate in the solution can then be estimated by the modified Berenblum and Chain procedure.

\section{Enzymic Methods}

Sensitive methods for the analysis of cerebral extracts for adenosine di- and triphosphates, phosphocreatine, di- and triphosphopyridine nucleotides, hexose phosphates, fructose-1 : 6-diphosphate, pyruvic acid and triose phosphates have been described (Kratzing and Narayanaswami, 1953; Thorn et al., 1955; Glock and McLean, 1955; Tower, 1958).

With the exception of methods for the determination of di- and triphosphopyridine nucleotides the other phosphates are determined by reactions involving the production of reduced or oxidized diphosphopyridine nucleotide and measurement of the change in absorption. In the method of Kratzing and Narayanaswami (adapted from that of Slater 1953) adenosine diphosphate and phosphocreatine are determined by difference. Adenosine triphosphate is determined directly after conversion of the $\gamma$-phosphorus to glucose-6-phosphate. This process appears to be specific since guanosine triphosphate is not determined by the hexokinase reaction (Sanadi et al., 1954). The methods of Thorn et al. estimate adenosine di- and triphosphates in separate reactions. Since both procedures also include certain intermediates such as phosphopyruvate in the values determined corrections must be applied. Normally, with cerebral tissues such corrections are low. Hexose phosphates have been estimated by conversion of fructose-6-phosphate to glucose-6-phosphate by hexose phosphate isomerase followed by the determination of glucose-6-phosphate by glucose-6-phosphate dehydrogenase (Tower, 1958; cf. Thorn et al., 1955). Glucose-6-phosphate was determined directly by 
the same reaction. Methods somewhat similar to those of Tower and Thorn et al. have been described by Morton (1958) but have not yet been applied to tissue extracts. The di- and triphosphopyridine nucleotides are estimated by coupling with cytochrome- $c$ reductase and measuring the rate of reduction. The oxidized forms are reduced by alcohol dehydrogenase and glucose-6-phosphate dehydrogenase. In this latter determination the nucleotides were extracted with hot $0 \cdot 1 \mathrm{NHCl}$, or $0 \cdot 1 \mathrm{~N} \mathrm{NaOH}$ (Glock and McLean, 1955). In the other methods extracts were made either in perchloric acid, most of which was removed as the potassium salt before analysis, or in trichloracetic acid which was later removed with ether.

The use of enzymes has provided a specific method for the estimation of radioactivity in the $\gamma$-phosphorus of adenosine and guanosine nucleotides. This is particularly valuable when investigating rates of incorporation of radioactive phosphate. The nucleotides are first separated by paper chromatography or ionophoresis, eluted from the paper and incubated with a potato apyrase preparation made according to the method of Lee and Eiler (1951) under the conditions described by those authors. At low temperatures, $2-7^{\circ}$, only the $\gamma$-phosphorus of adenosine or guanosine triphosphate is removed. This can be estimated as inorganic phosphate by the modified Berenblum and Chain technique, and counted for radioactivity in the same solution (Heald, 1956b).

\section{Analysis of Phosphates Insoluble in Acid Extractants}

'The writer's experience here has been with the separation of phosphates in the non-phospholipid fraction. Methods of analysis of phospholipids have been described by Sperry (1955), Lovern (1955) and Lees (1957). Details of the separation of phospholipids into groups by chromatography upon silicic acid, and methods of analysis of some of the fractions obtained have been described by Hanahan et al. (1957), Dittmer et al. (1955), Lea and Rhodes (1953, 1954), and Rhodes and Lea (1957), and the limitations of such methods have been noted (Barron and Hanahan, 1958). Analysis by preliminary separation into groups, alkaline hydrolysis and subsequent separation of the glyceride fractions by paper chromatography (Dawson, 1954) has been extensively used to study the metabolism of radioactive phosphate in cerebral lipids. 
Generally phospholipids are removed either by heating with mixtures of ether and ethanol, or preferably by the chloroformmethanol mixture of Folch et al. (1951) which appears to be the most effective as regards cerebral tissues both for completeness and extreme rapidity. The tissue remaining is then analysed for nucleic acids, phosphoproteins and residual organic phosphorus by differing methods. These have been critically assessed by Logan et al. (1952). When cerebral tissues are analysed for nucleic acids by the methods of Schneider (1946) or Schmidt and Thanhauser (1945) ribose nucleic acid is heavily contaminated with phosphorus from other fractions, though a reliable value is obtained for desoxyribonucleic acid. The difficulty can be overcome if the urea-saline method of Hammarsten (1947) is used (Strickland, 1952) when only nucleic acids are extracted. These are fractionated by copper precipitation methods. An alternative method for estimating the total nucleic acids involves the determination of the ultra-violet absorption of extracts prepared by the Schneider method (Logan et al., 1952). The residue remaining after removal of the nucleic acids is complex and is either reextracted with trichloracetic acid according to the Schneider procedure (Strickland, 1952), to remove the last traces of nucleic acids or else digested with normal $\mathrm{NaOH}$ at $37^{\circ}$ for $18 \mathrm{hr}$ according to the Schmidt-Thanhauser method. On acidification of the digest. a precipitate of an unidentified phosphate is obtained (probably containing a little DNA). The supernatant contains inorganic phosphate from the phosphoproteins and the remaining phosphorus compounds collectively known as " residual organic phosphorus".

Considerable care is needed when studying the metabolism of such groups of phosphates by means of radioactive phosphorus since traces of inorganic phosphorus adhering to the tissue residues appear in the various fractions. After precipitation with trichloracetic acid the residue must be washed five or six times with fresh trichloracetic acid, sometimes containing added inorganic phosphate as an inactive carrier (Strickland, 1952; Heald, 1957a). If this procedure does not remove all traces of added radioactivity the samples of radioactive phosphate are suspect. In such cases treatment as described by Ennor and Rosenberg (1954) has usually proved effective in reducing the source of error. The phosphoprotein fraction, estimated as inorganic phosphate, is particularly prone to contamination of this 
type. Phospholipids can be washed free of inorganic phosphate either with $0.25 \mathrm{M} \mathrm{MgCl}_{2}$ (Dawson, 1954) or, if extracts are made in chloroform-methanol, by use of a saline resembling the upper phase of a mixture of the extractant and $0.2 \mathrm{vol}$ of $0.03 \mathrm{M} \mathrm{NaCl}$ (Folch et al., 1954).

\section{REFERENCES}

Aвоod, L. G. (1956) Science 123, 545.

Aвood, L. G. and Gerard, R. W. (1952) Amer. F. Physiol. 168, 739.

BANDurski, R. S. and AXELrod, B. (1951) F. biol. chem. 193, 405.

Barron, E. J. and Hanahan, D. J. (1958) F. biol. chem. 231, 493.

Berenblum, I. and Chain, E. B. (1938) Biochem. F. 48, 6.

Block, R. M. and Alberty, R. A. (1951) F. biol. chem. 193, 435.

Bodian, D. and Dziewiatkowski, D. (1950) f. cell. comp. Physiol. 35, 155.

Bollard, B. and McIlwain, H. (1959) Biochem. Pharmacol. 2, 81.

Chance, M. R. A. and Yaxley, D. C. (1950) F. exp. Biol. 27, 311.

Dawson, R. M. C. (1954) Biochem. F. 57, 237.

Dawson, R. M. C. and Richter, D. (1950) Amer. F. Physiol. 160, 203.

Dittmer, J. C., Feminella, J. L. and Hanahan, D. J. (1958) F. biol. chem. 233, 862.

Doring, H. J. and Gerlach, E. (1957) Arch. exp. Pathol. Pharmacol. 232, 27.

Eggleston, L. V. and Hems, R. (1952) Biochem. F. 67, 529.

EnNor, A. H. and Rosenberg, H. (1952) Biochem. F. 51, 606.

Ennor, A. H. and Rosenberg, H. (1954) Austr. F. exp. biol. Med. Sci. 32, 701.

EnNoR, A. H. and Stocken, L. A. (1948) Biochem. F. 42, 519, 547.

Ernster, L., Zetterstrom, R. and Lindberg, O. (1950) Acta. chem. Scand. 4, 942.

Fiske, R. H. and Subarow, Y. (1925) F. biol. chem. 66, 375.

Folch, J., Ascoli, I., Lees, M., Meath, J. A. and Le Baron, F. N. (1951) F. biol. chem. 191, 833.

Folch, J., Lees, M. and Sloane-Stanley, G. H. (1954) Fed. Proc. 13, 209.

Friedkin, M. and Lehninger, A. C. (1949) F. biol. chem. 177, 775.

Furchgott, R. F. and DE GubarefF, T. (1956) $\mathcal{F}$. biol. chem. 223, 377.

Ganguli, N. C. (1953) Naturwiss. 40, 624.

Gerlach, E., Doring, H. J. and Fleckenstein, A. (1958) Pflügers Archiv. 266, 266.

Glock, G. E. and McClean, D. (1955) Biochem. F. 61, 381.

Gurdjian, E. S., Webster, J. E. and Stone, W. E. (1947) Assoc. research nerv. ment. dis. 26, 184.

Hammarsten, E. (1947) Acta. med. Scand. 128, Suppl. 196, 634.

Hanahan, D. J., Dittmer, J. C. and Warashima, E. (1947) F. biol. chem. 228, 685.

Hanes, C. S. and Isherwood, F. A. (1949) Nature, Lond. 164, 1107. 
Heald, P. J. (1954) Biochem. F. 57, 673.

Heald, P. J. (1956a) Biochem. F. 63, 235.

Heald, P. J. (1956b) Biochem. F. 63, 242.

Heald, P. J. (1957a) Biochem. F. 66, 659.

Heald, P. J. (1957b) Biochem. F. 67, 529.

Kaplan, N. O. and GreenberG, D. M. (1949) $\mathcal{F . ~ b i o l . ~ c h e m . ~ 1 5 6 , ~} 511$.

KERR, S. E. (1935) F. biol. chem. 110, 625.

KERR, S. E. (1942) F. biol. chem. 145, 647.

Kerr, S. E. and Seraidarian, K. (1945a) f. biol. chem. 159, 211.

Kerr, S. E. and Seraidarian, K. (1945b) F. biol. chem. 159, 637.

KING, E. J. (1932) Biochem. F. 35, 292.

KleIN, J. R. and Olsen, S. (1947) F. biol. chem. 167, 747.

Kosterlitz, H. and Ritchie, M. (1943) Biochem. F. 37, 181.

Koransky, W. (1958) Arch. exp. Pathol. Pharmacol. 234, 46.

Kratzing, C. C. and Narayanaswami, A. (1953) Biochem. F. 54, 317.

LEA, C. H. and Rhodes, D. N. (1953) Biochem. F. 54, 467.

LEA, C. H. and Rhodes, D. N. (1954) Biochem. F. 56, 613.

LEE, K. H. and Eiler, J. J. (1951) Science 114, 393.

LeEs, M. B. C. (1957) In Methods in Enzymology, Vol. III, p. 328 (Ed. by

S. P. Colowick and N. O. Kaplan), Academic Press, New York.

Le Baron, F. N. (1955) Biochem. F. 61, 80.

Le Page, G. A. (1946) Amer. F. Physiol. 146, 267.

Le Page, G. A. (1948) in Methods in Medical Research, Vol. I, p. 337 (Ed. by V. R. Potter), Year Book Publishers, London.

Le PAGE, G. A. (1957) in Manometric Techniques and Tissue Metabolism (Ed. by W. W. Umbreit, R. H. Burris and J. F. Stauffer), Burgess, Minneapolis.

Lin, S., Cohen, H. P. and Cohen, M. M. (1958) Neurology 8, Suppl. 1, 72.

Lindberg, O. and Ernster, L. (1950) Biochem. F. 46, 43.

Lindberg, O. and Ernster, L. (1956) in Methods of Biochemical Analysis, 3, 1 (Ed. by D. Glick), Interscience, New York.

Logan, J. E., Mannel, W. A. and Rossiter, R. J. (1952) Biochem. J. 51, 470.

Long, C. (1943) Biochem. F. 37, 415.

Lovern, J. A. (1955) The Chemistry of Lipids of Biochemical Significance, Methuen, London.

Lowry, O. H. and Lopez, J. M. (1946) F. biol. chem. 156, 511.

Lowry, O. H., Roberts, N. R., Leiner, K. Y., Wu, M. L. and FArr, A. L. (1954) F. biol. chem. 207, 1.

McIlwain, H., Buchel, L. and Cheshire, J. D. (1951) Biochem. F. 48, 12.

Mandel, P. and Harth, S. (1958) C.R. Acad. Sci. Paris 245, 1843.

Martin, J. H. and Doty, D. M. (1949) Anal. Chem. 21, 965.

Mommaerts, W. F. H. (1955) Methods in Medical Research, Vol. VII, p. 24

(Ed. by J. V. WARren). Year Book Publishers Inc., Chicago.

Morton, R. K. (1958) Biochem. F. 70, 134.

Peel, J. L., Fox, M.' and Elsden, S. R. (1955) Biochem. F. 60, 33 P. 
Rhodes, D. N. and LeA, C. H. (1957) Biochem. F. 65, 526.

Richter, D. (1950) F. Ment. Sci. (Recent Progress in Psychiatry, 2, 26).

Robins, E., Lowry, D. H., Eydt, K. and McCannon, R. E. (1956) F. biol. chem. 220, 661 .

SACKs, J. (1949) F. biol. chem. 181, 655.

Sanadi, R. R., Gibson, D. M. and Ayenger, P. (1954) Biochem. biophys. Acta 14, 434.

Schmitz, H., Hurlbert, R. B. and Potter, V. R. (1954) F. biol. chem. 209, 41.

Schmidt, G. and Thannhauser, S. J. (1945) F. biol. chem. 161, 293.

SCHNEIDER, W. C. (1946) F. biol. chem. 164, 747.

Schwimmer, S., Benevue, A. and Weston, W. J. (1956) Arch. Biochem. Biophys. 60, 279.

Slater, E. C. (1953) Biochem. F. 53, 157.

SPERry, W. W. (1955) in Methods of Biochemical Analysis, Vol. II, p. 83 (Ed. by D. GLICK), Interscience, New York.

StONE, W. E. (1940) F. biol. chem. 135, 43.

StONE, W. E. (1943) F. biol. chem. 149, 29.

Stone, W. E. (1948) in Methods in Medical Research, Vol. I (Ed. by V. R. Potter), Year Book Publishers, London.

Strickland, K. P. (1952) Canad. F. biochem. Physiol. 30, 484.

Thomas, J. (1957) Biochem. F. 66, 655.

Thorn, W., Pfleiderer, G., Frowein, R. A. and Ross, I. (1955) Pflügers Archiv. 201, 334.

Thorn, W., Pfleiderer, G., Frowein, R. A. and Ross, I. (1956) F. Neurochem. 2, 150.

Tower, D. B. (1958) F. Neurochem. 3, 185.

WADE, H. E. and Morgan, D. M. (1953) Nature, Lond. 171, 529.

Wade, H. E. and Morgan, D. M. (1954) Biochem. F. 49, 286.

Wahler, B. E. and Wollenberger, A. (1958) Biochem. Z. 329, 508.

Weil-Malherbe, H. and Green, R. H. (1951) Biochem. F. 49, 286. 


\section{AUTHOR INDEX}

Aвоор, L. G. 6, 7, 9, 10, 48, 75, $77,83,126,127,128,143,144$, $161,167,169$

Acs, G. 78, 102, 103

Agren, G. 14

Albaum, H. G. 7, 10, 50, 52

Albert, S. 13, 28, 41

Alberty, R. A. 172

AldRidge, W. N. 75, 77, 82, 83, 124

Allen, J. N. 80

Anderson, J. A. 64

Ansell, G. B. 11, 23, 26, 27, 46, $47,61,85,90$

ANTAKI, A. 54

ARTom, C. 13

Ashford, C. A. 128, 299

AXELROD, B. 169

Ayengar, P. 122

Ayres, P. J. W. 74, 112

BaIN, J. A. 7, 44, 46, 55, 59, 75, 76, $77,82,83,84,142,143,144,145$ BAKAY, L. 16, 17, 18, 19, 42, 63

BALACZ, R. 102

BANDURSKI, R. S. 169

BANGA, I. 81, 109

Baranov, N. M. 21

BARRON, E. J. 174

BENDICH, A. 14

BERENBLUM, I. 170

BERger, M. 143

Bernsohn, J. 144

BERRY, J. F. 90, 108

BERTI, T. 139

BiNKLEY, F. 87

BLIX, G. 8

BLock, R. M. 172
Bodian, D. 13, 15, 17, 19, 25, 27 , 44, 165

BoIvin, A. 36

Boldyreva, N. V. 66

Bollard, B. 41, 150, 171

Воотн, F. J. 11

BORELL, U. 19, 65

BOYER, P. 129

Bradley, D. F. 14

Brante, G. 39, 40, 66

BrierLey, J. B. 15

BRINK, F. 119

Britton, S. W. 50, 51, 52

Brodie, B. B. $16,75,76,77,82$, $83,84,138,142,143,145$

BuCHEL, L. 56, 139, 140

BurnetT, G. 95

Burton, K. 103

Burton, R. M. 8, 38

Butler, T. C. 138,139

Cardini, C. E. 8

CARR, C. T. 148

Case, E. M. 82, 108, 141

Century, B. 143,144

Chaikoff, I. L. 16, 41, 42

Chain, E. B. 170

Chance, M. R. A. 164

Changus, G. W. 23, 24, 42

Chapell, J. 127

Chargaff, E. 26

Cheshire, J. D. 55

Christie, G. S. 75, 77, 82, 83

Cicardo, V. H. 56

Cima, C. 139

Clouet, D. 29

Clowes, G. H. A. 82, 83, 127

Cohen, H. 45, 138 
Cohen, M. M. 45, 138, 147, 148, Ernster, L. 19, 20, 21, 22, 25, 161, 149

Cohn, W. E. 16

Colowick, S. P. 14, 82, 86

Crain, S. M. 34, 35, 77

Cremer, J. 64

Crossland, J. 157

Culbreth, G. G. 16, 19, 22

Daniel, P. 19

DAVENPORT, H. A. 11

Davies, P. W. 57,58

Davies, R. E. 128,158

Davis, E. W. 57

Davison, A. N. 41, 42

Dawson, R. M. C. 7, 10, 11, 22, $23,25,26,27,43,45,48,56,59$, $61,63,85,90,91,106,124,161$, 174,176

Deluca, H. A. 96

Deuel, H. J. 12

Dianzani, M. U. 82, 83

Dickens, F. $128,129,132$

DitTMer, J. C. 174

Dixon, K. C. $107,128,129$

Dobbing, J. 15, 41, 42

Dohman, H. 46, 47, 61

Doring, H. J. 7, 9, 44, 50, 52, 168

Dоту, D. M. 171

Dubois, K. P. 86

Dubuy, H. G. 75,77

Dusser de Barrene, J. G. 60

Dziewiatkowski, D. 13, 15, 17, $25,27,44,165$

EgGleston, L. V. 168

EgGLeton, G. P. 11

Eggleton, P. 11

EILER, J. J. 82, 84, 141, 174

EINARSON, L. 29, 49

Elliot, K. A. C. 73, 84, 86, 107, 133, 139

ELRULKAR, S. D. 82

ENGLEHARDT, V. A. 14

ENGSTROM, L. 14

ENNOR, A. H. 85, 87, 167, 172, 175

FAZEKAS, J. F. 21

Featherstone, R. M. 143

Feigin, I. 86

Feinstein, R. M. 95

Feuer, G. 91

Findlay, M. 88, 94, 96, 104, 107, $131,132,133,141$

FISKE, R. H. 170

FlexNeR, J. B. 36, 37, 38, 39

FleXNER, L. 34, 35, 36, 37, 38, 39

Florsheim, W. H. 66

FolCH, J. 8, 12, 13, 14, 26, 53, 40, $49,175,176$

FoRDA, O. 147, 151

FriedKIN, M. 167

Fries, B. A. 16, 23, 42, 80, 88, 89

FURChGOTT, R. F. 170, 171

Furst, S. 29

Gaitonde, M. K. 29

Gallagher, G. H. $77,83,84$

Ganguli, N. C. 169

GaRCIA-Aust, E. 37

Geiger, R. 48, 49

Geliazkowa, N. 86

Gerard, R. W. 11, 83, 126, 167

Gerlach, E. 7, 9, 40, 45, 50, 52, 162,168

Ghantus, M. 48

GibBs, F. A. 58

Glock, G. E. 9, 80, 88, 173, 174

Goldbaum, L. R. 139

GORDAN, J. J. 87

GoRE, M. B. R. 74, 79, 80, 81, 87, $102,103,108,113,123,124,129$, $132,133,144$

GreEN, R. H. 8, 171, 172

Greenberg, D. M. 15, 16, 163

GREENGARD, O. $79,113,147,150$, 151

GRENELL, R. 142

Greville, G. D. 127, 128, 129, 132

GubarefF, T. 170,171 
Gijrdian, E. S. 49, 50, 51, 52, 53, $56,57,58,59,167$

\section{HAHN, L. 23, 26}

HAMMARSTEN, E. 96, 175

Hanahan, D. J. 174

HaNeS, C. S. 169, 173

HaRTH, S. 9, 169

Heald, P. J. 7, 8, 9, 10, 13, 14, 28, $74,75,79,80,81,84,94,95$, $102,106,107,108,110,112,114$, $115,117,118,119,121,123,125$, $128,130,146,147,148,149,164$, $168,171,172,173,174,175$

Hearon, J. Z. 22

Невв, C. O. 75,157

Hems, R. 86, 123, 168

HENSELEIT, K. 74

Hesselbach, M. L. 75, 77

Hevesy, G. 23, 26

Hill, D. 34, 35

Himwich, H. E. $21,35,42,44,51$, 53

Hiмwich, W. 42

HiRSCH, H. 52

Hoagland, H. 128

Hodgrin, A. L. 120

НокIN, L. E. 27, 89, 91, 133, 134

Hokin, M. 27, 89, 91, 133, 134

Holton, F. 84

HoRwitT, B. 143, 144

Hughes, R. A. 60

Hulme, N. A. 143

Hunter, F. E. 138

HURLbert, F. E. 9

ISHERWOOD, F. A. 169, 173

ISSELHARD, W. 51, 153

JEDEICKEN, L. A. 91

JoHnson, A. C. 12

Johnson, L. M. 13, 28

JoHnson, W. J. 142

JORDAN, W. R. 60, 75

KaBAT, H. 7, 64

KALKAR, H. M. 86
KaPlan, N. O. 14, 163

KaRnOvSKY, M. L. 8

Keltch, A. K. 82, 83, 127

KenNEDy, E. P. 90, 91, 95, 119

KerR, S. E. $6,7,9,11,48,54,55$, 162,167

KETY, S. 47, 49

Keynes, R. D. 120

KING, E. J. 173

KLEIN, J. R. 7, 10, 46, 48, 52, 53, $55,57,59,113,116,162$

KLENK, E. 8

KLINE, R. F. 50, 51, 52

Koransky, W. 6, 7, 9, 169

KOREY, S. 128

KORNBERG, A. 81

KosterlitZ, H. W. 167

Krantz, J. C. 143

Kratzing, C. C. 6, 7, 10, 79, 80, $102,108,112,113,162,166$, 173

KrEBS, H. A. $74,86,103,123,128$, 158

KuFF, E. L. 76

Lajtha, A. 29

LARABEE, R. G. 145, 151

LEA, C. H. 174

LeBaron, F. N. 12, 14, 78, 164

Leblond, C. P. C. 41

LEE, K. H. 82, 84, 174

LEES, M. 174

LEHNINGER, A. C. 167

LELOIR, L. F. 8, 9

LENNOX, W. G. 49

LePAGE, G. E. 7, 10, 45, 61, 161, $163,166,170,171,172$

LEVY, L. 143

LI, C. L. 150

LIBET, B. 34

LiN, S. 7, 44, 45, 164, 169

LINDBERG, O. 11, 19, 20, 21, 22, $75,161,169$

LIPMANN, F. 123

Lissovskaya, N. P. 14, 28, 105

LJUNGREN, M. 19, 23

LoNG, C. 109, 116, 170

LOVERN, J. A. 174 
Lowry, O. 21, 86, 138, 158, 163, 170,173

LUNDSGAARD, E. 11

McClean, P. 9, 81, 88, 173, 174

McClennan, H. 139

MCEwen, W. K. 141

McGheE, E. C. 48

McIlwain, $H$. $1,7,8,14,15,20$, $21,34,35,55,73,74,79,82,83$, $88,102,103,105,106,107,108$, $109,111,112,116,124,126,127$, $129,132,139,140,147,150,151$, $166,171,172$

MCLeOD, I. 90

McKibBEn, J. M. 13, 26

McMurray, W. C. 8, 89, 90, 106, $108,121,122,123$

Magee, W. L. 64, 140

Maleci, A. 55

Mandel, P. 9, 36, 37, 40, 169

MANERY, J. F. 80

ManN, P. G. J. 88

MARCH, R. 75

MARK, L. C. 139

Marshall, C. 42, 63

Martin, J. H. 171

MAXWell, E. S. 8

Maxwell, R. E. 144

Messer, M. 141

Meyer, A. 49

Middleton, E. J. 14

Mommaertes, W. W. 161

Moog, F. 38

Morgan, D. M. 169, 170

Morton, M. E. 66

Morton, R. A. 173

Moser, H. 8

Muntz, J. A. 8

Myers, D. K. 159

NaChmanson, D. 158

Naidoo, D. 38,86

NajJar, V. A. 14

Narayanaswami, A. $6,7,10,75$, $79,80,83,85,87,112,123,126$, $147,162,166,173$

Neurath, H. 14
Nickel, V. S. 144

Norman, J. M. 11, 23

ОсноА, S. 20,81

Ochs, S. 126

Oliver, I. T. 86,87

OLSEN, N. S. 7, 10, 46, 48, 52, 53, $56,57,113,116,162$

Ostrom, A. 19,65

Paladini, M. J. 16

Palladin, A. V. 47

Pappius, H. 86, 133

Parker, V. H. 65

Partridge, S. M. 37

PeEl, J. L. 170

Perlman, G. E. 119

Perlman, I. 16

Peters, R. A. 7, 59

Plimmer, R. H. A. 123

Pollock, G. H. 7, 56

Posternak, J. M. 145, 151

Potter, V. R. 9, 38, 86

Pratt, O. E. 38,86

Pravdina, M. 14

Pritchard, E. T. 91

Pscheidt, G. 7, 59

Quastel, J. H. 88, 138, 142

Rabinowitz, M. 123

RANDALl, L. D. 48

REIS, J. L. 86

REISS, M. 65

RÉMOND, A. 57, 58

RHODES, D. N. 174

RICH, A. 14

Richter, D. 7, 10, 22, 25, 27, 29, $43,45,46,48,56,59,61,63,124$, $157,161,162$

Ritchie, M. 167

RoBinson, F. 60

RoDNight, R. 74, 88, 92, 106

RoMANCHEK, L. 126, 127

Rosenberg, H. 85, 87, 172, 175

Rossiter, R. J. 12, 14, 90, 91, 93

Rowsell, E. 113 
Ruben, S. 16

RuMley, M. K. 41

RYDON, H. N. 124

SACKS, J. 7, 11, 16, 19, 22, 163

SANADI, R. R. 173

SAvChENKo, O. N. 51, 53

SChACHNER, H. 88, 92, 105, 107

Schmidt, C. F. 49

Schmidt, G. 13, 175

Sснмiтz, H. 8, 9, 169

SCHNEIDER, M. 52, 53

SchNeIder, W. C. 13, 76, 175

SCHWERIN, P. 103

SCHWimmer, S. 169

SCRIBNEY, M. 91

SCURO, S. 83

SEAL, U. 87

SeEvers, M. H. 7, 64

Selverstone, B. 18

SERAidarian, K. 9, 167

Sнарот, V. S. 7, 62

SHEPHERD, J. A. 84

Shideman, F. E. 7, 64

SHOWACRE, J. L. 77

SidBuRY, J. 14

Slater, E. C. $84,159,173$

Sloane-Stanley, G. H. 11, 26, 92 , 93, 158, 164

Sмiтh, S. W. 119

Sols, A. 77

SPERry, W. W. 92, 174

Stancer, H. C. $80,108,121$, 123

Stekol, J. 105

Stern, J. R. 20, 107

Stern, W. E. 42, 63

STOCKEN, L. 167

Stone, W. E. 7, 10, 11, 45, 50, 51, $52,53,54,55,57,63,128,161$, $165,167,171$

Stoner, H. B. 7, 60, 64, 65

Straub, F. B. 102

Strickland, K. P. 12, 13, 19, 25, $28,88,90,93,96,104,105,107$, 140,175

SubBarow, Y. 170

SvenNERHOLM, L. 8
Sytinsky, I. A. 62

SZEPSENWOL, J. 37

TAkasadi, G. 129

TAYLOR, W. E. 13

Terner, C. 103,128

Thannhauser, S. J. 8,175

Thomas, J. 7, 8, 9, 78, 80, 104, 167

Thompson, R. H. S. 93

Thorn, W. 6, 7, 10, 51, 53, 162, 173

Threlfall, C. J. 7, 60, 64, 65

TORDA, C. 61,65

Tower, D. B. $1,79,169,173$

Traitt, E. B. 139,143

Tresize, M. A. 116

Tschirgi, R. D. 126

TSeitlin, L. A. 85

Tsukada, Y. 107, 129, 131, 132

TYRELL, L. W. 92

UMBREIT, W. W. 73

UTTER, M. F. 8,88

Uzman, L. L. 41

VENDRELy, C. 35

VENDRELY, R. 35

VIGNAIS, P. M. 83

Vignais, P. V. 83

Vladimirov, G. E. 10, 13, 14, 20 , $22,29,46,61,62$

Vladimirova, E. A. 62

VolK, M. E. 95

VOLKOVA, R. I. 15

WADE, H. E. 169,170

WAHLER, B. E. 171

WALKER, D. M. 11

Wallace, G. B. 16

WASE, A. W. 47

WebB, J. C. 84

Webster, G. R. 15

WeBster, J. E. 56

Weil-Malherbe, H. 8, 103, 171, 172

Weinhouse, S. 91

WeIss, J. B. 90 
184

WhitTaker, V. P. 75

Wolf, A. 86

Wolleman, M. 91

WOLLENBERGER, A. 111, 171

WOLPERT, A. 143

Wosilait, W. 14
AUTHOR INDEX

YAMASAKI, S. 49

YAXLEY, D. C. 164

Zamurovic, D. A. 65

ZETTERSTROM, R. 19, 23

Zilversmit, D. B. 22,84 


\section{SUBJECT INDEX}

ACETYL CHOLINE

Effect upon phospholipid metabolism in vitro, 133, 134

Requirements for adenosine triphosphate during synthesis, 157

ACETYL GALACTOSAMINE

In brain gangliosides, 8 ACID PHOSPHATASES

In brain in development, 38 ACID-SOLUBLE PHOSPHATES (see also individual names)

As basis for calculation of ${ }^{32} \mathrm{P}$ metabolism in vivo, 22, 24

Changes in, during growth and development, 34-37

Determination of by chemical methods, 170-173

by enzymic methods, 173, 174

Errors in computing turnover rates for, 20,22

Extractants for, from brain, 163

Extraction of from frozen brain, 161-164

Incorporation of ${ }^{32} \mathrm{P}$ into, 19,44 Quantities in brain of various species, 7, 9, 10

Separation of into groups, as calcium salts, 165

as barium salts, 166

by chromatographic techniques, 168-170

ACID-INSOLUBLE PHosphates (see also individual names)

Components of, 11

Uptake of ${ }^{32} \mathrm{P}$ by in vivo, 23-29

Quantities of in brain, 13

ADENOSINE PHOSPHATES

Adenosine monophosphate, appearance in anoxia, 50 deaminase for, 86

formation of inosine monophosphate from, 8

${ }^{32} \mathrm{P}$ incorporation into in vitro, 84

specific phosphatase for, 86 quantities in brain in vivo, 7 quantities in brain slices metabolizing glucose, 79

Adenosine diphosphate, determination of, by chemical methods, 172

by enzymic methods, 173

quantities in brain in vivo, 6,7

quantities in brain slices and effects of different substrates on, 101

Adenosine triphosphate, determination of

by chemical methods, 172

by enzymic methods, 173, 174

by chromatography, 168, 169

separation from phosphocreatine by precipitation methods, 165, 166 errors in, 167

effects upon seizures induced by acetyl choline, 60

extraction from brain, 161, 162 ${ }^{32} \mathrm{P}$ incorporation into in vivo, 20, 22, 23

${ }^{32} \mathrm{P}$ incorporation into different $\mathrm{P}$ atoms of, 23

${ }^{32} \mathrm{P}$ incorporation into in animals acclimatized to high altitudes, 51

${ }^{32} \mathrm{P}$ incorporation into in anaesthesia, 44-46 


\section{AdENOSINE PHOSPHATES}

Adenosine triphosphatecontinued

${ }^{32} \mathrm{P}$ incorporation into during during electrical stimulus, 116,117

${ }^{32} \mathrm{P}$ incorporation into $\alpha$-phosphorus of in vitro, 84

identification of in brain, 11

in the formation of inosine monophosphate, 8

quantities of in brain in vivo, 6,7

effects of anaesthesia on, 44 , 45

effects of removing brain and convulsions, 55-60

during development, 37

in hypoglycemia, 48

in anoxia, 50,51

in hypothermia, 51

in ischaemia, 53

in conditioned response, 62 following brain injury, 64 in virus infection, 64

in brain after poisoning with trialkyl tin compounds and dinitro-ocresol, 64, 65

in brain of thiamine deficient animals, 66

quantities of in cortical slices in vitro, 78,79

metabolic inhibitors on, 107 , 108

electrical stimulus on, 114, 115

barbiturates on, 141, 147 requirement for in the synthesis of phospholipids, 89, 90

role in changes following electrical stimulus of brain, 119 , 120

role in synthesis of guanine nucleotides in vitro, 80

ADENOSINE TRIPHOSPHATASE

Activity in cell dispersions, 86,123
Activation by depressants, 144

Activation by heavy metals, 127

Latent, in mitochondria, 82

Increase in activity during development, 38

Inhibition by fluoride, 82

AmMoniUm SUlphate

As extractant for labile phosphates, 163

AMOBARBITONE

Anaesthetic concentration in brain, 139

Effects upon oxidative phosphorylation by brain mitochondria, 142

ANAesthesia

Carbohydrate metabolism during, 44

Acid-soluble phosphates of brain during, 44-47

ANAlytical methods (see also individual phosphates)

for phosphate derivatives in brain, 161-176

ANOXIA

Changes in phosphocreatine, adenosine triphosphate and inorganic phosphate during, 49-51

effect on phosphocreatine synthesis in slices, 103-104

Lactic acid in brain during, 49, 51

Oxygen consumption in brain during, 49

AzIDE

Effects upon phosphates in vitro, 107,108

\section{BARBITONE}

Anaesthetic concentration in brain, 139

\section{BARBITURATES}

Anaesthetic concentrations in brain, 139

Effects of, on levels of phosphates in vivo, 44,45 on ${ }^{32} \mathrm{P}$ metabolism in adenosine triphosphate, 46 
BARBITURATES

Effects of-continued

on ${ }^{32} \mathrm{P}$ metabolism in hexose phosphates, 46

on adenosine triphosphate metabolism in brain slices, 141,142

on phosphate metabolism in electrically stimulated tissues, 147-149

on oxidative phosphorylation in brain dispersions and in mitochondria, 141-145

BLOOD

Content of brain, 22

Acid-soluble phosphates in, following convulsions, 56

BLOOD-BRAIN BARRIER

Attempts to define as anatomical structure, 15

In developing brain, 42

Transport of phosphate and other ions through, 15-19

BRAIN

Analysis of, 161-176

Extractants for phosphates from, 163-164

Techniques of freezing for, 161162

\section{BRAIN SLICES}

Acid-soluble phosphates in, 78, 79

Electrode holders for, 73

Phosphate loss to medium during incubation, 79

Techniques in preparation, 73

\section{CARBON DIOXIDE}

As freezing agent for brain, $6,161,163$

Effects of, on phosphate levels in convulsions, 59

Cephalins (see also Phosphatidyl ethanolamine, Phosphatidyl serine, Cephalin diphosphoinositide)

Incorporation of ${ }^{32} \mathrm{P}$ into in vivo, 26
Cephalin diphosphoinositide

Changes during development, 40 Enzymic degradation of in brain, 92

Monophosphoinositide in, 27

${ }^{32} \mathrm{P}$ metabolism of in vivo, 26, 27 in vitro, 88

effects of acetyl choline on, 136

effects of sedation and anaesthesia on, 47

effects of tranquillizing agents on, 140

Cerebrosides

In myelin lipids, 12

Chloretone

Effect on ${ }^{32} \mathrm{P}$ metabolism, 140

Suppression of adenosine triphosphate formation by in brain, dispersions, 142

\section{Chloral}

Anaesthetic concentration in brain, 139

Effects on oxidative phosphorylation, 141, 142-143

Effects on phosphate levels in brain slices, 140

Clorpromazine

Sedative concentration in brain, 139

Effects on glutamine synthesis in slices, 141

Effects on ${ }^{32} \mathrm{P}$ metabolism in slices, 140

Effects on oxidative phosphorylation, by mitochondria, 143

Cholesterol

In myelin lipids, 39

Choroid PLeXus

As route for entry of phosphorus to brain, 16

Chromatography

Analysis of acid-soluble phosphates by, 168-170

Convulsive ACTIVITY

Oxygen tensions in brain following, 52,58

Phosphate changes in, 56, 57 


\section{Convulsants}

Effects on phosphate levels, 140

Effects on oxidative phosphorylation in mitochondria, 143

CORTICOTROPHIN

Effects on phosphate metabolism, 65

\section{Creatine}

Determination of in phosphocreatine, 172

CREATINE PHOSPHOKINASE

Activity in cell dispersions, 87, 123

CyANide

Effect on phosphate metabolism in vivo, 52

Effect on phosphate metabolism in vitro, 107-108

\section{Cytidine}

Effects on phospholipid synthesis in hypoglycemic brain, 49

CYTIDINE PHOSPHATES

Participation of in synthesis of lecithins, 8, 89, 91

Phosphorylation of adenosine diphosphate by, 123

Quantities in brain in vivo, 9

\section{Decapitation}

Speed of phosphate changes following, 54

DEOXYRIBONUCLEIC ACID

Changes during development, 35-36

${ }^{32} \mathrm{P}$ metabolism of in vitro, 28 , 29

Quantities of in brain, 13

DePRESSANTS (see Barbiturates)

DEVELOPING BRAIN

Acid-soluble phosphates in, 34, 35

Adenosine triphosphate in, 37

Deoxyribonucleic acid in, 35,36

Diphosphopyridine nucleotide in, 38

Electrical activity of, 34,37

Phosphatases in, 38
${ }^{32} \mathrm{P}$ metabolism in lipids during, 41-43

Phosphocreatine in, 35-37

Stages of development, 34-35

DIPHOSPHOPYRIDINE NUCLEOTIDE

As regulator in cell metabolism, 159

Enzymic determination of, 173

Metabolism of in slices, 81

${ }^{32} \mathrm{P}$ metabolism of in vivo, 9, 23 in slices, 84

Quantities of in brain in vivo, 9 in brain slices, 79

DIPHOSPHOPYRIDINE NUCLEOTIDASE

Change of in developing brain, 38

Inhibition of in brain dispersions, 88

Drugs (see individual names)

Action on phosphate metabolism, 138-152

ELECTRICAL STIMULATION

Apparatus and techniques for, 111-113

Effects on phosphate levels, 113-115

on ${ }^{32} \mathrm{P}$ exchange, $116-119$

on oxidative phosphorylation in dispersions and mitochondria, 126-128

Speed of changes following, 114-115

EleCTROPHORESIS

Separation and analysis of acidsoluble phosphates by, 168 , 169

EleCtroshock

Effects on acid-soluble phosphates, 55

Effects on ${ }^{32} \mathrm{P}$ metabolism into phospholipids and phosphoproteins, 61

Phosphate levels in conditioned response to, 62

EMOTIONAL EXCITEMENT

Effects on phosphate metabolism, 61-63 
ETHER ANAESTHESIA

Quantities of acid-soluble phosphates in, 44-45

\section{FLUORIDE}

Effects on phosphate metabolism in vitro, 107-108

FLUOROCITRATE

Effects of convulsant doses on levels of phosphates, 59

FRUCTOSE $1: 6$ DIPHOSPHATE

Quantities in brain in vivo, 10

\section{Glucose-1-Phosphate}

Quantities in brain in vivo, 10

GLUCOSE-6-PHOSPHATE

Quantities in brain in vivo, 10

Glucose-1 : 6-DIPHOSPHATE

Quantities in brain in vivo, 10

Coenzyme function of, 11

Glutamate

Effects on phosphate levels in vitro, 102-103

\section{Glutamine}

Synthesis of as a measure of adenosine triphosphate synthesis, 141

GLYCERYL PHOSPHORYL CHOLINE

Hydrolysis by brain preparations, 93

GLYCERYL PHOSPHORYL ETHANOLAMINE

Isolation from brain, 11

${ }^{32} \mathrm{P}$ metabolism of in vivo, 23

GLYCERYL PHOSPHORYL SERINE

Effect of tranquillizing agents on ${ }^{32} \mathrm{P}$ metabolism of, 140

\section{GUANOSINE NUCLEOTIDES}

Quantities of in brain in vivo, 6-9

Quantities of in brain in vitro, 79

Effects of guanine and adenine on, 80

Isolation from brain, 8

Triphosphate, as precursor of phosphoprotein phosphorus, 121

effects of electrical stimulation on ${ }^{32} \mathrm{P}$ metabolism of, 119 role in phosphate changes following electrical stimulation, 120-121

\section{HeXobarbitone}

Anaesthetic concentration in brain, 139

\section{HEXOSE PHOSPHATES}

Separation and analysis of, as calcium or barium salts, 165 , 166

by electrophoresis, 165

by enzymic methods, 173

by ion exchange resins, 169

Monophosphates, ${ }^{32} \mathrm{P}$ incorporation into in vivo, 70

${ }^{32} \mathrm{P}$ metabolism during conditioned response, 62

quantities in slices in vitro, 79

\section{HYPOGLYCEMIA}

Change in acid-soluble phosphates in, 48

Effects upon phospholipids, 48 , 49

${ }^{32} \mathrm{P}$ metabolism in, 48

Oxygen consumption of brain during, 47

\section{HYPOTHERMIA}

Effects on phosphate levels, in anoxia, 51

in ischaemia, 53

\section{INORGANIC PHOSPHATE}

Analysis of in brain extracts, chemical methods, 170-171 errors in with ${ }^{32} \mathrm{P}, 167,175-$ 176

separation as $\mathrm{Ca}$ or $\mathrm{Ba}$ salts, 167

separation by chromatography, 168,170

Changes in brain in vivo, in anaesthesia, 44-45

in convulsions or death, 54,55

in hypoglycemia, 48

in hypoxia, 49-51

in ischaemia, 53 
INORGANIC PHOSPHATE-continued Changes in cerebral slices, in electrically stimulated tissue, $110-114$

with increased potassium salts, 179-180

speed of changes, 115

Loss from slices during incubation, 79

Necessity for in oxidation of substrates, 81

Radioactive phosphate, acclimatization to high altitudes on turnover of, 30

as standard for computing metabolic rates, 22

limitations to use as standard, 155

entry into brain in vivo, 15-17 metabolic processes in, 15 entry into slices in saline, 80 incorporation into adenosine triphosphate in vivo, 19

incorporation into phospholipids in vitro, 88-91

retention of by brain, 44 transport from cerebrospinal fluid to brain, 18

unequal penetration into areas of brain, 18, 21

vascularity and entry to brain areas, 19

Quantities of in brain in vivo, 6, 7 in brain slices, 78, 79

INOSINE PHOSPHATES

Monophosphate, quantities in brain in vivo, 9

formation from adenosine monophosphate, 8

Diphosphate, quantities in brain in vivo, 9

Triphosphate, phosphorylation of adenosine triphosphate by, 122-123

quantities in brain in vivo, 9 INOSITOL PHOSPHOLIPIDS (see also Cephalin diphosphoinositide)
In phosphatido-peptides, 14

In "residual organic phosphates", 14

Quantities in brain, 13

INJURY

Effects on phosphate metabolism, 63-64

INTRACISTERNAL INJECTION

In studies with ${ }^{32} \mathrm{P}$ in vivo, 19

IODOACETIC ACID

Effect on phosphate metabolism in vitro, 107-108

IsCHAEMIA (cerebral)

Effect on phosphate levels, 52-53

Lecithins (see also Phosphatidyl choline)

Cytidine triphosphate in synthesis of, 9, 90

Hydrolysis of by brain preparations, 92

Synthesis of in vitro, 90-91

Quantities of in vivo, 13

LIQUID NITROGEN

As coolant for freezing brain before analysis, 161-163

\section{Malonate}

Effect on phosphate metabolism in vitro, 107-108

METABOLIC INHIBITORS

Effects on quantities and ${ }^{32} \mathrm{P}$ metabolism of phosphates in vitro, 107-109

Metrazole

Changes in phosphates during convulsions induced by, 55

MITOCHONDRIA

Characteristics of brain preparations, 75-77

\section{Myelination}

Increase in acid-soluble phosphates during, 37

Increase in phospholipids during, 39,41

Physiological stages in, 35

Retention of ${ }^{32} \mathrm{P}$ in phospholipids during, 41-42 
MYELIN LIPIDS

Changes in during development, $39-40$

Components of, 11

MYOKINASE

In brain extracts, 87

\section{NicotinAmide}

Effect on diphosphopyridine nucleotides in development, 38

NitRous OXIDE

Effects on oxidative phosphorylation in mitochondria, 143

Nucleotides-NUCleosides (see individual names)

Precipitation as mercury salts, 167

Separation by chromatography, 168-170

\section{NUCLEOTIDASE}

Specific for 5 '-nucleotides, 86

NUCLEOTIDE DIPHOSPHOKINASES

Presence in brain, 122-123

NuClEIC ACIDS (see also individual names)

Determination of, 175

Loss of from perfused brain, 48

Radioactive phosphate metabolism of in vitro, 94, 96

depressants on, 141

electrical stimulation on, 117

metallic ions on, 131-133

metabolic inhibitors on, 117

Quantities in brain slices, 94

\section{OXIDATIVE PHOSPHORYLATION}

Depressants on in mitochondria, 141-145

Electrical stimulation and, 126128

In brain dispersions and mitochondria, 81-84

Substrates supporting, 83

Temperature effect on, 82

OXYGEN UPTAKE

Rates in vivo and in vitro, 20

in relation to phosphate levels in tissue, 109-111
OXYGEN TENSION

Effects of convulsive activity on, 57-58

\section{Pentobarbitone}

Anaesthetic concentrations in brain in vivo, 139

Effects on glutamine synthesis by brain slices, 141

on ${ }^{32} \mathrm{P}$ metabolism, 140

on oxidative phosphorylation, 141-142

Phenobarbitone

Anaesthetic concentration in brain in vivo, 139

Effects on glutamine synthesis in vitro, 141

on oxidative phosphorylation in brain dispersions, 141

on phosphate metabolism in electrically stimulated slices, 147-149

Phosphatido-Peptides

Inositol phosphates in, 14

Phosphatidic ACIDS

In brain microsomes, 27, 89

Intermediates in lecithin synthesis, 90,91

Precursors of, 91

${ }^{32} \mathrm{P}$ metabolism of, 27, 89, 91 acetyl choline on, 131 tranquillizers on, 140

Phosphatidyl ethanolamine

Changes in during development, 40

Hydrolysis by brain preparation, 92

Incorporation of phosphorylethanolamine into, 91

${ }^{32} \mathrm{P}$ metabolism of, 88

anaesthesia on, 47

Quantities of in brain, 13

Phosphatidyl CHOLINE

${ }^{32} \mathrm{P}$ incorporation into in vivo, 27

in vitro, 88

Phosphatidyl SERINe

Changes during development, 40 
Phosphatidyl Serine - continued

${ }^{32} \mathrm{P}$ incorporation into in vivo, 26 during anaesthesia, 47 in vitro, 88

Quantities in brain, 13

Phosphocreatine

Analysis of in brain, extractants for, 161-164 chemical and chromatographic methods, 168-172 enzymic methods, 173-174

Changes in vivo, in anaesthesia, 44-45

in conditioned response, 62

in convulsions, $56,57,59$

in developing brain, 36,37

in hyperventilation, 52

in hypoglycemia, 48

in hypoxia, 49-51

in hypothermia, 51 resynthesis after, 51,52

in brain injury, 63, 64

in ischaemia, 53

in poisoning by trialkyl tin compounds and dinitro-ocresol, 64-65

in thiamine deficiency, 66

in trauma, 60

in virus infection, 64

Effects of strychnine convulsions on, 60

Identification of in brain, 11

${ }^{32} \mathrm{P}$ incorporation into in vivo, 20 , 21

Quantities of in brain, 6, 7 after decapitation and shock, 54

sodium cyanide on, 52

In cerebral slices in vitro, adenosine triphosphate in synthesis of, 84,85

changes in, in electrically stimulated tissues, 110-113 changes in ${ }^{32} \mathrm{P}$ distribution following electrical stimulation, 116-117

metabolism in cell dispersions, 87 phenobarbitone on electrically stimulated metabolism, 147 rate of change following electrical stimulus, 113-115

turnover rate of, 116

quantities of, after incubation in saline, 79, 102

changes with increasing potassium salts, $129-130$

effects of depressants on, 140

effects of metabolic inhibitors on, 107-108

relation to oxygen uptake of slice, $110-111$

\section{PHOSPHOGLYCERIC ACID}

Quantities in brain in vivo, 10

Phospholipids (see also individual names)

Analysis of in brain, 174-175

Changes in, during development, 37-44

in electroshock, 61

in hypoglycemia, 48

uridine and cytidine on, 49

Enzymes hydrolysing, 92

Metabolic heterogeneity of, 25-27

${ }^{32} \mathrm{P}$ metabolism of in vivo, 16 , 23-27

anaesthesia on, 46-47

corticotrophin and hypophysectomy on, 65

emotional excitement on, 63 equilibrium during, 24 retention of by adult brain, 41-44

in trialkyl tin poisoning, 64

${ }^{32} \mathrm{P}$ metabolism of in vitro, 88-91 acetyl choline on, 133-134

depressants on, 140

electrical pulses on, 118

metabolic inhibitors on, 107108

potassium and other ions on, 131-133

substrates supporting, 104106

Quantities of in brain, 13 
Phosphoproteins

In brain in vivo, changes in, in

hypoglycemia, 48

enzymes as, 14

heterogeneity of, 28,29

intracellular localization of, 94

metabolic activity of, 14

${ }^{32} \mathrm{P}$ metabolism of, 28,29

electroshock on, 61

phosphorylserine from, 14, 95

quantities of, 12-13

In slices in vitro, determination of, $175-176$

loss to medium during incubation, 95

${ }^{32} \mathrm{P}$ metabolism of, 94 changes in electrical stimulation, 118

depressants on, 140

effect of inorganic ions on, 131-133

effect of metabolic inhibitors on, 107-108

nucleotide precursors of, 121-122

rate of metabolism of during electrical stimulation, 123

substrates supporting, 104106

quantities of, 94

PHOSPHOPROTEIN PHOSPHATASE

Presence in brain, 95

PHOSPHOPYRUVIC ACID

Quantities in brain in vivo, 10

PHOSPHORUS

Determination of total in brain, 172

PHOSPHORYL CHOLINE

Hydrolysis by brain dispersions, 93

PhosPhORYL ETHANOLAMINE

Hydrolysis by brain dispersions, 93

Incorporation of ${ }^{32} \mathrm{P}$ into in vivo, 23
Incorporation of phosphatidyl ethanolamine, 91

Quantities of in brain in vivo, 10

Separation of from other acidsoluble phosphates, 166

PHOSPHORYL SERINE

From cerebral phosphoproteins, 14,118

Hydrolysis of by brain preparations, 93

PHOSPHORYL TYROSINE

Hydrolysis by brain preparations, 93

Plasmalogens

Changes in during development, 40

In myelin sheath, 41

Potassium SALTS

Effects on metabolism of brain tissue, 128

on phosphate metabolism, 124

on ${ }^{32} \mathrm{P}$ metabolism into phospholids, nucleic acids and phosphoproteins, 131-132

on phosphocreatine levels, 130

Propanediol phosphate

Isolation of, 11

ProteIns

Metabolic activity and nucleic acid metabolism, 29

Pyrophosphatase

Activity in brain dispersions, 87

\section{RADIOAUTOGRAPHY}

In study of ${ }^{32} \mathrm{P}$ entry into brain, 16,18

RESIDUAL ORGANIC PHOSPHORUS

Components of, 14

Determination of, 175

Effect of electrical stimulation on metabolism of, 117

${ }^{32} \mathrm{P}$ metabolism of, 28,29

substrates supporting, 104

Quantities of in vivo, 13 
RiBonUCLEIC ACID

Determination of, 175-176

Incorporation of ${ }^{32} \mathrm{P}$ into in vivo, 28

substrates supporting in vitro, 104

Qualities of, 13

\section{Secobarbitone}

Anaesthetic concentration in brain, 139

\section{SPHINGOMYELIN}

Changes in during development, 39,40

Hydrolysis of by brain preparations, 92

In myelin lipids, 11

${ }^{32} \mathrm{P}$ metabolism into in vivo, 26 in vitro, 88

Quantities of in grey matter, 13

STERoIDS

(21 - hydroxy - pregnane - $3: 20$ dione-hemisuccinate)

Concentration in brain following anaesthetic dose, 139

Effect upon oxidative phosphorylation in mitochondria, 143

\section{Thiopentone}

Anaesthetic concentration in brain, 139

Effects on glutamine synthesis in slices, 141

on oxidative phosphorylation, 142

on ${ }^{32} \mathrm{P}$ metabolism in mitochondria, 144

THIOPHENOBARBITONE

Anaesthetic concentration in brain, 139

Tissue Dispersions

Cofactor requirements for, 75

TRANSPHOSPHORYLASES

In brain extracts, 86

TranQuillizing agents

Effects on ${ }^{32} \mathrm{P}$ metabolism in vitro, 140
TRIALKYL TIN COMPOUNDS

Phosphate metabolism after poisoning by, 64

TRICARBOXYLIC ACIDS

Effects on ${ }^{32} \mathrm{P}$ metabolism in slices, 104-106

Maintenance of levels of phosphates by, 104

Trichloroacetic ACID

Extractant for acid-soluble phosphates, 163, 164

Trimethadione

Effect upon phosphocreatine in electrically stimulated tissues, 150

TRIOSE-PHOSPHATES

Enzymic determination of, 173

Quantities of in vivo, 10

TRIPHOSPHOPYRIDINE NUCLEOTIDE

Enzymic determination, 173, 174

Quantities of in vivo, 9

in vitro, 79

Tumours

Uptake of phosphate by, 63

URIDINE

Effect upon phospholipid synthesis in hypoglycemic brain, 49

URIDINE PHOSPHATES

Mono-, di-, and tri-phosphates, levels in brain in vivo, 9

URIDINE DIPHOSPHATE ACETYL GLUCOSAMINE

Conversion to galactose derivative, 8

Quantities in brain, 9

URIDINE DIPHOSPHATE ACETYL GALACTOSAMINE

Formation from glucosamine derivative, 8

URIDINE DISPHOSPHATE GLUCOSE

Conversion to galactose derivative, 8

Quantities in brain in vivo, 9 
Ventricle LiNings

As route for entry of ${ }^{32} \mathrm{P}$ into brain, 16

VIRUS INFECTION

Effect upon cerebral phosphates 64
Xenon

Effect of anaesthetic mixtures of on oxidative phosphorylation in mitochondria, 143 X-Radiation

Effects on ${ }^{32} \mathrm{P}$ metabolism in brain, 65 




